\title{
Acute and chronic regulation of CD36-mediated fatty acid uptake by rat heart and skeletal muscle
}

Citation for published version (APA):

Koonen, D. P. Y. (2004). Acute and chronic regulation of CD36-mediated fatty acid uptake by rat heart and skeletal muscle. [Doctoral Thesis, Maastricht University]. Universiteit Maastricht. https://doi.org/10.26481/dis.20040915dk

Document status and date:

Published: 01/01/2004

DOI:

$10.26481 / \mathrm{dis} .20040915 \mathrm{dk}$

Document Version:

Publisher's PDF, also known as Version of record

\section{Please check the document version of this publication:}

- A submitted manuscript is the version of the article upon submission and before peer-review. There can be important differences between the submitted version and the official published version of record.

People interested in the research are advised to contact the author for the final version of the publication, or visit the DOI to the publisher's website.

- The final author version and the galley proof are versions of the publication after peer review.

- The final published version features the final layout of the paper including the volume, issue and page numbers.

Link to publication

\footnotetext{
General rights rights.

- You may freely distribute the URL identifying the publication in the public portal. please follow below link for the End User Agreement:

www.umlib.nl/taverne-license

Take down policy

If you believe that this document breaches copyright please contact us at:

repository@maastrichtuniversity.nl

providing details and we will investigate your claim.
}

Copyright and moral rights for the publications made accessible in the public portal are retained by the authors and/or other copyright owners and it is a condition of accessing publications that users recognise and abide by the legal requirements associated with these

- Users may download and print one copy of any publication from the public portal for the purpose of private study or research.

- You may not further distribute the material or use it for any profit-making activity or commercial gain

If the publication is distributed under the terms of Article $25 \mathrm{fa}$ of the Dutch Copyright Act, indicated by the "Taverne" license above, 
Acute and chronic regulation of

CD36-mediated fatty acid uptake by rat heart and skeletal muscle 
The studies presented in this thesis were performed at the Department of Physiology and the Department of Molecular Genetics, Cardiovascular Research Institute Maastricht, Maastricht University (CARIM), The Netherlands.

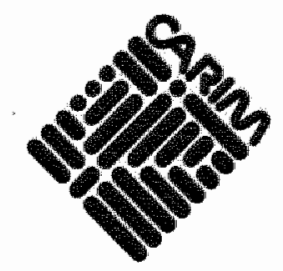

(C) DEBBY P.Y. KOONEN, MAASTRICHT 2004

All rights reserved. No part of this book may be translated or reproduced in any form by photo, photoprint, microfilm or any other means without written permission by the author.

ISBN 90-9018428-7

COVER DESIGN

Jodil Willems Design, Maastricht

CARTOON DESIGN

John Chase, Yakima (USA)

PRINTING AGENCY

Ponsen \& Looijen bv, Wageningen 


\section{Acute and chronic regulation of CD36-mediated fatty acid uptake by rat heart and skeletal muscle}

\section{PROEFSCHRIFT}

Ter verkrijging van de graad van doctor aan de Universiteit Maastricht, op gezag van de Rector Magnificus, Prof. Mr. G.P.M.F. Mols, volgens het besluit van het College van Decanen, in het openbaar te verdedigen op woensdag 15 september om 14.00 uur

door

DEBBY PIETER YVONNE KOONEN

Geboren te Brunssum op 30 juni 1976 


\section{Promotor:}

Prof. Dr. J.F.C. Glatz

\section{Co-promotor:}

Dr. J.J.F.P. Luiken

\section{Beoordelingscommissie :}

Prof. Dr. M.H. Hofker (voorzitter)

Prof. Dr. Ir. L.M. Havekes (TNO prevention and Heaith, Leiden)

Prof. Dr. A. Bonen (University of Guelph, Canada)

Prof. Dr. L. Hue (University of Louvain Medical School, Belgium)

Dr. M.P. Hesselink

The studies presented in this thesis were supported by the Netherlands Organization for Scientific Research (NWO), project 903-39-194, and the Van Walree Fund (Royal Netherlands Academy of Arts and Sciences, KNAW).

Financial support by the Netherlands Heart Foundation, and NWO for the publication of this thesis is gratefully acknowledged. 
What we do in life, echoes in eternity - the Gladiator-

A journey of a thousand miles begins with a single step -chinese proverb- 



\section{Contents}

\section{Chapter 1}

Introduction

\section{Chapter 2}

Long-chain fatty acid uptake and FAT/CD36 translocation in heart and skeletal muscle

\section{Chapter 3}

Giant membrane vesicles as a model to study cellular substrate uptake dissected from metabolism

\section{Chapter 4}

Different mechanisms can alter fatty acid transport when muscle contractile activity is chronically altered

\section{Chapter 5}

Insulin stimulates long-chain fatty acid utilization by rat cardiac myocytes through cellular redistribution of FAT/CD36

\section{Chapter 6}

Zaprinast selectively modulates cardiac substrate preference by increasing glucose uptake without altering long-chain fatty acid uptake

\section{Chapter 7}

General discussion

\section{Summary/Samenvatting}

\section{Curriculum Vitae}

\section{List of Publications}

Dankwoord/Acknowledgements 



\section{Introduction}




\section{Introduction}

One of the most serious health problems in industrialized societies is obesity (1). Obesity is a major risk factor for developing a cluster of cardiovascular and metabolic complications, such as dyslipidemia, coronary artery disease, hypertension, insulin resistance and diabetes, collectively known as the 'metabolic syndrome' or "syndrome $X$ " $(1,2)$. The prevalence of obesity is increasing worldwide and has reached epidemic proportions in the United States of America (USA) (3, 4), in Europe (5), and in the rest of the world (6). Enwironmental factors such as a sedentary lifestyle, a reduction in physical activity level and a change in dietary habits appear to be largely responsible for this dramatic increase $(1,7)$. Differences in genetic background might, however, contribute to the individual susceptibility seen in obesity towards these environmental factors (8).

Obesity occurs when there is an imbalance between energy intake and energy expenditure, and the resulting daily excess in lipid and carbohydrate intake is built up as fat in the adipose tissue compartment. Long-chain fatty acids (LCFA) play important physiological roles in skeletal muscle, heart and liver $(9,10)$, but chronically elevated LCFA appear to have pathophysiological consequences (10). In fact, elevated levels of LCFA derived from the enlarged adipose tissue mass are the predominant factor in obesity and have been proposed to contribute to peripheral insulin resistance of obesity and type 2 diabetes (11-13).

Insulin resistance or reduced insulin sensitivity refers to the inability of skeletal muscle cells to respond properly to the hormone insulin. Insulin normally maintains a constant glucose level in the blood by stimulating the uptake of sufficient amounts of glucose by skeletal muscle cells via a specific pathway known as the insulin signaling cascade (described below; Fig. 1.1). In the case of insulin resistance glucose metabolism is impaired. Substrate competition between LCFA and glucose as described by Sir Philip Randle in the glucose-fatty acid cycle (Randle cycle) over 40 years ago (14) is one of the possible explanations for the impaired glucose uptake seen in insulin-resistant skeletal muscle. More recent hypotheses proposed that LCFA and intracellular metabolites, such as diacylglycerol (DAG) and ceramides, interfere in the insulin signaling cascade thereby intibiting insulin to stimulate glucose transport in skeletal muscles (15-18).

Although it is commonly accepted that obesity affects LCFA metabolism (19, 20), LCFA uptake into skeletal muscle cells might be altered as well. The physiological uptake process of LCFA is, however, not yet well understood and should receive careful attention before any indications can be made to confirm a possible role of LCFA uptake under pathophysiological conditions, as obesity and insulin resistance.

This thesis therefore describes the role of LCFA uptake and regulation in skeletal and cardiac muscle cells under physiological conditions. This introduction aims to provide the reader with background information to comprehend the studies performed in this thesis. 


\section{Insulin signaling cascade}

Insulin modulates a variety of biological processes and metabolic pathways (21). Insulin promotes the synthesis and storage of carbohydrates, proteins and lipids, while in inhibits their breakdown and release into the circulation. Moreover, insulin stimulates the uptake of glucose and amino acids into cells, and stimulates cell growth and differentiation.

To perform these actions, insulin needs to bind to a specific insulin receptor, present in the membrane of the target cells (Figure 1.1).

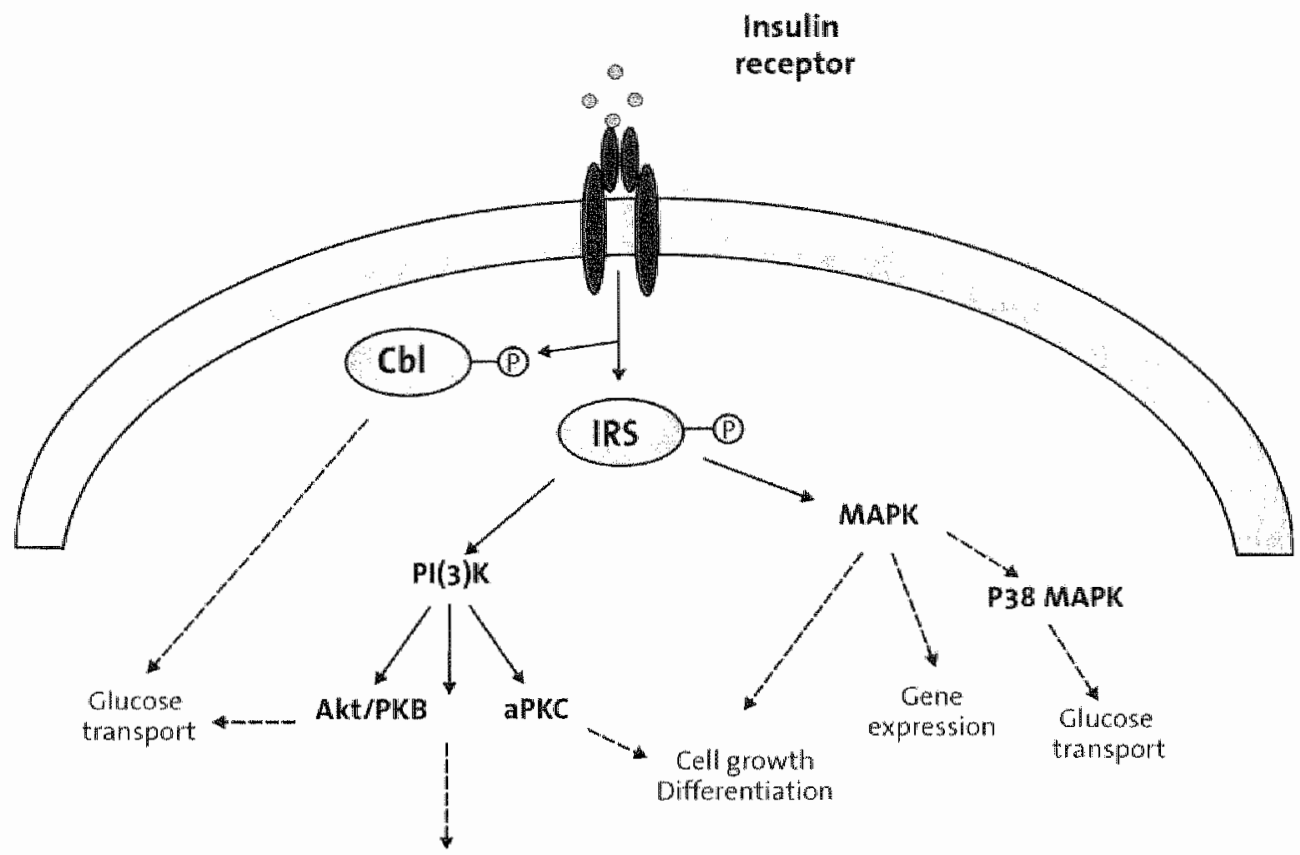

Glucose metabolism

Glycogen/lipid/protein syrthesis

Gene expression

Figure 1.1. Insulin signaling cascade. Schematic representation of the signaling cascades involved in the biological effects of imsulin on the regulation of glucose, protein and lipid metabolism. Binding of insulin to the insulin receptor on the cell surface results in autophosphorylation of this receptor and subsequent phosphorylation of cellular scaffold proteins, including the insulin receptor substrate protein (IRS) family and the proto-oncogene Cbl. These proteins will then activate several downstream targets via a phosphatidylinositol-3-OH-kinase (PI(3)K)-dependent or independent mechanism. Abbreviations: MAPK, mitogen-activated potein kinase; Akt/PKB, protein kinase $B_{*}$ aPKC, atypical protein kinase $C$.

Binding of insulin to the alpha-subunit of the insulin receptor activates the intracellular tyrosine kinase domain of the beta-subunit of the insulin receptor $(21,22)$. Autophosphorylation of the tyrosine residues in this domain will then directly catalyse 
the phosphorylation of cellular scaffold proteins, including the family of insulin receptor substrate (IRS)-proteins, the adaptor protein $S H C$, the proto-oncogene $\mathrm{Cbl}$, associated protein substrate (APS), Src homology 2-B (SH2B), GTP-ase-activating protein (GAB1/2), and the protein DOCK $1 / 2(21,23)$. Signaling complexes are then assembled around these scaffold proteins resulting in the generation of a diversity of intracellular signals (23). The IRS-1 and IRS-2 proteins mediate the insulin responses associated with substrate metabollism, and cell growth by interacting with phosphatidylinositol-3-OH kinase (PI(3)K) and the mitogen-activated protein (MAP) kinase extracellular signal-regulated kinase (ERK) cascades $(23,24)$.

The activation of $\mathrm{PI}(3) \mathrm{K}$ transmits several signals resulting in phosphorylation and activation of downstream effector kinases as protein kinase B (Akt/PKB) and atypical protein kinase C (aPKC) $(21,25)$. Activation of Akt/PKB plays an important role in both metabolic regulation and gene expression (23). MAP kinases (MAPK) phosphorylate a variety of transcription factors in the cell nucleus, leading to changes in protein expression, cell growth and differentiation (24). Although activation of MAPK by insulin appears to be less important in the control of glucose metabolism than components downstream of $\mathrm{PI}(3) \mathrm{K}$, insulin activation of $\mathrm{p} 38$ MAPK has been proposed to play a specific role in the stimulation of glucose uptake, e.g. through activation of membrane glucose transport $(26,27)$.

Tyrosine phosphorylation of the scaffold protein $\mathrm{Cbl}$, and interaction with its adapter protein $\mathrm{Cbl}$-associated protein (CAP) has been suggested to be involved in glucose uptake in lipid rafts (28), indicating the existence of an additional and $\mathrm{PI}(3) \mathrm{K}$-independent insulin signaling pathway to regulate glucose transport $(22,25)$. All initiated signaling cascades then act in a concerted fashion to coordinate the numerous processes involved in the insulin regulation of glucose, protein and lipid metabolism. Since insullin affects whole body metabolism, accurate insulin signaling is therefore crucial.

\section{Cellular uptake of glucose}

It has been well demonstrated that throughout the body a family of specific glucose transporter (GLUT) proteins mediate the cellular uptake of glucose (25). To date several isoforms have been identified (GLUT1-12) and found to show a specific distribution in the different tissues (29). GLUT1 and GLUT4 are the predominant isoform in tissues with insullin-sensitive glucose transport, i.e. skeletal and cardiac muscle (29). GLUT1, however, has a much more ubiquitous tissue distribution than CLUT 4 and is largely responsible for basal glucose uptake. In the nonstimulated, basal situation GLUT4 is largely confined to an intracellular storage site, while GLUT1 has a more pronounced sarcolemmal localization (30). Upon stimulation by insulin, GLUT4 is recruited to the plasma membrane resulting in the enhancement of glucose uptake in both heart and skeletal muscle $(31,32)$. In addition, muscle contractions have been shown to increase the cell surface GLUT4 content as well and, therefore, have an insulin-like effect on stimulating glucose uptake $(33,34)$. Although both stimuli enhance glucose transport, their signaling pathways appear to be distinct (35)(Figure 1.2). 
A

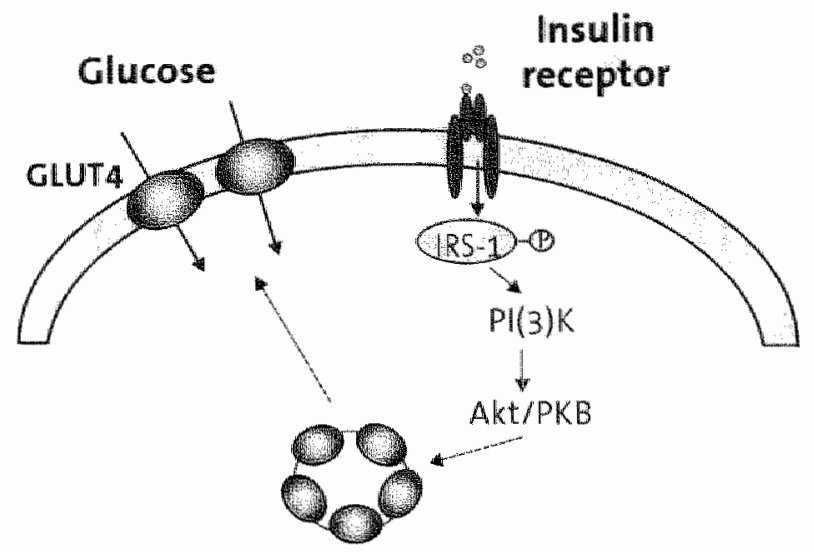

B

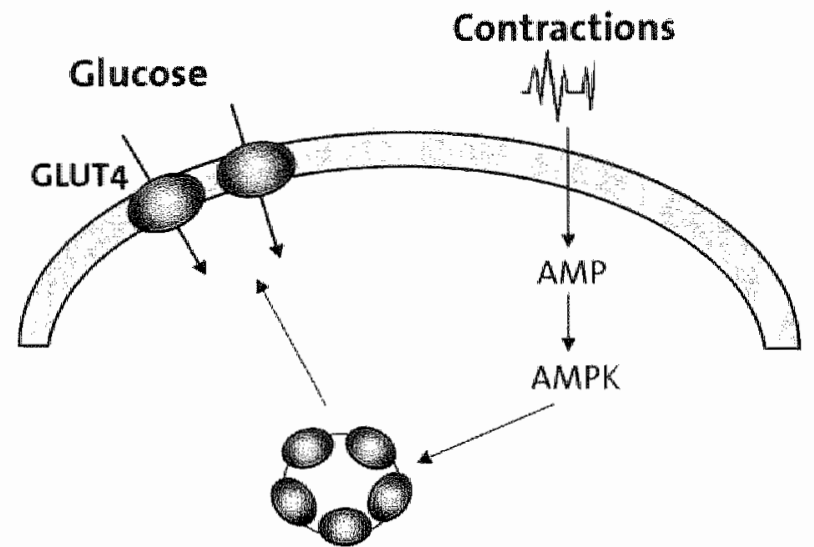

Figure 1.2. Mechanisms of glucose uptake by GLUT4 in heart and skeletal muscle. Both insulin and contractions increase gllucose uptake by the recruitment of GL.UT4 from intracellular storage sites to the cell surface, but different mechanisms are involved. Insulin increases glucose uptake via a $\mathrm{PI}(3) \mathrm{K}$-dependent mechanism, while contraction-induced glucose uptake depend on the activation of AMPK by an increase in the intracellular concentration of AMP.

Insulin has been shown to increase glucose uptake through the translocation of GLUT4 via a pathway mediated by PI(3) K, as described in section 1.2. Although, the mechanisms downstream of $\mathrm{PI}(3) \mathrm{K}$ are largely unknown, activation of Akt/PKB is a likely candidate to trigger this GLUT4 translocation event $(32,35)$. Muscle contraction, on the other hand, appears to induce GLUT4 translocation through a pathway that is independent of PI( 3 ) K activation (35). There is strong evidence to suggest that the fuel sensor 5'-AMP-activated protein kinase (AMPK) is part of the signaling mechanism by which contractions mediate glucose transport in heart and skeletal muscle $(36,37)$. In addition, conventional PKC (CPKC) might also play a role in exercise-stimulated glucose transport, because the rise in 
intracellular calcium concentration has been shown to activate the calcium sensitive CPKC. Because both insulin and cellular contractions are capable of stimulating glucose uptake by the recruitment of GLUT4 to the cell membrane, it is suggested that they share a common pathway downstream of Pl(3)K (32). An unknown target downstream of Akt/PKB has been suggested to represent this branch-point, since most studies did not report Akt/PKB as a mediator of contraction-induced glucose transport $(32,35)$. Conclusive evidence, however, is still lacking.

\section{Cellular uptake of fatty acids}

When compared to cellular glucose uptake, the uptake mechanism of LCFAs and its regulation are only poorly understood. Because of their long hydrophobic tail, LCFAs have a limited solubility in aqueous environments like blood plasma, interstitium, and the cellular cytoplasm (38). To overcome the problem of transport within these body fluids and to make them available for utilization by cardiac and skeletal muscle, LCFAs either are bound to specific carrier proteins (plasma albumin and cytoplasmic fatty acid-binding proteins (FABPC)) or are part of larger lipid-protein complexes (lipoproteins) $(38,39)$.

The mechanisms by which LCFAs are taken up by cells have long been a matter of debate. Diffusion of LCFAs through cellular membranes has initially been thought to be the sole mechanism of LCFA uptake (40-42). Evidence, however, suggests the co-existence of two components in the transport of LCFAs across the cellular membrane, that is, passive diffusion and protein-mediated transport (43-47). Presumably, passive diffusion and protein-mediated transport interact to facilitate the cellular sarcolemmal uptake of LCFAs (38), although some scepticism still remains $(48,49)$.

\section{Putative fatty acid translocase (FAT)/CD36}

One of the putative proteins that have been proposed to play a role in protein-mediated LCFA uptake is fatty acid translocase (FAT)/CD36. Over the years a significant amount of attention has been given to unravel the role of FAT/CD36 in facilitating sarcolemmal LCFA uptake. A wealth of evidence was gained from the generation of transgenic mouse models with either muscle-targeted overexpression of FAT/CD36 or complete absence of the gene for FAT/CD36 (FAT/CD36 knockout mice) (50-53). These models not only demonstrated the physiological role of FAT/CD 36 to facilitate cellular LCFA uptake in vivo but they also clearly demonstrated the importance of the LCFA uptake process to overall LCFA metabolism and glucose utilization.

Additionally, evidence was provided for a novel role of $F A T / C D 36$ in the acute regulation of LCFA transport in skeletal muscle (54). In skeletal muscle, two separate fractions of FAT/CD36 were observed, that is in the plasma membrane and in an intracellular compartment (54). Upon muscle contraction a portion of intracellularly stored FAT/CD36 was translocated to the membrane, thereby increasing LCFA uptake acutely (Figure 1.3). Although these results indicate that muscle contraction is capable of regulating LCFA 
uptake by means of a translocation of FAT/CD 36, the underlying mechanism for the triggering of the apparent translocation and regulation of LCFA uptake are not known.

\section{Contractions}

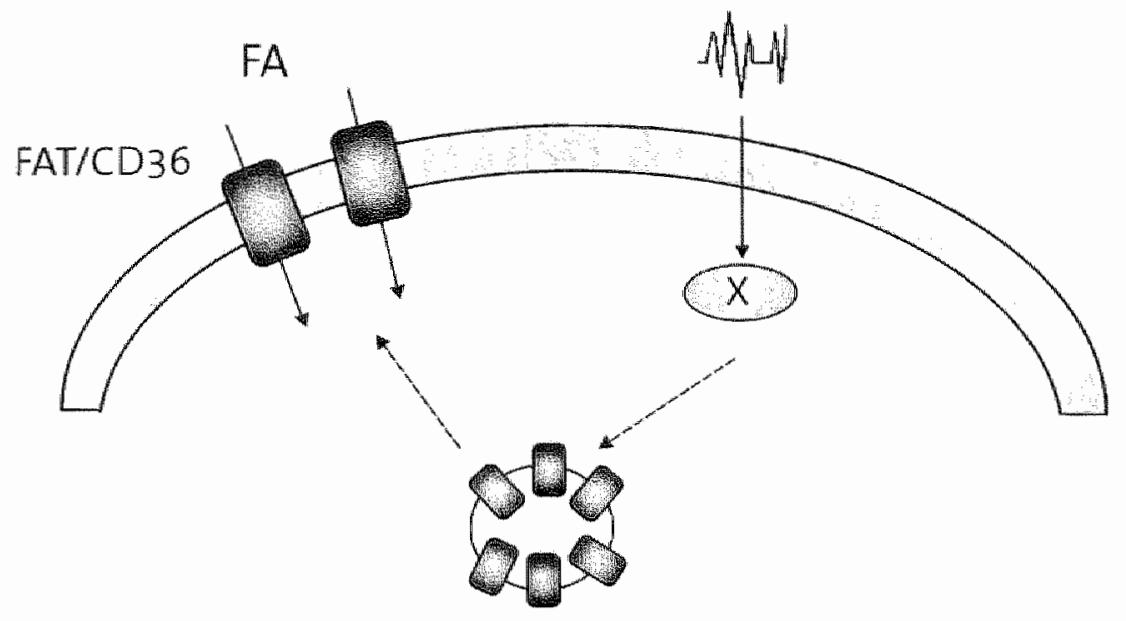

Figure 1.3. FAT/CD36-mediated LCFA uptake. Contractions increase LCFA uptake by recruiting FAT/CD36 from an intracellular storage site to the membrane. The signaling pathway involved in this regulation of LCFA uptake is still unknown (X). Abbreviations: FA, long-Chain fatty acids.

\section{Study objectives}

The studies conducted in this thesis are part of program grant provided by the Netherlands Organization for Scientific Research (NWO-MW, project 903-39-194) to the Gaubius Laboratory of TNO prevention and Health (Prof. Dr. L.M. Havekes) and Maastricht University. The project was aimed at unraveling the complex association between insulin resistance and obesity on one hand, and hyperlipidemia and coronary heart disease on the other hand. While studies performed in Leiden focussed on alterations in plasma lipoprotein metabolism and lipoprotein receptors on LCFA delivery to peripheral tissues, the investigations made in Maastricht adressed the acute and chronic regulation of cellular LCFA uptake, primarily in heart and skeletal muscle.

It is generally accepted that obesity affects lipid metabolism $(12,13,19)$. It is likely that a disturbance in LCFA transport across cellular membranes of peripheral target tissues is involved as well. To date, however, the mechanisms underlying the regulation of LCFA transport are still poorly described. Hence, it is of crucial importance to gain insight in the basic mechanisms of LCFA uptake and regulation in normal healthy tissues. The studies described in this thesis, therefore, explore the possible role of FAT/CD36 in the regulation of LCFA uptake in rat heart and skeletal muscle. 
The objectives of the research described in this thesis were fourfold. The first aim was to validate the research model of the giant sarcolemmal vesicles to study LCFA uptake in the absence of metabolism (chapter 3). The second aim was to examine the chronic regulation of LCFA uptake in skeletal muscle. For this, we chronically altered the activity level of skeletal muscle in vivo, and compared the effect of both a decrease (denervation) and an increase in muscle activity (stimulation) on LCFA uptake (chapter 4). The third objective was to study the acute regulation of LCFA uptake by insulin in cardiac muscle (chapter 5). The fourth and final objective was directed at unraveling the signaling pathways involved in the translocation of FAT/CD 36 from the intracellular storage site to the plasma membrane (chapter 6).

\section{Experimental models}

Two specific models (Figure 1.4) were used in this thesis to study the uptake and regulation of LCFAs in heart and skeletal muscle. These models are i) giant sarcolemmal vesicles, and ii) isolated cardiac myocytes.

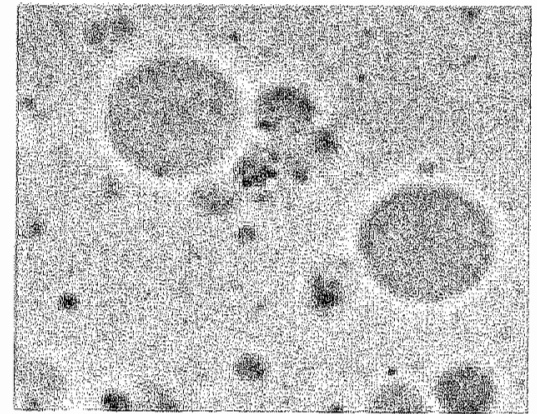

Giant sarcolemmal vesicles

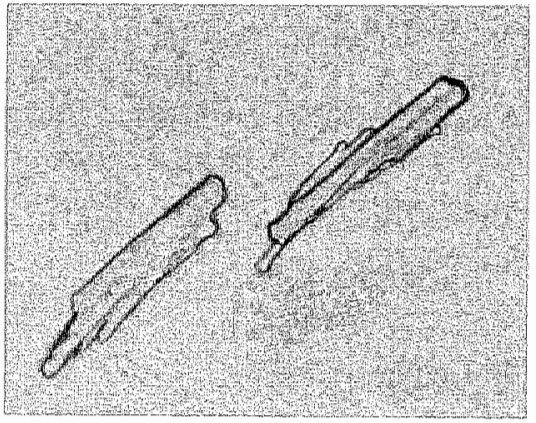

Cardliac myocytes

Figure 1.4. Two experimental tool systems to study LCFA uptake.

Giant sarcolemmal vesicles (chapters 3 and 4) are particularly suitable to study the mechanism of substrate (glucose, LCFAs) uptake in the absence of metabolism. They represent a unique tool to study the effects of in vivo alterations in substrate uptake (e.g. exercise) on the amount of substrate transporters (e.g. GLUT4, FAT/CD36) on the plasma membrane.

In contrast, isolated cardiac myocytes (chapters 5,6, and 7) are an adequate model to investigate substrate uptake in the presence of metabolism. Moreover, isolated cardiac myocytes form a reliable model to study the regulation of cardiac substrate transport (e.g. glucose, LCFAs)(55) and can be specifically used to unravel signaling pathways involved in substrate uptake and metabolism. 


\section{Outline of thesis}

A brief introduction on the mechanism of LCFA transport followed by a review of current concepts on the regulation of LCFA uptake by putative membrane transporters, in specific FAT/CD36 is presented in chapter 2.

To test the validity of giant sarcolemmal vesicles as a tool to study substrate uptake in the absence of intracellular metabolism, we characterized giant sarcolemmal vesicles derived from metabolically important tissues (heart, skeletal muscle, adipose tissue and liver). Chapter 3 reports the analysis of giant sarcolemmal vesicles with markers specific for distinct cell types and particular domains of the plasma membrane.

Chapter 4 describes the chronic regulation of LCFA uptake in skeletal muscle. We examined whether LCFA uptake, was altered when muscle activity was eliminated by denervation or increased by chronic stimulation. Giant sarcolemmal vesicles were used to measure LCFA transport rates and investigate the plasmalemmal presence of FAT/CD36 and plasmalemmal fatty acid binding protein (FABPpm) in denervated and stimulated hindlimb muscle.

Chapter 5 reports the acute regulation of cellular LCFA uptake by insulin and cellular contractions and illustrates the direct effects of both stimuli on the processes of LCFA uptake, esterification and oxidation in the heart. Chapter 5 describes a novel role of insulin in the recruitment of intracellular stored FAT/CD36 to the cell surface by a signaling cascade dependent on $\mathrm{PI}(3) \mathrm{K}$ and indicates that the signaling pathways involved in the uptake process of both glucose and LCFA in cardiac myocytes bear a striking resemblance.

Despite these similarities, we recently found evidence that the signaling cascades for GLUT4 and FAT/CD36 mobilization are independently regulated (56). The phosphodiesterase inhibitor Zaprinast was capable of enhancing glucose uptake without affecting LCFA uptake in cardiac myocytes (56). In order to unravel the signaling pathways involved in the translocation of GLUT4 and FAT/CD36, we aimed to study the selective recruitment of the substrate transporters GLUT4 and FAT/CD36 by the phosphodiesterase inhibitor Zaprinast. Chapter 6 reports the underlying mechanism and signaling cascades involved in the stimulation of glucose uptake by Zaprinast.

In Chapter 7 the main results of the above mentioned studies are summarized, discussed, and put into a broader perspective. Moreover, preliminary data are presented regarding a possible role for Akt/PKB in the insulin-signaling cascade leading to translocation of FAT/CD36. 


\section{References}

1. Montani, J. P., Antic, V., Yang, Z., and Dulloo, A. (2002) Pathways from obesity to hypertension: from the perspective of a vicious triangle. Int $J$ Obes Relat Metab Disord 26 Suppl $2,528-38$

2. Unger, R. H. (2003) Lipid overload and overflow: metabolic trauma and the metabolic syndrome. Trends in Endocrinology and Metabolism 14, 398-403

3. Kuczmarski, R. J., Flegal, K. M. Campbell, S. M., and Johnson, C. L. (1994) Increasing prevalence of overweight among US adults. The Nationall Health and Nutrition Examination Surveys, 1960 to 1991 . lama 272, 205-211

4. Hill, J. O., Melanson, E. L., and Wyatt. H. T. (2000) Dietary fat intake and regulation of energy balance: implications for obesity. $\mathcal{N}$ Nutr $130,2845-2885$

5. Bjorntorp, P. (1997) Obesity. Lancet 350, 423-426

6. Kopelman, P. G. (2000) Obesity as a medicall problem. Nature 404,635-643

7. Schmidt, 1. (2002) Metabolic diseases: the environment determines the odds, even for genes. News Physiol Sci 17, 115-121

8. Bouchard, C. (1995) Genetics and the metabolic syndrome. Int J Obes Relat Metab Disord 19 Suppl 1, 552-59

9. Faergeman, N. J., and Knudsen, J. (1997) Role of long-chain fatty acyl-CoA esters in the regulation of metabolism and in cell signalling. Biochem $/ 323$ ( Pt 1), 1-12

10. Glatz, \%. F, and Storch, J. (2001) Unravelling the significance of cellular fatty acid-binding proteins. Curr Opin Lipidol 12, 267-274

11. Boden, G. (1997) Role of fatty acids in the pathogenesis of insulin resistance and NIDDM. Diabetes 46, 3-10

12. Kelley: D. E., and Mandarino, L. J. (2000) Fuel selection in human skeletall muscle in insulin resistance: a reexamination. Diabetes $49,677-683$

13. Shulman, G. I. (2000) Cellular mechanisms of insulin resistance. J Clin Invest 106, 171-176

14. Randle, P. J, Garland, P. B., Hales, C. N., and Newsholme, E. A. (1963) The glucose fatty-acid cycle. 1 ts rolle in insulin sensitivity and the metabolic disturbances of diabetes mellitus. Lancet $1,785-789$

15. Petersen, K. F. and Shulman, G. I. (2002) Pathogenesis of skeletal muscle insulin resistance in type 2 diabetes mellitus. Am J Cardiol 90, 11G-18G

16. Roden, M., Price, T. B., Perseghin, G., Petersen, K. F., Rothman, D. L., Cline, G. W., and Shuiman, $G$. 1. (1996) Mechanism of free fatty acid-induced insulin resistance in humans. $J$ Clin Invest $97,2859-2865$

17. Schmitz-Peiffer, C., Craig, D. L., and Biden, T. J. (1999) Ceramide generation is sufficient to account for the inhibition of the insulin-stimulated PKB pathway in C2C12 skeletal muscle cells pretreated with palmitate. J Biol Chen 274, 24202-24210

18. Griffin, M. E., Marcucci, M. J., Cline, G. W., Bell, K., Barucci, N., Lee, D., Goodyear, L. J., Kraegen, E. W. White, M. F., and Shuman, G. 1. (1999) Free fatty acid-induced insulin resistance is associated with activation of protein kinase $C$ theta and alterations in the insulin signaling cascade. Diabetes $48,1270-1274$

19. McGarry. J. D. (2002) Banting lecture 2001: dysregulation of fatty acid metabolism in the etiology of type 2 diabetes. Diabetes $51,7-18$

20. Kelley, D. E., Goodpaster, B., Wing, R. R., and Simoneau, J. A. (1999) Skeletal muscle fatty acid metabolism in association with insulin resistance, obesity, and weight loss. Am I Physiol 277, E1130-1141

21. Saltiel, A. R., and Kahn, C. R. (2001) Insulin signalling and the regulation of glucose and lipid metabolism. Nature 414, 799-806

22. Pessin, I. E., and Saltiel, A. R. (2000) Signaling pathways in insulin action: molecular targets of insulin resistance. $J$ Clin Invest 106, 165-169

23. White, M. F. (2003) Insulin signaling in health and disease. Science 302, 1710-1711

24. Schmitz-Peiffer, C. (2000) Signalling aspects of insulin resistance in skeletal muscle: mechanisms induced by lipid oversupply. Cell signal 12, 583-594.

25. Khan, A. H., and Pessin, J. E. (2002) Insulin regulation of glucose uptake: a complex interplay of intracellular signalling pathways. Diabetologia $45,1475-1483$ 
26. Somwar, R., Niu, W., Kim, D. Y., Sweeney, G., Randhawa, V. K., Huang, C., Ramlal, T., and Klip. A. (2001) Differential effects of phosphatidylinositol 3-kinase inhibition on intracellular signals regulating GLUT4 translocation and glucose transport. I Biol Chen $276,46079-46087$

27. Sweeney, G., Somwar, R., Ramlal, T., Volchuk, A., Ueyama, A., and Klip, A. (1999) An inhibitor of p38 mitogen-activated protein kinase prevents insulin-stimulated glucose transport but not glucose transporter translocation in 3T3-L1 adipocytes and 166 myotubes. J Biol Chem 274, 10071-10078

28. Baumann, C. A., Ribon, V., Kanzaki, M., Thurmond, D. C., Mora, S., Shigematsu, S., Bickel, P. E., Pessin, J. E., and Saltiel, A. R. (2000) CAP defines a second signalling pathway required for insulin-stimulated glucose transport. Nature 407, 202-207

29. Rogers, S., Macheda, M. L., Docherty, S. E., Carty, M. D., Henderson, M. A. Soeller, W. C., Gibbs, E. M. James, D. E., and Best, J. D. (2002) Identification of a novel glucose transporter-like protein-GLUT-12. Am I Physiol Endocrinol Metab 282, E733-738

30. Fischer, Y., Thomas, J., Sevilla, L. Munoz, P., Becker, C., Holman, G., Kozka, I. J., Palacin, M., Testar, X. Kammermeier, $H_{\text {. }}$, and Zorzano, A. (1997) Insulin-induced recruitment of glucose transporter 4 (CLUT4) and GLUT1 in isolated rat cardiac myocytes. Evidence of the existence of different intracellular GLUT4 vesicle populations. J Biol Chem 272, 7085-7092

31. Slot, J. W., Geuze, H. J., Gigengack, S., James, D. E., and Lienhard, G. E. (1991) Translocation of the glucose transporter GLUT4 in cardiac myocytes of the rat. Proc Nat' Acad SCiU SA $88,7815-78119$

32. Brozinick, I. T., Jr., Etgen, G. J., Jr., Yaspelkis, B. B., 3rd, and Ivy, J. L. (1994) The effects of muscle contraction and insulin on glucose-transporter translocation in rat skeletal muscle. Biochem J 297 (Pt 3). 539.545

33. Roy, D., and Marette, A. (1996) Exercise induces the translocation of GLUT4 to transwerse tubules from an intracelluliar pool in rat skeletal muscle. Biochem Biophys Res Commun $223,147-152$

34. Roy, D., Johannsson, E., Bonen, A.y and Marette, A. (1997) Electrical stimulation induces. fiber type-specific translocation of GLUT-4 to T tubules in skeletal muscle. Am I Physiol 273. E688-694

35. Lund, S., Holman, G. D., Schmitz, O., and Pedersen, O. (1995) Contraction stimulates transilocation of glucose transporter GLUT4 in skeletal muscle through a mechanism distinct from that of insulin. Proc Nati Acad Sci U S A 92, 5817-5821

36. Coven, D. L., Hu, X., Cong, L., Bergeron, R., Shulman, G. I., Hardie, D. G., and Young, L. H. (2003) Physiological role of AMP-activated protein kinase in the heart: graded activation during exercise. Am I Physiol Endocrinol Metab 285, E629-636

37. Kurth-Kraczek, E. J., Hirshman, M. F. Goodyear, L. I, and Winder, W. W. (1999) 5" AMPactivated protein kinase activation causes GLUT4 translocation in skeletal muscle. Diabetes 48, 1667-1671

38. Glatz. J. F., Luiken, J. J., van Bilsen, M., and van der Vusse, G. J. (2002) Cellular lipid binding proteins as facilitators and regulators of lipid metabolism. Mol Cell Biochem 239, 3-7

39. Spector, A. A. (1984) Plasma lipid transport. Clin Physiol Biochem 2, 123-134.

40. Kamp, F., and Hamilton, J. A. (1992) pH gradients across phospholipid membranes caused by fast flip-flop of un-ionized fatty acids. Proc Nati ACad SCi U SA 89, 11367-11370

41. Hamilton, J. A. (1998) Fatty acid transport: difficult or easy? J Lipid Res 39, 467-481.

42. Hamilton, J. A. (1999) Transport of fatty acids across membranes by the diffusion mechanism. Prostaglandins Leukot Essent Fatty Acids 60, 291-297

43. Stump, D. D. Nunes, R. M., Sorrentino, D., Isola, L. M., and Berk, P. D. (1992) Characteristics of oleate binding to liver plasma membranes and its uptake by isolated hepatocytes. $f$ Hepatol 16, 304-315

44. Bonem, A., Luiken, J. J., Liu, S., Dyck, D. J., Kiens, B., Kristiansen, S., Turcotte, L. P., Van Der Vusse, G. J., and Gilatz, J. F. (1998) Palmitate transport and fatty acid transporters in red and white muscles. Am I Physiol 275. E471-478

45. Stremmel, W. (1988) Fatty acid uptake by isolated rat heart myocyles represents a carriermediated transport process. I Clin Invest $81.844-852$ 
46. Luiken, J. J., Turcotte, L. P." and Bonen, A. (1999) Protein-mediated palmitate uptake and expression of faty acid transport proteins in heart giant vesicles.J Lipid Res 40, 1007-1016

47. Luiken, J. I. Schaap, F. G., van Nieuwenhoven, F. A, van der Vusse, G. J., Bonen, A., and Glatz, J. F. (1999) Cellular fatty acid transport in heart and skeletal muscle as facilitated by proteins. Lipids 34 Suppl, $5169-175$

48. Hamilton, J. A. Guo, W., and Kamp, F. (2002) Mechanism of cellular uptake of long-chain fatty acids: Dowe need cellular proteins? Mol Cell Biochem 239, 17-23

49. Hamiton, J. A. (2003) Fast flip-flop of cholesterol and fatty acids in membranes: implications for membrane transport proteins. Curr Opin Lipidol 14, 263-271

50. Coburn, C. T., Knapp, F. F., Jr., Febbraio, M., Beets, A. L., Silverstein, R. L., and Abumrad, N. A. (2000) Defective uptake and utilization of long chain fatty acids in muscle and adipose tissues of CD 36 knockout mice. J Biol Chem 275, 32523-325.29

51. Febbraio, M., Abumrad, N. A., Hajjar, D. P. Sharma, K., Cheng, W., Pearce, S. F., and Silverstein, R. L. (1999) A null mutation in murine CD36 reveals an important role in fatty acid and lipoprotein metabolism. J Biol Chem 274, 19055-19062

52. Febbraio M., Guy, E., Coburn, C. Knapp, F. F., Jr., Beets, A. L., Abumrad, N. A., and Silverstein, R. L. (2002) The impact of overexpression and deficiency of fatty acid translocase (FAT)/CD36. Mol Cell Biochem 239, 193-197

53. Ibrahimi, A, Bonen, A., Blinn, W. D., Hajri, T., Li, $X_{\text {, }}$ Zhong, $K_{*}$, Cameron, R, and Abumrad, N. A. (1999) Muscle-specific overexpression of FAT/CD36 enhances fatty acid oxidation by contracting muscle, reduces plasma triglycerides and fatty acids, and increases plasma glucose and insulin. J Biol Chem 274, 26761-26766

54. Bonen, A. Luiken, J. J., Arumugam, Y., Glatz, J. F., and Tandon, N. N. (2000) Acute regulation of fatty acid uptake involwes the cellular redistribution of fatty acid translocase. $J$ Biol Chem 275, 14501.14508

55. Fischer, $Y_{\text {. }}$ Rose, $H_{4}$ and Kammermeier, $H$. (1991) Highly insulin-responsive isolated rat heart muscle cells yielded by a modified isolation method. Life Sci 49, 1679-1688

56. Luiken, J. J., Coort, S. L., Willems, J., Coumans, W. A., Bonen, A., van der Vusse, G. J., and Gilatz, 1. F. (2003) Contraction-induced fatty acid translocase/CD36 translocation in rat cardiac myocytes is mediated through AMP-activated protein kinase signaling. Diabetes $52,1627-1634$ 


\section{Long-chain fatty acid uptake and FAT/CD36 translocation in heart and skeletal muscle}

Debby P.Y. Koonen", Jan F.C. Glatz ${ }^{1}$, Arend Bonen ${ }^{2}$, and Joost J.F.P. Luiken ${ }^{1,3}$

1. Dept. of Molecular Genetics, Cardiovascullar Research Institute Maastricht (CARIM), Maastricht University, NL-6200 MD Maastricht, the Netherlands

2. Dept. of Human Biology and Nutritional Sciences, University of Guelph. Guelph, ON, N1G 2W1, Canada

3. Dept. of Biochemical Physiology and Institute of Biomembranes, Utrecht University, Utrecht, the Netherlands 


\section{Abstract}

Cellular long-chain fatty acid (LCFA) uptake constitutes a process that is not yet fully understood. LCFA uptake likely involves both passive diffusion and protein-mediated transport. Several lines of evidence support the involvement of several plasma membrane-associated proteins, including fatty acid translocase (FAT)/CD36, plasma membrane-bound fatty acid binding protein (FABPpm), and fatty acid transport protein (FATP). In skeletal muscle and heart primary attention has been given to unravel the mechanisms by which FAT/CD36 expression and function are regulated. It appears that both insulin and contractions in muscle and heart induce the translocation of intracellularly stored FAT/CD36 to the plasma membrane to increase cellular LCFA uptake. This review focuses on this novel mechanism of regulation of LCFA uptake in heart and skeletal muscle in health and disease. The distinct signaling pathways underlying insulin-induced and contraction-induced FAT/CD36 translocation will be discussed, and a comparison will be made with the well-defined glucose transport system involving the glucose transporter GLUT4. Finally, it will be hypothesized how malfunctioning of recycling of these transporters will lead to intracellular triacylglycerol (TAG) accumulation and cellular insulin resistance. The present data indicate a pivotal role for FAT/CD36 in the regulation of muscular LCFA utilization in both health and disease. Hence, FAT/CD36 might provide another therapeutic target for the prevention or treatment of insulin resistance.

\section{Introduction}

Long-chain fatty acids (LCFAs) exert a variety of functions, from building blocks for phospholipids to precursors for several intracellular signalling molecules, i.e., prostaglandins, leukotrienes, and thromboxanes (1-3). LCFAs are, however, also essential as a source of energy storage (4), and serve as metabolic substrates to generate ATP efficiently through mitochondrial $\beta$-oxidation. Cardiac and skeletal muscles neither have the ability to synthesize LCFA de novo, nor do they possess an unlimited storage capacity for LCFA (5). These tissues, therefore, rely extensively on the uptake of exogenous LCFA that are derived largely form the adipose tissue (6).

The major source of LCFA supply is derived from circulating albumin-bound LCFA, while triacylglycerols as part of very low-density lipoproteins (VLDL) and of chylomicrons form an additional but minor source of LCFAS $(5,7,8)$. Although extraction of albumin-bound LCFAs from the circulation is very efficient in the heart (5), LCFA uptake in cardiac and skeletal myocytes comprises a complex and incompletely understood process, involving their transfer through several barriers $(5,9,10)$. These barriers comprise the luminal and abluminal endothelial membranes, the endothelial cytoplasm, the interstitial phase and the sarcolemma $(9,10)$. The underlying mechanisms of LCFA transfer are only partly understood but it is generally believed that different mechanisms are involved. Kinetic evidence suggests that trans-capillary movement of LCFA may be facilitated by soluble fatty acid-binding proteins (FABPC) in the endothelial cytoplasm $(5,11)$, while albumin most likely mediates the movement of LCFA through the interstitium (5). Similar to their 
hypothetical function in endothelial cytoplasm, FABPC have been proposed as carriers of LCFA through the cytoplasm of heart and muscle cells to facilitate the exchange of LCFA between intracellular membranes $(12,13)$.

Although the transfer of LCFA through each barrier constitutes a relevant and important process (for review see $(5,14)$ ), this review will focus on the characteristics of one aspect of cellular LCFA uptake across the plasma membrane: that is protein-mediated LCFA uptake into heart and skeletal muscle cells. In recent years, prominent roles have been given to fatty acid translocase (FAT)/CD36, plasmalemmal fatty acid-binding protein (FABPpm), and fatty acid transport protein (FATP) in the facilitation of LCFA uptake by heart and skeletal muscles $(13,15)$. Recently, evidence was provided for an acute regulation of LCFA uptake by insulin and muscular contractions, involving FAT/CD36 translocation to the cell surface (13). The outline of this review is, therefore, first to give a brief background into cellular LCFA uptake, then to describe the underlying mechanism and signaling pathways involved in the acute regulation of LCFA uptake by recycling of FAT/CD36 between intracellular storage compartments and the plasma membrane. Finally, the attention will be drawn on the impact of physiologic stimuli (chronic exercise, aging, dietary interventions) and pathophysiological conditions (diabetes, obesity) on this novel regulatory mechanism of sarcolemmal LCFA transport.

\section{Sarcolemmal transport of LCFA}

\section{LCFA uptake mechanism: a controversial topic}

The mechanism of transfer of LCFA through the sarcolemmal barrier has been controversial for a long time. LCFAs are able to diffuse rapidly through the lipid bilayer by spontaneous flip-flop of non-ionized LCFAs with the transmembrane gradient of LCFAs as the driving force $(16,17)$. Although traditionally diffusion was believed to be sufficient to meet cellular LCFA demands $(16,17)$, an additional mechanism displaying specific features of protein-mediated transport (e.g." saturation and competitive inhibition) was observed in several tissues, including cardiac and skeletal muscles (18-22). The introduction of giant sarcolemmal vesicles in which LCFA transport across the plasma membrane is divorced from subsequent LCFA metabolism (for review see (23)), clearly emphasized the existence of a protein-mediated transport mechanism $(24,25)$. Furthermore, pharmacological inhibition of this protein-mediated transport system suggested the involvement of both diffusion and protein-mediated transport as coexisting components in sarcolemmal LCFA uptake to allow the migration of LCFAS through the plasma membrane $(13,15,24-26)$.

Several plasma membrane-associated proteins have been identified as candidate transport proteins according to their 'putative' rolle in protein-mediated LCFA transport (27-29). Substantial evidence for a prominent role in protein-mediated LCFA transport across the sarcolemmal barrier is available for FAT/CD 36, FABPpm, and FATP $(13,15,24$, 29,30 ). Because most of the features of LCFA uptake resemble that of a classic transport system, the protein-mediated LCFA uptake system has been termed a LCFA transport 
system for matter of convenience (23). However, current insight into the membrane topology of these proteins does not suggest these proteins to act as typical transporters, despite their apparent transport-like function (31).

\section{FAT/CD36, FABPpm and FATP}

FAT, the rat homologue of human CD36, is an $88-\mathrm{kDa}$ heavily glycosylated integral membrane protein with two transmembrane domains, two short cytoplasmic tails and an extracellular domain $(32,33)$. FAT/CD 36, once expressed into cells normally lacking this protein, can bind LCFAs with high affinity and has been shown to increase LCFA uptake (34). Furthermore, studies in FAT/CD36 transgenic and null mice emphasized a physiological role for FAT/CD36 by illustrating that altered changes in muscle LCFA uptake rates paralleled the changes in FAT/CD36 expression $(29,35-38)$. FAT/CD36 is predominantly expressed in tissues that favour LCFA utilization, e.g., heart, red skeletal muscles and adipocytes $(24,25,39-41)$. However, in liver, which organ plays a key role in body LCFA homeostasis, FAT/CD36 expression is relatively low (39). In muscle tissues FAT/CD36 expression is correlated with muscle oxidative capacity (heart $\gg$ red muscles $>$ white muscles) $(24,25,39,41)$.

FABPpm is a $43-\mathrm{kD}$ a peripheral membrane protein anchored with its hydrophobic tail to the outer leaflet of the plasma membrane, and is identical to mitochondrial aspartate aminotransferase (mAspAT) $(42,43)$. The reason why FABPpm is a bifunctional protein with two unrelated and entirely different functions is still unknown. Similar to FAT/CD36, FABPpm can bind LCFAs with high affinity, and a higher expression of FABPpm is directly linked to an increase in LCFA uptake $(30,44)$. Inhibition studies of FABPpm also indicated that reductions in LCFA uptake rates were directly parallel with the extent of FABPpm inhibition (22). FABPpm is ubiquitously expressed in liver, heart, skeletal muscle and adipose tissue and the expression pattern in different muscle types resembles that of FAT/CD36 (25).

In addition to FAT/CD36 and FABPpm, a family of LCFA transport proteins (FATPS) have been implicated in facilitating LCFA uptake as well. FATPs are integral membrane proteins with several transmembrane domains, and overexpression of FATP in cell lines has been shown to enhance LCFA uptake (45-47). Six members of the FATP family (FATP16) have been identified $(31,47,48)$, of which FATP1 and FATP4 are expressed in adipose tissue, heart and skeletal muscle $(45,48)$. The most recently identified member, FATP6, is heart-specific and is the predominant FATP family member in this organ (47).

\section{Molecular mechanism of transmembrane movement of LCFA}

The mechanisms by which FAT/CD36, FABPpm and FATP each are thought to facilitate LCFA uptake across phospholipid billayers are poorly described. Several predominantly hypothetical models have been proposed (48-52), and are outlined in Fig. 2.1. Besides passive diffusion of LCFA (Fig. 2.1; arrow 1), FAT/CD36 and FABPpm each have been suggested to mediate LCFA uptake by accelerating fatty acid dissociation from albumin (Fig. 2.1; arrow 2) (1, 42, 49-51). 


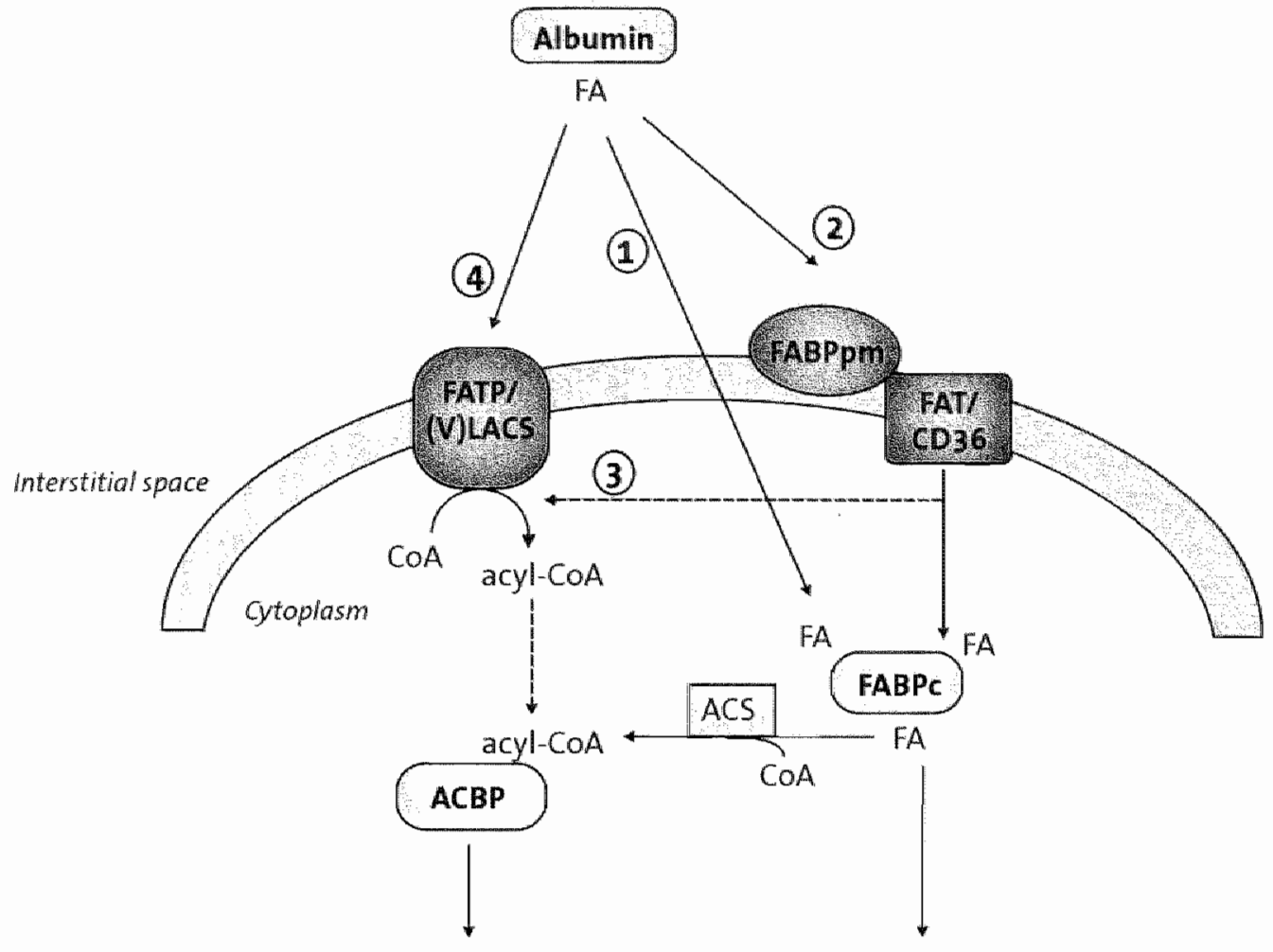

Oxidation/esterification/acylation Signal transduction

Figure 2.1. Schematic representation of LCFA transport in heart and skeletal muscle. The numbers 1-4 illustrate the proposed models of LCFA uptake. Besides passive diffusion (1), evidence suggests the interaction of FAT/CD36 and FABPpm in protein-mediated LCFA transport to accelerate the dissociation of LCFAs from albumin (2). FAT/CD 36 has also been proposed to interact with FATP for subsequent uptake of LCFAS (3). Alternatively, FATP has been suggested to transfer ICFAs directly across the plasma membrane (4). Once in the cytoplasm. LCFAs are bound to $A A B P C$, of upon activation to aCyl-COA at the AMP-binding site of FATP, the formed acyl-CoA esters will bind to acylCoA-binding protein (ACBP) before entering metabolic or other pathways (redrawn from $(13,178)$ ).

In addition FAT/CD36 has been proposed to promote facilitated diffusion by catalyzing the integration of protonized LCFA into the outer phospholipid bilayer (50). Consequently, accumulation of LCFA in the outer layer would occur, creating a diffusional gradient across the plasma membrane, thus facilitating LCFA flip-flop to the inner membrane (50). LCFA would subsequently bind to FABPC for transcytoplasmic transport to subcellular targets $(12,13,53)$. A role for FAT/CD36 in protein-membrane, proteinprotein, and protein-lipid interactions has been suggested by the finding that both the $N$ and C-terminal cytoplasmic tails of FAT/CD36 can be palmitoylated (33.54). A proteinprotein interaction between FAT/CD36 and FABPpm in the fatty acid uptake process has 
been proposed $(1,13)$. The view that both proteins might act in conjunction is plausible, since specific inhibition of either FAT/CD 36 or FABPpm reduced LCFA to a similar extent, while simultaneous inhibition of FAT/CD36 and FABPpm did not provoke an additional decrease in LCFA uptake (25). Notably, recent evidence has indicated that both FAT/CD36 and FABPpm are associated at the plasma membrane (Campbell S.E. and Bonen A.s unpublished data).

FAT/CD 36 has also been proposed to interact with FATP for subsequent uptake of LCFA (Fig. 2.1; arrow 3) $(3,47,48,51)$, which is supported by the finding of colocalization of FATPG and FAT/CD36 in cardiac sarcolemmal regions (47). Alternatively, FATPs have been suggested to transfer LCFA directly across the plasma membrane (Fig. 2.1; arrow 4) (45, 48). Most FATPS, including FATP1, exhibit intrinsic acyl-COA synthethase activity with a broad specificity for both LCFAs and very long-chain fatty acids (VLCFAs) $(49,55-57)$. FATPs might, therefore, facilitate LCFA uptake via esterification-coupled influx, also referred to as 'metabolic trapping' $(47,49)$. In addition to the putative binding site that is part of the acyl-COA synthetase reaction mechanism, FATP1 also contains a proposed ligand (fatty acid) binding pocket $(49,58)$. Hence, FATP1 has been proposed to be a bifunctional protein, and it remains to be investigated whether LCFA import is driven by this intrinsic acyl-COA synthethase activity or whether transport and activation are distinct functions of FATP1 (57).

\section{Acute regulation of sarcolemmal LCFA uptake}

Cardiac and skeletal myocytes strongly rely on the uptake of LCFAs for energy storage and supply. LCFAs, their COA derivatives and their metabolites are also directly or indirectly capable of regulating the activity of many cellular processes (i.e., gene expression, enzyme function, ion channel and membrane receptor activity) $(1,2,59)$. A tight regulation of all aspects of LCFA disposition, including LCFA uptake seems therefore desirable $(4,27)$. Recent insights indicate a pivotal role for FAT/CD36 in the acute regulation of muscular LCFA uptake and utilization. Therefore, we will now focus on the role of FAT/CD36 in the metabolic response of muscle to acute physiological stimuli such as cellular contractions and the hormone insulin.

\section{Effect of short-term electrical contractions on LCFA uptake}

Previously, it was shown that LCFA uptake is increased by applying short-term electrical contractions ( $<30 \mathrm{~min})$ to skeletal muscles in vivo $(60,61)$. Although direct proof was lacking, it was suggested that LCFA uptake in contracting muscles could be linked to an activation or translocation of LCFA transporters to the membrane, thereby promoting LCFA transfer across the plasma membrane. In subsequent work several lines of evidence revealed the regulation of LCFA uptake by a translocation mechanism of FAT/CD36 from an intracellular pool to the cell surface (62). Short-term electrically induced muscle contraction in vivo increased LCFA uptake into muscle giant vesicles, prepared from contracting muscle (Fig. 2.2A). 

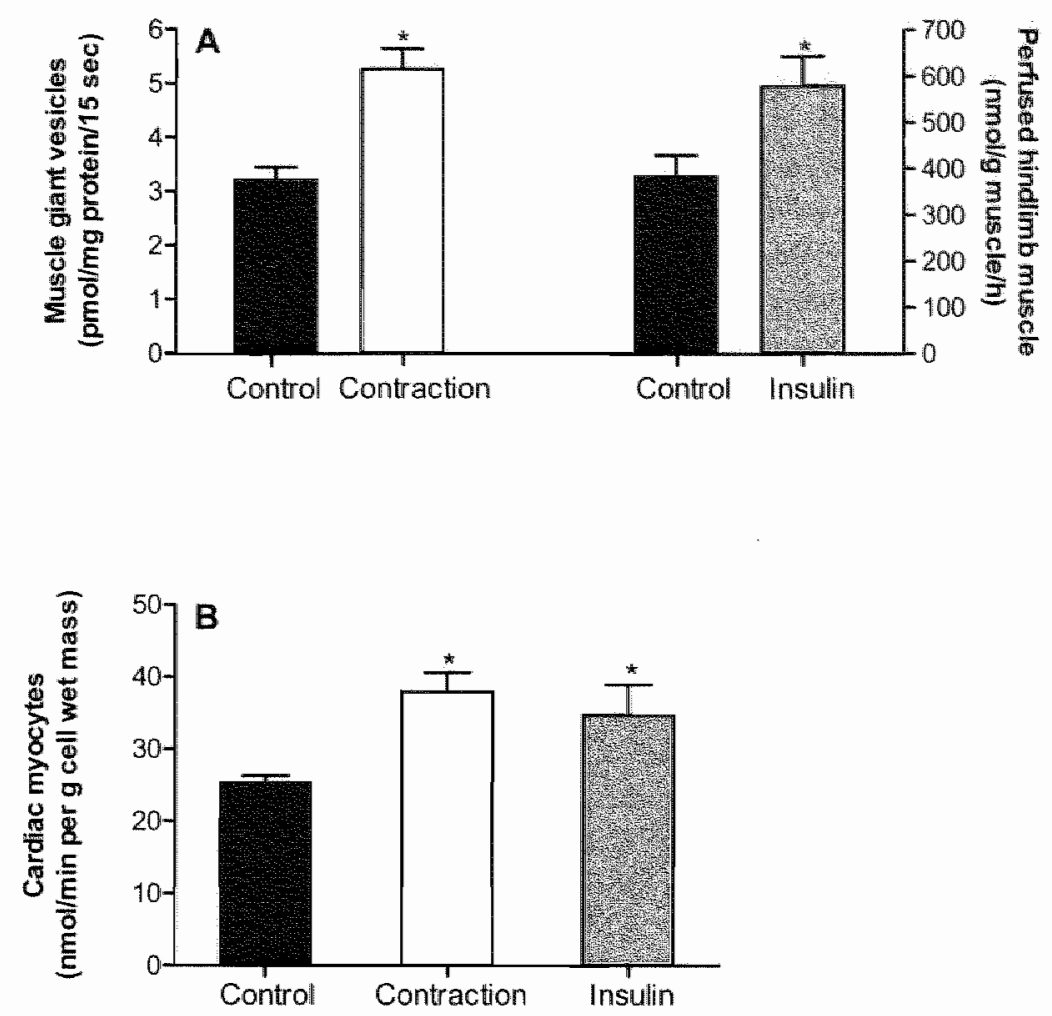

Figure 2.2. Effect of insulin and contractions on palmitate uptake in muscle giant vesicles, hindlimb muscle, and cardiac myocytes. Palmitate uptake is increased in giant vesiscles derived from 30 min. stimulated skeletal muscle ( $A$, left panel) and in cardiac myocytes stimulated to contract (B). In addition to contractions, palmitate uptake is enhanced by the hormone insulin in perfused hind limb muscle (A, right panel) and in cardiac myocytes (B) (redrawn from $(62,65,103)$ ).

This increase was inhibited by sulpho- $\mathrm{N}$-succinimidyloleate ( $\mathrm{SSO}$ ), a specific inhibitor of FAT/CD36 (63), emphasizing an FAT/CD36-mediated mechanism in contraction-inducible LCFA uptake (62). Fractionation studies in resting muscle demonstrated the presence of FAT/CD36 both at the surface and in an intracellular membrane compartment (Fig. 2.3). The onset of contractions caused a decrease in the amount of intracellular FAT/CD36, while FAT/CD36 at the surface was simultaneously increased (62). Since de novo synthesis of FAT/CD36 is not occurring within 30 mins of muscle contraction, acute regulation of LCFA uptake most likely occurs through a translocation of FAT/CD36 from an intracellular membrane compartment to the plasma membrane (62). Thus, when the contracting muscle cell requires additional LCFAs for oxidation, the translocation of FAT/CD 36 to the sarcolemma facilitates the additional influx of LCFAs for these purposes, while circulating LCFA concentrations are not altered. 
More recently, Luiken and co-workers (64) investigated the effect of contractions on FAT/CD 36 and LCFA uptake in cardiac myocytes in suspension by using electrical field stimulation. Stimulation (4 Hz, $30 \mathrm{~min}$ ) increased palmitate uptake (Fig. 2.2B) and oxidation, while esterification into cellular lipid pools was not significantly altered (64). Thus, during contractions the extra LCFAs taken up are efficiently channelled into mitochondrial $\beta$-oxidation. The increase in palmitate uptake was blocked in the presence of either verapamil (a contraction inhibitor) or sulfo- $\mathrm{N}$-succinimidyl-FA esters, further indicating that LCFA uptake in contracting cardiac myocytes is also increased due to increased flux through FAT/CD36 (64). Subsequently, solid evidence was obtained for a translocation of FAT/CD 36, similar to that in skeletal muscle, as the underlying mechanism to increase LCFA uptake in contracting cardiac myocytes (65)(Fig. 2.3).

\section{Contraction-mediated signaling pathway}

Exercise is known to stimulate several components of intracellular signaling pathways (66). The underlying mechanism of contraction-induced translocation of FAT/CD36 might be linked to the activation of the sympathetic nervous system, the actual metabolic status of the muscle during contraction, or to the intramyocellular $\mathrm{Ca}^{2+}$-concentration (for review see (67)). Likely candidates for kinases that may regulate LCFA transport in heart and muscle cells are therefore protein kinase A (PKA), adenosine monophosphate

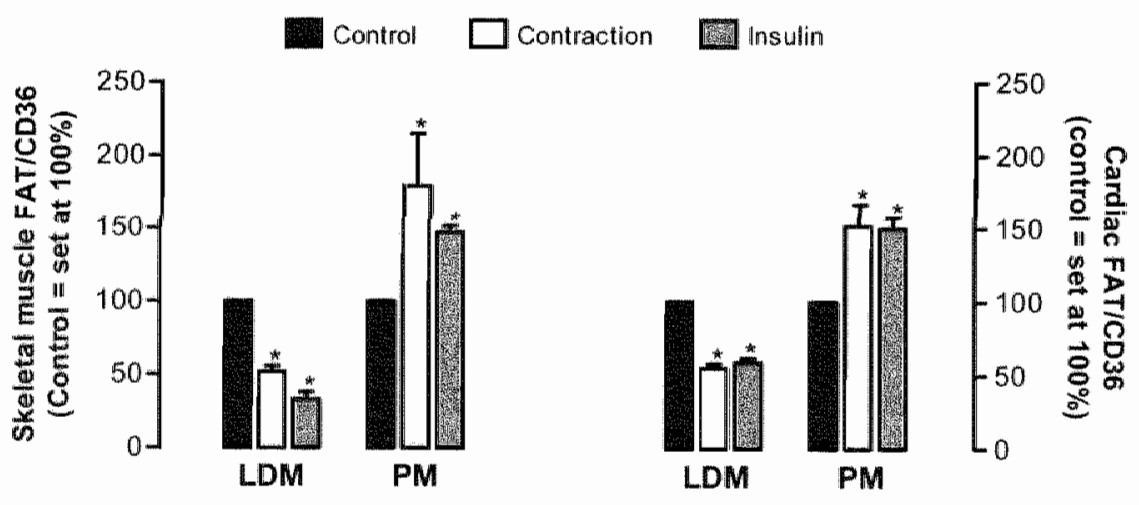

Figure 2.3. Effect of insulin and contractions on cellular distribution of FAT/CD36 in heart and skeletal muscle. In the presence of insulin, the FAT/CD36 content in the intracellular fraction (LDM) is reduced, while concomitantly the expression of FAT/CD36 in the plasma membrane fraction (PM) is increased in both muscle (left panel) and heart (right panell). Likewise, contractions induce the translocation of intracellular stored FAT/CD36 (LDM) to the plasma membrane (PM) in skeletal muscle (left panel) and heart (right panel) (redrawn from 62,65, 103, 104)).

(AMP)-activated protein kinase (AMPK), members of the protein kinase C (PKC) family, and mitogen-activated protein kinase (MAPK). 


\section{Protein kinase A}

It is well document that myocyte contractility is regulated by intracellular levels of adenosine $3^{\prime}: 5^{\prime}$-cyclic monophosphate (CAMP). Effects of CAMP on contraction are mediated through protein-kinase A (PKA) induced phosphorylation of proteins involved in myocardial $\mathrm{Ca}^{2+}$ regulation $(68,69)$. PKA has been shown to inhibit acetyl-CoA carboxylase (ACC), the rate limiting enzyme in malonyl-COA formation which has been shown to control LCFA oxidation (70).

Recently, it was confirmed that in rat cardiac myocytes LCFA oxidation is enhanced and esterification is simultaneously reduced via a CAMP-dependent PKA mechanism (71). However, in these studies there was no difference in net LCFA uptake when PKA was either activated by the $\beta$-agonist isoproterenol or by the cell permeable analogue dibutyryl CAMP (71). In contrast, an additional method to increase intracellular CAMP levels by inhibition of CAMP breakdown via different phosphodiesterase (PDE) inhibitors did not result in similar findings. Amrinone and zaprinast did not enhance LCFA uptake, whereas 3-isobutyl-1-methylxanthine (IBMX), milrinone and dipyridamole (DPY) did stimulate LCFA uptake in isolated cardiac myocytes. Evidently, the mechanism of action of these latter PDE inhibitors is unrelated to the induced elevation of CAMP (71). Both IBMX and milrinone were found to enhance an increase in intrinsic activity of FAT/CD36 at the plasma membrane, while DPY induced an intracellular translocation of FAT/CD36 to the membrane to increase LCFA sarcolemmal uptake (71).

\section{AMP-activated protein kinase}

AMPK, which acts as a metabolic sensor, can be activated by a change in energy state of the cell, as reflected by increases in the AMP/ATP ratio (72) and creatine/phosphocreatine ratio (73). Exercise is an important physiological stimulator of the AMP/ATP ratio, but this ratio can also be increased pharmacologically by the mitochondrial inhibitor oligomycin (65) (fig. 2.4). The cell-permeable adenosine analogue 5 -aminoimidazole-4-carboxamide-1- $\beta$-ribofuranoside (AICAR), can also activate AMPK pharmacologically, but through formation of AICAR monophosphate (ZMP) (74). In addition, AMPK can also be allosterically activated through phosphorylation by an upstream AMPK-kinase (AMPKK) (75).

AMPK activation has been shown to promote LCFA oxidation in heart $(76,77)$ and skeletal muscles (74, 78-80) through the phosphorylation and inhibition of acetyl-CoA carboxylase (ACC). ACC has been shown to produce malonyl-CoA, which inhibits carnitine palmitoyltransferase I (CPT1), the enzyme controlling the transfer of LCFAs into the mitochondria (74). Thus, in these tissues activation of AMPK results in a reduction of ACC activity, a decrease in malonyl-COA levels, and a stimulation of LCFA oxidation.

The ability of AICAR and oligomycin to stimulate LCFA uptake in a non-additive manner to electrical stimulation, provided the first evidence that AMPK activation is involved in contraction-induced FAT/CD36 translocation in cardiac myocytes (65). Previously, nonspecific effects of AICAR, unrelated to AMPK activation, have been reported on intermediary metabolism $(81,82)$. In the presence of the adenosine kinase inhibitor 5iodotubercidin the effect of AICAR on LCFA uptake was, however, abolished, indicating 
that AMPK activation by ZMP formation is necessary for AICAR to stimulate LCFA Uptake (65). Thus, the activation of AMPK has a wider impact on substrate metabolism than had previously been presumed. ACtivation of AMPK not only promotes LCFA oxidation (74, 7680) and glucose uptake through translocation of the glucose transporter GLUT4 (74, 83. 84). AMPK activation, however, also has a potent effect on LCFA uptake and inducing FAT/CD36 translocation (65). This allows an efficient channelling of the incoming LCFAs into mitochondrial $\beta$-oxidation during increased energy demands.

\section{Protein kinase $\mathrm{C}$}

Other candidate kinases mediating contraction-induced FAT/CD 36 translocation include the PKC family consisting of at least twelve isoforms. There are three classes of PKC isoforms, depending on their ability to be activated by $\mathrm{Ca}^{2 *}$ or by the lipid metabolite diacylglycerol (DAC) (85): i) the class of conventional PKC isoforms, activated by both $\mathrm{Ca}^{2 *}$ and DAG; ii) novel PKC isoforms, activated by DAG onlly; iii) atypical PKC isoforms, activated by neither $\mathrm{Ca}^{2+}$ nor DAG. Muscle contraction has been shown to activate both the conventional and novel PKC isoforms $(86,87)$ suggesting their involvement in substrate uptake. The phorbol ester, phorbol 12-myristate 13-acetate (PMA), is a cell-. permeable DAG analogue frequently used to pharmacologically activate the conventional and novel PKC isoforms. PMA has been shown to induce the translocation of GLUT4 in adipocytes, leading to enhanced glucose uptake $(88,89)$. Recently, it was shown that PMA stimulates both glucose and LCFA uptake in rat cardiac myocytes, but PMA was without effect on AMPK activation (90). Nometheless, in the presence of specific PKC inhibitors AMPK activation does not result in substrate transporter translocation (Luiken J.J.F.P., Willems J., Coort S.L.M. and Glatz J.F.C., unpublished data). Conventional and/or novel PKC isoforms might, therefore, be involved in contraction-induced translocation of both GLUT4 and FAT/CD36 in cardiac myocytes as a potential downstream target of AMPK. Interestingly, $\mathrm{Ca}^{2+}$-modulating agents do not stimulate substrate uptake by cardiac myocytes, hence Ca $\mathrm{Ca}^{2+}$-signaling is probably not necessary for the induction of substrate transported translocation (90). These observations, therefore, suggest that downstream of AMPK, but upstream of PKC, a lipid metabolizing enzyme must be activated to generate DAG necessary for subsequent PKC activation and translocation of GLUT4 and FAT/CD 36.

\section{MAPK signaling}

Mitogen-activated protein kinases (MAPKs) are ubiquitous signaling proteins involved in control of cell growth, differentiation and adaptation. Four parallel MAPK signaling cascades have been identified and the MAPK family members include the classic extracellular signal-regulated kinase (ERK) 1 (P44 MAPK) and 2 (P42 MAPK), the stressactivated protein kinase (SAPK)/Jun N-terminal kinases (JNK), P38 MAPK, and ERK3, -4 and $-5(91)$. 


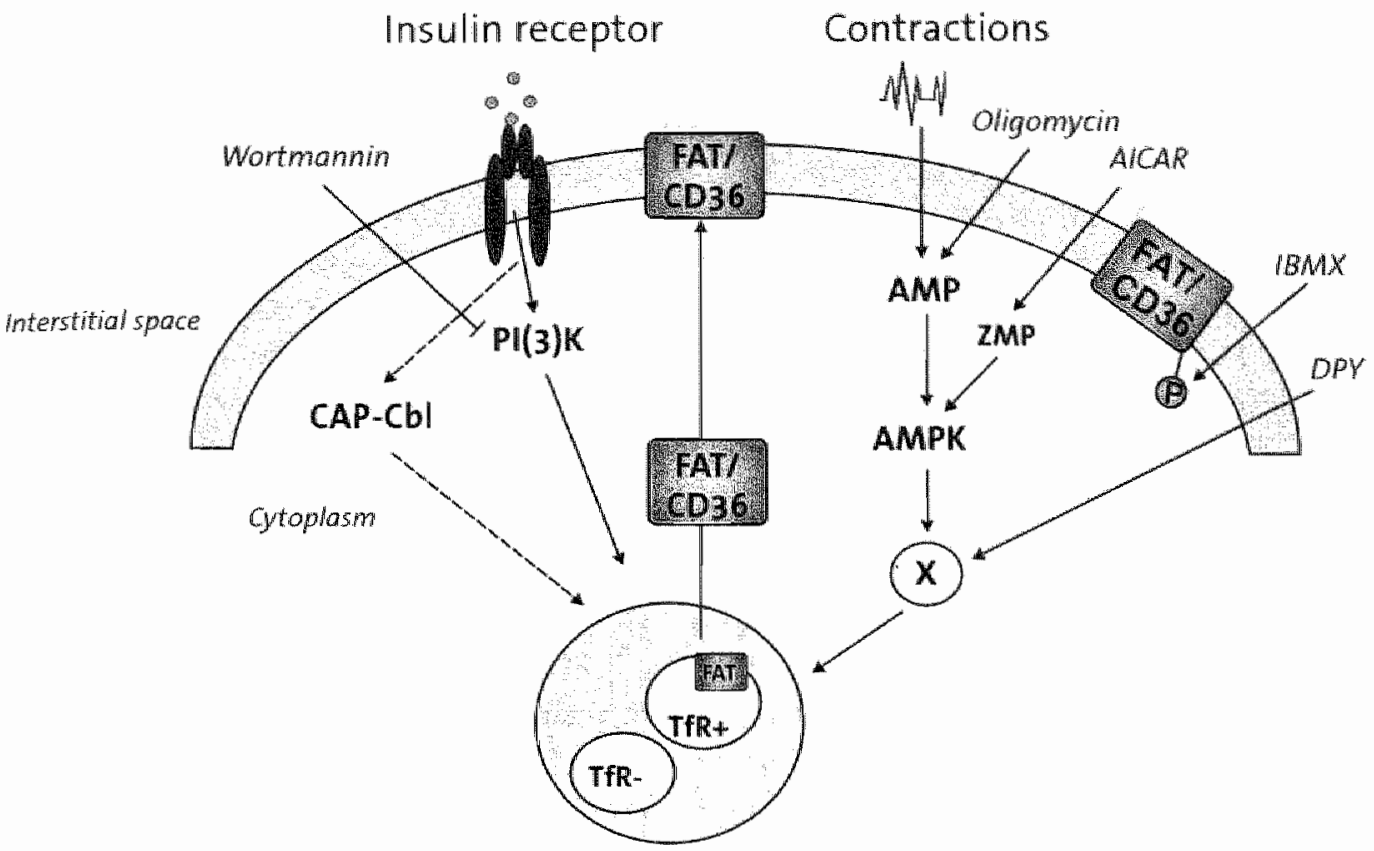

Figure 2.4. Schematic representation of the main signaling components involved in the mobilization of FAT/CD 36 by insulin and contractions in heart and skeletal muscle. Insulin recruits intracellular FAT/CD36 via a phosphatidylinositol-3-OH-kinase (PI(3)K)-dependent mechanism, since the the $\mathrm{PI}(3) \mathrm{K}$-inhibitor wortmannin reduces LCFA uptake. An additional PI(3)K-independent insulin-signaling pathway (CAP-CDI) might be involved in LCFA uptake in these tissues as well. Cellular contractions elevate intracellular AMP, activate AMP-activated protein kinase (AMPK) and hence induce FAT/CD 36 translocation. LCFA uptake can be enhanced by pharmacological activation of contraction-induced signaling by the mitochondrial F1FO-ATPase inhibitor oligomycin, and the cell permeable adenosine analog 5-aminoimidazole-4-carboximide-1-beta-D-ribofuranoside (AICAR). In contrast, the phosphodiesterase inhibitor 3-isobutyl-1-methylxanthine ( BMX) increases the intrinsic activity of FAT/CD 36, whereas dipyridamole (DPY) provokes FAT/CD36 translocation via stimulation of an unknown target $(X)$ downstream of AMPK.

Phosphorylation is required for the activation of MAPK, and for the subsequent phosphorylation of different cytoplasmic targets or translocation to the nucleus to affect transcription (92). Cardiac and skeletal muscle cells have been shown to express components of MAPK signaling pathways $(93,94)$, and MAPK signaling has been suggested to mediate substrate uptake and metabolism in muscle in response to exercise $(66,93,95,96)$. Physical exercise is a potent stimulator of P42/44 MAPK and P38 MAPK signaling in human and skeletal muscle $(66,94,97)$. Activation of upstream and downstream targets of p42/44 and p38 MAPK signaling have been seen in response to exercise and muscle contraction evoked by electrical stimulation $(94,96,98,99)$. 
Substantial evidence has ruled out a role for contraction-activated p42/44 MAPK signaling in the acute regulation of glucose transport and glycogen synthesis in skeletal muscle $(93.95)$. In contrast, activation of p38 MAPK is likely to participate in the stimulation of glucose uptake in contracting skeletal muscles (96). Partial reductions in contraction-induced glucose uptake have been observed in rat skeletal muscle by SB203580, a specific inhibitor of the P38 MAPKo and $-\beta$ isoforms (96). Since P38 MAPK is not likely to interfere with GLUT4 translocation from intracellular stores to the cell surface (100), p38 MAPK has been proposed to function as an integral component of the signaling pathway regulating GLUT4 activity. Although an increase in intrinsic activity of FAT/CD36 has been seen in cardiac myocytes upon incubation with the PDE inhibitors milrinone and IBMX (71) (Fig. 2.4), it is highly speculative to suggest a role for MAPK herein. To date, it remains to be investigated whether MAPK pathways might be involved in the acute regulation of contraction-induced LCFA uptake by FAT/CD36.

\section{Effect of insulin on regulation of LCFA transport}

Insulin is the most potent anabolic hormone and has a profound impact on cellular metabolism in general (for review see (101)). Insulin promotes the synthesis and storage of carbohydrates, lipids and proteins, inhibits their degradation and release into the circulation, and stimulates glucose and amino acid uptake into cells.

Recently, evidence was provided for a stimulatory role of insulin on muscular LCFA uptake as well (102-104). The novel observation was made that insulin was capable of increasing LCFA uptake in both skeletal muscles and cardiac myocytes (102-104) (Fig. 2.2). This acute effect of insulin on LCFA uptake was attributable to a translocation of intracellular stored FAT/CD36 to the plasma membrane, thereby promoting sarcolemmal LCFA uptake, both in vitro and in vivo (103,104) (Fig. 2.3). Notably, in the presence of insulin, the extra palmitate taken up is exclusively directed toward lipid esterification into triacylglycerols (TAG) $(102,103)$. In skeletal muscle, insulin has been shown to increase LCFA esterification while simultaneously reducing LCFA oxidlation (102). The exact mechanism of insulin's inhibition on LCFA oxidation is not known, but might be related to the level of AMPK activity. In AICAR perfused muscle, and in the working and ischaemic heart where the level of AMPK activity is increased, insulin has been shown to inhibit AMPK activity $(26,105-109)$. As a result, the phosphorylation of ACC is increased and LCFA oxidation is reduced. In addition, AMPK has been shown to inhibit glycerol-3phosphate acyitransferase (GPAT), the enzyme that catalysis the initial and committed step in glycerolipid biosynthesis (79). The observed insulin-mediated increase in GPAT and subsequent rise in LCFA esterification might therefore be explained by the insulininduced attenuation in AMPK activity in muscle. In addition, insulin is belleved to be the most important anti-lipolytic hormone and might contribute, via lowered CAMP levels, to the increase in LCFA esterification by mediating hormone sensitive lipase, a key enzyme in the mobilization of TAG (110). 


\section{Signaling events involved in insulin-induced FAT/CD 36 translocation}

\section{$\mathrm{PI}(3) \mathrm{K}$-dependent insulin signaling pathway}

in unraveling the signaling pathway involved in the stimulation of LCFA uptake by insulin-induced FAT/CD36 translocation, it was observed that blocking phosphatidylinositol-3-OH kinase $(\mathrm{PI}(3) \mathrm{K})$ by structurally unrelated $\mathrm{PI}(3) \mathrm{K}$ inhibitors (wortmannin, LY-294002) prevented the insulin-induced translocation of FAT/CD36 in cardiac and skeletal muscles (103, 104). Clearly, a Pl(3)K-dependent mechanism is involved in the signal transduction pathway utillized by insulin to stimulate LCFA uptake in these tissues. Since activation of $\mathrm{P} \|(3) \mathrm{K}$ is known to promote glucose uptake through translocation of GLUT4 (111), LCFA uptake presumably requires a similar mechanism, upstream of PI(3)K activation. Therefore, insulin stimulation of PI(3)K in LCFA uptake most likely includes autophosphorylation of the insulin receptor, activation of intrinsic receptor kinase activity, and subsequent phosphorylation of insulin receptor substrates $($ IRS-1/-2) (112). Two downstream effectors of $\mathrm{PI}(3) \mathrm{K}$ have been proposed in insulinstimulated GLUT4 translocation, i.e., the serine/threonine Akt or protein kinase $B$ (Akt/PKB) (113), and atypical isoforms of protein kinase $C$, i.e., PKC $\zeta$ and $\lambda$, which are not activated by phorbol esters (114). Whether similar downstream targets of PI(3)K are required for FAT/CD36 translocation is currently unknown.

\section{PI(3)K-independent insulin signaling pathway}

Evidence is accumulating for the presence of a novel insulin signaling pathway in adipocytes, initiated by the phosphorylation of the proto-oncogene product, $\mathrm{Cbl}$, followed by localization of $\mathrm{Cbl}$-assaciated protein (CAP)/Cbl complexes to lipid raft subdomains of the plasma membrane (caveolae) and eventually leading to GLUT4 translocation (115). In contrast to the classic pathway of insulin signaling, the activation of $\mathrm{cbl}$ initiates an insulin signaling cascade independent of PI(3)K and Akt/PKB signaling, but is however crucial to insulin-stimulated GLUT4 translocation (115-117). Since, transcripts of the key players CAP and TC10 are enriched in both skeletal and cardiac muscle, this CAP-Cbl pathway might play a specific role in insulin signaling to glucose uptake in these tissues as well $(116,118)$. Furthermore, it remains to be established whether this PI(3)K/PKB-independent signaling process is also involved in FAT/CD36 translocation in cardiac and skeletal muscles.

\section{MAPK signaling}

While contractions have been shown to activate MAPK signaling (section 3.2.4), insullin has also been shown to activate MAPK signaling in skeletal muscle $(66,95,96,119)$. The classic Erk1 and Erk2 MAPK (P44/42 MAPK), however, do not play a major role in mediating insulin's metabolic responses. The activation of glucose and amino acid transport and of glycogen synthase in response to insulin have been shown to be independent of p42/44 MAPK signaling (95). Therefore, p42/44 MAPK activation by insulin is unlikely to play a role in the activation of LCFA transport by FAT/CD36. In contrast, insulin does activate p38 MAPKa and p38 MAPK $\beta(96,119,120)$, and inhibition 
of 938 MAPK has been shown to reduce the insullin-stimulated glucose uptake in skeletal muscle partially. Since, P38 MAPK does not affect CLUT4 insertion into the plasma membrane, 138 MAPK has been proposed to regulate glucose transport by increasing the intrinsic activity of GLUT4 on the membrane $(96,119,121)$, and as such might play a role in LCFA uptake as well.

\section{FAT/CD36 intracellular storage pools}

From the novel observations outlined above, it can be pointed out that there is a remarkable parallel between the acute regulation of FAT/CD36-mediated LCFA uptake and the regulation of glucose uptake by GLUT4 in heart and skeletal muscles. In line with glucose uptake, insulin and contractions exhibit an additive effect on LCFA uptake in heart and skeletal muscle $(65,102,104)$. Notably, PI(3)K-signaling is not involved in the regulation of LCFA uptake in electrostimulated and AICAR-/oligomycin-treated cardiomyocytes $(65,104)$, and vice versa AMPK activation is not part of the insulinsignaling pathway involved in the recruitment of FAT/CO36 (65). Therefore, it might be emphasized that at least two separate signaling pathways exist by which FAT/CD36 can be recruited to the cell surface. Since, identical signaling pathways are involved in the intracellular recruitment of GLUT4 $(84,122,123)$, it might be hypothesized that both FAT/CD36 and GLUT4 reside in similar intracellular storage compartments. Identification of GLUT4 containing intracellular pools, revealed the existence of both large and small depots, representing the GLUT4 specific pre-endosomal storage compartment and the recycling endosomal compartment, respectively (124-126). These small depots, i.e., recycling endosomes, can be subdivided into transferrin receptor (TfR)-positive depots primarily recruited by contractions and TfR-negative depots mainly recruited by insulin $(125,127)$.

Colocalization of FAT/CD 36 and the majority of intracellular stored GLUT4 was, however, not observed, excluding the GLUT4-specific pre-endosomal storage compartment as an intracellular depot of FAT/CD36 (128). The same authors did find a colocalization between FAT/CD36 and a member of the Rab family, Rab11, which predominantly resides within the recycling endosomes (128). This observation emphasizes the possible involvement of recycling endosomes in the storage of intraceliular FAT/CD36. Immunohistochemical studies are, however, needed to examine whether FAT/CD36 is stored intracellularly into similar contraction- and insulin-sensitive depots within the recycling endosomes.

\section{LCFA uptake in health and disease}

\section{Physiological significance of LCFA transporter expression in LCFA uptake}

Over the last few years, the physiological role of the putative fatty acid transporters FAT/CD36 and FABPpm in LCFA uptake have become more evident. Regulation of LCFA uptake in response to several stimuli has been observed in cardiac and skeletal muscle. 
Cardiac gene expression of FAT/CD36 is increased in a rat model of short bowel syndrome to compensate for the decreased supply of LCFA to the heart due to malabsorption of dietary fat intake (129). Treatment of these rats with a high-fat diet reduced FAT/CD36 expression in the rat myocardium (129).

In muscle, the LCFA uptake system is capable of adapting to changes in muscle activity, diet and aging by changing the expression levels of the putative LCFA transport proteins FAT/CD36 and/or FABPpm. The cellular content of FABPpm has been shown to increase after long-term exercise, such as endurance training $(130,131)$. In contrast, FABPpm gene and protein expression were not increased after short-term exercise training for 9 days, while LCFA oxidation was significantly increased and adaptations were seen in FAT/CD36 gene and protein contents (132). On the other hand, chronic low frequency muscle stimulation has been shown to enhance LCFA uptake, while FAT/CD36 and FABPpm protein and sarcolemmal expression were concomitantly increased $(133,134)$. An increased abundance of skeletal muscle FABPpm has been observed in short-term fasting, a nutritional intervention resulting in an increased reliance on LCFAs as oxidizable fuel (135). Rapid increases in FAT/CD36 gene expression have been shown after lipid infusion in human adipocytes (136) and in rat skeletal muscle (137). Similarly, increases in FAT/CD36 protein in skeletal muscle have been reported after high-fat feeding (138). The increase in LCFA uptake seen in skeletal muscle of aged rats (24months) has recently been reported to coincide with increased FAT/CD36 and FABPpm protein content (139).

\section{LCFA transporter relocation}

In line with all these observations, a change in the level of gene and protein expression has been commonly seen as underlying mechanism in this adaptation process. Gene and/or protein expression is, however, not always altered, as observed in chronic leptin administration, in obesity, and after sciatic nerve denervation in which LCFA uptake is significantly changed (Table 2.1). Palmitate transport rates into giant sarcolemmal vesicles, as well as FAT/CD36 mRNA and protein expression were reduced following two weeks of leptin treatment (140). However, FABPpm mRNA and total protein expression were not altered, whereas less FABPpm was present on the plasma membrane (140). Recently, additional evidence was provided for an altered subcellular distribution pattern, i.e., relocation, of both FAT/CD 36 and FABPpm. We observed that 7 days of muscle inactivity (sciatic nerve denervation) concomitantly reduced LCFA uptake and sarcolemmal expression of FAT/CD36 and FABPpm, whereas transporter protein expression in the denervated hindlimb was unaltered (134). Reciprocally, an increase in plasma membrane expression of FAT/CD36 and FABPpm and LCFA uptake was observed in the hearts and skeletal muscle of obese Zucker rats, while protein expression was not altered (141). Collectively, these data suggest that cycling of these transporters between the plasma membrane and the intracellular depot has been altered chronically. Most likely, this impaired transporter cycling might be due to an increased exocytosis (release) 
of stored LCFA transporters, a decrease in endocytosis (internalization) of plasma membrane-bound LCFA transporters, or a combination of both.

\begin{tabular}{|c|c|c|c|c|c|}
\hline \multirow[t]{2}{*}{ Condition } & \multirow[t]{2}{*}{ LCFA uptake } & \multicolumn{2}{|c|}{ Total content } & \multicolumn{2}{|c|}{ Sarcolemmal content } \\
\hline & & FAT/CD 36 & FABPpm & FAT/CD 36 & FABPpm \\
\hline \multicolumn{6}{|l|}{ Interventions (muscle tissue) } \\
\hline Acute stimulation $(62,65,71)$ & 1 & $=$ & $=$ & $\uparrow$ & H \\
\hline Chronic stimulation $(133,134)$ & 1 & $\uparrow$ & $\uparrow$ & $\uparrow$ & $\uparrow$ \\
\hline Denerwation $(134)$ & $\downarrow$ & $=$ & $=$ & $\downarrow$ & $\downarrow$ \\
\hline Leptin treatment $(140)$ & $\downarrow$ & $\downarrow$ & $=$ & $\Downarrow$ & $\sharp$ \\
\hline Aging (139) & 1 & $\$$ & 4 & nd & nd \\
\hline \multicolumn{6}{|l|}{ Disease-related (cardiac tissue) } \\
\hline STZ-rats $(176)$ & 1 & 1 & 1 & 1 & $\uparrow$ \\
\hline Obesity $(141)$ & $\uparrow$ & $=$ & $\approx$ & $\uparrow$ & 4 \\
\hline
\end{tabular}

Table 2.1. Effects of physiological and pathophysiological stimuli on LCFA uptake and expression of the putative LCFA transporters, FAT/CD36 and FABPpm. An increase in total cellular expression of FAT/CD 36 and FABPpm is one mechanism by which LCFA uptake is regulated, as observed in skeletal muscle upon chronic stimulation (133,134), and by aging (139), and in streptozotocin (5T2)-treated rats (176). Regulation of LCFA uptake does not necessarily involve alterations in total protein expression. Instead, FAT/CD36 and FABPpm might be relocated towards the cell surface, as seen in acute stimulation $(62,65,177)$ and in obesity $(141)$, or, as observed in 7 -day denervated hindlimb muscle (134) and upon leptin treatment, back towards the storage compartment. Abbreviations: ind, not determined.

\section{LCFA uptake and insulin resistance}

Mary insulin-resistant states such as obesity and type 2 diabetes have been associated with an increase in plasma LCFA and an accumulation of intramuscular triacylglycerols (TAG) (142). This intracellular rise in TAG by itself is not harmful, but is an indicator of elevated levels of other lipid intermediates such as DAG, ceramides and long-chain acylCoAs (142-144). These lipid intermediates have been proposed to interfere in the insulinsignaling cascade by activating several isoforms of PKC and by inhibiting Akt/PKB activation. For instance, DAG might lead to activation of PKC $\theta$ and $\varepsilon(144-146)$. These PKC isoforms can phosphorylate and inhibit tyrosine kinase activity of the insulin receptor and IRS-1, thereby preventing insulin to properly stimulate glucose transport into muscle and causing peripheral insulin resistance $(144,147)$. Ceramides might interfere with insulin signaling at a more downstream level as these metabolites are regarded as 
specific inhibitors of Akt/PKB activation (147). Finally, acyl-CoAs might directly affect glucose utilization by altering the activity of glycolytic enzymes (148).

Skeletal muscle accounts for the majority of insulin-stimulated glucose utilization, and is, thus, regarded as the major site of insulin resistance in obesity and type 2 diabetes (149). However, dramatic increases in myocardial TAG content are positively correlated with the development of insulin resistance as well (150-152). To date, the mechanism(s) responsible for accumulation of TAG and lipid derivatives in both skeletal muscle and heart are not evident. Several mechanisms have been postulated, and it remains to be investigated whether LCFA-mediated insulin resistance is the result of i) a decrease in LCFA oxidation, ii) an increase in LCFA delivery/supply, or iii) alternatively an increase in LCFA uptake.

i) Oxidation. A defect in LCFA oxidation, i.e., reduced activity of oxidative enzymes in skeletal muscle has been found in obesity and in relation to insulin resistance (153-156). It is questionable, however, whether an altered oxidation rate might be the primary factor in developing lipid-mediated insulin resistance. Although, LCFA oxidation is decreased in skeletal muscle of extremely obese individuals, no reduction in oxidative rate has been observed in skeletal muscle of moderate obese/overweight humans (157159). Moreover, accumulation of intramyocellular long-chain fatty acyl-CoAs is not solely a result of reduced LCFA oxidation, since elevations in long-chain fatty acyl-CoAs content have been observed in skeletal muscles of both extremely and moderately obese humans (158). In hearts of pre-diabetic insulin-resistant obese Zucker rats, LCFA oxidation is only impaired upon fasting $(151,160)$, whereas fasting did not affect LCFA oxidation in the isolated working heart of insulin-resistant JCR:LA-CP rats (152). Hence, additional factors, i.e., supply or uptake, must be involved to explain the initial accumulation of TAG in insulin resistant skeletal muscle and heart.

ii) Supply. Plasma LCFAs are commonly elevated in obesity and have previously been suggested to represent the link between obesity and insulin resistance (161). An increase in LCFA delivery into the cell can trigger insulin resistance, as was shown in transgenic mice with muscle overexpression of lipoprotein lipase, the rate controlling enzyme involved in TAG hydrolysis (162). Generally, there is good evidence to suggest that an increase in circulating LCFAs can induce insulin resistance by interfering with insulin signaling $(142,161,163,164)$. Acute elevations of plasma LCFA levels produce insulin resistance in healthy and diabetic subjects, while lowering chronically elevated plasma LCFA levels overnight results in significantly improved insulin sensitivity in obese diabetic patients (165-167). However, plasma LCFAs and TAC are not increased in every insulinresistant model $(141,162,168)$. Notably, an increase in plasma LCFAs and TAG per sé does not necessarily result in peripheral insulin resistance, but might be related to improvements in insulin sensitivity instead (169-171). In mice overexpressing human apoC1, strongly elevated plasma LCFA levels were found in combination with increased insulin sensitivity (169). Moreover, insulin sensitivity is improved in mice deficient for CD36, in which plasma LCFA and TAG levels are increased, due to the reduced peripheral LCFA uptake $(170,171)$. In addition, a recent report on FATP1 knockout mice, indicated that, despite elevations in plasma LCFA levels, FATP1 knockout mice were protected from 
lipid-induced increases in intramuscular fatty acyl-COA and insulin resistance (172). Collectively these studies indicate that insulin resistance is not increased by simply elevating the circulating plasma concentrations of LCFAs. Only when the excess of LCFAS can enter the cell, insulin sensitivity is impaired. Thus, altering the rate of LCFA transport into muscle cells may have a key role in insulin resistance.

iii) Uptake. In both cardiac and skeletal muscle giant sarcolemmal vesicles as well as in cardiac myocytes obtained from obese, pre-diabetic Zucker rats, the rate of LCFA uptake is markedly upregulated $(118,141,173)$. The increase in LCFA transport is not associated with an increase in the total expression of FAT/CD36, but is rather associated with an increase in FAT/CD36 on the cell surface $(141,173)$. Although the observed increase in cardiac TAG esterification was reflective to a 2 -fold increase in FAT/CD36 abundance at the plasma membrane (160), more definite evidence for a direct link between increased LCFA flux and sarcolemmal FAT/CD36 levels was provided with the specific FAT/CD36 inhibitor, 550 (63). FAT/CD36-mediated LCFA uptake, esterification into TAG, and the level of unesterified LCFAs in cardiac myocytes from obese Zucker rats were reduced by treatment with 550 to basal levels as seen in lean littermates (160).

Likewise, an elevated LCFA uptake rate has been observed in skeletal muscle of obese and type 2 diabetic patients (159). Notably, the excess accumulation of intramuscular TAG was strongly associated with an upregulation of the LCFA transport rate across the sarcolemma due to an increased amount of FAT/CD36 on the cell surface (159). Thus, it is likely that impaired FAT/CD36 cycling is responsible for elevated LCFA uptake and accumulation of TAG in obese heart and skeletal muscle in rodents and humans. In addition, it is well known that GLUT4 cycling between the cell surface and intracellular depots is impaired, and GLUT4 is retained in the intracellular depots, despite similar levels of total available GLUT4 (174). Thus, impairment of GLUT4 and FAT/CD36 recycling in obesity and diabetes type 2 results in opposite effects on their subcellular redistribution, i.e. GLUT4 is retained within intracellular depots, whereas FAT/CD36 is retained at the cell surface (141).

Interestingly, in cardiac myocytes of 11-week old pre-diabetic insulin-resistant obese Zucker rats displaying 7-fold elevated blood insulin levels and normal glucose levels, basal and insulin-stimulated glucose uptake were not significantly different from lean littermates (173). However, basal LCFA uptake was upregulated in cardiac myocytes of obese Zucker rats, and insulin lost the ability to further enhance LCFA uptake in these rats (173). This suggests that, at least in heart, alterations in FAT/CD36 regulation might be an early step in developing insulin resistance.

\section{Future perspectives}

Since FAT/CD36 is likely to contribute to the etiology of insulin resistance, FAT/CD36 might provide another therapeutic target for the prevention or treatment of insulin resistance. Hence, unravelling the molecular mechanisms of FAT/CD 36 translocation is very important. In specific, the differences with the regulation of translocation of GLUT4 can help to identify therapeutic strategies to allow selective manipulation of substrate 
transporter recruitment, and thus, can help to restore normal substrate balance. In this respect, it was recently found, that the PDE inhibitor dipyridamole (DPY) specifically enhanced cardiac LCFA uptake by recruiting FAT/CD36 to the cell surface (71), while DPY did not influence glucose uptake nor did it induce GLUT4 translocation (175). The stimulatory action of DPY on LCFA uptake was related to a PI(3)K-independent signaling mechanism and involved an unknown target downstream of AMPK. Hence, it might be speculated that downstream of AMPK the contraction-induced signaling cascade branches off into two separate pathways, each leading to specific mobilization of intracellularly stored GLUT4 and FAT/CD36. Whether a similar mechanism holds true for insulin-stimulated FAT/CD36 and GLUT4 signaling is unknown. Hence, more research is needed to unravel the mechanisms involved in mediating the insulin-and contractioninduced FAT/CD36 cycling in cardiac and skeletal muscle.

Although FAT/CD36 has been recognised as responsible for most LCFA uptake in heart and skeletal muscles, it should be emphasized that little is known about FABPpm, FATP1 and the heart-specific FATP6. Hormonal regulation of FATP1 by insulin has been observed in adipocytes (46), but to date no information is available whether FATP1 or FATP6 can be regulated in skeletal muscle and heart. Recent data from FATP1 knockout mice, however, has indicated an important role for FATP1 in the pathogenesis of type 2 diabetes (172). Hence, the putative LCFA transporters FAT/CD36 and FATP1 are both likely to represent an attractive therapeutic target for the prevention or treatment of insulin resistance.

\section{Acknowledgements}

The studies performed in the authors' laboratories have been supported by grants from the Netherlands Organization for Scientific Research (ZonMW 903.39.194), the Canadian Institutes of Health Research (CIHR), the Natural Sciences and Engineering Research Council of Canada (NSERC), and the Canada Research Chair program.

A. Bonen holds a Canada Research Chair in Metabolism and Health.

J.F.C. Glatz is Netherlands Heart Foundation Professor of Cardiac Metabolism.

J.J.F.P. Luiken is a recipient of a VIDI-Innovation Research Grant from the Netherlands Organization for Scientific Research (ZonMw 016.036.305). 


\section{References}

1.

Glatz, J. F., Borchers, T., Spener, F., and van der Vusse, G. J. (1995) Fatty acids in cell signalling: modulation by lipid binding proteins. Prostaglandins Leukot Essent Fatty Acids $52,121.127$

MeArthur, M. 1., Atshaves, B. P., Frolov, A., Foxworth, W. D. Kier, A. B., and Schroeder, F. (1999) Cellular uptake and intracellular trafficking of long chain fatty acids. ILipid Res 40 , $1371-1383$

3. Brinkmann, J. F., Abumrad, N. A., Ibrahimi, A., van der Vusse, C. 1., and Glatz, J. F. (2002) New insights into long-chain fatty acid uptake by heart muscle: a crucial role for fatty acid translocase/CD36. Biochem/367,561-570

4. Henin, N., Vincent, M. F., Gruber, H. E., and Van den Berghe, G. (1995) Inhibition of fatty acid and cholesterol synthesis by stimulation of AMP-activated protein kinase. Faseb / 9 , $541-546$

5. van der Vusse, G. J., Glatz, f. F, Stam, H. C., and Reneman, R. S. (1992) Fatty acid homeostasis in the normoxic and ischemic heart. Physiol Rev 72, 881-940

6. Van der Vusse, G. J., van Bilsen, M. Glatz, J. F., Hasselbaink, D. M., and Luiken, J. J. (2002) Critical steps in cellular fatty acid uptake and utilization. Mol Cell Biochem 239, 9-15

7. Carlson, L. A., Kaijser, L., and Lassers, B. W. (1970) Myocardial metabolism of plasma triglycerides in man. I Mol Cell Cardiol $1,467-475$

8. Jensen, M. D. (2003) Fate of fatty acids at rest and during exercise: regulatory mechanisms. Acta Physiol Scand 178, 385-390

9. Bassingthwaighte, J. B., Noodleman, L., van der Vusse, G., and Glatz, J. F. (1989) Modeling of palmitate transport in the heart. Mol Cell Biochem $88,51-58$

10. Berk, P. D., and Stump, D. D. (1999) Mechanisms of cellular uptake of long chain free fatty acids. Mol Cell Biochem 192, 17-31

11. Goresky, C. A., Stremmel, W., Rose, C. P., Guirguis, S., Schwab. A. J., Diede, H. E., and Ibrahim, E. (1994) The capillary transport system for free fatty acids in the heart. Circ Res 74. $1015-1026$

12. Schaap, F. G., Binas, B., Danneberg, H., van der Vusse, G. I., and Glatz, 1. F. (1999) Impaired long-chain fatty acid utilization by cardiac myocytes isolated from mice lacking the hearttype fatty acid binding protein gene. Circ Res $85,329-337$

13. Glatz, J. F. and Storch, J. (2001) Unravelling the significance of cellular fatty acid-binding proteins. Curr Opin Lipidol 12, 267-274

14. van der Vusse, G. J., vam Bilsen, M., and Glatz, J. F. (2000) Cardiac fatty acid uptake and transport in health and disease. Cardiovasc Res $45,279-293$

15. Schaffer, J. E. (2002) Fatty acid transport: the roads taken. Am I Physial Endocrinol Metab $282, E 239-246$

16. Zakim, D. (1996) Fatty acids enter cells by simple diffusion. Proc Soc Exp Biol Med 212, 5-14

17. Hamilton, 1. A. (1999) Transpont of fatty acids across membranes by the diffusion mechanism. Prostaglandins Leukot Essent Fatty Acids 60, 291-297

18. Abumrad, N. A. Perkins, R. C., Park, J. H., and Park, C. R. (1981) Mechanism of long chain fatty acid permeation in the isolated adipocyte. $J$ Biol Chem 256, 9183-9191

19. Abumrad, N. A., Park, J. H., and Park, C. R. (1984) Permeation of long-chain fatty acid into adipocytes. Kinetics, specificity, and evidence for involvement of a membrane protein. I Biol Chem 259, 8945-8953

20. Stremmel, W. and Berk, P. D. (1986) Hepatocellular influx of [14C]oleate reflects membrane transport rather than intracellular metabolism or binding. Proc Nat/ Acad SciU SA $83,3086-3090$

21. Sorrentino, D., Stump, D., Potter, B. J., Robinson, R. B., White, R., Kiang, C. L., and Berk, P. D. (1988) Oleate uptake by cardiac myocytes is carrier mediated and involves a 40-kD plasma membrane fatty acid binding protein similar to that in liver, adipose tissue, and gut. $J$ Clin invest $82,928.935$

22. Turcotte, L. P., Swenberger, J. R., Tucker, M. Z., Yee, A. J., Trump, G., Luiken, J. J., and Bonen, A. (2000) Muscle palmitate uptake and binding are saturable and inhibited by antibodies to FABP(PM). Mol Cell Biochem 210, 53-63 
Bonen, A. Luiken, J. J., and Gilatz, J. F. (2002) Regulation of fatty acid transport and membrane transporters in health and disease. Mol Cell Biochem 239, 181-192

24. Bonen, A., Luiken, J. J., Lu, S., Dyck, D. I., Kiens, B., Kristiansen, S., Turcotte, L. P., Van Der Vusse, G.J., and Glatz, J. F. (1998) Palmitate transport and fatty acid transporters in red and white muscles. Am I Physiol 275, E471-478

25. Luiken, J. J., Turcotte, L. P., and Bonen, A. (1999) Protein-mediated palmitate uptake and expression of fatty acid transport proteins in heart giant vesicles /Lipid Res 40, 1007-1016 Glatz, J. F., Luiken, J. J., wan Nieuwenhoven, F. A., and Van der Vusse, G. J. (1997) Molecular mechanism of cellular uptake and intracellular translocation of fatty acids. Prostaglandins Leukat Essent Fatty Acids 5.7. 3-9

27. Berk, P. D., Zhou, S. L. Kiang, C. L., Stump, D., Bradbury, M., and Isola, L. M. (1997) Uptake of long chain free fatty acids is selectively up-regulated in adipocytes of Zucker rats with genetic obesity and non-insulin-dependent diabetes mellitus. J Biol Chem 272,8830-8835

28. Hui, T. Y., and Bernlohr, D. A. (1997) Fatty acid transporters in animal cells. Front Biosci 2, d $222-231$

29. Bonen, A., Benton, C. R., Campbell, 5. E., Chabowski, A., Clarke, D. C., Han, X. X., Glatz, J. F., and Luiken, J. 1. (2003) Plasmalemmal fatty acid transport is regulated in heart and skeletal muscle by contraction, insulin and leptin, and in obesity and diabetes. Acta Physiol Scand $178,347-356$

30. Clarke, D. C., Miskovic, D., Han, X.-X., Calles-Escandon, J., Glatz, J. F., Luiken, J. J., and Bonen, A. (2004) Overexpression of Membrane Associated Fatty Acid Binding Protein (FABPpm) in Vivo Increases Fatty Acid Sarcolemmal Transport and Metabolism. Physiol. Genomics $17(1): 31-7$

31. Lewis, S. E., Listenberger, L. L., Ory, D. S., and Schaffer, J. E. (2001) Membrane topology of the murine fatty acid transport protein 1. J Biol Chem 276, 37042-37050

32. Greenwalt, D. E., Scheck, S. H., and Rhinehart-Jones, T. (1995) Heart CD36 expression is increased in murine models of diabetes and in mice fed a high fat diet. $J$ Clin Invest 96 , $1382-1388$

33. Tao, N., Wagner, S. J., and Lublin, D. M. (1996) CD36 is palmitoylated on both $\mathbb{N}_{-}$and C. terminal cytoplasmic taills. J Biol Chem 271, 22315-22320

34. Ibrahimi, A., Sfeir, Z., Magharaie, H., Amri, E. Z, Grimaldi, P., and Abumrad, N. A. (1996) Expression of the CD36 homolog (FAT) in fibroblast cells: effects on fatty acid transport. Proc Nat/ Acad SciU SA 93, 2646-2651

35. Febbraio, M. Abumrad, N. A., Hajjar, D. P., Sharma, K., Cheng, W., Pearce, S. F., and Silverstein, R. L. (1999) A mull mutation in murine CD36 reveals an important role in fatty acid and lipoprotein metabolism. I Biol Chem 274, 19055-19062

36. Ibrahimi, A., Bonen, A., Blinn, W. D., Hajri, T., Li, X., Zhong. K., Cameron, R. and Abumad, N. A. (1999) Muscle-specific overexpression of FAT/CD36 enhances fatty acid oxidation by contracting muscle, reduces plasma triglycerides and fatty acids, and increases plasma glucose and insulin. J Biol Chem 274, 26761-26766

37. Coburn, C. T., Knapp, F. F., Jr., Febbraío, M., Beets, A. L., Silverstein, R. L., and Abumrad, N. A. (2000) Defective uptake and utilization of long chain fatty acids in muscle and adipose tissues of CD36 knockout mice. J Bial Chem 275, 32523-32529

38. Febbraio, M., Guy, E., Coburn, C., Knapp, F. F., Jr., Beets, A. L., Abumrad, N. A., and Silverstein, R. L. (2002) The impact of overexpression and deficiency of fatty acid transllocase (FAT)/CD36. Mol Cell Biachem 239, 193-197

39. Van Nieuwenhoven, F. A., Verstijnen, C. P., Abumrad, N. A., Willemsen, P. H., Van Eys, G. ע., Van der Vusse, G. J., and Glatz, J. F. (1995) Putative membrane fatty acid translocase and cytoplasmic fatty acid-binding protein are co-expressed in rat heart and skeletal muscles. Biochem Biophys Res Commun 207, 747-752

40. Abumrad, N., Harmon, C, and Ibrahimi, A. (1998) Membrane transport of long-chain fatty acids: evidence for a facilitated process. / Lipid Res 39, 2309-231.8

41. Pelsers, M. M., Lutgerink, J. T., Nieuwenhoven, F. A., Tandon, N. N., van der Vusse, G. I., Arends, J. W., Hoogenboom, H. R., and Glatz, J. F. (1999) A sensitive immunoassay for rat fatty acid translocase (CD36) using phage antibodies selected on cell transfectants: 
abundant presence of fatty acid translocase/CD 36 in cardiac and red skeletal muscle and up-regulation in diabetes. Biochem 337 ( Pt 3), 407-414

42. Stremmel, W. Strohmeyer, G., Borchard, F, Kochwa, S, and Berk, P. D. (1985) Isolation and partial characterization of a fatty acid binding protein in rat liver plasma membranes. Proc Nati Acad Sci USA 82, 4-8

43. Berk, P. D., Wada, H., Horio, Y., Potter, B. J.s Sorrentino, D., Zhou, S. L., Isola, L. M., Stump, D., Kiang, $C_{n} L_{n}$, and Thung, 5. (1990) Plasma membrane fatty acid-binding protein and mitochondrial glutamic-oxaloacetic transaminase of rat liver are related. Proc Natl Acad SciU S.A $87,3.484-3.488$

44. Isola, L. M. Zhou, 5. L. Kiang, C. L., Stump, D. D., Bradbury, M. W., and Berk, P. D. (1995) 3 T3 fibroblasts transfected with a CDNA for mitochondrial aspartate aminotransferase express plasma membrane fatty acid-binding protein and saturable fatty acid uptake. Proc Natl Acad Sci U S A 92,9866-9870

45. Schaffer, J. E, and Lodish, H. F. (1994) Expression cloning and characterization of a novel adipocyte long chain fatty acid transport protein. Cell 79, 427-436

46. Stahl, A., Evans, J. G., Pattel, S., Hirsch, D., and Lodish, H. F. (2002) Insulin causes fatty acid transport protein translocation and enhanced fatty acid uptake in adipocytes. Dev Cell 2. $477 \cdot 488$

47. Gimeno, R. E., Ortegon, A. M., Patel, S., Punreddy, S., Ge, P., Sun, Y., Lodish, H. F., and Stahl, A. (2003) Characterization of a heart-specific fatty acid transport protein. 1 Biol Chem 278 , $16039-16044$

48. Stahl, A., Gimeno, R. E., Tartaglia, L. A., and Lodish, H. F. (2001) Fatty acid transport proteins: a current view of a growing family. Trends Endocrinol Metab 12, 266-273

49. Coe, N. R., Smith, A. J., Frohnert, B. I., Watkins, P. A., and Bernlohr, D. A. (1999) The fatty acid transport protein (FATP1) is a very long chain acyl COA synthetase. $J$ Biol Chem 274 . 36300 36304

50. Stremmel, W., Pohl, L., Ring, A., and Herrmann, T. (2001) A new concept of cellular uptake and intracellular trafficking of long-chain fatty acids. Lipids 36, 981-989

51. Glatz, J. F., Schaap, F. G., Binas, B., Bonen, A., Van Der Vusse, G. J., and Luiken, J. J. (2003) Cytoplasmic fatty acid-binding protein facilitates fatty acid utilization by skeletal muscle. Acta Physiol Scand 178, 367-371

52. Herrmann, T., van der Hoeven, F., Girone, H. J., Stewart, A. F., Langbein, L., Kaiser, I., Liebisch, G., Gosch, I., Buchkremer, F., Drobnik, W., Schmitz, G., and Stremmel, W. (2003) Mice with targeted disruption of the fatty acid transport protein 4 (Fatp 4, Slc27a4) gene show features of lethal restrictive dermopathy. I Cell Biol 161, 1105-1115

53. Spitsberg, V. L. Matitashvili, E., and Gorewit, R. C. (1995) Association and coexpression of fatty-acid-binding protein and glycoprotein $C D 36$ in the bovine mammary gland. Eur $f$ Biochem 230, 872-878

54. Jochen, A., and Hays, J. (1993) Purification of the major substrate for palmitoylation in rat adipocytes: N-terminal homology with CD36 and evidence for cell surface acylation. $J$ Lipid Res 34, 1783-1792

55. Hermanif, T., Buchkremer, F., Gosch, I., Hall, A. M., Bernlohr, D. A., and Stremmel, W. (2001) Mouse fatty acid transport protein 4. (FATP4): characterization of the gene and functional assessment as a very long chain acyl-CoA synthetase. Gene 270,31-40

56. Hatch, G. M., Smith, A. I., Xu, F. Y., Hall, A. M., and Bernlohr, D. A. (2002) FATP1 chamnels exogenous FA into 1,2,3-triacyl-sin.glycerol and down-regulates sphingomyelin and cholesterol metabolism in growing 293 cells. J Lipid Res 43,1380 -1389

57. Hall, A. M. smith, A. J., and Bernlohr, D. A. (2003) Characterization of the Acyl-CoA synthetase activity of purified murine fatty acid transport protein 1. 1 Biol Chem 278 , 43008-43013

58. Watkins, P. A., Lu, J. F., Steinberg, S. J., Gould, S. J., Smith, K. D., and Braiterman, L. T. (1998) Disruption of the Saccharomyces cerevisiae FAT1 gene decreases very long-chain fatty acyl-CoA synthetase activity and elevates intracellular very long-chain fatty acid concentrations. I Biol Chem 273, 18210.18219. 
59. Schmitz-Peiffer, C. (2000) Signalling aspects of insulin resistance in skeletal muscle: mechanisms induced by lipid oversupply. Cell Signal 12, 583-594.

60. Gorski, 1, and Bonen, A. (1997) Palmitate incorporation into lipids pools of contracting red and white muscles. Mol Cell Biochem 166, 73-83

61. Dyck, D. J., and Bonen, A. (1998) Muscle contraction increases palmitate esterification and oxidation and triacylglycerol oxidation. AmJ Physiol 275, E888-896

62. Bonen, A., Luiken, J. J., Arumugam, Y., Giatz, J. F., and Tandon, N. N. (2000) Acute regulation of fatty acid uptake involves the cellular redistribution of fatty acid translocase. Biol Chem 275, 14501-14508

63. Coort, S. L., Willems, J., Coumans, W. A., van der Vusse, G. 1., Bonen, A., Glatz, J. F., and Luiken, J. J. (2002) Sulfo-N-succinimidyl esters of long chain fatty acids specifically inhibit fatty acid translocase (FAT/CD 36)-mediated cellular fatty acid uptake. Mol Cell Biochem $239,213-219$

64. Luiken, J. J., Willems, J., van der Vusse, G. J., and Glatz, J. F. (2001) Electrostimulation enhances FAT/CD 36-mediated long-chain fatty acid uptake by isolated rat cardiac myocytes. Am I Physiol Endocrinol Metab 281, E704-712

65. Luikein, J. J., Coort, S. L., Willems, J., Coumans, W. A., Bonen, A., van der Vusse, G. J., and Glatz. J. F. (2003) Contraction-induced fatty acid translocase/CD36 translocation in rat cardiac myocytes is mediated through AMP-activated protein kinase signaling. Diabetes $52,1627-1634$

66. Goodyear, L. I., Chang, P. Y., Sherwood, D. I., Dufresne, S. D., and Moller, D. E. (1996) Effects of exercise and insulin on mitogen-activated protein kinase signaling pathways in rat skeletal musclle. Am J Physiol 271, E403-408

67. Richter, E. A., Nielsen, J. N., Jorgensen, S. B., Frosig, C., and Wojtaszewski, J. F. (2003) Signalling to glucose transport in skeletal muscle during exercise. Acta Physiol Scand 178 , 329-335

68. Rose, H., Strotmann, K. H., Popping, S., Fischer, Y., Kulsch, D., and Kammermeier, H. (1991) Simultaneous measurement of contraction and oxygen consumption in cardiac myocytes. Am J Physiol 261, H1329-1334

69. Hatmi, M., Gavaret, J. M., Elalamy, I., Vargaftig, B. B., and Jacquemin, C. (1996) Evidence for CAMP-dependent platelet ectoprotein kinase activity that phosphorylates platelet glycoprotein IV (CD36). J Biol Chen 271, 24776-24780

70. Dyck, J. R., Kudo, N., Barr, A. J., Davies, S. P., Hardie, D. G., and Lopaschuk, G. D. (1999) Phosphorylation control of cardiac acetyl-CoA carboxylase by CAMPmdependent protein kinase and 5".AMP activated protein kinase. Eur \& Biochem 262, 184-190

71. Luiken, J. J., Willems, J., Coort, S. L., Coumans, W. A., Bonen, A., Van Der Vusse, G. J., and Glatz, J. F. (2002) Effects of CAMP modulators on long-chain fatty-acid uptake and utilization by electrically stimulated rat cardiac myocytes. Biochem / 367, 881-887

72. Moore, F., Weekes, J. and Hardie, D. G. (1991) Evidence that AMP triggers phosphorylation as well as direct allosteric activation of rat liver AMP-activated protein kinase. A sensitive mechanism to protect the cell against ATP depletion. Eur J Biochem 199,691-697

73. Ponticos, M., Lu, Q. L. Morgan, J. E., Hardie, D. G. Partridge, T. A., and Carling, D. (1.998) Dual regulation of the AMP-activated protein kinase provides a novel mechanism for the control of creatine kinase in skeletal muscle. Embo J 17, 1688-1699

74. Merrill, G. F., Kurth, E. J., Hardie, D. G., and Winder, W. W. (1997) AlCA riboside increases AMP-activated protein kinase, fatty acid oxidation, and glucose uptake in rat muscle. Am Physiol 273, E1107-1112

75. Hardie, D. G., Carling, D., and Carlson, M. (1998) The AMP-activated/5NF1 protein kinase subfamily: metabolic sensors of the eukaryotic cell? Annu Rev Biochem 67.821-855

76. Saddik, M., Gamble, J., Witters, L. A., and Lopaschuk, G. D. (1993) Acetyl-CoA carboxylase regulation of fatty acid oxidation in the heart. J Biol Chem $268,25836-258.45$

77. Awan, M. M., and Saggerson, E. D. (1993) Malonyl-CoA metabolism in cardiac myocytes and its relevance to the control of fatty acid oxidation. Biochem / 295 (Pt 1), 61.66 
78. Vavvas, D., Apazidis, A., Saha, A. K., Gamble, J., Patel, A, Kemp, B. E., Witters, L. A., and Ruderman, N. B. (1997) Contraction-induced changes in acetyl-CoA carboxylase and 5 AMP-activated kinase in skeletal muscle. J Biol Chem 272, 13255-13261

79. Muojo, D. M. Seefeld, K., Witters, L. A., and Coleman, R. A. (1999) AMP-activated kinase reciprocally regulates triacylglycerol synthesis and fatty acid oxidation in liver and muscle: evidence that sn-glycerol-3-phosphate acyltransferase is a novel target. Biochem / 338 ( Pt 3). $783-791$

80. Säha, A. K., Schwarsin, A. J, Roduit, R., Masse, F., Kaushik, V., Tornheim, K., Prentki, M., and Ruderman, N. B. (2000) Activation of malonyl-CoA decarboxylase in rat skeletal muscle by contraction and the AMP-activated protein kinase activator 5-aminoimidazole-4carboxamide-1-beta -D ribofuranoside. I Biol Chem 275, 24279-24283

81. Javaux, F., Vincent, M. F. Wagner, D. R., and van den Berghe, G. (1995) Cell-type specificity of inhibition of glycolysis by 5-amino-4-imidazolecarboxamide riboside. Lack of effect in rabbit cardiomyocytes and human erythrocytes, and inhibition in FTO- $2 \mathrm{~B}$ rat hepatoma cells. Biochem 305 ( Pt 3), 913-919

82. Corton, J. M. Gillespie, J. G. Hawley, S. A., and Hardie, D. G. (1995) 5-aminoimidazole-4carboxamide ribonucleoside. A specific method for activating AMP-activated protein kinase in intact cells? Eur \& Biochem 229, 558-565

83. Hayashi, T., Hirshman, M. F., Kurth, E. J., Winder, W. W., and Goodyear, L. J. (1998) Evidence for $5^{\prime}$ AMP-activated protein kinase mediation of the effect of muscle contraction on glucose transport. Diabetes $47,1369-1373$

84. Russell, R. R., 3rd, Bergeron, R., Shulman, G. I., and Young, L. H. (1999) Translocation of myocardial GLUT-4 and increased glucose uptake through activation of AMPK by AlCAR. Am J Physiol 277, H643.649

85. Braiman, L., Alt, A., Kuroki, T.8 Ohba, M., Bak, A., Tennenbaum, T, and Sampson, S. R. (1999) Protein kinase Cdelta mediates insulin-induced glucose transport in primary cultures of rat skeletal muscle. Mol Endocrinol 13, 2002-2012

86. Richter, E. A., Cleland, P. J., Rattigan, S., and Clark, M. G. (1987) Contraction-associated translocation of protein kinase $C$ in rat skeletal muscle. FEBS Lett 217, 232-236

87. Cleland, P. J., Appleby, G. J, Rattigan, S., and Clark, M. G. (1989) Exercise-induced translocation of protein kinase $C$ and production of diacylglycerol and phosphatidic acid in rat skeletal muscle in vivo. Relationship to changes in glucose transport. \& Biol Chem 264 , 17704-17711

88. Vogt, B., Mushack, J., Seffer, E., and Haring, H. U. (1991) The translocation of the glucose transporter sub-types GLUT1 and GLUT4 in isolated fat cells is differently regulated by phorbol esters. Biochem / 275 ( Pt 3), 597-600

89. Nishimura. $H_{\text {., }}$ and Simpson, I. A. (1994) Staurosporine inhibits phorbol 12-myristate 13acetate- and insulin-stimulated tramslocation of GLUT1 and GLUTA glucose transporters in rat adipose cells. Biochem / 302 ( Pt 1), 271-277

90. Luiken, J. J., Coort, S. L., Koonen, D. P., Bonen, A., and Glatz, J. F. (2004) Signalling components involved in contraction-inducible substrate uptake into cardiac myocytes. Proc Nutr Soc 63, 1-8

91. Weng, L. P., smith. W. M., Brown, J. L., and Eng, C. (2001) PTEN inhibits insulin-stimulated MEK/MAPK activation and cell growth by blocking IRS-1 phosphorylation and IRS-1/Grb2/Sos complex formation in a breast cancer model. Hum Mol Genet 10, 605-616

92. Wretman, C. Lionikas, A., Widegren, U., Lannergren, J., Westerblad, H., and Henriksson, J. (2001) Effects of concentric and eccentric contractions on phosphorylation of MAPK(erk1/2) and MAPK(p38) in isolated rat skeletal muscle. J Physio/ 535, 155-164

93. Hayashi, T., Hirshman, M. F., Dufresne, S. D., and Goodyear, L. J. (1999) 5 keletal muscle contractile activity in vitro stimulates mitogen-activated protein kinase signaling. Am $/$ Physiol 277, C701-707

94. Krook, A." Widegren, U. Jiang, X. J., Henriksson, J., Wallberg.Henriksson, H., Alessi, D., and Zierath, J. R. (2000) Effects of exercise on mitogen- and stress-activated kinase signal transduction in human skeletal muscle. Am / Physiol Regul integr Comp Physial 279, R1716-1721 
95. Wojtaszewski, J. F., Lynge, J., Jakobsen, A. B., Goodyear, L. J., and Richter, E. A. (1999) Differential regulation of MAP kinase by contraction and insulin in skeletal muscle: metabolic implications. Am J Physiol 277, E724-732

96. Somwar, R., Perreault, M., Kapur, S., Taha, C., Sweeney, G., Ramlal, T, Kim, D. Y. Keen, J, Cote, C. H., Klip, A., and Marette, A. (2000) Activation of p38 mitogen-activated protein kinase alpha and beta by insulin and contraction in rat skeletal muscle: potential role in the stimulation of glucose transport. Diabetes $49,1794-1800$

97. Aronson, D., Violan, M. A., Dufresne, 5. D., Zangen, D., Fielding, R. A, and Goodyear, L. J. (1997) Exercise stimulates the mitogenactivated protein kinase pathway in human skeletal muscle J Clin invest 99, 1251-1257

98. Aronson, D., Dufresne, S. D., and Goodyear, L. J. (1997) Contractile activity stimulates the cJun NH2-terminal kinase pathway in rat skeletal muscle. I Biol Chem 272, 25636-25640

99. Ryder, J. W., Fahlman, R., Wallberg-Henriksson, H. Alessi, D. R., Krook, A., and Zierath J. R. (2000) Effect of contraction on mitogen-activated protein kinase signal transduction in skeletal muscle. Involvement of the mitogen- and stress-actiwated protein kinase 1. J Biol Chem 275, 1457-1462

100. Sweeney, G., Somwar, R., Ramlal, T., Volchuk, A., Ueyama, A., and Klip, A. (1999) An inhibitor of p38 mitogen-activated protein kinase prevents insulin-stimulated glucose transport but not glucose transporter translocation in 3T3-L1 adipocytes and $L 6$ myotubes. 1 Biol Chem 274, 10071-10078

101. Saltiel, A. R, and Kahn, C.R. (2001) \#nsulin signalling and the regulation of glucose and lipid metabolism. Nature 414, 799-806

102. Dyck, D. J., Steinberg, G., and Bonen, A. (2001) Insulin increases FA uptake and esterification but reduces lipid utilization in isolated contracting muscle. Am I Physiol Endocrinol Metab 281, E600-607

103. Luiken, J. J., Dyck, D. J., Han, X. X., Tandon, N. N., Arumugam, $V_{*}$, Glatz, I. $\mathbb{F}_{*}$, and Bonen, A. (2002) Insulin induces the translocation of the fatty acid transporter FAT/CD 36 to the plasma membrane. Am J Physiol Endocrinol Metab 282, E491-495

104. Luiken, J. J., Koonen, D. P., Willems, J., Zorzano, A., Becker, C., Fischer, Y., Tandon, N. N., Van Der Vusse, G. J., Bonen, A., and Glatz, J. F. (2002) Insulin stimullates long-chain fatty acid utilization by rat cardiac myocytes through cellular redistribution of FAT/CD36. Diabetes 51, 3113-3119

105. Witters, L. A., and Kemp, B. E. (1992) \|nsulin activation of acetyl-CoA carboxylase accompanied by inhibition of the 5'-AMP-activated protein kinase. I' Bial Chem 267, 28642867

106. Gamble, d, and Lopaschuk, G. D. (1997) Insulin inhibition of '5' adenosine monophosphateactivated protein kinase in the heart results in activation of acetyl coenzyme $A$ carboxylase and inhibition of fatty acid oxidation. Metabolism 46, 1270-1274.

107. Winder, W. W. and Holmes, B. F. (2000) Insulin stimulation of glucose uptake fails to decrease palmitate oxidation in muscle if AMPK is activated. I Appl Physiol 89, 2430-24,37

108. Beauloye, C., Marsin, A. S., Bertrand, L. Krause, U., Hardie, D. G., Vanoverschelde, J. L., and Hue, L. (2001) Insulin antagonizes AMP.activated protein kinase activation by ischemia or anoxia in rat hearts, without affecting total adenine nucleotides. FEBS Lett 505, 348-352

109. Atkinson, L. L. Fischer, M. A., and Lopaschuk, G. D. (2002) Leptin activates cardiac fatty acid oxidation independent of changes in the AMP-activated protein kinase-acetyl-CoA. carboxylase-malonyl-CoA axis. J Bial Chem 277, 29424-29430

110. Hollm, C. (2003) Molecular mechanisms regulating hormone-sensitive lipase and lipolysis. Biochem Sac Trans 31, 1120-1124

111. Farese. R. V. (1996) Insulin-sensitive phospholipid signaling systems and glucose transport: an update. Proc Soc Exp Biol Med 213, 1-12

112. Cheatham, B., and Kahn, C. R. (1995) Insulin action and the insulin signaling network. Endocr Rev 16, 117-142

113. Downward, J. (1995) Signal transduction. A target for PI(3) kinase. Nature 376, 553-554

114. Farese, R. V. (2002) Function and dysfunction of aPKC isoforms for glucose transport in insulin-sensitive and insulin-resistant states. Am J Physiol Endocrinol Metab 283, E1-11 
115. Baumann, C. A. Ribon, V., Kanzaki, M., Thurmond, D. C., Mora, S., Shigematsu, S., Bickel, P. E. Pessin, J. E., and Saltiel, A. R. (2000) CAP defines a second signalling pathway required for insulin-stimulated glucose transport. Nature 407, 202-207

116. Khan, A. H., and Pessin, J. E. (2002) Insulin regulation of glucose uptake: a complex interplay of intracellular signalling pathways. Diabetologia $45,1475-1483$

11.7. Liu, J., DeYoung, 5. M., Hwang, J. B., O'Leary, E. E., and Saltiel, A. R. (2003) The roles of Cbl-b and $\mathrm{c}-\mathrm{Cb}$ in insulin-stimulated glucose transport. 1. Biol. Chem. 278(38):36754-62

118. Rome, S., Clement, K., Rabasa-Lhoret, R., Loizon, E., Poitou, C., Barsh, G. S., Riou, J. P. Laville, M., and Vidal, H. (2003) Microarray profiling of human skeletal muscle reveals that insulin regulates approximately 800 genes during a hyperinsulinemic clamp. I Biol Chem 278 , $18063-18068$

119. Somwar, R., Wiu, W., Kim, D. Y., Sweeney, G., Randhawa, V. K., Huang, C., Ramlal, T., and Klip. A. (2001) Differential effects of phosphatidylinositol 3-kinase inhibition on intiracellular signals regulating GLUT4 translocation and glucose transport. I Biol Chem $276,46079-46087$

120. Tardif, A., Julien, N., Chiasson, J. L., and Coderre, L. (2003) Stimulation of glucose uptake by chronic vanadate pretreatment in cardiomyocytes requires PI 3-kinase and P38 MAPK activation. Am J Physiol Endocrinol Metab 284, E1055-1064

121. Michelle Furtado, L., Poon, $V_{\text {, }}$ and Klip, A. (2003) GLUT4 activation: thoughts on possible mechanism5. Acta Physiol Scand 178, 287-296

122. Zorzano, A., Sewilla, L., Camps, M., Becker, C., Meyer, J., Kammermeier, H., Munoz, P., Guma, A., Testar, K., Palacin, M., Blasi, I., and Fischer, Y. (1997) Regulation of glucose transport, and glucose transporters expression and trafficking in the heart: studies in cardiac myocytes. Am I Cardiol $80,65 \mathrm{~A}-76 \mathrm{~A}$

123. Brozinick, J. T., Jr., and Birmbaum, M. I. (1998) Insulin, but not contraction, activates Akt/PKB in isolated rat skeletal muscle. J Biol Chem 273, 14679-14682

12.4. Fischer, Y., Thomas, J., Sevilla, L., Munoz, P. Becker, C., Holman, G., Kozka, I. J., Palacin, M., Testar, X., Kammermeier. H., and Zorzano, A. (1997) Insulin-induced recruitment of glucose transporter 4 (GLUT4) and GLUT1 in isolated rat cardiac myocytes. Evidence of the existence of different intracellular GLUT4 vesicle populations. I Biol Chem 272, 7085-7092

125. Ploug, T., van Deurs, B., Ai, H., Cushman, S. W., and Raiston, E. (1998) Alnalysis of GiLUT4 distribution in whole skeletal muscle fibers: identification of distinct storage compartments that are recruited by insulin and muscle contractions. I Cell Biol 142, 14291.446

126. Kessler, A., Tomas, E., Immler, D., Meyer, H. E., Zorzano, A., and Eckel, J. (2000) Rab11 is associated with GLUT4-containing vesicles and redistributes in response to insulin. Diabetologia $43,1.518-1527$

127. Lemieux, K., Han, X. X., Dombrowski, L., Bonen, A., and Marette, A. (2000) The transferrin receptor defines two distinct contraction-responsive GLUT4 vesile populations in skeletal muscle. Diabetes $49,183-189$

128. Muller, H., Deckers, K., and Eckel, 1. (2002) The fatty acid translocase (FAT)/CD36 and the glucose transporter GLUT4 are localized in different cellular compartments in rat cardiac muscle. Biochem Biophys Res Commun 293,665-669

129. Sukhotnik, h, May, N., Gork, A. S., Chen, M., Drongowski, R. A., Coran, A. G., and Harmon, C. M. (2002) Effect of bowel resection and high-fat diet on heart $\mathrm{CO} 36 /$ fatty-acid translocase expression in a rat model of short-bowel syndrome. Pediatr Surg int 18, 620-623

130. Kiens, B., Kristianser, S., Jensen, P., Richter, E. A., and Turcotte, L. P. (1997) Membrane associated fatty acid binding protein (FABPpm) in human skeletal muscle is increased by endurance training. Biochem Biophys Res Commun 231, 463-4.65

131. Turcotte, L. P., Swenberger, J. R., Tucker, M. Z., and Yee, A. J. (1999) Training-induced elevation in FAEP(PM) is associated with increased pallmitate use in contracting muscle. $J$ Appl Physiol 87, 285-293

132. Tunstall, R. J., Mehan, K. A., Wadley, G. D., Collier, G. R., Bonen, A., Hargreaves, M., and Cameron-Smith, D. (2002) Exercise training increases lipid metabolism gene expression in human skeletal muscle. Am / Physiol Endocrinol Metab 283, E66-72 
133. Bonen, A., Dyck, D. J., Ibrahimi, A., and Abumrad, N. A. (1999) Muscle contractile activity increases fatty acid metabolism and transport and FAT/CD36. Am J Physiol 276, E642-649

134. Koonen, D. P. Y., Benton, C., Arumugam, Y., Tandon, N. N., Calles-Escandon, J., Glatz, J. F. C., Luiken, J. J. F. P., and Bonen, A. (2004) Different mechanisms can alter fatty acid transport when muscle contractile activity is chronically altered. Am I Physiol Endocrinol Metob 286(6): $\mathrm{E} 1042-9$

135. Turcotte, L. P., Srivastava, A. K., and Chiasson, J. L. (1997) Fasting increases plasma membrane fatty acid-binding protein (FABP(PM)) in red skeletall muscle. Mol Cell Biochem $166,153-158$

136. Nisoli. E., Carruba, M. O., Tonello, C., Macor, C., Federspill, G, and Vettor, R. (2000) Induction of fatty acid translocase/CD36, peroxisome proliferator-activated receptorgamma2, leptin, uncoupling proteins 2 and 3 , and tumor necrosis factor-alpha gene expression in human subcutaneous fat by lipid infusion. Diabetes $49,319-324$

137. Fabris, R., Nisoli, E., Lombardi, A. M., Tonello, C., Serra, R., Granzotto, M., Cusin, I., RohnerJeanrenaud, F., Federspil, G., Carruba, M. O., and Vettor, R. (2001). Preferential channeling of energy fuels toward fat rather than muscle during high free fatty acid availability in rats. Diabetes $50,601-608$

138. Cameron-Smith, D., Burke, L. M., Angus, D. J., Tunstall, R. J., Cox, G. R., Bonen, A., Hawley, J. A., and Hargreaves, M. (2003) A short-term, high-fat diet up-regulates lipid metabolism and gene expression in human skeletal muscle. Am J Clin Nutr 77, 313-318

139. Tucker, M. Z. and Turcotte, L. P. (2003) Aging is associated with elevated muscle triglyceride content and increased insulin-stimulated fatty acid uptake. Am I Physiol Endocrinol Metab

140. Steinberg, G. R., Dyck, D. J., Calles-Escandon, J., Tandon, N. N., Luiken, J. J., Glatz, „J. $\mathbb{F}$. and Bonen, A. (2002) Chronic leptim administration decreases fatty acid uptake and fatty acid transporters in rat skeletal muscle. I Biol Chem 277, 8854-8860

141. Luiken, J. J., Arumugam, Y., Dyck, D. J., Bell, R. C., Pelsers, M. M., Turcotte, L. P., Tandon, N. N., Glatz, J. F., and Bonen, A. (2001) Increased rates of fatty acid uptake and plasmalemmal fatty acid transporters in obese Zucker rats. J Biol Chem 276, 40567-40573

142. Shulman, G. I. (2000) Cellular mechanisms of insulin resistance. J Clin Invest 106, 171-176

143. Roden, M., Price, T. B., Perseghin, G., Petersen, K. F., Rothman, D. L., Cline, G. W., and Shulman, G. I. (1996) Mechanism of free fatty acid-induced insulin resistance in humans. $J$ Clin invest $97,2859-2865$

144. Schimitz-Peiffer, C., Browne, C. L., Oakes, N. D., Watkinson, A., Chisholm, D. J., Kraegen, E. W., and Biden, T. J. (1997) Alterations in the expression and cellular localization of protein kinase $C$ isozymes epsilon and theta are associated with insulin resistance in skeletal muscle of the high-fat-fed rat. Diabetes $46,169-178$.

145. Griffin, M. E., Marcucci, M. J., Cline, G. W., Bell, K, Barucci, N., Lee, D., Goodyear, L. J., Kraegen, E. W., White, M. F., and Shulman, G. I. (1999) Free fatty acid-induced insulin resistarice is associated with activation of protein kinase $C$ theta and alterations in the insulin signaling cascade. Diabetes $48,1270-1274$

146. Itani, 5.I., Pories, W. J., Macdonald, K. G., and Dohm, G. L. (2001) Increased protein kinase C theta in skeletal muscle of diabetic patients. Metabolism 50, $553-557$

147. Schmitz-Peiffer, C., Craig, D. L., and Biden, T. J. (1999) Ceramide generation is sufficient to account for the inhibition of the insulin-stimulated PKB pathway in C2C12 skeletal muscle cells pretreated with palmitate. I Biol Chem 274, 24202-24210.

1.48. Thompson, A. $L_{*}$ and Cooney, G. J. (2000) Acyl-CoA inhibition of hexokinase in rat and human skeletal muscle is a potential mechanism of lipid-induced insulin resistance. Diabetes 49, 1761-1765

149. Kelley, D. E.x Goodpaster, B. H., and Storlien, L. (2002) Muscle triglyceride and insulin resistance. Annu Rev Nutr 22, 325-346

150. Zhou, Y.-T., Grayburn, P., Karim, A., Shimabukuro, M., Higa, M., Baetens, D., Orci, L., and Unger, R. H. (2000) Lipotoxic heart disease in obese rats: Implications for human obesity. PNAS 97, 1784-1789 
151. Young, M. E., Guthrie, P. H., Razeghi, P., Leighton, B., Abbasi, S., Patil, S., Youker, K. A., and raegtmeyer. H. (2002) Impaired long-chain fatty acid oxidation and contractle dysfunction in the obesie Zucker rat heart. Diabetes $51,2587-2595$

152. Atkinson, L. L, Kozak, R., Kelly, 5. E, Onay Besikci, A., Russell, J. C. and Lopaschuk, G. D. (2003) Potential mechanisms and consequences of cardiac triacylglycerol accumulation in insulin-resistant rats. Am f Physiol Endocrinol Metab 284, E923-930

153. Ferrato, R. T., Eckel, R. H. Larson, D. E., Fontvieille, A. Mr, Rising, R., Jensen, D. R., and Ravussin, E. (1993) Relationship between skeletal muscle lipoprotein lipase activity and 24-hour macronutrient oxidation. J Clin Invest $92,441-445$

154. Zurlo, F, Nemeth, P. M. Choksi, R. M., Sesodia, S, and Ravussin, E. (1994) Whole-body energy metabohism and skeletal muscle biochemical characteristics. Metabolism 43, 481. 486

155. Simoneau, J. A., Veerkamp, J. H. Turcotte, L. P., and Kelley, D. E. (1999) Markers of capacity to utilize fatty acids in human skeletal muscle: relation to insulin resistance and obesity and effects of weight loss. Faseb / 13, 2051-2060

156. Kelley, D. E., Goodpaster, B., Wing, R. R., and Simoneau, I. A. (1999) Skeletal muscle fatty acid metabolism in association with insulin resistance, obesity, and weight loss. Am : Physiol 277, E1130-1141

157. Steinberg, G. R., Parolin, M. L., Heigenhauser, G. J., and Dyck, D. J. (2002) Leptin increases FA oxidation in lean but not obese human skeletal muscle: evidence of peripheral leptin resistance. Am J Physiol Endocrinal Metab 283, E187-192

158. Hulver, M. W. Berggren, 1. R., Cortright, R. N. Dudek, R. W., Thompson, R. P., Pories, W. J., MacDonald, K. G., Cline, G. W. Shulman, G. I., Dahm, G. L., and Houmard, J. A. (2003) Skeletal muscle lipid metabolism with obesity. Am J Physiol Endocrinol Metab 284, E741747

159. Bonen, A., Parolin, M. L., Steinberg, G. R., Calles-Escandon, J., Tandon, N. N., Glatz, J. F., Luiken, J. J., Heigenhauser, G. J, and Dyck, D. J. (2004) Triacylglycerol Accumulation in Human Obesity and type 2 Diabetes is Associated with Increased rates of Skeletal Muscle Fatty Acid Transport and Increased Sarcolemmal FAT/CD36. FASEB J 18(10):1144-6

160. Coort, S. L., Hasselbaink, D. M., Koonen, D. P., Willems, J., Coumans, W. A., van der Vusse, G. J., Bonen, A., Glatz, J. F., and Luiken, J. J.(2004) Impaired insulin sensitivity causes enhanced sarcolemmal FAT/CD36 levels and triacylglycerol storage in cardiac myocytes from obese Zucker rats. Diabetes $53(7): 1655 * 63$

161. Boden, G. (1997) Role of fatty acids in the pathogenesis of insulin resistance and NIDDM. Diabetes $46,3-10$

162. Kim, J. K., Fillmore, J. J., Chen, Y., Yu, C., Moore, I. K., Pypaert, M., Lutz, E. P., Kako, Y., VelezCarrasco, W., Goldberg, I. J., Breslow, J. L. and Shulman, G. I. (2001) Tissue-specific overexpression of lipoprotein lipase causes tissue-specific insulin resistance. Proc Natl Acad SciU SA 98, 7522-7527

163. Dresner, A. Laurent, D., Marcucci, M., Griffin, M. E, Dufour, S, Cline, G. W., Slezak, L. A., Andersen, D. K. Hundal, R. S., Rothman, D. L., Petersem, K. F., and Shulman, G. 1. (1999) Effects of free fatty acids on glucose transport and IRS-1-associated phosphatidylinositol 3-kinase activity. $J$ Clin invest 103, 253-259.

164. Boden, G., and Carnell, L. H. (2003) Nutritional effects of fat on carbohydrate metabolism. Best Pract Res Clin Endocrimol Metab 17. 399-410

165. Boden, G., Jadali, F., White, J., Liang, Y., Mozzoli, M., Chen, X., Coleman, E., and 5 mith, C. (1991) Effects of fat on insulin-stimulated carbohydrate metabolism in normal men.J Clin invest $88,960-966$

166. Boden, $G_{\text {, }}$ and $C h e n, X$ (1995) Effects of fat on glucose uptake and utilization in patients with non-insulin-dependent diabetes. J Clin invest $96,1261-1268$

167. Santomauro, A. T., Boden, G., Silva, M. E., Rocha, D. M., Santos, R. F., Ursich, M. J., Strassmann, P. G. and Wajchenberg, B. L. (1999) Overnight lowering of free fatty acids with Acipimox improves insulin resistance and glucose tolerance in obese diabetic and nondiabetic subjects. Diabetes $48,1836-1841$ 
168. Guerre-Millo, M., Rouault, C., Poulain, P., Andre, J, Poitout, W., Peters, 1. M., Gonzalez, F. $l_{\text {, }}$ Fruchart, J. C., Reach, G., and Staels, B. (2001) PPAR-alpha-null mice are protected from high-fat diet-induced insulin resistance. Diabetes $50,2809-2814$

169. Koopmans, S. J., Jong, M. C., Que, I, Dahlmans, V. E., Pijl, H., Radder, J. K., Frolich, M., and Havekes, L. M. (2001) Hyperlipidaemia is associated with increased insulin-mediated glucose metabolism, reduced fatty acid metabolism and normal blood pressure in transgenic mice overexpressing human apolipoprotein C1. Diabetologia $44,437-443$

170. Hajri, T., Han, X. X., Bonen, A., and Abumrad, N. A. (2002) Defective fatty acid uptake modulates insulin responsiveness and metabolic responses to diet in CD36-null mice. $J$ Clin Invest 109, 1381-1389

171. Goudriaan, J. R., Dahlmans, V. E., Teusink, B., Ouwens, D. M. Febbraio, M. Maassen, J. A.; Romijn, I. A. Havekes, L. M., and Voshol, P. J. (2003) CD36 deficiency increases insulin sensitivity in muscle, but induces insulin resistance in the liver in mice. I Lipid Res 44. 2270-2277

172. Kim, J. K., Gimeno, R. E., Higashimori, T., Kim, H. J., Choi, H., Punreddy, S., Mozell, R. L., Tan, G., Stricker-Krongrad, A., Hirsch, D. J., Fillmore, J. J., Liu, Z. X., Dong, J., Cline, G., Stahl, A., Lodish, H. F., and Shulman, G. 1. (2004) Inactivation of fatty acid transport protein 1. prevents fat-induced insulin resistance in skeletal muscle. J Clin invest 113, 756-763

173. Coort, S. L., Luiken, 1. J., Van Der Vusse, G. J., Bonen, A., and Glatz, J. F. (2004) \|ncreased FAT (fatty acid translocase)/CD36-mediated long-chain fatty acid uptake in cardiac myocytes from obese Zucker rats. Biochem Soc Trans $32,83-85$

174. Goodyear, L. J., and Kahn, B. B. (1998) Exercise, glucose transport, and insullin sensitivity. Annu Rev Med 49, 235-261

175. Luiken, J. J. F. P., Coort, S. L. M., Willems, J, Coumans, W. A., Bonen, A., and Glatz, J. F. C. (2004) Dipyridamole Alters Cardiac Substrate Preference by Inducing Translocation of FAT/CD36, but Not That of GLUT4. Mol Pharmacol 65, 639-645

176. Luiken, J. J., Arumugam, Y., Biell, R. C., Calles-Escandon, J., Tandon, N. N., Glatz, J. F, and Bonen, A. (2002) Changes in fatty acid transport and transporters are related to the severity of insulin deficiency. Am J Physiol Endocrinol Metab 283, E612-621

177. Luiken, J. J., Bonen, A., and Glatz, J. F. (2002) Cellular fatty acid uptake is acutely regulated by membrane-associated fatty acid-binding proteins. Prostaglandins Leukot Essent Fatty Acids $67,73-78$

178. Luiken, J. J., Schaap, F. G. van Nieuwenhoven, F. A., van der Vusse, G. I., Bonen, A., and Glatz, J. F. (1999) Cellular fatty acid transport in heart and skeletal muscle as facilitated by proteins. Lipids 34 Suppl, 5169-175 


\section{Giant membrane vesicles as a model to study cellular substrate uptake dissected from metabolism}

Koonen D.P.Y. ${ }^{1}$, Coumans W.A. ${ }^{1}$, Arumugam $Y^{2}{ }^{2}$ Bonen A. ${ }^{2}$, Glatz J.F.C. ${ }^{1}$ and J.J.F.P. Luiken'.

1. Dept. of Physiology, Cardiovascular Research Institute Maastiricht (CARIM), Maastricht University, NL 6200 MD Maastricht, the Netherlands

2. Dept of Kinesiology, University of Waterloo, Waterloo, ON, N2L 3G1, Canada 


\section{Abstract}

In order to use giant vesicles for substrate uptake studies in metabolically important tissues, we characterized giant vesicles isolated from heart, liver, skeletal muscle and adipose tissue. We investigated which cell types and which plasma membrane regions are involved in giant vesicle formation and we examined the presence of transporters for metabolic substrates. Analysis of giant vesicles with markers specific for distinct cell types and distinct domains of the plasma membrane reveals that the plasma membrane of parenchymal cells, but not endothelial cells, are the source of the wesicle membranes. In addition, plasma membrane regions enriched in caveolae and involved in docking of recycling vesicles from the endosomal compartment are retained in giant vesicles, indicating that $\mathrm{KCl}$ induced alterations in recycling processes are involved in giant vesicle formation. Giant vesicles contain vesicular lumen consisting of the soluble constituents of the cytoplasm including, fatty-acid binding proteins. Furthermore, giant vesicles isolated from heart, liver, skeletal muscle and adipose tissue are similar in size (10-15 $\mu \mathrm{m}$, and shape and do not contain subcellular organelles, providing the advantage that substrate fluxes in the different organs can be studied independently of the surface/volume ratio but most importantly in the absence of intracellular metabolism.

\section{Introduction}

Studies on the cellular uptake of metabolic substrates, such as long-chain fatty acids (FA) (1.3), glucose (4,5) and lactate (6) are usually carried out with isolated cells. A major difficulty of these studies, however, is that the uptake process cannot be separated from subsequent metabolism. Therefore, plasma membrane vesicles have been proposed as an alternative model to study substrate uptake. In contrast to isolated cells, membrane vesicles consisting of plasma membranes do not contain subcellular organelles, thus providing the advantage that ligand uptake can be studied in the absence of metabolism. Routinuously, plasma membranes have been prepared from a crude membrane fraction obtained by extensive homogenization, followed by differential centrifugation and purification on density gradients. Such membrane vesicles are relatively small ( $<1 \mu \mathrm{m}$ ) (7-10) and are oriented only 50-60\% right-side out. Moreover, small vesicles have a variable degree of contamination with intracellular membranes $(8,10-13)$.

In an attempt to overcome these disadvantages of the use of small vesicles for uptake studies, a preparative method was developed to obtain giant membrane vesicles (14). Their discovery was the result of a coincidental observation in patch-clamp studies with frog skeletal muscle (14). It was found that large membrane structures cleave off from cutaneous pectoris muscle when treated with collagenase in the presence of high (120 $\mathrm{mM} \mathrm{KCl}(14)$. The molecular mechanism leading to excision of large membrane spheres from the surface of muscle cells is not yet understood. In this respect, it has been abserved that the proteolytic treatment by itself is not sufficient for formation of vesicles from the sarcolemma, but that the combination of a collagenase with $\mathrm{KCl}$, as iso-osmotic medium, is crucial to initiate this budding process (14). It has been speculated that a high extracellular $\mathrm{KCl}$ concentration causes a disequilibrium between cellular endocytotic and 
exocytotic pathways resulting in an increased delivery of membranes to the sarcolemma (14). Collagenase activity is probably solely required to degrade the collagen matrix for creating space for the buddling event. It is likely that the budding-off of large membrane structures from the sarcolemma might be a compensatory mechanism for the sarcolemma to prevent package problems due to excessive supply of membranes from the recycling compartment.

Initially, giant vesicles were obtained from rat and human skeletal muscle in sufficient yield to allow the measurement of transport rates of ions and substrates $(9,14)$. Applying the established procedure for isolation of giant vesicles from rat hindlimb muscle but using a different type of collagenase, we succeeded in harvesting giant vesicular structures also from heart, epididymal fat pads and, liver $(3,15)$. Giant vesicles have two major advantages when compared to small vesicles, as they are fully right-side-out and, on average, have a 10-fold greater diameter. The latter leads to a 103-fold greater volume over small vesicles and a surface-to-volume ratio similar to that of mammalian cells, which allows a more accurate study of initial uptake rates of substrates because of a volume-dependent delay in their efflux (14). Furthermore, studies analyzing possible contamination of the vesicle preparation with intracellular membranes concluded that giant vesicle membranes were largely, if not completely, of sarcolemmal origin $(9,14$, 16). However, it is not known whether the membranes of the giant vesicles are randomly build up of plasma membrane, or, alternatively, that specialized regions of the plasma membrane contribute to the formation of giant vesicles. Furthermore, considering the heterogeneity of cell types present in the different mammalian organs, it might be possible that both parenchymal (myocytes, hepatocytes, adipocytes) and endothelial cells deliver plasma membranes for the formation of giant vesicles. Although microscopic studies indicate that the process of giant vesicle formation in heart and skeletal muscle occurs at the level of myocytes (14), we cannot exclude that endothelial cells are involved in giant vesicle formation.

In order to use giant vesicles for substrate uptake studies in metabolically important tissues, a more complete characterization is appropriate. Therefore, we investigated (i) which cell types and (ii) which plasma membrane regions are involved in giant vesicle formation from rat heart, skeletal muscle, liver and epididymal fat pads. These study aims were addressed by measuring marker proteins in the various preparations. In addition, we investigated (iii) the presence of transporters for metabolic substrates in giant vesicles from these tissues, namely two membrane FA transporters FA translocase (FAT/CD36) and plasmalemmal FA binding protein (FABPpm), the cytoplasmic FA transporter FABPC and the membrane glucose transporter GLUT4.

\section{Materials \& Methods}

\section{Materials}

Bovine serum albumin (BSA) (fraction $V$ ) and collagenases type $2 a$ and type VII were purchased from Sigma, St. Louis, MO, USA. Collagenase type II was from Worthington 
(Freehold, NI, USA). Non-fat dry milk (Marvel) was obtained from Premier Brands, Moreton, UK. Western blot reagents were from Bio-Rad Laboratories (Hercules, CA, USA) and the enhanced chemiluminescence (ECL) kit was from Amersham Pharmacia Biotech (Buckingham, UK). Gp60 was detected with a polyclonal antibody, kindly provided by Dr. C. Tiruppathi, University of Illinois, Chicago, IL, USA. Caveolae were detected with a rabbit polyclonal (cav-1) and a monoclonal (cav-3) antibody purchased from Transduction Laboratories (Lexington, KY, USA). Dihydropyridine receptor (DHPR) was detected with a mouse monoclonal (IgG2a) antibody (Affinity Bioreagents, Inc.) against the $\alpha 2$-subunit of rat skeletal muscle DHPR, abunit also common to the cardiac channel isoform (17). Anti-Pan Cadherin, a rabbit monoclonal antibody (Sigma, St. Louis, MO, USA) was used for detection of $\mathrm{N}$-Cadherin, whereas the insulin receptor was detected with a mouse monoclonal (IgG1) antibody (Transduction Laboratories, Lexington, KY, USA) directed against the Buchain of the insulin receptor (IRB). A mouse monoclonal (IgG2a) antibody (Biogenesis, Poole, UK) was used to recognise the rat transferrin receptor protein. FAT/CD36 was detected with a monoclonal antibody (MO25) directed against human CD36, kindly provided by Dr. N. Tandon, Otsuka Pharmaceuticals, Bethesda, MD, USA. A rabbit polyclonal against rat hepatic membrane fatty acid binding protein (2) was used to detect FABPpm (gift from Dr. D.Sorentino, Mount Sinai Medical Centre, New York City, USA). A polyclonal immuno-A purified GLUT4 antibody was obtained from East Acres Biologicals (Southbridge, MA, USA). Rabbit anti-mouse and pork anti-rabbit immunoglobulin horseradish peroxidase were obtained from DAKO (Clostrup, Denmark).

\section{Isolation of giant vesicles}

Giant vesicles were prepared from skeletal muscle, heart, liver and adipose fat pads of adult Sprague-Dawley rats. In general, tissues were cut into thin layers ( $1-3 \mathrm{~mm}$ thick) and incubated in vesicle preparation medium (140 $\mathrm{mM} \mathrm{KCl} / 10 \mathrm{mM}$ MOPS (pH 7.4)) supplemented with aprotinin $(10 \mathrm{mg} / \mathrm{ml})$ and collagenase type $11(150 \mathrm{U} / \mathrm{ml})$ for $1 \mathrm{~h}$ at $34^{\circ} \mathrm{C}$ in a shaking waterbath. Following incubation, tissues were washed with KCIMMPS and $10 \mathrm{mM}$ EDTA. The supernatant was collected and Percoll (final concentrations of $16 \%(\mathrm{v} / \mathrm{v})$ ) and aprotinin $(10 \mathrm{mg} / \mathrm{ml})$ were added. The resulting suspension was placed at the bottom of a density gradient consisting of a $3-\mathrm{ml}$ middle layer of $4 \%$ Nycodenz $(\mathrm{w} / \mathrm{v})$ and a $1-\mathrm{ml}$ KCl/MOPS upper layer. This sample was centrifugated at $60 \mathrm{~g}$ for $45 \mathrm{~min}$ at room temperature. Subsequently, the vesicles were harvested from the interface of the upper and middle layer, diluted in KCl/MOPS, recentrifugated at 12,000g for 5 min, and finally resuspended in KCl/MOPS. Minor adjustments were made to this method to prepare giant vesicles from heart and epididymal fat pads. Collagenase type $\|(0.3 \%$, w/v) was used for heart tissue, while collagenase type 2 a $(0.05 \%$, w/w) was used for adipose tissues. Furthermore, $100 \mathrm{mM} \mathrm{CaCl} 2$ was added to the incubation medium of heart and adipose tissues, and heart tissues were incubated for $90 \mathrm{~min}$. Protein concentration was determined and vesicles were immediately used for glucose and FA transport experiments. Vesicles were photographed and sized from the photomicrograph. Thereafter, vesicle samples were stored at $-80^{\circ} \mathrm{C}$ for immunoanalyses. 


\section{Fatty acid and glucose uptake by giant vesicles}

Palmitate uptake was measured by addition of unlabeled and radiolabeled $0.3 \mu \mathrm{Ci}[9,10$ $\left.{ }^{3} \mathrm{H}\right]$ palmitate and $0.06 \mu \mathrm{Ci}\left[{ }^{14} \mathrm{C}\right]$ mannitol in a $0.1 \% \mathrm{BSA}$ KCL/MOPS solution to $40 \mu \mathrm{l}$ of vesicles ( $~ 80 \mu \mathrm{g}$ protein). The reaction was carried out at room temperature for precisely $15 \mathrm{sec}$. Palmitate uptake was terminated by addition of $1.4 \mathrm{ml}$ of ice-cold KCL/MOPS-2.5 $\mathrm{mM} \mathrm{HgCl}$ and $0.1 \% \mathrm{BSA}$. The sample was quickly recentrifuged at maximal speed in a microcentrifuge for $2 \mathrm{~min}$. The supernatant was discarded, and radioactivity was measured in the tip of the tube. Non-specific uptake was measured by adding the stop solution prior to the addition of the radiolabeled palmitate solution.

Glucose uptake studies were carried out by addition of $40 \mu \mathrm{l} 0.1 \% \mathrm{BSA}$ in $\mathrm{KCl} / \mathrm{MOPS}$ containing $0.3 \mu \mathrm{Ci}\left[{ }^{3} \mathrm{H}\right] \mathrm{D}$-glucose $(200 \mu \mathrm{M})$ and $0.06 \mu \mathrm{Ci}\left[{ }^{14} \mathrm{C}\right]$ mannitol. Incubations were carried out at roomtemperature for precisely $2 \mathrm{~min}$ and radioactivity was determined as described above.

\section{Sample preparation for western blotting}

Total tissue homogenates were prepared from heart, liver, skeletal muscle and adipose tissues. Briefly, tissues ( $\sim 60 \mathrm{mg}$ ) were homogenized in $1 \mathrm{ml}$ of TES-buffer (10 $\mathrm{mM}$ Tris$\mathrm{HCL}, 2 \mathrm{mM}$ diNaEDTA, $250 \mathrm{mM}$ sucrose, $\mathrm{pH}$ 7.4) supplemented with leupeptine (1mg/100ml) and PMSF-DMSO for 5 interrupted 5-5 bursts with an Ultra Turrax homogenizer (Janke \& Kunkel, Ika-Labortechnik) set at 24,000 rpm. Thereafter, cells were disintegrated in 4 cycles (5-s on, 15-5 off) with an amplitude of 10-12 using an Ultrasonic Disintigrater (Soniprep 150, Sanyo Gallenkamp Plc.). Protein concentration was determined in triplicate by the Bicinchonic acid assay (Sigma, St. Louis, MO, USA) with the use of BSA as standard and samples were stored at $-80^{\circ} \mathrm{C}$.

\section{Western Blotting}

Total tissue homogenates $(10 \mu \mathrm{g})$ and vesicle $(5 \mu \mathrm{g})$ samples were separated on $10 \%$ and $12 \%$ SDS-polyacrylamide gels ( $150 \mathrm{~V}$ for $1 \mathrm{~h}$ ). GLUT4 was detected by loading $10 \mu \mathrm{g}$ of homogenate and vesicle protein. Proteins were then transferred to Trans-Blot ${ }^{\infty}$ pure nitrocellulose membranes (Bio-Rad Laboratories, Hercules, CA) (100 V for $90 \mathrm{~min}$ ). The membranes were blocked with TBS-T (20 mM Tris-base, $137 \mathrm{mM} \mathrm{NaCl}, 0.1 \mathrm{M} \mathrm{HCl}$ (pH 7.5), $0.1 \%$ Tween-20) containing either $7.5 \%$ BSA (FAT/CD36), or $5 \%$ non-fat dry milk (FABPpm, cav-1, cav-3, GP60, IR $\beta$, DHPR, transferrin receptor) for $1 \mathrm{~h}$ at room temperature. Membranes were incubated overnight at $4 O C$ using the relevant primary antibodies diluted in i) TBS-T (FAT/CD36), ii) TBS-T containing $5 \%$ non-fat dry milk (FABPpm, cav-1, GLUT-4, N-cadherin, IRB, DHPR), iii) 1\% non-fat dry milk (cav-3, GP60), and iv) TBS-T with $1 \%$ BSA (transferrin receptor). The following concentrations of primary antibodies were used: FAT/CD36 1:20.000, FABPpm 1:3000, cav-1 1:5000, cav-3 1:6000, GP60 1:500, GLUT4 1:7000, N-cadherin 1:3000, IRß 1:3000, DHPR 1:6000, and transferrin 1:1000. Following primary antibody incubation membranes were washed $5 \times 5$ min with TBS-T and incubated for $1 \mathrm{~h}$ at room temperature with either rabbit-anti mouse (FAT/CD36, IRB, DHPR 1:20.000; cav-3 1:24.000; transferrin receptor 1:2000) or porc-anti rabbit (FABPpm, GP60, N-cadherin 1:3000; cav-1 1:5000; GLUT-4 1:7000) G-horseradish peroxidase- 
conjugated secondary antibody. Thereafter, membranes were washed $5 \times 5$ min with TBS-T and 1* 5 min with TBS. Immune complexes were detected with enhanced chemiluminescence (ECL) by expasing the membranes to film (Hyperfilm-ECL) at room temperature according to the instructions of the manufacturer. Protein band densities. were obtained by scanning the films with a Multimager (Fluors ${ }^{2}$, Bio-rad) connected to a personal computer followed by densitometry using the computer program Quantity One (Bio-Rad Laboratories, Hercules, CA).

\section{Assay of amount of H-FABP and L-FABP}

The content of heart-type cytoplasmic FABP (H-FABP) in homogenates and giant vesicles from heart and skeletal muscles were determined by a sandwich-type enzyme-linked immunosorbent assay (ELISA) as previously described (18). The content of liver-type cytoplasmic FABP (L-FABP) in homogenates and liver giant vesicles was also determined by a sandwich ELISA (18).

\section{Statistical analysis}

Data are represented as mean \pm SEM. Statistical significance was calculated with paired t-tests $(\mathrm{p} \leq 0.05)$.

\section{Results and Discussion}

\section{Size determination of giant membrane vesicles}

The average sizes of giant vesicles from the various tissues were measured to be between 10 and $15 \mu \mathrm{m}$ (Table 3.1), which is in agreement with earlier studies $(15,19)$.

\begin{tabular}{ll}
\hline Tissue & Vesicle diameter (um) \\
\hline Heart & $12.6 \pm 0.5$ \\
Skeletal muscle & $14.3 \pm 0.7^{*}$ \\
Liver & $11.4 \pm 0.5^{*}$ \\
Adipose tissue & $14.8 \pm 0.5$ \\
\hline
\end{tabular}

Table 3.1. Sizes of giant vesicles prepared from different tissues. Comparison in heart, skeletal muscle and liver giant vesicles are based on 125 vesicles measured in each tissue from 5 rats. Adipose tissue vesicles were measured in 3 rats (75 vesicles). Data are represented as mean \pm sem. - Significantly different from hindlimb muscle and adipose tissue (P<0.05).

The striking similarity in vesicles sizes among the different organs (only liver vesicles were slightly, but significantly smaller than adipose and heart vesicles, $P<0.05$ ) are in marked contrast with the difference in average sizes of the cells from which the vesicles 
originate. For example, the average cardiac myocyte is a rod shaped cell, measuring 100 $\mu \mathrm{m}$ in length and $30 \mu \mathrm{m}$ in width, while the average hepatocyte measures $20 \mu \mathrm{m}$ in diameter. Moreover, skeletal muscle cells are not single-cell entities but form multinucleated muscle fibers of considerable length upon cell fusion processes. Another example is the similarity in diameter of adipose vesicles obtained from lean and from obese Zucker rats (15), despite the fact that the cell diameter of obese adipocytes is considerably greater (20). Taken together, these findings suggest that the molecular mechanism of vesicle formation is not dependent on cell form or size, but probably involves protein complexes in the plasma membrane at distinct distances of each other. These protein complexes could then be involved in the vesicle budding event in a manner resembling other subcellular vesicle formation processes such as endocytosis and exacytosis.

\section{Characterization of giant vesicles}

The degree of enrichment of cell-specific and plasma membrane region-specific markers within the plasma membranes of giant vesicles was assessed by a comparison of their relative abundance in these vesicles and in the original tissue. For a proper comparison one must know the relative contribution of plasma membrane proteins to the total protein content in both giant vesicles and tissue crude homogenates. A fractionation study of giant vesicles from skeletal muscle into membranes and lumen indicated that $10 \%$ of the total vesicular protein amount was plasma membrane-associated $(14,21)$. Fractionation of heart giant vesicles yielded a similar ratio (19). In most mammalian cells 5 to $10 \%$ of the total cellular protein resides in the plasma membrane. Thus, the contribution of plasma membrane protein to total protein is similar in giant vesicles and in the cells from which they are derived. By inference, when a cell-specific or membrane region-specific marker protein shows a similar abundance in the giant vesicle total protein pool and in the protein pool of a total homogenate of the corresponding organ, that cell type and/or particular membrane region is involved in the formation of giant vesicles.

\section{Cell-specific and membrane domain-specific marker proteins}

To assess the presence of membranes from different cell types in giant vesicle membranes, we have used the endothelium-specific markers Gp60 and caveolin type 1 (cav-1), and the myocyte-specific marker caveolin type 3 (cav-3). The presence of distinct plasma membrane domains was evaluated using cav-1 and cav-3 as markers for caveolae, the dihydropyridine receptor as marker for T-tubuli (in muscle), and neural cadherin was used as marker for membrane regions involved in cell-cell interactions. Furthermore, the insulin receptor was used as marker of insulin-sensitive tissues, whereas the transferrin receptor was used to mark the endosomall compartment.

$\mathrm{Cp} 60$, a glycoprotein of $60 \mathrm{kD}$, is a major constituent of the endothelial glycocalyx and functions as a receptor for albumin. Schnitzer et al. (22) reported that its expression is restricted to tissues with microvascular beds lined with continuous endothelium. Accordingly, we found it to be present in homogenates from heart, skeletal muscle and 
adipose tissue, in abundance decreasing in this order (Fig. 3.1A). However, we also detected Gp60 in liver, which tissue has a sinusoidal endothelium. Gp60 was not detected in giant vesicles from heart, muscle and liver (Fig. 3.1A), indicating that in these tissues giant vesicle membranes are not derived from endothelial cells. The presence of Gp60 in giant vesicles from adipose tissue (Fig. 3.1A) may indicate that in this case endothelial cells participate in giant vesicle formation or that adipocytes themselves express G 600 .

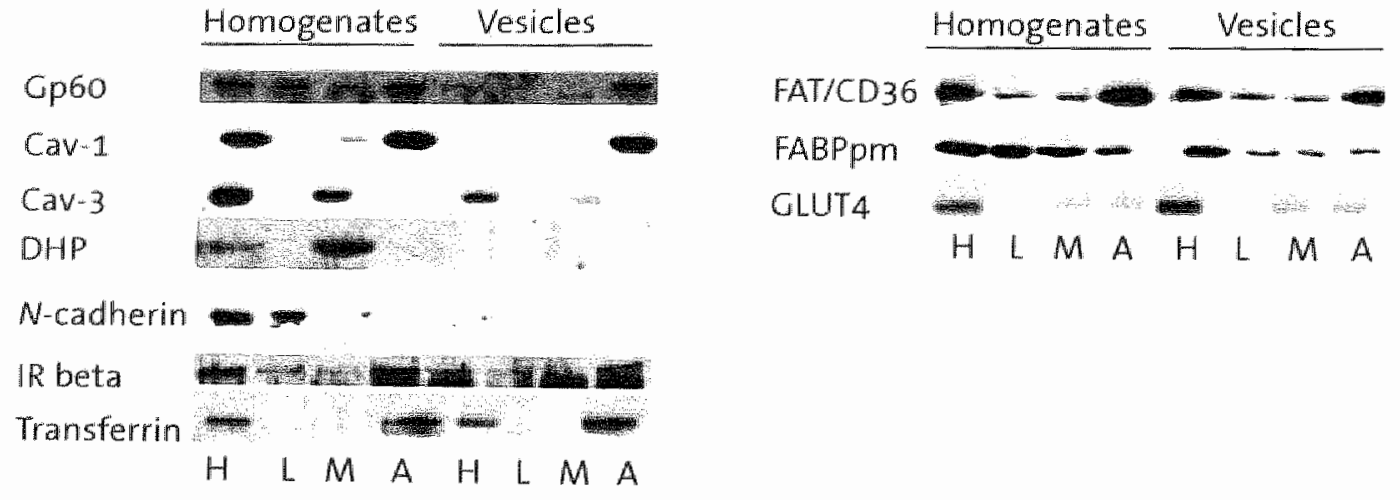

Figure 3.1. Representative western blots of albumin-binding protein (gp60), caveolin type 1 and 3 $($ (Cav-1, cav-3), dihydropyridine receptor (OHP), neural-cadherin, insulin receptor bèta (IR) and transferrin receptor (A) and of the substrate transporters FAT/CD36, FABPpm and GLUT4 (B) in homogenates and giant vesicles. $H$, heart; $L$, liver; $M$, skeletal muscle; $A$, adipose tissue.

Cav-1 and cav-3 are members of the protein family of caveolins, which play major roles in the architecture of caveolae. Caveolae are membrane domains with specialized functions, including sorting processes, transmembrane signaling, and molecular transport across membranes $(23,24)$. The expression of cav-1 is restricted to endothelium, adipocytes, smooth muscle cells, and fibroblasts (24-26), while cav-3 specifically occurs in (all types of) muscle cells (27). In line with this, both cav-1 (endothelium) and cava3 (myocytes) were observed in heart and skeletal muscle homogenates, whereas only cav-3 was present in giant vesicles (in similar amounts as in the homogenates) (Fig. 3.1A). These findings indicate that heart and muscle giant vesicles are solely derived from myocytes and include caveolae. Cav-1 and cav-3 were not detectable in liver tissue, which is in agreement with previous results (24). In epididymal fat pads, similar amounts of cav-1 were found in homogenates and giant vesicles, indicating that in adipose tissue endothelial cells and/or caveolar plasma membrane regions are involved in giant vesicle formation.

The dihydropyridine receptor (DHPR), or L-type $\mathrm{Ca}^{2+}$ channel, is localized in transverse invaginations of the muscle cell surface, the T-tubuli. Since the proportion of junctional T-tubules is higher in fast-contracting than in slow fibres (23), we observed the DHPR in greater amounts in skeletal muscle than in heart, and absent in liver and adipose tissue 
which lack T-tubuli (Fig. 3.1A). Importantly, DHPR was not detectable in giant vesicles (Fig. 3.1A) confirming previous results of Ploug et al. (1993)(14) and indicating that T. tubuli are not involved in giant vesicle formation from muscle tissue.

Neural cadherin ( $\mathrm{N}$-cadherin) belongs to the cadherins, a family of cell adhesion proteins, and was used for the detection of plasma membrane regions involved in cell-cell interaction. In cardiac myocytes $N$-cadherin is localized in the intercalated disks $(28,29)$, the membrane regions involved in mediating the electric pulse from cell to cell, but skeletal muscle fibers, which are a longitudinal continuum of multiple fused cells, lack this membrane domain (30). $\mathrm{N}$-cadherin was found in homogenates from heart and liver, not in skeletal muscle and adipose tissue (Fig. 3.1A). Its presence in liver was reported earlier (31), and may relate to a role for $\mathrm{N}$-cadherin in selective cell-cell adhesion (32). $N$ cadherin was neither detected in heart nor in liver giant vesicles, suggesting that this specialized portion of the plasma membrane is mot involved in the formation of giant vesicles.

The insulin receptor is an important hallmark of the plasma membrane of insulinsensitive tissues such as heart, skeletal muscle, liver and adipose tissue (33). The insulin receptor $\beta$-subunit was found in each of the tissue homogenates, and most abundantly in heart and adipose tissue (Fig. 3.1A). This observation confirms other studies on tissue characteristics of insulin binding (34). The $\beta$-subunit was also present in giant vesicles derived from heart, liver, muscle, and epididymal fat pads in similar amounts as in the total tissue homogenates. This observation provides additional evidence for the plasmalemmal origin of giant vesicles.

The transferrin receptor is a commonly used marker of the endosomal compartment, because the vast majority of this protein is stored intracellularly. In contrast to the glucose transporter GLUT4 (see below), insulin recruits only a small portion of the transferrin receptor to the sarcolemma (35). The transferrin receptor was detected in heart and muscle, but not in liver and adipose tissue (Fig. 3.1A). Others allso reported that the transferrin receptor is absent from liver and occurs in only minute quantities in adipose tissue $(35,36)$. The observation that in heart and muscle this receptor is present in similar amounts in total tissue homogenates and glant vesicles indicates that the endosomal compartment contributes to the delivery of membranes for giant vesicles.

\section{Transporters for long-chain fatty acids and for glucose}

FAT/CD36 and FABPpm are functionally important membrane FA transporters in heart, skeletal muscle and adipose tissue, and FABPpm also in liver (FAT/CD36 is viltually absent in liver (37-40), but inducable in this organ (41). In heart the total amount of FAT/CD36 is about equally distributed between myocytes and endothelial cells (42). At least in myocytes, we have demonstrated that FAT/CD36 is present both at the sarcolemma and in an intracellular (endosomal) compartment from which it can be translocated to the sarcolemma in response to cellular contractions $(43,44)$ or insulin $(45)$. FABPpm is highly homologous, if not identical, to mitochondrial aspartate aminotransferase (mAAT) (46), and, apart from this, may also be present in an intracellular (endosomal, nonmitochondrial) pool (15). FAT/CD36 and FABPpm were present in total homogenates and 
in giant vesicles of each of the four tissues studied, thereby showing a similar tissue distribution pattern (Fig. 3.18). This observation also indicates that the plasma membrane and endosomal membranes each contribute to giant vesicle formation.

GLUT4 is the major glucose transporter in insulin-sensitive tissues (47). Insulin stimulates glucose transport through translocation of GLUT4 from an endosomal storage depot to the plasma membrane. Under basal (non-stimulated conditions) the majority of GLUT4 resides intracellularly, so that GLUT4, similar to the transferrin receptor, can be regarded as an endosomal protein rather than a plasma membrane marker (35). Total tissue homogenates and giant vesicles displayed the same tissue distibution pattern of CLUT4 in that it is most abundant in heart, followed by adipose tissue and muscle, and is absent in liver (Fig. 3.1B). In each tissue, GLUT4 was equally abundant in giant vesicles and total tissue homogenates, indicating that GLUT4 containing endosomal compartments are involved in vesicle formation.

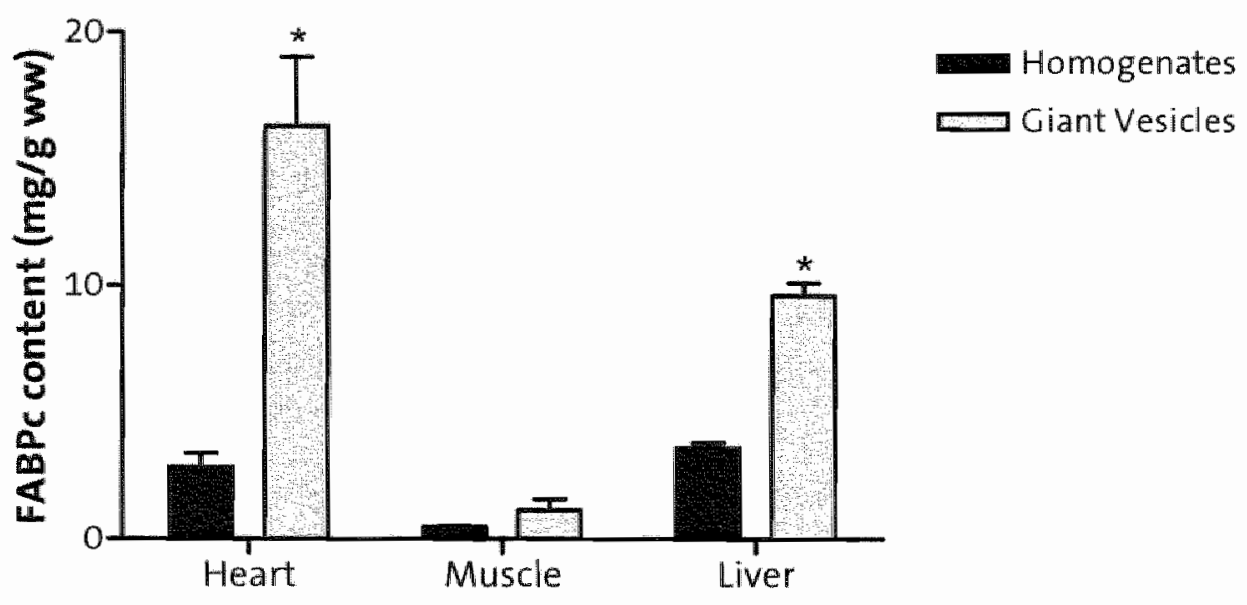

Figure 3.2. Cytoplasmic FABP content in homogenates and giant vesicles from heart and skeletal muscle tissues (H.FABP) and liver (L-FABP). H-FABP and L-FABP were determined by a sandwich-type enzyme-linked immunosorbent assay (ELISA) and are based upon 5-6 sample sizes. ${ }^{*} P<0.05$.

FABPC a $15 \mathrm{kD}$ cytoplasmic protein acting as intracellular acceptor and carrier of FA, occurs in several distinct types each showing a characteristic tissue distribution $(40,48)$. Heart-type FABPC (H-FABPC) is present in heart and to a lesser extent in muscle, and is absent in liver and adipose tissue (Fig. 3.2). Liver-type FABPC (L-FABPC) is specifically expressed in liver (Fig. 3.2). For both H-FABPC and L-FABPC we observed a 3-4-fold enrichment in giant vesicles compared to total tissue homogenates. Previously, we established that the vesicular lumen consists of the soluble portion of the cytoplasm (18). The enrichment of FABPC isoforms in giant vesicles can then be explained by exclusion of other portions of the cytoplasm, because myosin (9), components of cytoskeletal and myofibrillar network $(14)$, and mitochondria $(14,19)$ are absent in giant vesicles. Giant vesicles from adipose tissue were previously found to contain adipocyte-type FABPc 
(usually referred to as adipocyte lipid binding protein, ALBP) (15). The presence of FABPC inside giant vesicles permits the proper study of FA uptake as FABP then can act as a (natural) sink for these hydrophobic substrates.

\section{Application of giant membrane vesicles for substrate uptake studies}

The great similarity in size $(10-15 \mu \mathrm{m})$ and shape (spherical) of giant vesicles from different tissues indicates that it is possible for the first time to compare metabolic substrate fluxes among these organs independently of the surface/volume ratio. This could provide additional insight into the organ-differences in functioning of membrane transporters involved in cellular uptake of metabolic substrates.
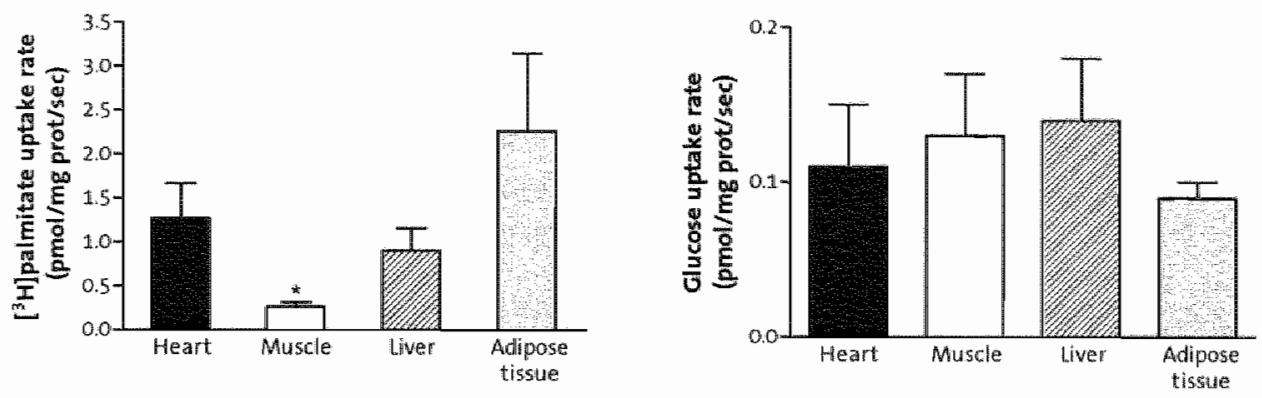

Fig. 3.3. Palmiltate and glucose uptake rate into giant sarcolemmall vesicles obtained from heart, skeletal muscle, liwer, and adipose tissue. Data are the means of of 3-4 experiments carried out with the vesicle preparations as described in the methods section. ${ }^{*}<<0.05$.

The rate of FA uptake by giant vesicles prepared from heart, muscle, adipose tissue and liver varied considerably (Fig. 3.3). For heart, muscle and adipose tissue the content of FAT/CD 36 per organ correllated well with the FA uptake rate ( $r$ for linear fit $=0.85$; Fig. 3.4 left panel). In contrast, no significant correlation among the tissues was found between FA uptake and the contents of FABPpm ( $r$ for linear fit $=0.27$; Fig. 3.4 right panel). These findings confirm the view that FABPpm is necessary, but not rate limiting in FA uptake, since we $(19)$ and others $(1,49)$ previously showed that FA uptake in heart could be largely inhibited by a polyclonal anti-FABPpm antiserum, indicating the involvement of this transporter in their bulk uptake. It appears, therefore, that FAT/CD36 and FABPpm cooperate in a joint fashion to translocate long-chain fatty acids across the sarcolemma. Whether this means that FAT/CD36 and FABPpm are two protein-Components of a single LCFA transport system remains to be established. In contrast to FA uptake, glucose uptake among the various tissues is remarkably similar (only adipose fat pads display a slightly lower uptake rate than the other tissues; Fig. 3.3). However, we did not find a significant correlation between glucose uptake rate and heart, muscle, and adipose tissue content of GLUT4 ( $r$ for linear fit $=0.0$; data not shown). Since heart, skeletal muscle, liver and adipose tissues are known to express different glucose transporter 
isoforms (50), this lack of correlation might be explained by the simultaneous expression of other glucose transporter isoforms.

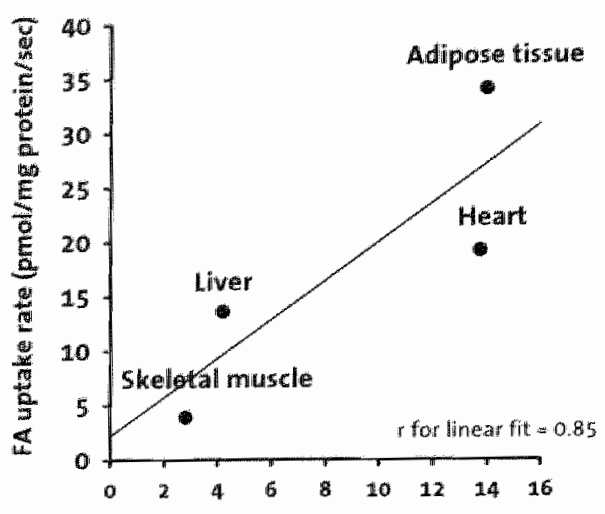

FAT/CD 36 content in vesicles (arb. units)

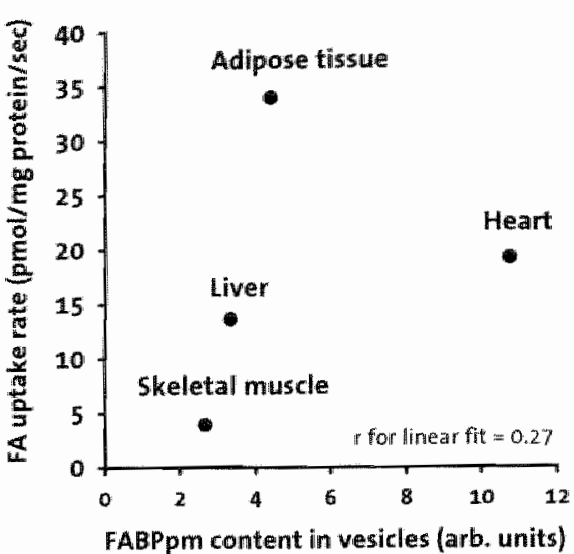

FABPpm content in vesicles (arb. units)

Figure 3.4. Comparison of FAT/CD36 and FABPpm in vesicle membranes obtained from heart (H). skeletal muscle (M), liver (L), and adipose tissue (A) with palmitate uptake rates by these vesicles. The transport protein data are those from fig. 1B, and the palmitate uptake experiments are those represented in fig. 3 (top panel).

For instance, GLUT1 is recognized to be the most ubiquitously expressed glucose transporter, and is often expressed in conjunction with a more tissue-restricted glucose transporter isoform, that is GLUT2 in liver, and GLUT4 in heart, muscle and adipose tissue. We therefore speculate that GLUT1 is responsible for the bulk of glucose uptake in giant vesicles. This notion is strenghtened by observations in heart and skeletal muscle, where GLUT1 protein levels were found to be $\geq 3$-fold enriched in giant vesicles compared to total tissue homogenates (data not shown).

\section{Conclusion}

This is the first study to compare the characteristics of giant membrane vesicles obtained from rat heart, skeletal muscle, liver and adipose tissue. This comparison not only provides knowledge on the properties and composition of the vesicles, which information is needed for proper interpretation of experimental studies using this model system, but also gives further insight into the mechanism of giant vesicle formation.

Using plasma membrane markers from different cell types, we could establish that at least in heart, muscle and liver parenchymal cells, and not endothelial cells, are involved in vesicle formation. For adipose tissue, conclusive evidence could not be obtained, but given the findings on the other tissues, adipocyte giant vesicles most likely consist only of adipocyte plasma membranes. The presence of tissue-specific types of FABPC in the 
lumen of the giant vesicles also points towards parenchymal cells as the predominant source of giant vesicles.

Our data show that selected plasma membrane regions are involved in vesicle formation. In heart and muscle, the T-tubuli are not involved in giant vesicle formation, whereas in heart and liver, membrane regions involved in specific cell-cell interactions are not present in giant vesicles. Therefore, we speculate that membrane regions shared by the various parenchymal cell types, such as those involved in binding of ligands, transport of substrates, and regions containing caveolae, are the source of giant vesicle membranes, while regions with cell-specific functions are not.

Furthermore, we obtained additional evidence that endosomal membranes contribute to the formation of giant vesicles, as suggested by Ploug et al. (1993). Previously, the presence of an endosomal protein involved in the regulation of vesicular trafficking, vesicle-associated membrane protein-2 (VAMP-2), was demonstrated in giant vesicles (51). In this study, both GLUT4 and the transferrin receptor were found to be present in giant vesicles. Moreover, caveolin, which was abundant in giant vesicles, is supposed to be involved in endosomal-vesicular trafficking (23). As established in adipocytes, a small portion $(\approx 20 \%)$ of the cellular amount of caveolin is present in an insulin-sensitive recycling compartment. Since caveolae are enriched in GLUT4, a colocalization of surface caveolin with GLUT4 was suggested $(23,52,53)$. There is however no general consensus on this view $(23,52,53)$. Taken together, the notion arises that the giant vesicle membranes are a continuum of combined endosomal regions with plasma membrane regions and are involved in docking of recycling endosomal vesicles at the plasma membrane. The large size of the vesicles raises the question whether the endosomal compartment can recruit sufficient membranes and suggests that extensive plasma membrane regions must be included in giant vesicles. In agreement with this suggestion, heart and muscle giant vesicles have been found in earlier studies to be enriched in wellestablished plasma membrane markers p-nitrophenylphosphatase and 5'nucleotidase $(16,19,21)$. Moreover, giant vesiclles from all selected tissues were found to contain the insulin receptor, GLUT1 and caveolins, all of which are predominantly plasmalemmal proteins. The putative involvement of plasma membrane fusion and excision events in the $\mathrm{KCl}$-induced giant vesicle formation process allows the use of giant vesicles as a model to study vesicular trafficking processes. In addition, based on the absence of metabolism, giant vesicles from heart, liver, skeletal muscle and adipose tissue are very suitable to study substrate uptake.

\section{Acknowledgements}

Antibodies for FABPpm and FAT/CD36 were kindly provided by Dr. D. Sorrentino, Mount Sinai Medical Center, New York City, USA, and by Dr. N. Tandon, Otsuka Pharmaceuticals, Bethesda MD, USA. Gp60 antibody was a kind gift from Dr. C. Tirrupathi, University of Illinois, Chicago IL, USA. This study was supported by NWO-MW: 903-39-194, the Canadian Institutes of Health Research (CIHR), and the Heart and Stroke Foundation of Ontario. 


\section{References}

1. Stremmel, W. (1988) Fatty acid uptake by isolated rat heart myocytes represents a carriermediated transport process. I Cin Invest 81, 844-852

2. Sorrentino, D., Stump, D. Potter, B. I. Robinson, R. B., White, R., Kiang, C. L., and Berk, P. D. (1988) Oleate uptake by cardiac myocytes is carrier mediated and inwolves a 40-kD plasma membrane fatty acid binding protein similar to that in liver, adipose tissue, and gut. 1 clin invest $82,928-935$

3. Luiken, I. I., van Nieuwenhoven, F. A., America, G. van der Vusse, G. J., and Glatz, J. F. (1997) Uptake and metabolism of palmitate by isolated cardiac myocytes from adult rats: involvement of sarcolemmal proteins. I Lipid Res 38,745-758

4. Fischer, Y., Thomas, I, Sevilla, L., Munoz, P., Becker, C., Holman, G., Kozka, I. I., Palacin, M., Testar, $X$., Kammermeier. $H$., and Zorzano, A. (1997) Insulin-induced recruitment of glucase transporter 4 (CLUT4) and GLUT1 in isolated rat cardiac myocytes. Evidence of the existence of different intracellular GLUT4 wesicle populations. I Biol Chem 272,7085-7092

5. Russell, R. R., 3rd, Bergeron, R. Shulman, G. I., and Young, L. H. (1999) Translocation of myocardial GLUT-4 and increased glucose uptake through activation of AMPK by AICAR. An S Physiol 277, H643-649

6. Juel, C. (1988) Intracellular pH recovery and lactate efflux in mouse soleus muscles: stimulated in vitro: the involvement of sodium/proton exchange and a lactate carrier. Acta Physiol Scand 132, 363-371

7. Grimditch, G. K., Barnard, R. J., Kaplan, S. A., and Sternlicht, E. (1985) Insulin binding and glucose transport in rat skeletal muscle sarcolemmal vesicles. Am J Physiol 249, E398-408

8. King, P. A., Hirshman, M. F., Horton, E. D., and Horton, E. S. (1989) Glucose transport in skeletal muscle membrane vesicles from control and exercised rats. Am I Physiol 257 , C1128-1134

9. Juel, C. (1991) Muscle lactate transport studied in sarcolemmal giant vesicles. Biochim Biophys Acta 1065, 15-20

10. Ahmed, A., Taylor, P. M. and Rennie, M. J. (1990) Characteristics of glutamine transport in sarcolemmal vesicles from rat skeletal muscle. Am J Physiol 259, E284-291

11. van Amelswoort, J. M., Sips, H. J., and van Dam, K. (1978) Sodium-dependent alanine transport in plasma-membrane vesicles from rat liver. Biochem $/ 174,1083-1086$

12. Berardi, S., Stieger, B. Hagenbuch, B., Carafoli, E., and Krahenbuhl, S. (2000) Characterization of L-camitine transport into rat skeletal muscle plasma membrane vesicles. Eur I Biochem 267, 1985-1994

13. Bersohn, M. M. (1995) Sodium pump inhibition in sarcolemma from ischemic hearts. 1 Mol Cell Cardiol 27, 1483-1489

14. Ploug, T., Wojtaszewski, J., Kristiansen, S., Hespel, P., Galbo, H., and Richter, E. A. (1993) Glucose transport and transporters in muscle giant vesicles: differential effects of insulin and contractions. Am J Physiol 264, E270-278

15. Luiken, J. J., Arumugam, Y., Dyck, D. J., Bell, R. C., Pelsers, M. M., Turcotte, L. P., Tandon, N. N., Glatz, J.F., and Bonen, A. (2001) Increased rates of fatty acid uptake and plasmalemmal fatty acid transporters in obese Zucker rats. $J$ Biol Chem $276,40567-40573$

16. McCullagh, K. J., Juel, C., O'Brien, M., and Bonen, A. (1996) Chronic muscle stimulation increases lactate transport in rat skeletal muscle. Mol Cell Biochem 156, 51-57

17. Tokumaru, H. Anzai, K., Abe, T., and Kirino,. . (1992) Purification of the cardiac 1,4dihydropyridine receptor using immunoaffinity chromatography with a monoclonal antibody against the alpha 2 delta subunit of the skeletal muscle dihydropyridine receptor. Eurs Pharmacol 227, 363-370

18. Van Nieuwenthoven, F. A., Verstijnen, C. P., Van Eys, G. J., Van Breda, E., De Jong, Y. F., Van der Vusse, G. J., and Glatz, I. F. (1994) Fatty acid transfer across the myocardial capillary wall: no evidence of a substantial role for cytoplasmic fatty acid-binding protein. $J$ Mol Cell Cardiol 26, 1635-1647

19. Luiken, J. J. Turcotte, L. P., and Bonen, A. (1999) Protein-mediated palmitate uptake and expression of fatty acid transport proteins in heart giant vesicles. 1 Lipid Res 40, 1007-1016 
Berk, P. D., Zhou, S. L., Klang, C. L., Stump, D. Bradbury, M., and 1sola, L. M. (1997) Uptake of long chain free fatty acids is selectively upiregulated in adipocytes of Zucker rats with genetic obesity and non-insulin-dependent diabetes mellitus. $/$ Biol Chem 272, 8830-8835

21. Bonen, A., Luiken, J. J., Liu, S., Dyck, D. J., Kiens, B. Kristiansen, S., Turcotte, L. Po, Van Der Vusse, G. J. and Glatz, J.F. (1998) Palmitate transport and fatty acid transporters in red and white muscles. Am J Physiol 275, E471-478

22. Schnitzer, J. E., Sung, A., Horvat, R., and Bravo, J. (1992) Preferential interaction of albumim. binding proteins, gP30 and gP18, with conformationally modified albumins. Presence in many cells and tissues with a possible role in catabolism. J Biol Chem 267, 24544m 24553

23. Munoz, P., Mora, S., Sevilla, L., Kaliman, P., Tomas, E, Guma, A., Testar, X., Palacin, M. and Zorzano, A. (1996) Expression and insulin-regulated distribution of caveolin in skeletal muscle. Caveolin does not colocalize with GLUT4 in intracellular membranes. 1 Biol chem $271,8133-8139$

24. Kogo, H., and Fujimoto, T. (2000) Caveolin-1 isoforms are encoded by distinct mRNAs. Identification of mouse caveolin-1 MRNA variants caused by alternative transcription initiation and splicing. FEBS Lett 465, 119-123

25. Oka, N. Asai, K., Kudej, R. K., Edwards, J. G., Toya, Y., Schwencke, C., Vatner, D. E., Vatner, S.

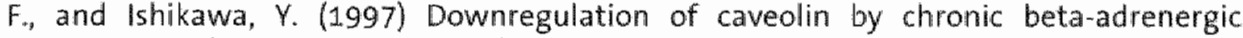
receptor stimulation in mice. Am I Physiol 273, C1957-1962

26. Song, K. S., Li, S., Okamoto, T., Quilliam, L. A., Sargiacomo, M., and Lisanti, M. P. (1996) Copurification and direct interaction of Ras with caveolin, an integral membrane protein of caveolae microdomains. Detergent-free purification of caveolae microdomains. I Biol Chem 271, 9690-9697

27. Song, K. S., Scherer, P. E., Tang, Z., Okamoto, T., Li, S., Chafel, M., Chu, C., Kohtz, D. S., and Lisanti, M. P. (1996) Expression of caveolin-3 in skeletal, cardiac, and smooth muscle cells. Caveolin-3 is a component of the sarcolemma and co-fractionates with dystrophin and dystrophin-associated glycoproteins. J Bial Chem 271, 1.5160-15165

28. Knudsen, K. A., Soler, A. P., Johnson, K. R., and Wheelock, M. J. (1995) Interaction of alphaactinin with the cadherin/catenin cell-cell adhesion complex via alpha-catenim. / Cell Biol $130,67-77$

29. Rimm, D. L., Koslov, E. R., Kebriaei, P., Cianci, C. D., and Morrow, J. S. (1995) Alpha 1(E)catenin is an actin-binding and -bundling protein mediating the attachment of F-actin to the membrane adhesion complex. Proc Natl Acad Sci U S A 92, 8813-8817

30. Imanaka-Yoshida, K., Knudsen, K. A., and Linask K. K. (1998) N-cadherin is required for the differentiation and initial myofibrillogenesis of chick cardiomyocytes. Cell Motil cytoskeleton $39.52-62$

31. Linnemann, D., Gaardsvoll, H., Dalseg, A. M., Zhernosekov, D. Lundgren, T., Edvardsen, $K_{\text {., }}$ and Bock, E. (1994) Characterization of N-cadherin messenger RNA and polypeptide expression in rat. Int I Dev Neurosci 12, 441-450

32. Miyatani, S., Shimamura, K., Hatta, M., Nagafuchi, A.., Nose, A., Matsunaga, M., Hatta, K., and Takeichi, M. (1989) Neural cadherin: role in selective cell-cell adhesion. Science 245. $631-635$

33. Gustavsson, J., Parpal, S., Karlsson, M., Ramising, C., Thorn, H., Borg. M., Lindroth, M., Peterson, K. H., Magnusson, K. E., and Stralfors, P. (1999) Localization of the insulin receptor in caveolae of adipocyte plasma membrane. Faseb / 13, 1961-1971

34. Torlinska, T., Mackowiak, P., Nogowski, L., Nowak, K. W., Madry, E. and Perz, M.. (1998) Characteristics of insulin receptor binding to various rat tissues. I Physiol Pharmacal 49. $261-270$

35. Kandror, K. V., and Pilch, P.F. (1996) Compartmentalization of protein traffic in insulin. sensitive cells. Am I Physiol 271, E1-14

36. Jefferies, W. A., Brandon, M. R. Williams, A. F., and Hunt, S. V. (1985) Analysis of lymphopoietic stem cells with a monoclonal antibody to the rat transferrin receptor. immunology 54.333-341 
37. Abumrad, M., Coburn, C., and lbrahimi, A. (1999) Membrane proteins implicated in longchain fatty acid uptake by mammalian cells: CD36, FATP and FABPm. Biochim Biophys Acta 1441, 4-13

38. Luiken, J. 1., Schaap, F. G., van Nieuwenhoven, F. A., wan der Vusse, G. 1., Bonen, A., and Glatz. I. F. (1999) Cellular fatty acid transport in heart and skeletal muscle as facilitated by proteins. Lipids 34, S169-175

39. Febbraic, M. Hajjar, D. P., and Silverstein, R. L. (2001) CD36: a class B scavenger receptor involved in angiogenesis, atherosclerosis, inflammation, and lipid metabolism. I Clin invest $108,785-791$

40. Glatz, J. F., and Storch, J. (2001) Unravelling the significance of cellular fatty acid-binding proteins. Curr Opin Lipidol 12, 267-274

41. Motojima, K., Passilly, P., Peters, J. M., Gonzalez, F. J., and Latruffe, N. (1998) Expression of putative fatty acid transporter genes are regulated by peroxisome proliferator-activated receptor alpha and gamma activators in a tissue-and inducer-specific manner. I Biol Chem 273, 16710-16714

42. Brinkmann, J. F., Abumrad, N. A., lbrahimi, A., van der Vusse, G. J., and Glatz, J. F. (2002) New insights into long-chain fatty acid uptake by heart muscle: a crucial role for fatty acid translocase/CD 36. Biochem \& 367,561-570

43. Bonen, A., Luiken, J. J., Arumugam, Y., Glatz, J. F., and Tandon, N. N. (2000) Acute regulation of fatty acid uptake involves the cellular redistribution of fatty acid translocase. J Biol Chem 275, 14501-14508

44. Luiken, J. J., Willems, J. van der Vusse, G. J., and Glatz, I. F. (2001) Electrostimulation enhances FAT/CD36-mediated long-chain fatty acid uptake by isolated rat cardiac myocytes. Am J Physiol Endocrinol Metab 281, E704 712

45. Luiken, J. J. Dyck, D. J., Han, X. X., Tandon. N. N., Arumugam, Y., Glatz, J. F., and Bonen, A. (2002) Insulin induces the translocation of the fatty acid transporter FAT/CD36 to the plasma membrane. Am I Physiol Endocrinol Metab 282, E491-495

46. Stump, D. D., Zhou, S. L., and Berk, P. D. (1993) Comparison of plasma membrane FABP and mitochondrial isoform of aspartate aminotransferase from rat liver. Am / Physiol 265. G894-902

47. Zorzano, A., Sevilla, L., Camps, M., Becker, C., Meyer, J., Kammermeier, H., Munoz, P., Guma, A., Testar, X., Palacin, M., Blasi, I., and Fischer, Y. (1997) Regulation of glucose transport, and glucose transporters expression and trafficking in the heart: studies in cardiac myocytes. Am / Cardiol 80,65A-76A

48. Storch, 1., and Thumser, A. E. (2000) The fatty acid transport function of fatty acid-binding proteins. Biochin Biophys Acta 1486, 28-44

49. Stremmel. W., and Berk, P. D. (1986) Hepalocellular influx of [14C]oleate reflects membrane transport rather than intracellullar metabolism or binding. Proc Natl Acad SCIU S.A 83, 3086-3090

50. Mueckler, M. (1994) Facilitative glucose transporters. Fur J Biochem 219, 713-725

51. Kristiansen, S., Hargreaves, M.; and Richter, E. A. (1996) Exercise-induced increase in glucose transport, GLUT-4, and VAMP-2 in plasma membrane from human muscle. Am J Physiol 270, E197-201

52. Scherer, P. E., Lisanti, M. P. Baldini, G. Sargiacomo, M. Mastick, C. C., and Lodish, H. F. (1994) Induction of caveolin during adipogenesis and association of GLUT4 with caveolinrich vesicles. I Cell Biol 127, 1233-1243

53. Kandror, K. V., Stephens, J. M., and Pilch, P. F. (1995) Expression and compartmentalization of caveolin in adipose cells: coordinate regulation with and structural segregation from GiluT 4. I Cell Biol 129, 999-1006 


\section{Different mechanisms \\ can alter fatty acid transport \\ when muscle contractile activity \\ is chronically altered}

Debby P.Y. Koonen ${ }^{1}$, Carley R. Benton ${ }^{2}$, Yoga Arumugam ${ }^{5}$, Narendra N. Tandon", Jorge Calles-Escandon ${ }^{4}$, Jan F.C. Glatz ${ }^{1}$, Joost J.F.P. Luiken ${ }^{1}$, and Arend Bonen ${ }^{5}$

1. Department of Molecular Genetics, Cardiovascular Research Institute Maastricht, Maastricht Uniwersity. NL-6200 MD Maastricht. The Netherlands.

2. Department of Kinesiology, University of Waterloo, Waterloo, Ontario N2L 361 , Canada

3. Thrombosis Research Biology Laboratory, Otsuka America Pharmaceutical Inc. 9900 Medical Center Driwe, Rockville MD 20850, USA

4. Section of Endocrinology and Metabolism. Wake Forest University School of Medicine \& Baptist Medical Center, Winston-Sallem NC, U.S.A. 27157

5. Department of Human Biology and Nutritional Sciences, University of Guelph, Guelph, Ontario, N1G 2W1, Canada 


\section{Abstract}

We examined whether skeletal muscle transport rates of long chain fatty acids (LCFAs) were altered when muscle activity was eliminated (denervation) or increased (chronic stimulation:. After 7 days of chronically stimulating the hindlimb muscles of female Sprague-Dawley rats, the LCFA transporter proteins FAT/CD36 (+43\%) and FABPpm $(+30 \%)$ were increased $(P<0.05)$, which resulted in the increased plasmalemmal content of these proteins (FAT/CD 36, $+42 \%$; FABPpm $+13 \%, P<0.05$ ), and a concomitant increase in the LCFA transport rate into giant sarcolemmal vesicles $(+44 \%, P<0.05)$. While the total muscle contents of FAT/CD36 and FABPpm were not altered $(P>0.05)$ after 7 days of denervation, the LCFA transport rate was markedly decreased (-39\%). This was associated with reductions in plasmalemmal FAT/CD36 (-24\%) and FABPpm $(-28 \%)$. These data suggest that these LCFA transporters were resequestered to their intracellular depot(s) within the muscle. Combining the results from these experiments indicated that changes in rates of LCFA transport were correlated with concomitant changes in plasmallemal FAT/CD36 and FABPpm, but not necessarily their total muscle content. Thus, chronic alterations in muscle activity can alter the rates of LCFA transport via different mechanisms, either a) by increasing the total muscle content of FAT/CD36 and FABPpm resulting in a concomitant increase at the sarcolemma, or b) by reducing the plasma membrane content of these proteins, in the absence of any changes in their total muscle content.

\section{Introduction}

Skeletal muscles depend on long-chain fatty acids (LCFAS) to maintain ATP production during contractile activity. When muscle activity is increased, progressively more LCFAs are taken up into the muscle (1). It is now recognized that LCFAs cross the sarcolemma via simple diffusion and a protein-mediated system (2-5). Several proteins have been identified as LCFA transporters. Fatty acid translocase (FAT/CD36), and plasma membrane associated fatty acid-binding protein (FABPpm) have been shown to facilitate LCFA transport into heart and skeletal muscle $(2,5-7)$, while fatty acid transport protein 1 (FATP1) appears to be involved in the transport of LCFAs and acylation of very long-chain fatty acids (8-11).

Skeletal muscle metabolism is remarkably capable of adapting to changes in muscle activity pattern $(12,13)$. Chronic changes in muscle activity can also alter the expression of several substrate transporters, and hence substrate transport. For example, increasing muscle activity by chronic stimulation enhances glucose and lactate transport and their respective transporters GLUT4 (14-16) and the monocarboxylate transporter MCT1 (1719). Conversely, reductions in muscle activity, induced by denervation, result in decrements in glucose and lactate transport and their accompanying transporters GLUT4 $(20-23)$, MCT1 and MCT4 $(17,24,25)$. While it has been shown that increased muscle activity can increase FAT/CD 36 (26) and FABPpm $(16,27)$, as well as LCFA transport (26), the effects of reducing muscle activity on LCFA transport and transporters are not known. 
In previous studies we have shown (2) that LCFA uptake is subject to short-term regulation by a brief period (5-30 $\mathrm{min}$ ) of muscle contraction, involving the translocation of FAT/CD36 from intracellular stores to the sarcolemma. Subsequently, we demonstrated that insulin is also able to translocate FAT/CD 36 in muscle (28) and cardiac myocytes (29) via the PI3-kinase signaling pathway $(28,29)$. The total muscle content of LCFA transporters has been shown to be a key factor influencing the plasmalemmal content of LCFA transporters, and hence the rate of LCFA transport in skeletal muscle (30, 31). However, we (32) have also shown, in obese Zucker rats, that rates of LCFA transport into muscle and heart can be increased by a permanent relocation of FAT/CD36 from their intracellular depots to the plasma membrane, without observing any changes in the total muscle content of this transporter. Thus, just as for glucose transport and GLUT 4 (33), it is important to account for changes in LCFA transport by examining both the total muscle content and the plasmalemmal content of FAT/CD36 and FABPPm. Since LCFAs are an important substrate for skeletal muscle and the rate of LCFA transport can regulate the cellular metabolism of this substrate in this tissue (34), we have examined the effects of altered muscle activity on LCFA transport and the mechanisms involved. Specifically, we investigated the effects of an increase in muscle activity (7 days chronic stimulation) and a decrease in muscle activity (7 days denervation) on i) the total muscle content of the LCFA transport proteins, FAT/CD36 and FABPpm, ii) their plasmalemmal content and iii) the rates of LCFA transport into giant sarcolemmal vesicles. The contralateral muscles, in each of these treatments, served as controls.

\section{Methods}

\section{Materials}

Bovine serum albumin (BSA) (fraction $V$ ) and collagenase type $V$ II were purchased from Sigma-Aldrich (St. Louis, Missouri). Non-fat dry millk and western blot reagents were from Bio-Rad Laboratories (Hercules, CA) and the enhanced chemiluminescence (ECL) kit was from Amersham Pharmacia Biotech (Buckingham, UK). FAT/CD36 was detected with a monoclonal antibody (MO25) directed against human CD36 (35). A rabbit polyclonal against rat-hepatic membrane associated LCFA binding protein was used to detect FABPpm (36). A goat polyclonal immuno-A purified GLUT4 antibody and dorkey-anti-goat igG-HRP conjugated were obtained from Santa Cruz Biotechnology, Inc (Santa Cruz, CA, USA). Goat anti-mouse and donkey anti-rabbit IgG-HRP were obtained from Santa cruz Biotechnology, Inc (Santa Cruz, CA, USA) and from Amersham Pharmacia Biotech (Buckingham, UK).

\section{Animals}

Female Sprague-Dawley rats, weighing $200-250 \mathrm{~g}$ were used. Animals were housed in a temperature-controlled room on a reversed $12: 12 \mathrm{kh}$ light-dark cycle and fed a Purina Chow diet and water ad libitum. Immediately before surgery rats were anesthetized using halothane, followed by a subcutaneous injection with buprenorphine 
hydrochloride $(0.3 \mathrm{mg} / \mathrm{ml})(0.12 \mu \mathrm{l} / \mathrm{kg})$. After surgery animals were housed individually (chronic stimulation) or were housed together in a cage (denervation). Ethical approval for all experimental procedures was obtained from the Committee on Animal Care at the University of Guelph.

\section{Chronic stimulation of rat hindlimb muscles}

Rat muscles were prepared and chronically stimulated as we have previously described $(14,17-19,26)$. For these purposes we have routinely stimulated the EDL and red and white tibialis anterior $(17,19)$. In anesthetized rats, two stainless steel electrodes were sutured to the underlying muscle on either side of the common peroneal nerve (Fig. 4.1).

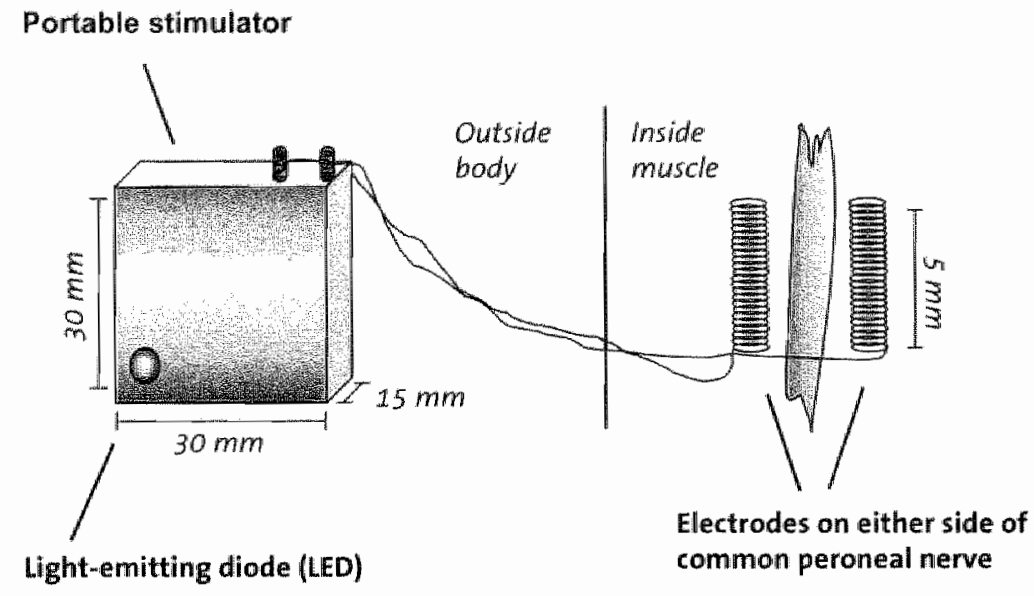

Figure 4.1. Procedure of chronic muscle stimulation. in anesthetized rats, two stainless steel electrodes were sutured to the underlying muscle on either side of the common peroneal nerve. These electrodes were then passed subcutaneously from the thigh, exteriorized at the back of the neck and subsequently attached to a miniature electronic stimulator.

These electrodes were then passed subcutaneously from the thigh exteriorized at the back of the neck and subsequently attached to a miniature electronic stimulator. The overlying muscle was sutured and the skin was stapled. Muscles from the contralateral limb were used as a nonstimulated, internal control and were therefore sham-operated. Only when animals had regained at least $100 \%$ of their preoperative bodyweight ( 5 days) and had recovered from surgery for a minimum of 6-7 days, was chronic stimulation initiated. The common peroneal nerve, which innervates the EDL and TA muscles, was stimulated at $12 \mathrm{~Hz}, 24 \mathrm{~h} /$ day for 7 days. Thereafter, animals were subdivided into two groups. In the first group ( $n=5)$ total FAT/CD36, FABPpm and GLUT4 protein levels were measured in chronically stimulated and control EDL and red and white TA muscles. In a second group of rats $(n=15)$, the EDL and TA muscles were pooled $(n=3$ rats/pool) for the 
purpose of preparing giant sarcolemmal vesicles in order to measure rates of palmitate uptake. FAT/CD36, FABPpm and GLUT4 (positive controll) were measured in plasma membranes of giant vesicles prepared from these pooled control and chronically stimulated muscles.

\section{Denervation of rat hindlimb muscles}

Muscle activity was eliminated in one hindlimb by denervating the lower leg muscles of that hindlimb. For these purposes we have routinely examined soleus and red and white gastrocnemius in our work (23-25). Briefly, a small superficial incision was made in the posterior aspect of the hindlimb to expose the sciatic nerve, a $1 \mathrm{~cm}$ section of the sciatic nerve was removed, and the incision was closed with sutures and staples (Fig. 4.2).
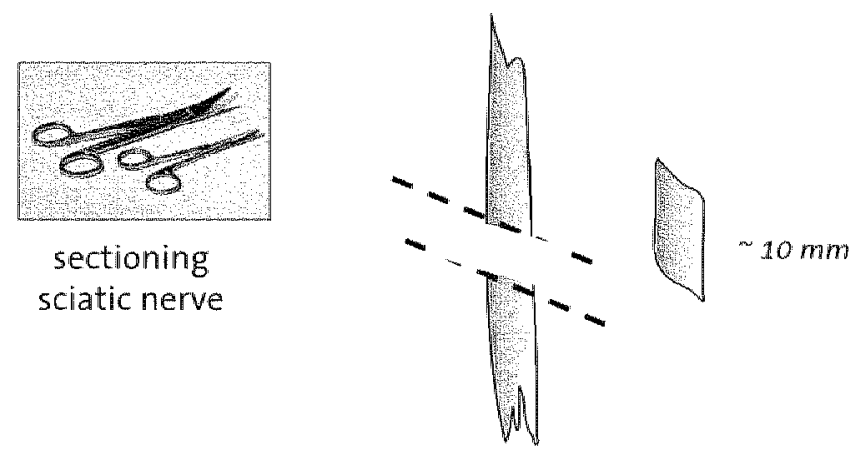

sciatic nerve

Figure 4.2. Procedure of nerve denervation. In the posterior aspect of the hindlimb a small incision was made to expose the sciatic nerve. Subsequenlty, a $1 \mathrm{~cm}$ section of the sciatic nerve was removed, and the incision was closed with sutures and staples.

The contralateral leg was sham-operated without touching the nerve. Muscles in this limb served as a non-denervated, control. After denervation rats were randomly divided into two groups. In the first group $(n=10)$ FAT/CD36, FABPpm and GLUT4 protein were measured in denervated and control soleus, red and white gastrocnemius muscles. In a second group of rats $(n=12)$, the denervated muscles were pooled $(n=2$ rats/pool) to prepare giant sarcolemmal vesicles in order to measure rates of palmitate uptake by giant vesicles. FAT/CD36, FABPpm, and GLUT4 (positive control) were measured in plasma membranes of giant vesicles prepared from control and denervated hindlimb muscles.

\section{Preparation of giant sarcolemmal vesicles}

Giant vesicles from control, denervated and chronically stimulated skeletal muscles were prepared as previously described $(2,37,38)$. Briefly, muscles were cut into thin layers ( $\sim 1$ $3 \mathrm{~mm}$ thick) and incubated for $1 \mathrm{hr}$ at $34^{\circ} \mathrm{C}$ in $140 \mathrm{mM} \mathrm{KCl}, 10 \mathrm{mM} \mathrm{MOPS}(\mathrm{pH} 7.4)$, and aprotinin $(10 \mathrm{mg} / \mathrm{ml})$, and collagenase type $\mathrm{VII}(150 \mathrm{U} / \mathrm{ml})$ in a shaking water bath. The 
tissues were then washed with KCl/MOPS and $10 \mathrm{mM}$ EDTA and the supernatant was collected. Percoll (final concentration 16\%) and aprotinin were added to the supernatant. This supernatant was placed at the bottom of a density gradient consisting of a $3 \mathrm{ml}$ middle layer of $4 \%$ Nycodenz (wt/vol) and a $1 \mathrm{ml} \mathrm{KCl/MOPS}$ upper layer. The samples were centrifuged (GS-15 centrifuge, Beckman, USA) at $60 \mathrm{~g}$ for $45 \mathrm{~min}$ at room temperature. After centrifugation, the vesicles were harvested from the interface of the two upper solutions. The vesicles were diluted in KCl/MOPS and recentrifuged (Sorvall MC $12 \mathrm{~V}$, DuPont, USA) at $12000 \times \mathrm{g}$ for $5 \mathrm{~min}$. Vesicles $(\sim 50 \mu \mathrm{g})$ were stored at $-80^{\circ} \mathrm{C}$ until analyzed by Western blotting for FAT/CD36, FABPpm, and GLUT4.

\section{Palmitate uptake by giant vesicles}

Palmitate uptake was measured as described previously $(2,3,38)$. Briefly, unlabeled and radiolabeled $0.3 \mu \mathrm{Ci}\left[9,10 .{ }^{3} \mathrm{H}\right]$ palmitate and $0.06 \mu \mathrm{Ci}\left[{ }^{14} \mathrm{C}\right]$ mannitol in a $0.1 \% \mathrm{BSA}$ $\mathrm{KCl} / \mathrm{MOPS}$ solution were added to $40 \mu \mathrm{ll}$ of vesicles ( $~ 80 \mu g$ protein). The reaction was carried out at room temperature for $15 \mathrm{~s}$. Palmitate uptake was terminated by addition of $1.4 \mathrm{ml}$ of ice-cold KCL/MOPS $-2.5 \mathrm{mM} \mathrm{HgCl}$ and $0.1 \%$ BSA. The sample was quickly centrifuged at maximal speed in a micro centrifuge for $1 \mathrm{~min}$. The supernatant was discarded, and radioactivity was measured in the tip of the tube.

\section{Sample preparation for Western blotting}

Samples were prepared as described in detail elsewhere $(2,3)$. Briefly, total tissue homogenates were prepared from individual muscles. For these purposes tissues ( $" 60 \mathrm{mg})$ were homogenized in $2 \mathrm{ml}$ of buffer A (210 mM sucrose, $2 \mathrm{mM}$ EGTA, $40 \mathrm{mM}$ $\mathrm{NaCl}, 30 \mathrm{mM}$ Hepes, $5 \mathrm{mM}$ EDTA, $2 \mathrm{mM}$ phenylmethylsulphonyl fluoride (PMSF), pH 7.4) for two interrupted $15 \mathrm{sec}$ bursts with a Polytron homogenizer (Kinematica, Switzerland) set at 7. Subsequently, $2 \mathrm{ml}$ of buffer $\mathrm{A}$ and $3 \mathrm{ml}$ of buffer $B(1.167 \mathrm{M} \mathrm{KCl}, 58.3 \mathrm{mM}$ tetrasodium pyrophosphate) were added, mixed briefly, and set on ice for $15 \mathrm{~min}$. Following centrifugation (XL-90 ultracentrifuge, Beckman, USA) at 50,000 rpm for $75 \mathrm{~min}$ at $4^{\circ} \mathrm{C}$. the supernatant fluid was discarded and the pellet was washed thoroughly with $1-2 \mathrm{ml}$ of buffer C (10 mM Tris-base, $1 \mathrm{mM}$ EDTA, pH 7.4). The pellet was resuspended in $600 \mu$ i of buffer $\mathrm{C}$ and homogenized for two interrupted 10 sec bursts with a Polytron set at 7 . Then $200 \mu l$ of $16 \%$ SDS were added, samples were removed from ice, vortex mixed and centrifuged (Sorvall MC 12V, DuPont, USA) at $3000 \mathrm{rpm}$ for $15 \mathrm{~min}$ at room temperature. The supernatant was divided into aliquots and protein concentration was determined in triplicate by the bicinchonic acid assay (Sigma, 5t. Louis, MO, USA) with BSA as standard. samples were stored at $-80^{\circ} \mathrm{C}$ for immunoblot detection of FAT/CD36, FABPpm, and GLUT4. For detection of proteins by Western blotting $10 \mu \mathrm{g}$ of muscle and vesicle protein samples were separated on $10 \%$ SDS-polyacrylamide gels $(150 \mathrm{~V}, 1 \mathrm{hr})$. Proteins were then transferred to Immobilon PVDF membranes (Bio-Rad Laboratories, Hercules, CA, USA) using a Trans-Blot SD-Dry Transfer Cell (Bio-Rad Laboratories, Hercules, CA, USA). Membranes were incubated overnight at $4^{\circ} \mathrm{C}$, and immune complexes were detected with enhanced chemiluminescence (ECL; Amersham Pharmacia Biotech, Buckingham, UK). Blots were quantified on a densitometer connected to a computer with appropriate 
software. Blots were normalized across different gels using a standard sample and arbitrarily setting control muscle optical density readings to 100 in each gel. These are typical normalization procedures used in our laboratory $(2,3,17,28,30,32,39)$.

\section{Statistical analyses}

The transport data, as well as the plasma membrane protein content (i.e. separate analyses for FAT/CD 36 and FABPPM), were each analyzed using a 2 factor (stimulation vs denervation) repeated measures (control muscles vs experimental muscles) analysis of variance. For muscles with the same fiber composition in the two experiments (i.e. muscles rich in either FOG or FG fibers), the homogenate Western blotting data were also analyzed with a 2 factor (stimulation vs denervation) repeated measures (control muscles vs experimentall muscles) analysis of variance. Because some muscles examined do not have the same muscle fiber composition (i.e. chronic stimulation: EDL mixed FG and FOG; denervation: soleus, primarily 5O), we analyzed each of these muscles independently, using a repeated measures (control muscles ws experimental muscles) analysis of variance. Linear regression analyses were performed to compare plasmalemmal protein content with rates of palmitate transport. All data are presented as means $\pm 5 E$.

\section{Results}

Within the first three days after the surgery the rats lost $10 \%$ of their body weight. Thereafter, they regained weight and after 7 days of denervation animals had regained $100 \%$ of their pre-surgical bodyweight (data not shown). In the chronic stimulation experiments rats had regained their pre-surgical body weight after 5 days (data not: shown). During the 7 days of chronic stimulation the rats continued to gain body weight (data not shown), as we have reported previously (17-19).

\section{Rates of palmitate uptake, and muscle and plasmalemmal content of FAT/CD36 and FABPpm}

\section{Palmitate uptake by giant sarcolemmal vesicles.}

Because tissue requirements for preparation of giant vesicles are relatively high, it was necessary to pool the red and white denervated muscles, and the red and white chronically stimulated muscles. There were considerable differences in LCFA uptake rates in vesicles from chronically stimulated and denervated hindlimb muscles. After 7 days of chronic stimulation the uptake of palmitate by giant sarcolemmal vesicles was significantly increased $(+4.4 \%)(P<0.05$. Fig. 4.3) compared to the contralateral control muscles. In contrast, after 7 days of denervation there was a marked decrease $(-39 \%)$ in the uptake rate of palmitate compared to contralateral control muscles (P<0.05, Fig. 4.3). 


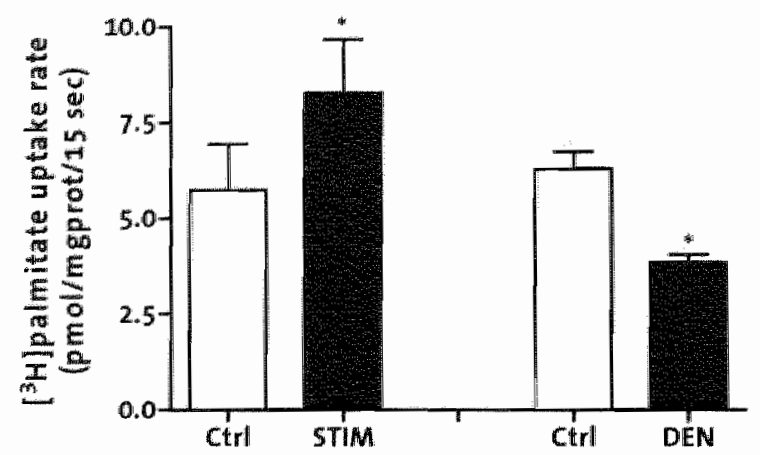

Figure 4.3. Long-chain fatty acid (LCFA) transport into giant sarcolemmal vesicles prepared from 7day chronically stimulated (STIM) and 7-day denervated (DEN) hindlimb muscle. Vesicles were prepared from pooled fast-twitch oxidative-glycolytic (FOG) and fast-twitch glycolytic (FG) chronically stimulated or denervated muscles. For chronic stimulation treatment, tissues of 3 animals were pooled for each independent experiment; for denervation treatment, tissues from 2 animals were pooled for each independent experiment. Values are means $\pm S E$; $n=5$ independent experiments for chronically stimulated treatment; $n=6$ independent experiments for denervation treatment. "Significantly different from control ( $P<0.05)$.

\section{FAT/CD36 and FABPpm protein total muscle content in chronically stimulated and denervated muscles.}

Since the muscle fiber composition of the red and white gastrocnemius is similar to that of the red and white tibialis anterior used in the chronic stimulation studies $(19,22,39)$, comparisons between chronically stimulated (red and white tibialis anterior) and denervated muscles (red and white gastrocnemius) are reported according to their fiber composition. FOG designates the red gastrocnemius and red tibialis anterior and FG designates the white gastrocnemius and white tibialis anterior. Because we also examined the EDL muscle in the chronic stimulation experiments and soleus muscle in the denervation experiments we have also reported the data using their fiber composition (EDL: FGJFOG; soleus: SO).

After 7 days of chronic stimulation the total muscle content of FAT/CD 36 was increased $+66 \%$ in the $F G / F O G,+77.5 \%$ in the FG and $+18 \%$ in the FOG muscles (P<0.05, Fig. 4.4). FABPpm total muscle content was also increased in the chronically stimulated muscles (FG/FOG +22.5\%; FG +38.8\%; FOG +30\%) (P<0.05; Fig. 4.4). In contrast, 7 days of denervation failed to alter the total muscle content of either FAT/CD36 or FABPPm in any of the muscles examined (P>0.05; Fig. 4.4; lower panel). As a positive control we also measured the total muscle content of GLUT4. This protein was increased in chronically stimulated muscles ( $F G / F O G+46.3 \%$; FG $+30.3 \%$; FOG $+124 \%$ ) (P<0.05; Fig. 4.5) and reduced in denervated muscles (5O-54.5\%; FG $-55.6 \%$; FOG $-24.6 \%$ ) (P<0.05; Fig. 4.5), as we $(14,15,22,23)$ have previously reported in these two models. 

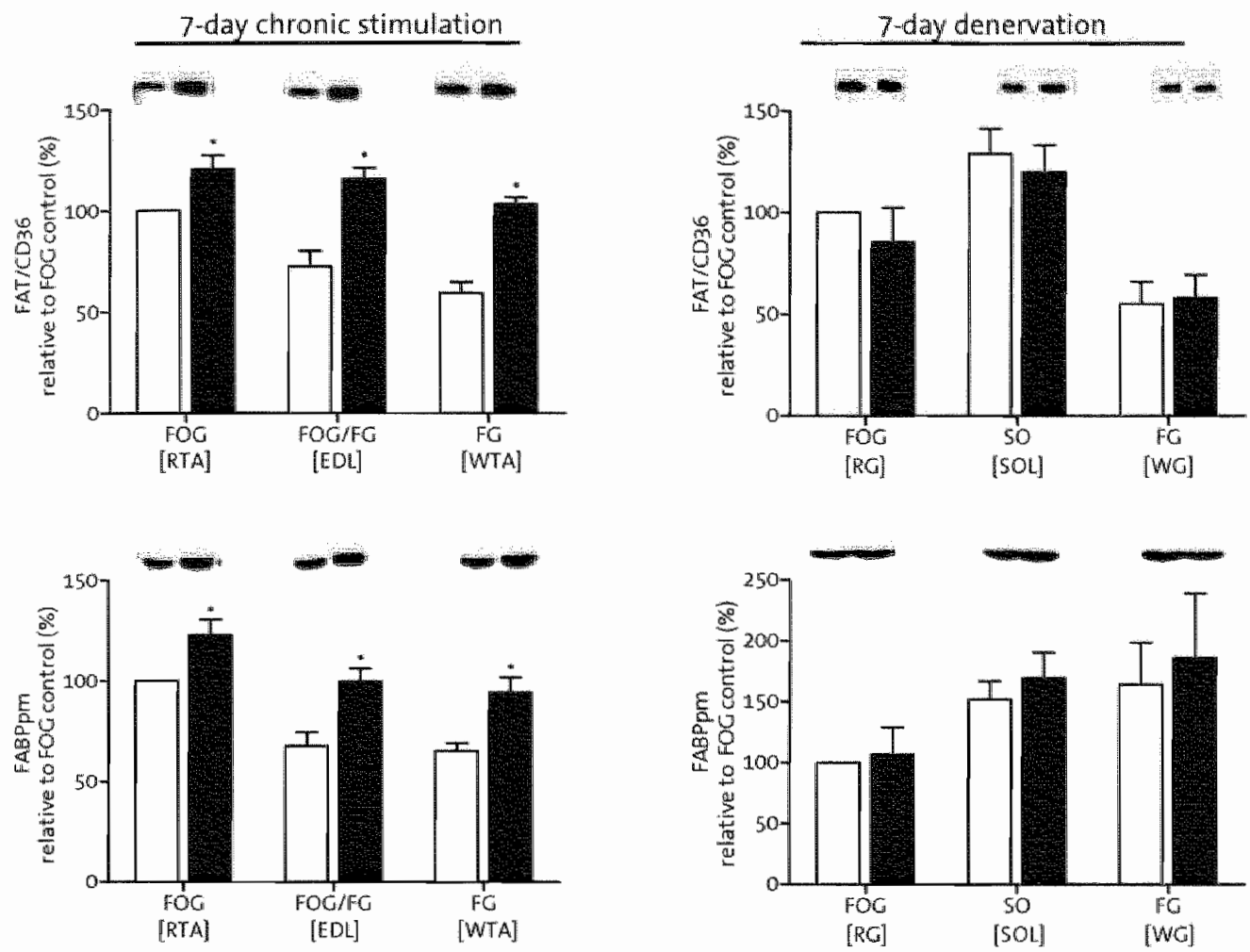

Figure 4.4. Muscle homogenate protein expression of fatty acid translocase (FAT)/CD36 and plasma membrane-associated fatty acid binding protein (FABPpm) in red and white chronically stimulated (left panel) or denervated (right panel) muscle. Muscle fiber type composition in rat hindlimb muscles has been reported previously in our studies $(5,42,43$ ). Red gastrocnemius (RG, denervation) and red tibialis anterior (RTA, chronic stimulation) are primarily composed of FOG fibers. White gastrocnemius (WG, denervation) and white tibialis anterior (WTA chronic stimulation) are primarily composed of FG fibers. Extensor digitorum longus (EDL) muscle (chromic stimulation) is composed of similar proportions of FG and FOG fibers. Soleus muscle ( $5 O L$, denervation) is primarily composed of slow-twitch oxidative (SO) fibers. Values are means $\pm S E$; $n=$ 5.7 independent experiments. Control muscles were set to 100, and experimentall muscles were expressed relative to this. * Signüficantly different from control $(P<0.05)$.

\section{Changes in plasmalemmal FAT/CD36 and FABPpm in chronically stimulated and denervated muscles.}

The sarcolemmal content of FAT/CD36 and FABPpm was measured on plasma membranes of giant vesicles prepared from chronically stimulated and denervated, pooled rat hindlimb muscles, as well as pooled contralateral control muscles. After 7 days of chronic stimulation, plasmalemmal FAT/CD36 $(+42 \%)$, and plasmalemmal FABPPm $(+13 \%)$ were significantly increased $(P<0.05$. Fig. 4.6), as well as plasmalemmal GLUT4 
(+4.4\%; Fig. 4.5). In contrast, in denervated muscles, plasmalemmal FAT/CD36 (-24\%), FABPpm $(-28 \%)$, and plasmalemmal GLUT4 $(-68.7 \%)$ were reduced $P<0.05$. Fig. 4.5; Fig. 4.6).
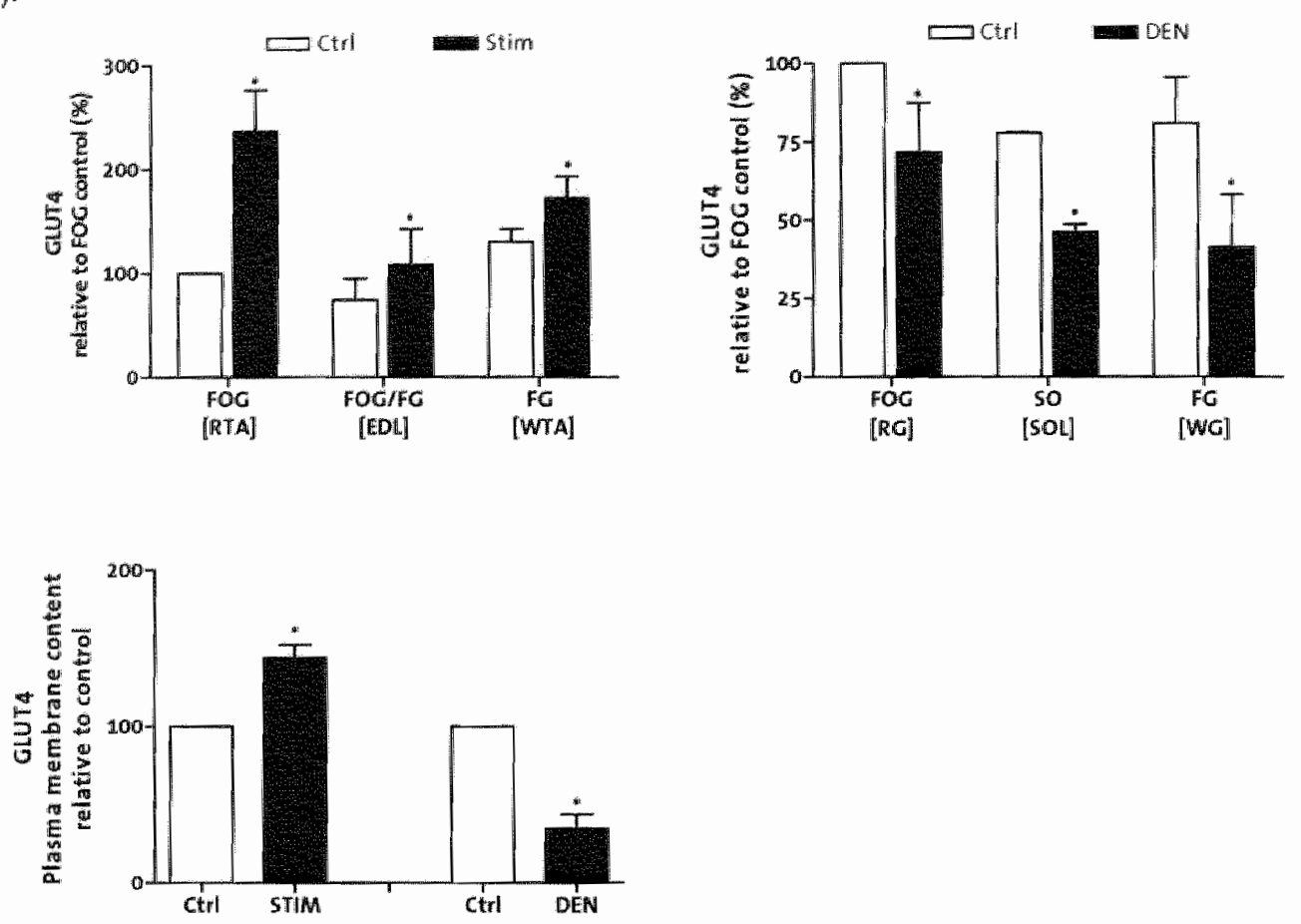

Figure 4.5. Muscle homogenate protein expression of GLUT4 in red and white chronically stimulated and denervated muscle, and plasma membrane GLUT4 in giant vesicles derived from these muscle. Vesicles were prepared from pooled FOG and FC chronically stimulated or denervated muscles. For chronic stimulation treatment, tissues from 3 animals were pooled for each independent experiment, and for denervation treatment, tissues form 2 animals were pooled for each independent experiment. Values are means $\pm S E ; n=4$ independent experiments. Control muscles were set to 100 , and experimental muscles were expressed relative to this. "Significantly" different from control $(P<0.05)$.

\section{Comparison of LCFA transport and plasma membrane FAT/CD36 and FABPpm}

Since the plasmalemmal content of the LCFA transporters is expected to be related with rates of LCFA transport, we compared the plasmalemmal FAT/CD36 and FABPpm with rates of palmitate uptake into giant vesicles prepared from chronically stimulated and denervated hindlimb muscles. Since the LCFA transport rates in the control vesicles did not differ in the chronically stimulated and denervation groups, the control data were pooled. There was a highly linear relationship between plasma membrane FAT/CD36 and rates of palmitate transport into giant sarcolemmal vesicles (Fig. 4.7a) and between 
plasma membrane FABPpm and rates of palmitate transport into giant sarcolemmal vesicles (Fig. 4.7 b).

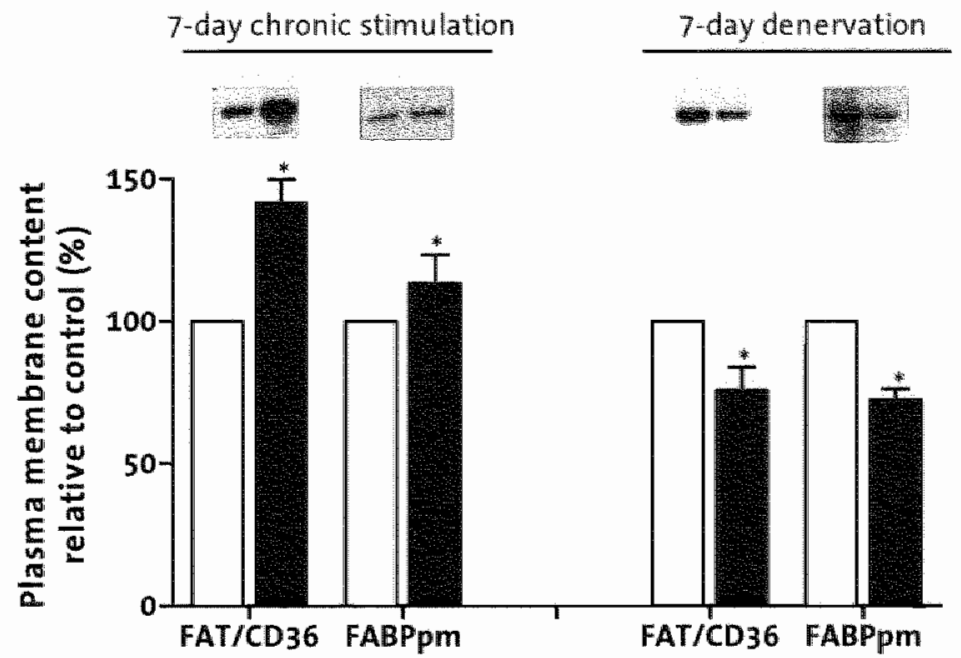

Figure 4.6. Plasma membrane FAT/CD36 and FABPpm in giant vesicles derived from chronically stimulated and denervated muscle. Vesicles were prepared from pooled FOG and FG chronically stimulated or denerwated muscles. For chronic stimullation treatment, tissues from 3 animals were pooled for each independent experiment, and for denervation treatment, tissues form 2 animals were pooled for each independent experiment. Data are expressed relative to control muscles in each experiment $(100 \%)$. Values are means $\pm S E_{i} n=5$ independent experiments for chronically stimulated treatment, and $n=6$ independent experiments for denervation treatment. "Significantly different from control $(P<0.05)$.

\section{Discussion}

By examining chronically stimulated muscles and denervated muscles we have shown 1) that muscle activity patterns can regulate LCFA transport into skeletal muscle of healthy animals, since LCFA transport is down-regulated when muscle activity is inhibited, and up-regulated when muscle activity is increased. In addition, our studies also show 2) that protein-mediated LCFA transport can be regulated by several means, either by a) increasing total muscle LCFA transport protein content, thereby increasing plasmalemmal LCFA transporters, or b) by reducing plasmalemmal LCFA transporters while not altering their total muscle content.

\section{Denervation Studies}

Muscle activity is completely abolished with the denervation protocol used in the present investigation. In previous studies, denervation has led to a reduced insulin-stimulated glucose transport due to the repression of GLUT4 (20-23) and reductions in lactate 
transport as a result of the repression of $M C T 1$ and $M C T 4(17,24,25)$. In marked contrast. we observed that chronic muscle inactivity does not repress the LCFA transporters, FAT/CD36 and FABPpm, despite the fact that GLUT4 protein was reduced in these muscles (data not shown). Thus, denervation does not regulate LCFA transporters in the same manner as has been observed for glucose and monocarboxylate transporters. But, despite the unaltered LCFA transporters in denervated muscle, LCFA transport was markedly reduced. This was associated with concomitant reductions in plasmalemmal FAT/CD36 and FABPpm. Considerable care needs to be taken when alterations in LCFA transport are associated with changes in total muscle FABPpm content. The reason is that FABPpm is also known as mitochondrial aspartate aminotransferase (mAspAT) (4042). mAspAT is present on the inner mitochondrial membrane, where this protein binds to the alpha-ketoglutarate dehydrogenase complex $(43,44)$ and catalyzes the following reversible reaction: glutamate + oxaloacetate $<-\cdots$ aspartate +2 -oxoglutarate (45). However, giant sarcolemmal vesicles do not contain mitochondria, and therefore, the reductions in plasmallemal FABPpm in denervated muscle is not confounded by mitochondrial FABPpm/mAspAT.

A

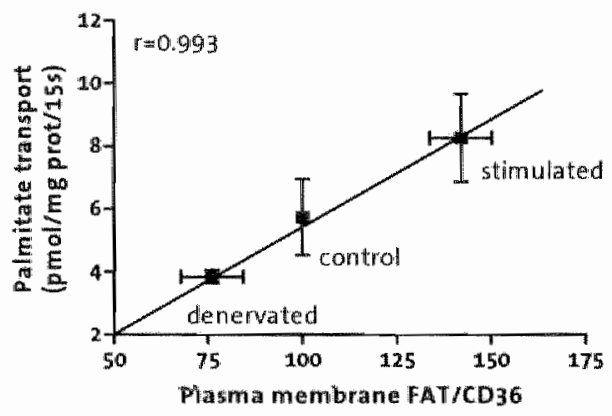

B

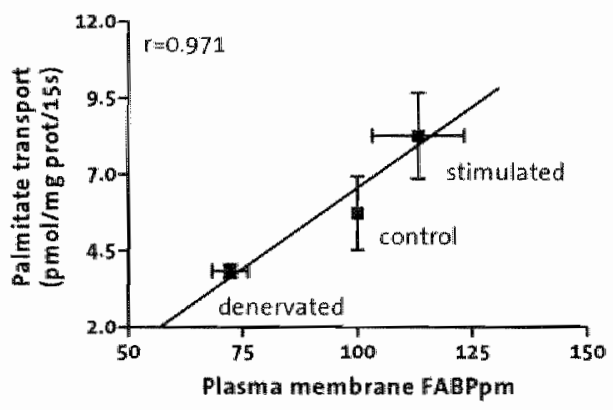

Figure 4.7. Relationship between plasma membrane FAT/CD36 (A) and FABPPm (B) and rates of palmitate transport into giant sarcolemmal vesicles (mean \pm SE). Control data in the 2 experiments did not differ and were therefore pooled. Transport data and plasma membrane data were not allways obtained on the same animals; therefore, results from each group of animals were pooled. Thereafter, linear regression analyses were performed by using these mean data. Data are derived from Figures 4.3 and 4.6.

\section{Chronic stimulation studies}

The increase in the total content of FAT/CD36 in chronically stimulated muscle was observed previously in our laboratory (26). However, the increase in both the total content of FABPpm and at sarcolemma in chronically active muscle has not been reported previously. An increase in the total content of FABPpm has been observed after a period of exercise training $(27,46)$. In previous studies the total muscle content of other 
transport proteins, such as the monocarboxylate transporter MCT1 (17-19, 25) and the glucose transporter GLUT4 (14-16) were also increased by chronic low frequency stimulation. We also observed an increase in GLUT4 in the present studies (data not shown). However, such an up-regulation of transport proteins is not a generallized response in this chronic contraction model, since the MCT4 transporter content is not increased (17). The increase in LCFA transporter content in chronically stimulated muscle would seem to account for their increased presence in the plasma membrane, since the relative increases in the plasma membrane transporter FAT/CD36 and the total pool of this transporters were of the same order of magnitude. Nevertheless, the relative increase in plasmalemmal FABPpm was, however, smaller than the relative increase in the total FABPpm content in muscle homogenates. This suggests that there was a substantially larger increase in mitochondrial FABPpm/mAspAT than in plasmalemmal FABPpm.

\section{Correlation between muscle activity and plasmalemmal LCFA transporters}

A strong correlation was found between the rates of palmitate uptake and the plasma membrane content of FAT/CD36 and FABPpm in giant vesicles prepared from chronically stimulated and denervated hindlimb muscles. Clearly, chronically altered muscle activity regulates the plasmalemmal content of LCFA transporters. Given that both FAT/CD36 and FABPpm were altered in concert, in both denervated and chronically stimulated muscles, this might indicate that FAT/CD36 and FABPpm cooperate in a joint fashion to translocate LCFA across the sarcolemma. While there is some preliminary evidence for this suggestion (7), ather data indicate that LCFA transport can be altered when only plasmalemmal FAT/CD36 is increased (32) or when only FABPpm is increased (47). These studies $(32,47)$, however, do not rule out that it is still necessary to have both FAT/CD36 and FABPpm present at the sarcolemma to facilitate the Uptake of LCFAs. It remains to be established whether FAT/CD36 and FABPpm are indeed two protein-components of a single LCFA transport system.

\section{Intracellular cycling of LCFA transporters}

Despite the bellief that LCFAs enter the cell via diffusion (32, 47-50), there is now considerable mollecular data which demonstrates that LCFA transport is regulated, in part, by LCFA transport proteins $(2,28,29,31,34,51-54)$. Our present studies show clearly that changes in LCFA transport are directly associated with concomitant changes in plasmalemmal FAT/CD36. This supports previous studies from our laboratory in which we have shown that plasmalemmal FAT/CD36 transporters are altered in direct relation to the changes in their total muscle content $(31,55)$. But, we have also observed previously that LCFA transport into muscle is increased when only plasmalemmal FAT/CD36 is increased, while no changes occurred in the total content of this protein in muscle (32). This can occur because FAT/CD36 can cycle between an intracellular depot and the plasma membrane in skeletal muscle and in the heart $(2,28,29)$. In the present 
study, the plasmalemmal FAT/CD36 was reduced with denervation despite the fact that FAT/CD 36 content in muscle was not altered. These observations suggest that FAT/CD36 was resequestered to its intracellular depot(s).

In the face of the unaltered total FABPpm content in the denervated muscle, the reduction in plasmalemmal FABPpm in denervated muscle was unexpected. It had been thought that this protein was only present at the plasma membrane, aside from being identical to mAspAT and being present in mitochondria $(40,42,54)$. The present studies however indicated that FABPpm might also be present in an intracellular depot, as the plasmalemmal FABPpm was altered while no change in total muscle FABPpm content was observed. We have now been able to confirm that there is an intracellular FABPpm depot in both muscle and heart (47). Thus, it would seem that in denervated muscle the reduced LCFA uptake was also associated with a resequestering of FABPpm to its intracellular depot. This strategy of not altering LCFA transport protein content while still altering their plasmalemmal protein content (denervated muscies in present studies and in obese Zucker rats (32)), has also been observed with GLUT4. In obesity, total muscle GLUT4 content is not altered, but insulin-induced GLUT4 translocation is impaired ( 33 , 56, 57) and thus, plasmalemma! GLUT4 is reduced. Clearly, the cycling of transport proteins between the muscle's surface and intracellular depots is an important mechanism regulating substrate transport rates.

\section{Possible muscle-activity related mechanisms that regulate LCFA transporter content and subcellular distribution}

The mechanism inducing the changes in LCFA transporters in the present study are speculative. With chronic stimulation the increased metabolic rate is well known to act as a very strong stimulus to rapidly upregulate the muscle content of many proteins (58). Presumably, this involves activation of the AMPK signaling pathway (13), although this remains to be determined for specific proteins, including LCFA transporters. Because of the increased metabolic rate in chronically stimulated muscles, more substrate for ATP production is also required, and hence, increasing the plasmalemmal content of LCFA transporters can effectively deliver more LCFAs into the muscle, where they can be oxidized. This process of providing more LCFA transport proteins at the sarcolemma may also be due to AMPK activation in chronically stimulated skeletal muscle, as we (59) have recently shown that FAT/CD36 translocation is induced by AMPK activation in cardiac myocytes.

In contrast to chronic stimulation, the muscles' energetic demands are lowered with denervation. This may involve the down regulation of AMP-kinase, since activating AMPkinase in denervated muscle with AICAR (5-aminoimidazole-4-carboxamide-1-beta-Dribofuranoside), prevented the decline in GLUT-4 in denervated gastrocnemius muscles, though not in denervated soleus muscles (13). In our studies, the total LCFA transporter content in denervated muscle was not reduced. This may suggest that the reduction in AMP-kinase activation in denervated muscle (13) is not sufficiently large to affect the LCFA transport protein content. Or alternatively, AMPK is not involved in regulating LCFA 
transporter content in denervated muscles. On the other hand, LCFA provision into the denervated muscles was reduced, since there were fewer plasmalemmal LCFA transporters. This failure to maintain plasmalemmal LCFA transporters, as distinct from maintaining the total pool of LCFA transporters, could well be due to the lowered AMPK activity in denervated muscle, since AMPK is known to induce the translocation of LCFA transporters (59). Thus, the reduced AMP-kinase activation in denervated muscle (13) may be seen as reduction in the stimulus that induces the translocation of LCFA transporters to the plasma membrane. We $(2,3)$ have previously reported that the translocation of FAT/CD36 to the plasma membrane is regulated by the intensity of muscle contraction (30 min), and presumably therefore, by the extent of AMP-kinase activation. Clearly, an examination of the involvement of AMPK signaling with respect to LCFA transporter content and subcellular localization in skeletal muscle is warranted.

\section{Summary}

We have shown that alterations in LCFA uptake in chronically stimulated and denervated hindlimb muscles occur via different mechanisms. The present data reveal that while the rates of LCFA transport are associated with concomitant changes in plasmalemmal FAT/CD36 and FABPPm, the mechanisms involved in altering these transport proteins at the sarcolemma are fundamentally different in denervated and chronically stimulated muscles. The increase in LCFA uptake, induced by chronic stimulation, is attributable to an increased content of FAT/CD36 and FABPpm, which results in an increased sarcolemmal content of these LCFA transporters. In contrast, the reduction in LCFA transport in denervated hindlimb muscles cannot be explained by a repression of the LCFA transporters. Instead, a diminished abundance of the LCFA transporters at the plasma membrane suggests that they were resequestered to their intracellular depots. The present studies indicate that LCFA transport in muscle can be regulated by a) altering the total muscle content of LCFA transporter's and b) by altering the distribution of these proteins between the plasma membrane and their intracellular depots.

\section{Acknowledgements}

The authors greatly acknowledge M.M.A.L. Pelsers for valuable technical assistance. These studies were funded by the Van Walree Fund granted by the Royal Netherlands Academy of Arts and Sciences (KNAW), and by grants from the Netherlands Organization for Scientific Research (ZonMW:903-39-194), the Canadian Institutes of Health Research (CIHR), the Natural Sciences and Engineering Research Council of Canada (NSERC), and the Canada Research Chair program. J.F.C. Glatz is Netherlands Heart Foundation Professor of Cardiac Metabolism. J.J.F.P. Luiken is a recipient of a VIDI-Innovation Research Gramt from the Netherlands Organization for Scientific Research (NWO-ZONMW grant 016.036.305). A. Bonen is Canada Research Chair in Metabolism and Health. 


\section{References}

1. Dyck, D. J., and Bonen, A. (1998) Muscle contraction increases palmitate esterification and oxidation and triacylglycerol oxidation. Am I Physiol 275. E888-896

2. Bonen, A., Luken, J. J, Arumugam, Y., Glatz, J. F., and Tandon, N. N. (2000) Acute regulation of fatty acid uptake inwolves the cellular redistribution of fatty acid translocase. J Biol Chem 275, 14501-14508

3. Bonen, A., Luiken, J. J., Liu, S., Dyck, D. I., Kiens, B., Kristiansen, S., Turcotte, L. P., Van Der Vusse, G. J., and Glatz. J.F. (1998) Palmitate transport and fatty acid transporters in red and white muscles. Am I Physiol 275, E471-478

4. Luiken, J. I. Glatz, I. F., and Bonen, A. (2000) Fatty acid transport proteins facilitate fatty acid uptake in skeletal muscle. Can $\$$ Appl Physiol 25, 333-352

5. Schaffer, J. E. (2002) Fatty acid transport: the roads taken. Am I Physiol Endocrinol Metab 282, E239-246

6. Hui, T. $Y_{,}$and Bernlohr, D. A. (1997) Fatty acid transporters in animal cells. Front Biosci 2 , d $2222-231$

7. Luiken, 1. I., Turcotte, L. P., and Bonen, A. (1999) Protein-mediated palmitate uptake and expression of fatty acid transport proteins in heart giant vesicles. I Lipid Res 40, 1007-1016

8. Coe, N. R., Smith, A. J., Frohnert, B. I., Watkins, P. A., and Bernlohr, D. A. (1999) The fatty acid transport protein (FATP1) is a very long chain acyl-COA synthetase. $J$ Biol Chem 274 . 36300-36304

9. Richards, M. R, Listenberger, L. L., Kelly, A. A., Lewis, S. E., Ory, D. S., and Schaffer, J. E. (2003) Oligomerization of the murine fatty acid transport protein 1. I Biol Chem 278 , 10477-10483

10. Watkins, P. A., Lu, J. F., Steinberg, S. J., Gould, S. J., Smith, K. D., and Braiterman, L. T. (1998) Disruption of the Saccharomyces cerevisiae FAT1 gene decreases very long-chain fatty acyl-COA symthetase activity and elevates intracellular very long-chain fatty acid concentrations. J Biol Chem 273, 18210-18219

11. Zou, Z, Dikusso, C. C., Ctrnacta, V., and Black, P. N. (2002) Fatty acid transport in Saccharomyces cerevisiae. Directed mutagenesis of FAT1 distinguishes the biochemical activities associated with Fat1p. I Biol Chem 277, 31062-31071

12. Booth, F. W. and Thomason, D. B. (1991) Molecular and cellular adaptation of muscle in response to exercise: perspectives of warious models. Physiol Rev 71,541-585

13. Paulsen, S. R., Rubink, D. 5., and Winder, W. W. (2001) AMP-activated protein kinase activation prevents denervation-induced decline in gastrocnemius GLUT-4. I Appi Physiol 91, 2102-2108

14. Johannsson, E., McCullagh, K. J., Han, X. X., Fernando, P. K., Jensen, J., Dahl, H. A., and Bonen, A. (1996) Effect of overexpressing GLUT-1 and GLUT-4 on insulin-and contractionstimullated glucose transport in muscle. Am I Physiol 271, E547-555

15. Roy, D., Johannsson, E., Bonen, A., and Marette, A. (1997) Electrical stimulation induces fiber type-specific translocation of GLUT-4 to T tubules in skeletal muscle. Am I Physiol $273, \mathrm{E} 688-694$

16. Vaspelkis, B. B., 3rd Castle, A. L., Farrar, R. P., and Ivy, I. L. (1997) Contraction-induced intracellular signals and their relationship to muscle GLUT-4 concentration. Am J Physiol 272, E118-1.25

17. Bonen, A., Tonouchi, M. Miskovic, D., Heddle, C., Heikkila, J. I., and Halestrap, A. P. (2000) Isoform-specific regulation of the lactate transporters MCT1 and MCT4 by contractile activity. Am J Physiol Endocrinol Metab 279, E1131-1138

18. McCullagh, K. J., Juel, C., O'Brien, M., and Bonen, A. (1996) Chronic muscle stimulation increases lactate transport in rat skeletal muscle. Mol Cell Biochem 1.56, 51-57

19. McCullagh, K. J., Poole, R. C., Halestrap. A. P., Tipton, K. F., O"Brien, M., and Bonen, A. (1997) Chronic electrical stimulation increases MCT1 and lactate uptake in red and white skeletal muscle. Am J Physiol 273, E239-246

20. Coderre, L., Monfar, M. M., Chen, K. S., Heydrick, S. J., Kurowski, T. G., Ruderman, N. B., and Pilch, P. F. (1992) Alteration in the expression of GLUT-1 and GLUT-4 protein and messenger RNA levels in denervated rat muscles. Endocrinology 131, 1821-1825 
21. Henriksen, E. J., Rodnick, K.J., Mondon, C. E., James, D. E., and Holloszy, J. O. (1991) Effect of denervation or unweighting on GLUT-4 protein in rat soleus muscle. $J$ Appl Physiol $70_{*}$ 2322-2327

22. Megeney, L. A., Neufer, P. D., Dohm, G. L., Tan, M. H., Blewett, C. A., Elder G. C., and Bonen, A. (1993) Effects of muscle activity and fiber composition on glucose transport and GLUT. 4. Am IPhysial 264, E583-593

23. Wilkes, J. J., and Bonen, A. (2000) Reduced insulinwstimulated glucose transport in denervated muscle is associated with impaired Akt-alpha activation. Am I Physiol Endocrinol Metab 279. E912-919

24. McCullagh, K. I., and Bonen, A. (1995) Reduced lactate transport in denervated rat skeletal muscle. Am J Physiol 268, R884-888

25. Wilson, M. C., Jackson, V. N., Heddle, C., Price, N. T., Pilegaard, H., Juel, C., Bonen, A., Montgomery, I., Hutter, O. F., and Halestrap, A. P. (1998) Lactic acid efflux from white skeletal muscle is catalyzed by the monocarboxylate transporter isoform MCT3. I Biol Chem 273, 15920-15926

26. Bonen, A., Dyck, D. J., Ibrahimi, A., and Abumrad, N. A. (1999) Muscle contractile activity increases fatty acid metabolism and transport and FAT/CD36. Am J Physio/ 276, E642-649

27. Kiens, B., Kristiansen, S., Jensen, P., Richter, E. A. and Turcotte, L. P. (1997) Membrane associated fatty acid binding protein (FABPpm) in human skeletal muscle is increased by endurance training. Biochem Biophys Res Commun 231, 463-465

28. Luiken, J. J., Dyck, D. J., Han, X. X., Tandon, N. N., Arumugam, Y., Glatz, J. F., and Bonen, A. (2002) Insulin induces the translocation of the fatty acid transporter FAT/CD 36 to the plasma membrane. Am I Physial Endocrinol Metab 282, E491-495

29. Luiken. J. J., Koonen, D. P., Willem5, J., Zorzano, A., Becker, C., Fischer, Y., Tandon, N. N., Van Der Vusse, G. J., Bonen, A., and Glatz, ل. F. (2002) Insulin stimulates long-chain fatty acid utilization by rat cardiac myocytes through cellular redistribution of FAT/CD36. Diabetes 51, 3113-3119

30. Luiken, J. J., Arumugam, Y., Bell, R. C., Calles-Escandon, J., Tandon, N. N., Glatz, J. F., and Bonen. A. (2002) Changes in fatty acid transport and transporters are related to the severity of insulin deficiency. Am I Physial Endocrinal Metab 283, E612-621

31. Steinberg, G. R., Dyck, D. J., Calles-Escandon, J., Tandon, N. NN., Luiken, J. J., Glatz, J. F., and Bonen, A. (2002) Chronic leptin administration decreases fatty acid uptake and fatty acid transporters in rat skelletal muscle. J Biol Chem 277,8854-8860

32. Luiken, J. J., Arumugam, Y., Dyck, D. J., Bell, R. C., Pelsers, M. M., Turcotte, L. P., Tandon, N. N., Glatz, J.F., and Bonen, A. (2001) Increased rates of fatty acid uptake and plasmalemmal fatty acid transporters in obese Zucker rats. J Biol Chem 276, 40567-40573

33. Goodyear, L. J., and Kahn, B. B. (1998) Exercise, glucose transport, and insulin sensitivity. AnnuRev Med 49, 235-261

34. Ibrahimi, A, Bonen, A., Blinn, W. D., Hajri, T., Li, X., Zhong, K., Cameron, R., and Abumrad, N. A. (1999) Muscle-specific overexpression of FAT/CD36 enhances fatty acid oxidation by contracting muscle, reduces plasma triglycerides and fatty acids and increases plasma glucose and insulin. $J$ Biol Chem 274, 26761-26766

35. Matsuno, K., Diaz-Ricart, M., Montgomery, R. R., Aster, R. H., Jamieson, G. A., and Tandon, N. N. (1996) Inhibition of platelet adhesion to collagen by monoclonal anti-CD36 antibodies. Br J Haematol $92,960-967$

36. Calles-Escandon, 1. Sweet, L. Ljungqvist, O, and Hirshman, M. F. (1996) The membraneassociated $40 \mathrm{KD}$ fatty acid binding protein (Berk's protein), a putative fatty acid transporter is present in human skeletal muscle. Life Sci $58,191-28$

37. Bonen, A., Dyck, D. I., and Luiken, J. J. (1998) Skeletal muscle fatty acid transport and transporters. Adv Exp Med Biol 441, 193-205

38. Koonen, D. P., Coumans, W. A., Arumugam, Y., Bonen, A., Glatz, J. F, and luiken, J. J. (2002) Giant membrane vesicles as a madel to study cellular substrate uptake dissected from metabolism. Mol Cell Biochem 239, 121-130 


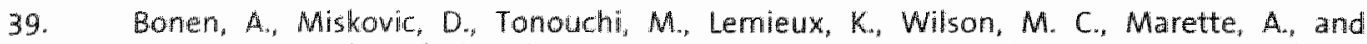
Halestrap. A.P. (2000) Abundance and subcellular distribution of MCT1 and MCT4 in heart and fast-twitch skeletal muscles. Am I Physiol Endocrinol Metab 278, E1067-1077

40. Bradbury, M. W., and Berk, P. D. (2000) Mitochondrial aspartate aminotransferase: direction of a single protein with two distinct functions to two subcellular sites does not require alternative splicing of the mRNA. Biochem J $345 \mathrm{Pt} 3,423-427$

41. Cechetto, J. D., Sadacharan, S. K. Berk, P. D., and Gupta, R. S. (2002) Immunogold localization of mitochondrial aspantate aminotransferase in mitochondria and on the cell surface in normal rat tissues. Histol Histopathol 17,353-364

42. Stump, D. D. Zhou, S. L, and Berk, P. D. (1993) Comparison of plasma membrane FABP and mitochondrial isoform of aspartate aminotransferase from rat liwer. Am J Physiol 265. G894-902

43. Fahien, L. A., Davis, J. W., and Laboy, 1. 1993) Interactions between pyruvate carboxylase and other mitochondrial enzymes.J Biol chem 268, 17935-17942

44. Teller, J. K., Fahien, L. A., and Valdivia, E. (1990) Interactions among mitochondrial aspartate aminotransferase, malate dehydrogenase, and the inner mitochondrial membrane from heart, hepatoma, and liver. IBiol Chem 265, 19486-19494

45. Lehninger, A., Nelson, D., and Cox, M. (1993) Principles of Biochemistry, Worth Publishers, New York

46. Turcotte, L. P., Swenberger, J. R., Tucker, M. Z., and Yee, A. J. (1999) Training-induced elevation in FABP(PM) is associated with increased palmitate use in contracting muscle. $J$ Appl Physiol 87, 285-293

47. Clarke, D. C., Miskovic, D., Han, X-X., Calles-Escandon, J., Glatz, J. F., Luiken, J. J. and Bonen, A. (2003) Overexpression of Membrane Associated Fatty Acid Binding Protein (FABPpm) in Vivo Increases Fatty Acid Sarcolemmal Transport and Metabolism. Physiol. Genomics, 00190.02003

48. Hamilton, ل1. A. (1999) Tramsport of fatty acids across membranes by the diffusion mechanism. Prostaglandins Leukot Essent Fatty Acids 60, 291-297

49. Hamilton, J. A., Guo, W., and Kamp, F. (2002) Mechanism of cellular uptake of long-chain fatty acids: Do we need cellular proteins? Mol Cell Biochem 239, 17-23

50. Zakim, D. (1996) Fatty acids enter cells by simple diffusion. Proc Soc Exp Biol Med 212, 5-14

51. Coburn, C. T., Hajri, T., Ibrahimi, A., and Abumirad, N. A. (2001) Role of CD36 in membrane transport and utilization of long-chain fatty acids by different tissues. I Mol Neurosci 16, 117-121; discussion 151-117

52. Febbraio, M., Abumrad, N. A., Hajjar, D. P., Sharma, K., Cheng, W., Pearce, S. F., and Silverstein, R. L. (1999) A null mutation in murine CD36 reveals an important role in fatty acid and lipoprotein metabolism. J Biol Chem 274, 19055-19062

53. Ibrahimi, A., Sfeir, Z., Magharaie, H., Amri, E. Z., Grimaldi, P., and Abumrad, N. A. (1996) Expression of the CD36 homolog (FAT) in fibroblast cells: effects on fatty acid transport. Proc Natl Acad Sci US A 93, 2646-2651

54. Isola, L. M. Zhou, S. L. Kiang, C. L., Stump, D. D., Bradbury, M. W., and Berk, P. D. (1995) 3 T3 fibroblasts transfected with a CDNA for mitochondrial aspartate aminotransferase express plasma membrane fatty acid-binding protein and saturable fatty acid uptake. Proc Nati Acad SCI USA 92, 9866-9870

55. Luiken, J. J., Koonen, D. P., Coumans, W. A., Pelsers, M. M., Binas, B., Bonen, A., and Glatz, J. F. (2003) Long-chain fatty acid uptake by skeletal muscle is impaired in homozygous, but not heterozygous, heart-type-FABP null mice. Lipids 38, 491-496

56. Brozinick, J. T., Ir, Etgen, G. J., Ir, Yaspelkis, B. B., 3rd, Kang, H. Y., and Ivy J. L. (1993) Effects of exercise training on muscle GLUT-4 protein content and translocation in obese Zueker rats. Am I Physiol 265, E419-427

57. Uphues, i., Chem, Y., and Eckel, J. (1995) insulin dependent translocation of the small GTP. binding protein rab $3 C$ in cardiac muscle: studies on insulin-resistant Zucker rats. FEBS Lett 377. 109-112

58. Pette, D. (1984) J.B. Wolffe memorial lecture. Activity-induced fast to slow transitions in mammalian muscle. Med Sci Sponts Exerc 16, 517-528 
59. Luiken, J. J., Coort, S. L., Willems, I., Coumans, W. A., Bonen, A., van der Vusse, G. J., and Glatz, J. F. (2003) Contraction-induced fatty acid translocase/CD36 translocation in rat cardiac myocytes is mediated through AMP-activated protein kinase signaling. Diabetes $52,1627-1634$ 


\section{Insulin stimulates long-chain fatty acid utilization by rat cardiac myocytes through cellular redistribution of FAT/CD36}

Joost J.F.P. Luiken ${ }^{1}$, Debby P.Y. Koonen ${ }^{1}$, Jodil Willems ${ }^{1}$, Antonio Zorzano ${ }^{2}$, Christoph Becker ${ }^{3}$, Yvan Fischer ${ }^{3}$, Narendra N. Tandon ${ }^{4}$, Ger J. van der Vusse ${ }^{1}$, Arend Bonen ${ }^{5}$ and Jan F.C. Glatz ${ }^{1}$.

1. Department of Physiology, Cardiovascular Research Institute Maastricht (CARIM), Maastricht University, the Netherlands

2. Department de Bioquímica i Biologia Molecular, Facultat de Biologia, Universitat de Barcelona, Spain

3. Institute of Physiology, Medical Faculty, RWTH Aachen, Germany

4. Thrombosis and Vascular Biology Laboratory, Otsuka America Pharmaceuticall, Inc., Rockville, Maryland, USA

5. Department of Kinesiology, University af Waterloo, Waterloo, Ontario, Canada 


\section{Abstract}

The existence of an intracellular pool of FAT/CD36, an $88 \mathrm{kDa}$ membrane transporter for long-chain fatty acids (FA), and the ability of insulin to induce translocation events prompted us to investigate the direct effects of insulin on cellular uptake of FA by the heart. Insulin ( $0.1 \mathrm{nM} / \mathrm{l}$ and higher) increased FA uptake by isolated rat cardiac myocytes by 1.5-fold. This insulin-induced increase in FA uptake was completely blocked by phloretin, sulfo-N-succinimidylpalmitate (5SP) and wortmannin, indicating the involvement of FAT/CD36 and the dependence on phosphatidylinositol-3 (PI-3) kinase activation. Subcellular fractionation of insulin-stimulated cardiac myocytes demonstrated a 1.5-fold increase in sarcolemmal FAT/CD36 and a $62 \%$ decrease in intracellular FAT/CD36 with parallel changes in subcellular distribution of GLUT4. Induction of cellular contractions upon electrostimulation at $4 \mathrm{~Hz}$ enhanced cellular FA uptake 1.6-fold, independent of $\mathrm{Pl}-3$ kinase. Addition of insulin to $4 \mathrm{~Hz}$-stimulated cells further stimulated FA uptake to 2.3-fold, indicating that there are at least two functionally independent intracellular FAT/CD 36 pools, one recruited by insulin, the other mobilized by contractions. In conclusion, we have demonstrated a novel role of insulin in cardiac FA utilization. Malfunctioning of insulin-induced FAT/CD36 translocation may be involved in the development of type 2-diabetic cardiomyopathies.

\section{Introduction}

The heart is among the most sensitive organs to insulin action. This hormone has multiple effects on cardiac intermediary metabolism; one of the best described being the stimulation of glucose transport through translocation of GLUT4 from intracellular vesicular structures to the cardiac sarcolemma (1). Compared to insulin's effects on glucose utilization by the heart, little information is available about its effects on cardiac long-chain fatty acid (FA) utilization. Insulin is known to decrease FA oxidation through inhibition of carnitine palmitoyltransferase 1 , the effect of which effect is most likely mediated through increased intracellular levels of malonyl-COA $(2,3)$. In skeletal muscle, the insulin-mediated drop in FA oxidation is accompanied by an increase in FA esterification into intracellular triacylglycerol stores (4). Because the stimulation of FA esterification exceeded the inhibition of FA oxidation, it can be deduced that the net effect on FA uptake was stimulatory, and expected to lead to accumulation of neutral lipid in muscle (4).

There is essentially no information available about the potential influence of insulin on transport of FA across the cardiac sarcolemma. A regulatory role of insulin on FA transport has not been considered because of the generally accepted notion that cellular uptake of FA is governed by passive diffusion and merely dependent on the metabolic demands of the tissue $(5,6)$. However, the accumulating evidence that membraneassociated proteins are involved in cellular FA uptake $(7,8)$ opens the possibility that insulin may also influence FA utilization at the level of trans-sarcolemmal transport. There is functional evidence for their involvement in FA transport of three distinct sarcolemmal proteins: the $43 \mathrm{kDa}$ plasma membrane FA binding protein (FABPpm), the 
$62 \mathrm{kDa}$ FA transport protein (FATP), and the $88 \mathrm{kDa}$ FA translocase (FAT), the rat homologue of human CD36 $(9,10)$. Using cardiac myocytes (7) and heart giant vesicles (11) we found that the bulk of cardiac FA uptake is mediated by the FA transporter FAT/CD36. Furthermore, the generation of transgenic mouse models for FAT/CD36 helped to reveal the in vivo importance of this transporter in cardiac and skeletal muscle FA utilization. First, muscle-specific FAT/CD36 overexpressor mice have demonstrated lowered plasma triacylglycerols and FA concentrations together with elevated glucose and insulin levels (12). Second, CD36 knockout mice exhibit elevated levels of plasma FA and triacylglycerols in combination with decreased FA uptake into tissues that normally express relatively high levels of this transporter, i.e. heart, skeletal muscle and adipose tissue $(13,14)$.

FAT/CD 36 was found to be involved in the acute regulation of FA uptake by skeletal muscle. Upon short-term electrical stimulation of rat hindlimb, an increase in FA uptake was observed accompanied by translocation of FAT/CD36 from intracellular sites to the cell surface (15). In addition, using isolated cardiac myocytes, electrically stimulated to contract the increase in mechanical activity resulted in an increase in FA uptake. This increase was blunted by sulfo-N-succinimidyl-FA esters strongly suggesting the involvement of FAT/CD36 in mediating cardiac FA uptake under increased metabolic demands (16). Recently, we have gathered evidence that in short-term stimulated skeletal muscles FAT/CD36 and GLUT4 display similar subcellular migration patterns (15). The translocation of FAT/CD36 as a regulatory mechanism for cellular uptake of FA by muscle and the ability of insulin to induce translocation processes, such as that of GLUT4, led us to hypothesize that insulin regulates cardiac FA uptake through translocation of FAT/CD36. For this, we studied the influence of insulim on FA uptake and on subcellular FAT/CD36 distribution in cardiac myocytes, in parallell with insulin's well-described effects on glucose transport and GLUT4 translocation. To verify the in vivo importance of these effects of insulin in cardiac myocytes, we examined the subcellular distribution of FAT/CD36 in the heart upon intravenous administration of insulin to rats. To assess the involvement of insulin-dependent signaling in the regulation of FA uptake, we used wortmannin, an inhibitor of Pl-3 kinase activity. Furthermore, to assess the degree of convergence of putative insulin-mediated FAT/CD36 recycling with recently established contraction-induced FAT/CD36 translocation $(15,16)$, we investigated the effects of insulin on FA uptake by $4-\mathrm{Hz}$ electrostimulated cells in the absence or presence of wortmannin. Finally, the rates of FA axidation and esterification by cardiac myocytes were measured in order to explore the link between insulin-induced alterations in FA uptake and the consequences for subsequent FA metabolism. Mapping of the effect(s) of insulin on FA utilization by the heart is likely to shed more light on the development of insulin-resistance related cardiomyopathies. 


\section{Materials and Methods}

\section{Materials}

$\left[1{ }^{14} \mathrm{C}\right]$ palmitic acid and 2-deoxy-D-[1- $\left.{ }^{3} \mathrm{H}\right]$ glucose were obtained from Amersham Life Science Ltd., Little Chalfont, U.K. BSA (fraction V, essentially FA free), wortmannin and phlaretin were obtained from Sigma (St. Louis, MO, USA). Collagenase type 2 was purchased from Worthington (Lakewood, NJ, USA). BCA protein assay reagent kit was purchased from Pierce (Rockford, IL, USA). Antibodies against GLUT4 were obtained from Sanver Tech (Heerhugowaard, the Netherlands). SSP was routinuously synthesized in our laboratory, as previously described (17). Its purity was confirmed with infrared spectroscopy (kindly performed by Dr. van Genderen, Eindhoven Technical University, the Netherlands).

\section{Animals}

Male Lewis rats weighing 200-250g were used in this study. Animals were kept on a 12:12-h light-dark cycle and fed a Purina Chow diet and water ad libitum. Before experiments were conducted, rats were subjected to overnight fasting to lower systemic insulin concentrations. Ethical approval for all experimental procedures was obtained from the Experimental Animal Committee of Maastricht University.

\section{Isolation of cardiac myocytes}

Cardiac myocytes were isolated using a Langendorff perfusion system and a modified Krebs-Henseleit bicarbonate buffer equilibrated with $95 \% \mathrm{O}$ and $5 \% \mathrm{CO}_{2}$ (medium A) at $37^{\circ} \mathrm{C}$ as previously described (7). The isolated cells were allowed to recover for approximately $1.5 \mathrm{~h}$ at room temperature in medium $\mathrm{A}$ supplemented with $1.0 \mathrm{mM} \mathrm{CaCl}$ and $2 \%(w / w)$ BSA (medium $B)$. Cellullar wet mass was obtained from cell samples taken the recovery period and determined after centrifugation for $30 \mathrm{~s}$ in a microcentrifuge and subsequent removal of the supernatant. Isolated cardiomyocytes were used for subsequent tracer studies when $>80 \%$ of the cells had a rod-shaped appearance and excluded tryphan blue.

\section{Substrate utilization by cardiac myocytes}

Cells (1.8 $\mathrm{ml} ; 5.8 \mathrm{mg}$ wet mass $/ \mathrm{ml})$, suspended in medium $B$, were preincubated in capped $20-\mathrm{m} / \mathrm{incubation}$ vials for $1.5 \mathrm{~min}$ at $37^{\circ} \mathrm{C}$ under continuous shaking. At the start of the incubations, $0.6 \mathrm{ml}$ of the $\left[1{ }^{14} \mathrm{C}\right]$ palmitate/BSA complex was added so that the final concentration of palmitate amounted to $100 \mu \mathrm{M}$ with a corresponding palmitate/BSA ratio of 0.3 . This palmitate/BSA complex was prepared as previously described (7). Palmitate uptake ( 3 min incubation), oxidation (measured as production of ${ }^{14} \mathrm{CO}_{2}$ after $20 \mathrm{~min}$ of incubation) and esterification (measured as incorporation of radiolabel into phospholipids and triacylglycerols after $20 \mathrm{~min}$ of incubation) were determined as previously described (7). Uptake of $100 \mu \mathrm{M}$ 2-deoxy-D-[1- $\left.{ }^{3} \mathrm{H}\right]$ glucose by cardiac myocytes after 3 min of incubation was also measured as previously described (7). 


\section{Subcellular fractionation of cardiac myocytes}

Cardiac myocytes $(2.25 \mathrm{~m} / 20-25 \mathrm{mg}$ wet mass $/ \mathrm{ml})$ were incubated in medium $B$ in the absence and presence of $10 \mathrm{nmol} / \mathrm{l}$ insulin for $15 \mathrm{~min}$. At the end of the incubation, the total cell suspension was diluted with $1.0-\mathrm{ml}$ water and $\mathrm{NaN}_{3}$ was added to a final concentration of $5 \mathrm{mM}$ in order to stop ATP-dependent vesicular trafficking events such as GLUT4 translocation (18). Immediately thereafter cell suspensions were homogenized in a tightly fitting 10-ml Potter-Elvejhem glass homogenizer with 10 strokes, and frozen in liquid nitrogen. Subsequently, fractionation was carried out according to Fischer et al. (19). Briefly, the thawed homogenates were centrifuged for $15 \mathrm{~min}$ at $17,000 \times 9$. The pellet was washed once with $5 \mathrm{ml}$ TES-buffer $(20 \mathrm{mM}$ Tris-pH 7.4, $1 \mathrm{mM}$ EDTA, $250 \mathrm{mM}$ sucrose, supplemented with $100 \mu \mathrm{M}$ phenylmethylsulfonyl fluoride) executing a 17,000gspin for $20 \mathrm{~min}$, and resuspended in $1.5 \mathrm{ml}$ TES-buffer. This total volume was layered on top of a sucrose cushion $(38 \%$ wt/vol) in $20 \mathrm{mM}$ Tris $\mathrm{pH} 7.4,1 \mathrm{mM}$ EDTA, and ultracentrifuged for $65 \mathrm{~min}$ at $65,000 \mathrm{~g}$ using a Beckmann 5 W 41 rotor. The interface was collected, amply diluted with TES-buffer and pelleted at 48,000 x 9 during $30 \mathrm{~min}$. The pellet was resuspended in $100 \mu \mathrm{T}$ TES-buffer and referred to as the plasma membrane (PM) fraction, since it is 13.5-fold enriched with ouabain-sensitive p-nitrophenylphosphatase, whereas the specific activity of the sarcoplasmatic EGTA-sensitive Ca*. ATPase was 3.6-fold decreased. For collection of intracellular membrane-pools containing recycling proteins, the supernatant of the first $17,000 \mathrm{~g}$ spin was centrifuged for 30 min at $48,000 \mathrm{~g}$ resulting in the separation of a high-density microsomal fraction (pellet) and a low-density microsomal (LDM) fraction (supernatant). Pelleting of LDM occurred with a $250,000 \times \mathrm{g}$ spin for $65 \mathrm{~min}$, after which this fraction was resuspended in $100 \mu \mathrm{l}$ TESbuffer. The high-density microsomes were contaminated with plasma membranes. In the LDM fraction, no activity of p-nitrophenyl-phosphatase or of $\mathrm{Ca}^{2+}$-ATPase could be detected, indicating that this fraction was devoid of plasma membrane and of sarcoplasmic reticulum.

\section{Electrical stimulation of cardiac myocytes in suspension}

Cell suspensions were subjected to an electric field via 2 platinum electrodes (distance $1.4 \mathrm{~cm}$ ) which were connected to a pulse generator, capable of generating biphasic pulses up to $250 \mathrm{~V}(16)$. The monophasic components of the pulses exhibit a block profile. The duration of a monophasic pulse was set at $100 \mu s$, and the time interwal between the monophasic components before reversal of the voltage was set at 10 us. The voltage was set at $200 \mathrm{~V}(140 \mathrm{~V} / \mathrm{cm})$, and the stimulation frequency at $4 \mathrm{~Hz}$.

\section{Subcellular fractionation of hearts}

Rats were injected intravenously with insulin (2 U/kg body mass) or an equal volume of saline. 15 min upon insulin injection, rats were sacrificed and hearts were freezeclamped in liquid nitrogen. Upon thawing, hearts were diced, and incubated for $30 \mathrm{~min}$ in high-salt solution ( $2 \mathrm{M} \mathrm{NaCl}, 20 \mathrm{mM}$ Hepes $\mathrm{pH} 7.4$ and $5 \mathrm{mM} \mathrm{NaN}_{3}$ ) at $4^{\circ} \mathrm{C}$ as recommended by Fuller et al. (20). Thereafter, the suspension was centrifuged for 5 min at 1,000g, and the pellet was homogenized in $6.0 \mathrm{ml}$ TES-buffer using a tightly fitting 10 - 
$\mathrm{ml}$ Potter-Elvejhem glass homogenizer with 10 strokes. The resulting homogenate was centrifuged for $5 \mathrm{~min}$ at $1,000 \mathrm{~g}$, after which the pellet was rehomogenized in $4.0 \mathrm{ml}$ TESbuffer with 10 strokes, and then recombined with the 1,000g supernatant. Subsequently, fractionation was carried out as described by Fuller et al. (20). In brief, the homogenate was centrifuged for $10 \mathrm{~min}$ at $100 \mathrm{~g}$. The pellet (P1) was resuspended in $300 \mu \mathrm{ll}$ TES-buffer and saved. The supernatant was centrifuged for $10 \mathrm{~min}$ at $5,000 \mathrm{~g}$. The pellet $(\mathrm{P} 2)$ was resuspended in $300 \mu \mathrm{l}$ TES buffer and saved. The supernatant was centrifuged for $20 \mathrm{~min}$ at $20,000 \mathrm{~g}$. The pellet (P3) was resuspended in $300 \mu \mathrm{l}$ TES-buffer and saved. The supernatant was centrifuged for $30 \mathrm{~min}$ at $48,000 \mathrm{~g}$. The pellet (P4) was resuspended in $150 \mu \mathrm{l} \mathrm{TES}$-buffer and saved. The supernatant was centrifuged for $65 \mathrm{~min}$ at $250,000 \mathrm{~g}$. The pellet (P5) was resuspended in $150 \mu 1$ TES-buffer and saved. Upon analysis of P1 to P5 with ouabain-sensitive $p$-nitrophenyl-phosphatase and with EGTA-sensitive Ca ${ }^{2 *}$-ATPase, we decided to refer to $\mathrm{P} 2$ as $\mathrm{PM}$-fraction, and to $\mathrm{P} 5$ as LDM fraction.

\section{Western blotting}

For determination of the GLUT4 and FAT/CD36 content in PM and LDM, aliquots of the membrame fractions were separated with SDS-polyacrylamide gel electrophoresis and Western blotting, as we have described recently (15). To detect FAT/CD36, MO25 was used, and for detection of GLUT4, a polyclonal antiserum was applied. Signals obtained by Western blotting were quantified by densitometry.

\section{Other procedures}

Giant vesicles were isolated from heart muscle, and palmitate uptake rates by these vesicles were determined as previously described (11).

Protein was quantified according to the bicinchoninic acid (BCA) method. Determination of blood glucose was carried out with Euroflash teststrips and a blood glucose meter (Lifescan Diagnostics, Beerse, Belgium) according to manufacturer's instructions. Ouabain-sensitive p-nitrophenyl-phosphatase was determined according to Bers (21), and EGTA-sensitive Ca ${ }^{2 *}$-ATPase according to Jones et al. (22).

\section{Statistical analysis}

All data are presented as means \pm S.D. for the indicated number of myocyte preparations. Statistical difference between groups of observations was tested with a paired Student's $t$-test. $P$ values equal to or less than 0.05 were considered significant.

\section{Results}

\section{Influence of insulin on deoxyglucose uptake by cardiac myocytes}

Insulin induced deoxyglucose uptake by more than 2-fold. This effect was already near maximal at $0.1 \mathrm{nM}$, i.e., a low physiological concentration (Fig. 5.1). This establishes that the cardiac myacytes were insulin sensitive towards hexose uptake under physiological circumstances. 

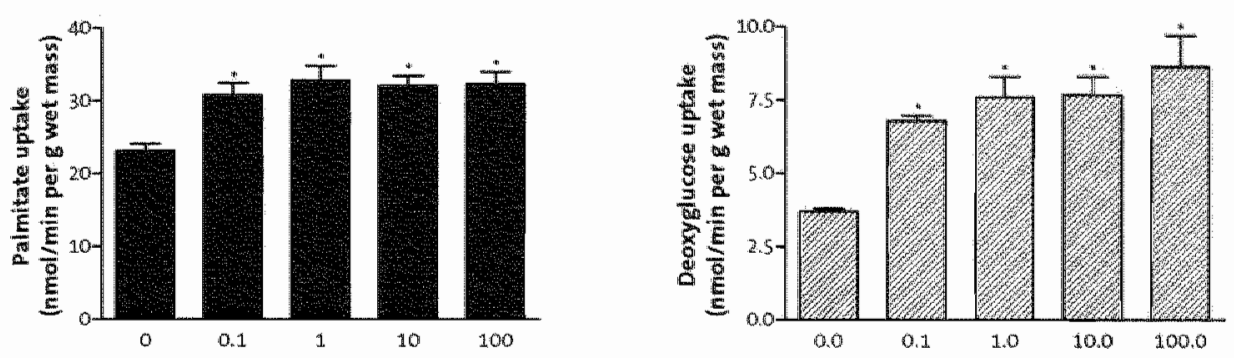

Figure 5.1. Insulin-induced stimulation of uptake of palmitate and deoxyglucose by cardiac myocytes as function of the insulin concentration. Cardiac myocytes were suspended in medium $B$ as described under Research Desigm and Methods. Cells were preincubated with varying amounts of insulin, and cellular uptake of palmitate and deoxyglucose was determined during 3 min after substrate addition. Data are means \pm SD of 3 experiments carried out with different cardiomyocyte preparations. *Significantly different from the control (no additions; $P<0,05$ ).

Wortmannin, an inhibitor of phosphatidylinositol-3 (PI-3) kinase, had no effect on basal glucose uptake, but completely inhibited the insulin-sensitive glucose uptake (Fig. 5.2). These findings are in close agreement with studies of Ramrath et al. (23) in cardiac myocytes. Addition of SSP, a specific inhibitor of $\operatorname{FAT} / C D 36(11,24)$ had no significant effect on basal or insulin-sensitive deoxyglucose uptake (Fig. 5.2).

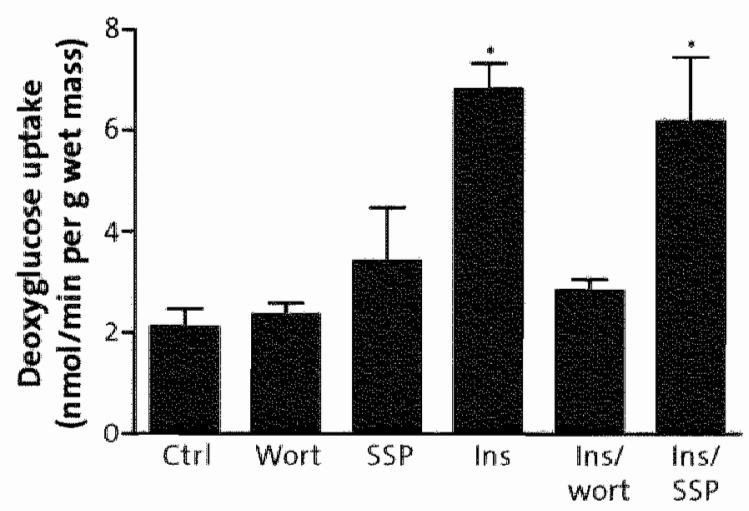

Figure 5.2. Effects of wortmannin and SSP on insulin-induced deoxyglucose uptake by cardiac myocytes. Cardiac myocytes were suspended in medium $B$ as described in Research Design and Methods. Following preincubations with the applied agents, cellular uptake of deoxyglucose was determined during $3 \mathrm{~min}$ after substrate addition. None, no additions (control); $\| n s$, insulin added at $10 \mathrm{nM}$ final concentration; Wort, wortmannin added at $200 \mathrm{nM}$ final concentration. Data are means \pm 5D of 5 experiments carried out with different cardiomyocyte preparations. "Significantly different from the control (no additions; $P<0,05$ ). 


\section{Influence of insulin on palmitate uptake by cardiac myocytes}

Insulin stimulated FA uptake by cardiac myocytes up to 1.5-fold (Fig. 5.1.5.3 and 5.4). This effect was already apparent within 305 after addition of radiolabeled palmitate (Fig. 5.3), and, similar to deoxyglucose, near maximal at $0.1 \mathrm{nM}$ of insulin (Fig. 5.1). Whereas phloretin inhibited basal FA uptake by $87 \%$, in agreement with our previous observations (7). insulin was not able to increase palmitate uptake in the presence of this general inhibitor of carrier-mediated membrane transport processes. FA uptake in fasted cardiac myocytes is inhibited by SSP by $25 \%$. In the presence of this inhibitor, cellular FA uptake is not altered upon insulin addition (Fig. 5.4). Hence, inhibition of FAT/CD36 action abolishes insulin-inducible FA uptake completely. To investigate the role of Pl-3 kinase an cardiomyocytic FA uptake, wortmannin was used at a concentration range from 50 to $200 \mathrm{nM}$. The effects of wortmannin on aspects of vesicular trafficking are routinuously carried out at $200 \mathrm{nM}$, and higher (e.g. see refs. $(23,25)$. However, side effects on PI-4 kinase, which is also inhibited by wortmannin, are negligible at $50 \mathrm{nM}(26)$. Wortmannin had no effect on basal FA uptake, and inhibited insulin-sensitive FA uptake completely at both concentrations tested (Fig. 5.4).

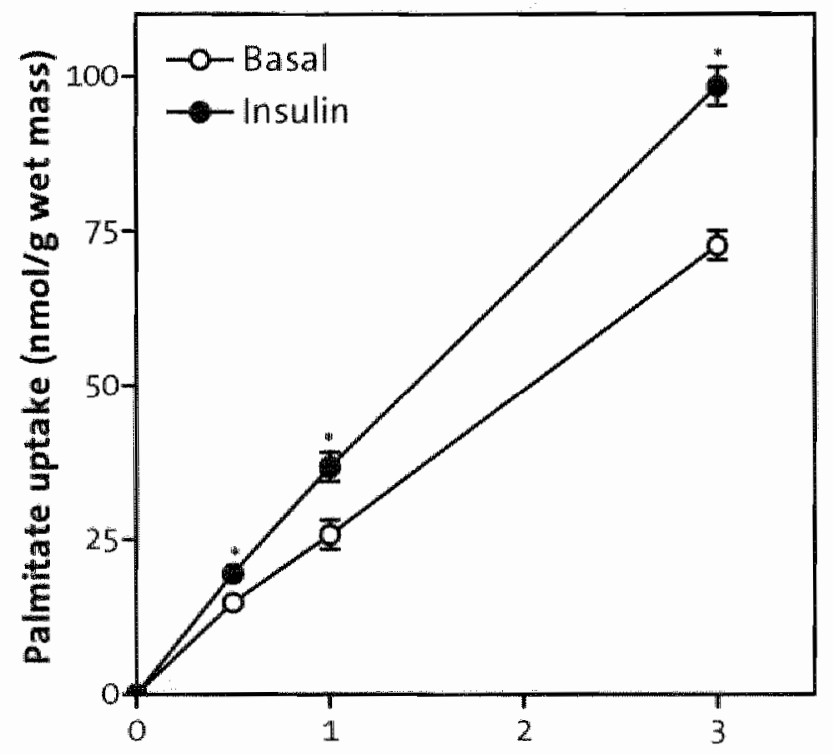

Figure 5.3. Insullin-induced stimulation of palmitate uptake by cardiac myocytes as function of time. Cardiac myocytes were suspended in medium $B$ as described in Research Design and Methods. Cells were preincubated with $10 \mathrm{nM}$ insulin, and the uptake of palmitate was measured during $30 \mathrm{~s}, 1$ min and 3 min incubation. Basal, no additions; +Ins, 10 nM insulin. Data are means + SD of 3 experiments carried out with different cardiomyocyte preparations. "Significantly different from "Basal" (no additions, $P<0,05)$. 


\section{Influence of insulin on transporter localization in cardiac myocytes}

Preincubation of cardiac myocytes for $15 \mathrm{~min}$ in the presence of $10 \mathrm{nM}$ insulin resulted in an increase in the amount of GLUT4 and of FAT/CD36 in the PM by 1.91-fold and 1.45fold respectively, and a simultaneous decrease in the LDM by $61 \%$ and $62 \%$, respectively (Fig. 5.5). To verify whether these in vitro effects of insulin were also occurring in vivo, rats were injected with insulin $(2 \mathrm{U} / \mathrm{kg}$ rat) and sacrificed $15 \mathrm{~min}$ later. At the time of sacrifice blood glucose levels were $4.55 \pm 0.30 \mathrm{mM}$ in control (saline-injected) rats (means \pm S.D., $n=4)$, and $2.52 \pm 0.26$ in insulin-treated rats $(n=5)$, confirming that insulin administration resulted in a rapid physiological response. Compared to the in vitroresults with cardiac myocytes, in vivo administration of insulin elicited similar effects on distribution of both GLUT4 and FAT/CD36 between PM and LDM in the heart (Fig. 5.5).

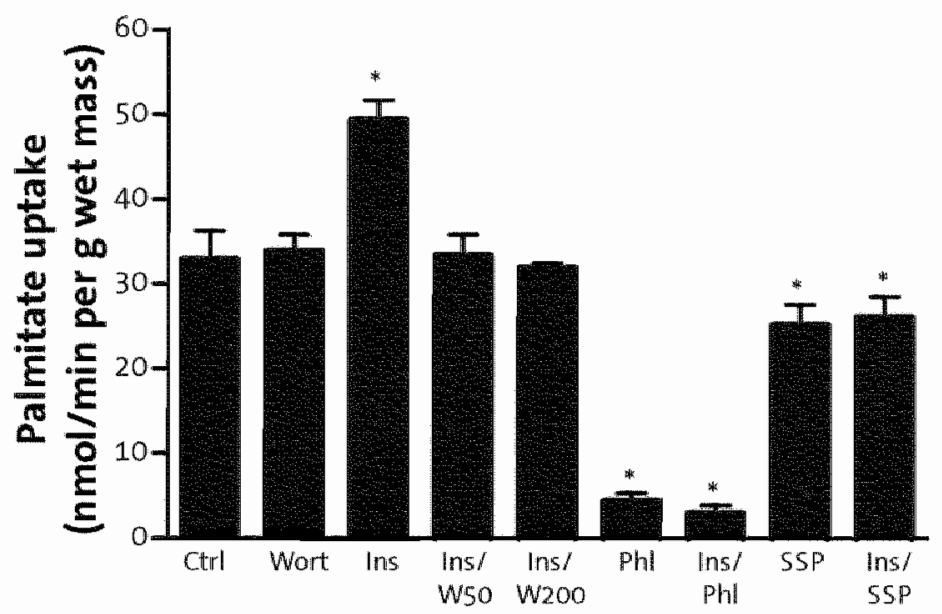

Figure 5.4. Effects of wortmannin, phloretin and SSP on insulin-induced palmitate uptake by cardiac myocytes. Cardiac myocytes were suspended in medium $B$ as described in Research Design and Methods. Preincubations with the applied agents were performed as descibed in Research Design and Methods. Cellular uptake of palmitate was determined during 3 min after addition of palmitate complexed to BSA to final concentrations of 90 and $300 \mu \mathrm{M}$, respectively, (palmitate / BSA molar ratio 0.3). None, no additions (control); ins, insulin added at $10 \mathrm{mM}$ final concentration: Wort 50, wortmannin added at $50 \mathrm{nM}$ final concentration; Wort200, wortmanrin added at $200 \mathrm{nM}$ finall concentration; Phl, phloretin. Data are means 1 SD of 5 experiments carried out with different cardiomyocyte preparations. "Significantly different from the control (no additions: $P<0,05$ ).

\section{Direct effect of insulin on palmitate uptake by heart giant vesicles}

The ability of vanadate, an insulin-mimetic agent, to alter the intrinsic activity of GLUT4. upon preincubation of giant vesicles from skeletal muscle with this compound (27). indicates the suitability of these vesicles to investigate aspects of insulin-signaling at the sarcolemmal level. Basal FA uptake by these vesicles amounted $1.14 \pm 0.08 \mathrm{pmol} / \mathrm{mg}$ protein per $s(n=6)$. Preimcubation of giant vesicles for 15 min with insulin resulted in an 
uptake rate of $1.06 \pm 0.14$ pmol/mg protein per $s(\mathrm{n}=3)$. Hence, insullin had no direct effect on FA uptake by giant vesides.
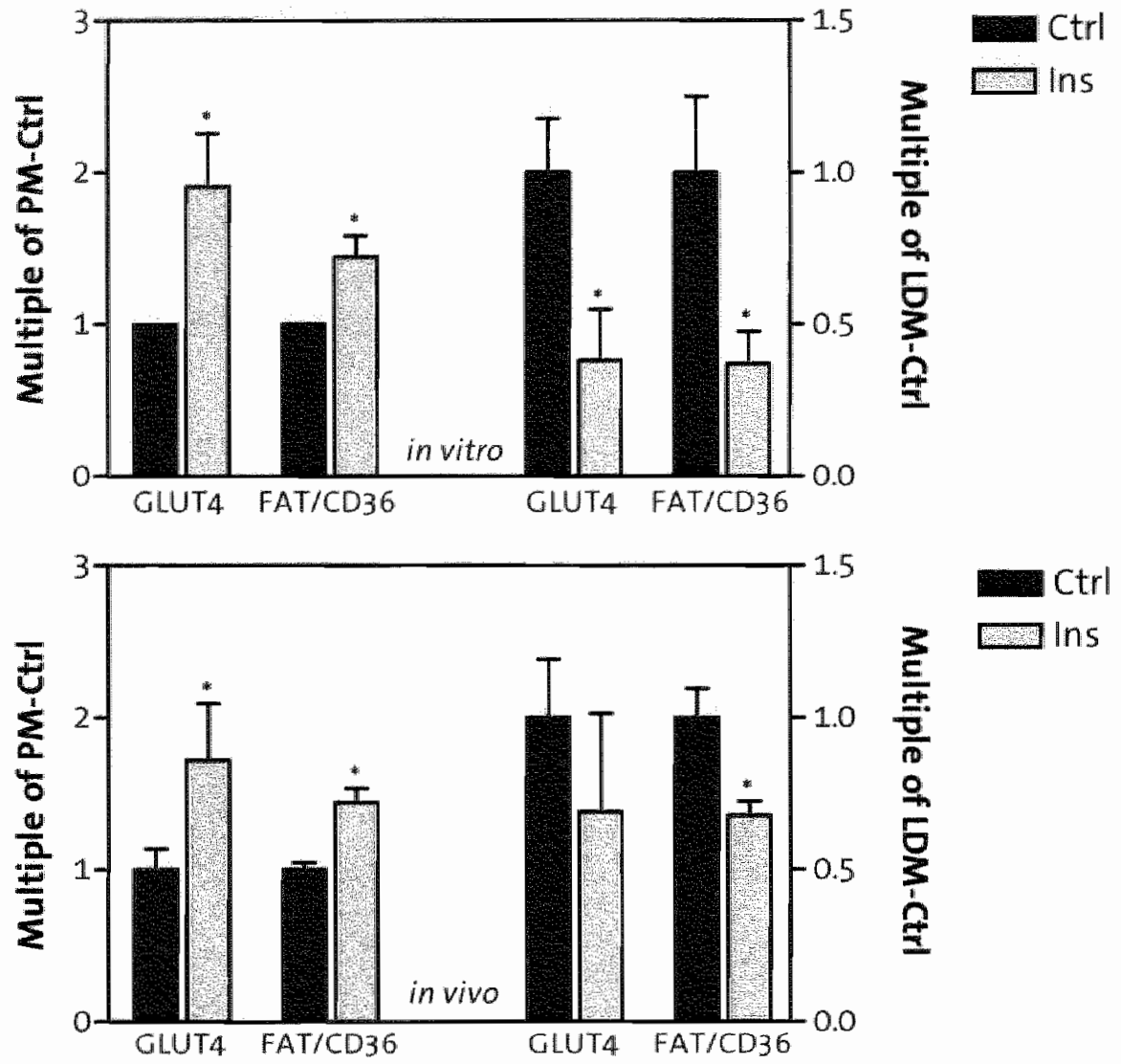

Figure 5.5. Quantitative analysis of the effect of insulin on subcellular distribution of GLUT4 and FAT/CD36 in the heart in vitro and in wivo. For in witro transporter distribution, cardiac myocytes were incubated, as described in the legends to figure 4, for $10 \mathrm{~min}$ with $10 \mathrm{nM}$ insulin (top panel). For in vivo transporter distribution, hearts were removed from rats $1.5 \mathrm{~min}$ after intravenous injection of insulin (2 U/kg body mass) (lower panel). Subcellular fractionation was carried out as outlined in Research Design and Methods. Fractions were subjected to electrophoresis and Western blotting and signals were quantified by densitometry. Transporter content was expressed as multiple of control (basal) in the corresponding fraction. PM, plasma membrane fraction; LDM, low density microsomal fraction, fins, in the presence of insulin at $10 \mathrm{nM}$ (in vitro) or at $2 \mathrm{U} / \mathrm{kg}$ body mass (in wivo). Data are means \pm SD of 10 experiments carried out with different cardiomyocyte preparations. Representative Westerm blots are shown. GLUT4 was detected at $45 \mathrm{kDa}$, and FAT/CD36 at $88 \mathrm{kDa}$. "Significantly different from the control (no additions; $P<0,05$ ). 


\section{Combined effects of insulin and contractions on palmitate uptake in electrically stimulated cardiac myocytes}

In the absence of electrostimulation and in agreement with experiments shown in Figure 5.4, insulin at $10 \mathrm{nM}$ stimulated FA uptake by 1.51-fold, and this effect was completely abolished in the presence of wortmannin or of SSP (Fig. 5.6).

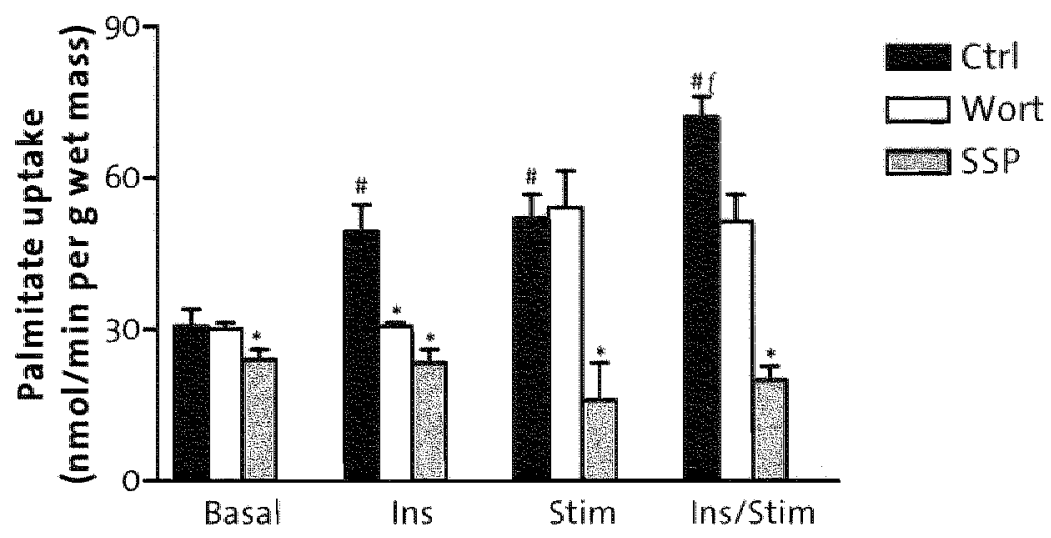

Figure 5.6. Additivity of insulin and cellular contractions in stimulating FA uptake by cardiac myocytes. Cardiac myocytes were suspended in medium B as described in Research Design and Methods. Following preincubations with the applied agents, cellular uptake of palmitate was determined during $3 \mathrm{~min}$ after substrate addition. None, no additions (control); Ins, insulin added at $10 \mathrm{nM}$ final concentration; Wort, wortmannin added at $200 \mathrm{nM}$ final concentration; Stim, electrical stimulation of cardiac myocytes at $4 \mathrm{~Hz}$. Data are means \pm SD of $4-5$ experiments carried out with different cardiomyocyte preparations. "Significantly different from the control (no additions; $P<0.05$ ) ** Significantly different from both 'Ins' and 'Stim'.

Electrical stimulation of cardiac mycytes at $4 \mathrm{~Hz}$ and $200 \mathrm{~V}$ caused FA uptake to increase by 1.64-fold, an effect that is remarkably similar in magnitude compared to insulin's maximal effect. In addition, SSP was able to antagonize FA uptake into electrically stimulated cardiac myocytes, in agreement with our earlier observations (16). However, contraction-inducible FA uptake was not reversed by $200 \mathrm{nM}$ wortmannin, indicating that insulin and contractions use different signaling pathways to recruit FAT/CD 36 . Indeed, when electrically stimulated cells were also stimulated with insulin, FA uptake was increased by 2.29 -fold (Fig. 5.6). This effect is similar to the sum of the individual effects of contractions and of insulin on FA uptake. Furthermore, in the presence of both insulin and cellular contractions, SSP reduced FA uptake to the level observed when SSP was added to non-stimulated (control) cardiac myocytes, whereas the inhibitory effect of wortmannin was only partial (Fig. 5.6). Thus, despite that the effects of insulin and cellular contractions on cellular FA uptake are additive, indicating their mutual independence, the effects of both stimuli are dependent on FAT/CD36. 


\section{Metabolic fate of palmitate taken up by cardiac myocytes upon contractions and insulin}

Wortmannin or insulin (Fig. 5.7) did not influence palmitate oxidation rates. In contrast. palmitate oxidation was markedly (2.77-fold) enhanced in contracting cells, which is in agreement with previous observations (16). Taking oxidation rates in these contracting myocytes as reference point, wortmannin and insulin were again without significant effect (Fig. 5.7). When examining intracellular storage of FA, the rate of palmitate esterification into cellular lipid pools was increased by insulin (1.36-fold), whille contractions were without effect (Fig. 5.7).

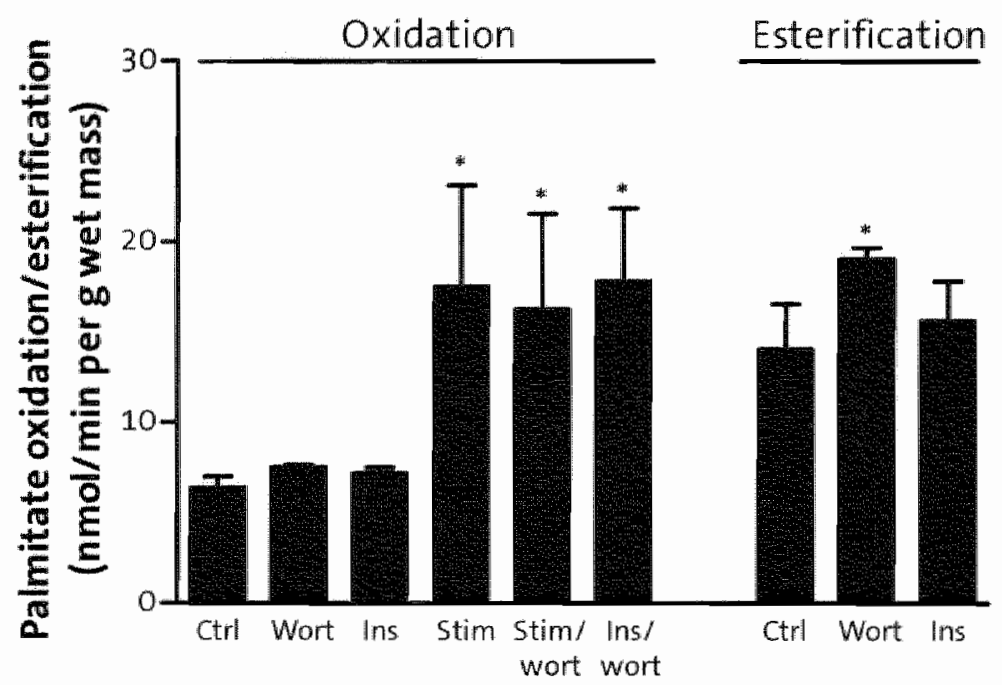

Figure 5.7. Effects of insulin and cellular contractions on FA metabolism by cardiac myocytes. Cardiac myocytes were suspended in medium B as described in Research Design and Methods. Following preincubations with the applied agents, oxidation and esterification of palmitate were determined during $20 \mathrm{~min}$ after substrate addition. None, no additions (control); Ins, insulin added at $10 \mathrm{nM}$ final concentration; Wort, wortmannin added at $200 \mathrm{nM}$ final concentration; Stim, electrical stimulation of cardiac myocytes at $4 \mathrm{~Hz}$. Data are means \pm SD of 3-5 experiments carried out with different cardiomyocyte preparations. "Significantly different from the control (no additions; $P<0.051$.

\section{Discussion}

This study demonstrates for the first time, that insulin directly stimulates FA uptake by cardiac myocytes, i.e., by approximately 1.5-fold. The abilities of wortmannin (inhibition of PI-3 kinase) and SSP (specific inhibitor of FAT/CD36) (16) to fully antagonize the effect of insulin on FA uptake indicate that both FAT/CD36 and PI-3 kinase are involved in this insulin effect. Using subcellular fractionation of cardiac myocytes, we discovered that insulin is able to increase surface amounts of FAT/CD36 at the expense of intracellularly stored FAT/CD 36, both in vitro and in vivo. In vivo insulin administration undoubtedly 
lowered circulating glucose, but in vitro insulin-inducible FA uptake and FAT/CD36 translocation were observed in the absence of glucose in the medium. Yet, despite these differences in the glucose milieu in these models, the FAT/CD36 translocation was remarkably similar in magnitude. Hence, it is very unlikely that the observed translocation should be attributed to an indirect effect of glucose. Furthermore, the insulin-induced increase in surface content of FAT/CD36 in cardiac myocytes (1.45-fold in vitro and 1.49-fold in vivo) closely parallels the effect of insulin on FA uptake (1.51-fold), indicating that the increase in surface amount of FAT/CD 36 can fully account for the enhanced FA fluxes in the presence of insulin. In agreement with this notion, the fact that insulin did not influence FA uptake by heart giant vesicles, which lack endosomal storage compartments (11) "argues against an insulin-induced change in intrinsic activity of FAT/CD36, such as through altered phosphorylation, as a likely mechanism to explain the insulin-induced increase in FA uptake.

It is obvious that the effects of insulin on surface accumulation of GLUT4 are somewhat more pronounced than its effects on surface content of FAT/CD36 (Fig. 5.5). In contrast, the relative insulin-induced alteration in intracellular contents of both GLUT4 (minus $61 \%$ ) and FAT/CD36 (minus 62\%) are very similar. This implies that the portion of FAT/CD36 that is stored intracellularly under basal conditions is substantially smaller compared to that of GLUT4, of which more than $80 \%$ is stored in endosomal compartments in quiescent myocytes $(1,28,29)$. These very similar relative decreases in intracellular GLUT4 and FAT/CD36 upon insulin addition may suggest that both transporters are localized in the same endosomal compartment and share the cellular machinery involved in their recruitment.

The similarity of regulation of FAT/CD36 translocation with that of GLUT4 translocation by contractions and by insulin is striking, and allows the speculation that the analogy goes even further. In this respect, the generally held view is that the effects of insulin and contractions on GLUT4 translocation are additive and that both factors recruit GLUT4 from distinct intracellular storage compartments involving different signal transduction pathways $(25,30,31)$. Using wortmannin at low concentrations so as to specifically inhibit PI-3 kinase, we were able to show that insulin induces FAT/CD36 translocation through $\mathrm{Pl}-3$ kinase dependent signaling and that contraction-induced FAT/CD36 translocation occurs independent of Pl-3 kinase action, again in analogy with GLUT4 translocation $(25,30)$. The observation that the effects of contractions and of insulin on FA uptake are additive, also points towards two functionally distinct intracellular FAT/CD36 stores, and shows that cardiac myocytes are able to mobilize these stores simultaneously when both types of stimuli are present.

Both insulin and contractions stimulate cellular FA uptake to a similar extent, i.e., 1.5-1.6 fold, by means of FAT/CD36 translocation, despite the fact that different signaling pathways are being used. Importantly, the metabolic fate of the extra palmitate taken up in the presence of insulin is different from that taken up with cellular contractions. Notably, in the presence of insulin, the extra palmitate taken up is solely directed towards lipid esterification with the oxidation rate remaining unchanged. In contrast, in the presence cellular contractions the extra palmitate is oxidized, and esterification 
remains unchanged. It is tempting to speculate that the differences in recruitment of FAT/CD36 between stimulation by insulin and by contractions underlie the differences in metabolic fate of incoming FA. However, it is questionable whether contractionrecruitable FAT/CD36, once present at the sarcolemma, is functionally and spatially distinguishable from its insulin-recruitable counterpart. Besides uptake of FA by FAT/CD36, another important and possibly rate limiting step in FA utilization is the conversion of fatty acyl-coenzyme $A$ into fatty acyl-L-carnitine by carnitine palmitoyltransferase-1 prior to mitochondrial entry (32). CPT1 is sensitive to inhibition of malonyl-COA, a 'by-product' from FA metabolism, and is formed from the linkage of $\beta$ oxidation-derived acetyl-COA with $\mathrm{CO} 2$ by acetyl-COA carboxylase. Insulin is known to increase malonyl-CoA levels through dephosphorylation of acetyl-CoA carboxylase $(2,3)$, while increased workload of the heart is accompanied by decreased malonyl-CoA (33). Thus, it is conceivable that intracellular levels of malonyl-CoA could regulate the destination of the extra incoming FA in the presence of insulin or contractions. In addition, regulation of FA metabolism at other sites is plausible. For instance, insulin is known to rapidly increase glycerol-3-phosphate acyltransferase, at least in adipocytes (34). which could explain accelerated FA esterification in insulin's presence.

In summary, we have demonstrated a novel role of insulin in FA utilization by the heart. Insulin induces a translocation of FAT/CD 36 from an intracellular pooll to the sarcolemma of cardiac myocytes thereby permitting an increased rate of cellular uptake of FA. Preliminary studies have shown that insulin also induces FAT/CD36 translocation in rat skeletal muscle (35). The induction of FAT/CD36 translocation by insulin allows the speculation that this translocation could be malfunctioning in type 2 diabetes-related syndromes. There is ample evidence showing disturbances in cardiac and skeletal muscle lipid metabolism in insulin-resistant conditions (36-38). For instance, increased triacylglycerol stores characterise the type 2-diabetic heart, which most likely is the result of a mismatch between uptake and utilization of FA. In recent studies with obese Zucker rats, we observed an increased abundance of FAT/CD36 at the sarcolemma while in comparison to lean non-diabetic Zucker rats the total cardiac expression of this transporter was not altered (39). This more permanent relocalization of FAT/CD36 to the sarcolemma suggests that there is a chronic elevation of FAT/CD36-mediated FA influx, which then leads to the progressive build-up of intracellular lipid stores. The greater size of these triacylglycerol pools could be one of the critical factors leading to insulin resistance and the development of type 2 -diabetic cardiomyopathies $(37,38)$.

\section{Acknowledgements}

The authors would like to thank ing. W.A. Coumans for his expert technical assistence with the synthesis of SSP, and S.L.M. Coort for her participation in the subcellular fractionation procedures. This study was supported by the Netherlands Heart Foundation. grant D98.01.2, and by the Heart \& Stroke Foundation of Ontario. Dr. J.J.F.P. Luiken is a Dekker post-doctoral fellow of the Netherlands Heart Foundation. 


\section{References}

1. Zorzano, A., Sevilla, L., Camps, M., Becker, C., Meyer, 1., Kammermeier, H, Munoz, P., Guma, A., Testar, X., Palacin, M., Blasi, J., and Fischer, Y. (1997) Regulation of glucose transport, and glucose tramsporters expression and trafficking in the heart: studies in cardiac myocytes. Am J Cardiol 80,65A-76A

2. Awan, M. M., and Saggerson, E. D. (1993) Malonyl-CoA metabolism in cardiac myocytes and its relevance to the control of fatty acid oxidation. Biochem 295 (Pt 1),61-66

3. Gamble, J., and Lopaschuk G. D. (1997) Insulin inhibition of 5 "adenosine monophosphateactivated protein kinase in the heart results in activation of acetyl coenzyme $A$ carboxylase and inhibition of fatty acid oxidation. Metabolism 46, 1270-1274

4. Muoio, D. M., Dohm, G. L., Tapscott, E. B., and Coleman, R. A. (1999) Leptin opposes insulin's effects on fatty acid partitioning in muscles isolated from obese ob/ob mice. Am J Physiol 276, E913-921

5. Rose, $H_{.,}$Hennecke, $T_{\text {., }}$ and Kammermeier, H. (1990) Sarcolemmal fatty acid transfer in isolated cardiomyocytes governed by albumin/membrane- lipid partition. 1 Mol Cell Cardiol $22,883-892$

6. Hamilton, 1. A., and Kamp, F. (1999) How are free fatty acids transported in membranes? Is it by proteins or by free diffusion through the lipids? Diabetes $48,2255-2269$

7. Luiken, J. J., van Nieuwenhoven, F. A., America, G., van der Vusse, G. J. and Glatz, I. F. (1997) Uptake and metabolism of palmitate by isolated cardiac myocytes from adult rats: involvement of sal"colemmal proteins. J Lipid Res 38, 745-758

8. Bonen, A. Luiken, J. J., Liu, S., Dyck, D. J. Kiens, B. Kristiansen, S., Turcotte, L. P., Van Der Vusse, G. J., and Glatz, J.F. (1998) Palmitate transport and fatty acid transporters in red and white muscles. Am I Physjol 275, E471-478

9. Luiken, J. J., Schaap, F. G., van Nieuwenhoven, F. A., van der Vusse, G. J., Bonen, A., and Glatz, J.F. (1999) Cellular fatty acid transport in heart and skeletal muscle as facilitated by proteins. Lipids 34 Suppl, $5169-175$

10. Abumrad, N., Coburn, C., and lbrahimi, A. (1999) Membrane proteins implicated in longchain fatty acid uptake by mammalian cells: CD36, FATP and FABPm. Biochim Biophys Acta $1441,4-13$

11. Luiken, J. J., Turcotte, L. P., and Bonen, A. (1999) Protein-mediated palmitate uptake and expression of fiatty acid transport proteins in heart giant vesicles. I Lipid Res 40, 1007-1016

12. Ibrahimi, A., Bonen, A., Blinm, W. D., Hajri, T., Li, X., Zhong, K., Cameron, R., and Abumrad, N. A. (1999) Muscle-specific overexpression of FAT/CD36 enhances fatty acid oxidation by contracting muscle, reduces plasma triglycerides and fatty acids, and increases plasma glucose and insulin. J Biol Chem 274, 26761-26766

13. Febbraio, M. Abumrad, N. A., Hajjar, D. P., Sharma, K., Cheng, W., Pearce, 5 . F." and Silverstein, R. L. (1999) A null mutation in murine CD36 reveals an important role in fatty acid and lipoprotein metabolis m. Biol Chem 274, 19055-19062

14. Coburn, C. T., Knapp, F. F., Jr., Febbraio, M., Beets, A. L., Silverstein, R. L., and Abumrad, N. A. (2000) Defective uptake and utilization of long chain fatty acids in muscle and adipose tissues of CD 36 knockout mice. J Biol Chem 275,32523-32529

15. Bonen, A., Luiken, 1. I., Arumugam, Y., Glatz, J. F, and Tandon, N. N. (2000) Acute regulation of fatty acid uptake inwolves the cellular redistribution of fatty acid translocase. $f$ Biol Chem 275, 14501-14508

16. Luiken, J. J., Willems, J., van der Vusse, G. J., and Glatz, J. F. (2001) Electrostimulation enhances FAT/CD36-mediated long-chain fatty acid uptake by isolated rat cardiac myocytes. Am I Physiol Endocrinol Metab 281, E704-712

17. Staros, J. V. (1982) N-hydroxysulfosuccinimide active esters: bis(N-hydroxysulfosuccinimide) esters of two dicarboxylic acids are hydrophilic, membrane-impermeant, protein cross-linkers. Biochemistry 21,3950-3955

118. Klip, A., Ramlal, T., Young, D. A., and Holloszy, J. O. (1987) Insulin-induced translocation of glucose transporters in rat hindlimb muscles. FEBS Lett 224, 224\%230 
19. Fischer, $\gamma_{.}$, Thomas, 1., Rosen, P., and Kammermeier, H. (1995) Action of metformin on glucose transport and glucose transporter GLUT1 and GLUT4 in heart muscle cells from heathy and diabetic rats. Endocrinology $136,412-420$

20. Fuller, W., Eaton, P., Medina, R. A. Bell, I, and Shattock, M. J. (2001) Differential centrifugation separates cardiac sarcolemmal and endosomal membranes from Langendorff-perfused rat hearts. Anal Biochem 293, 216-223

21. Bers, D. M. (1979) isolation and characterization of cardiac sarcolemma. Biochim Biophys Acta $555,131-146$

22. Jones, L. R., Besch, H. R., Jr., Fleming, J. W., McConnaughey, M. M., and Watanabe, A. M. (1979) Separation of vesicles of cardiac sarcolemma from vesicles of cardiac sarcoplasmic reticulum. Comparative biochemical analysis of component activities. I Biol Chem 254. $530-539$

23. Ramrath, 5., Tritschler, H. J., and Eckel, J. (1999) Stimulation of cardiac glucose transport by thioctic acid and insulin. Horm Metab Res 31, 632-635

24. Harmon, C. M. Luce, P., Beth, A. H., and Abumrad, N. A. (1991) Labeling of adipocyte membranes by sulfo- $\mathbb{N}$-succinimidyl derivatives of long-chain fatty acids: imhibition of fatty acid transport. I Membr Biol 121, 261-268

25. Lund, S., Holman, G. D., Schmitz, O., and Pedersen, O. (1995) Contraction stimulates translacation of glucose transporter GLUT4 in skeletal muscle through a mechanism distinct from that of insulin. Proc Nati Acad Sci U S A 92, 5817-5821.

26. Nakanishi, S., Catt, K. J., and Balla, T. (1995) A wortmannin-sensitive phosphatidylinositol 4-kinase that regulates hormone-sensitive pools of inositolphospholipids. Proc Natl Acad SCIUSA $92,5317-5321$

27. Kristiansen, S., Youn, J., and Richter, E. A. (1996) Effect of vanadate on glucose transporter (GLUT4) intrinsic activity in skeletal muscle plasma membrane giant vesicles. Biochim Biophys Acta 1282, 71:75

28. Slot, J. W., Geuze, H. J., Gigengack, S., James, D. E., and Lienhard, G. E. (1991) Translocation of the glucose transporter GLUT4 in cardiac myocytes of the rat. Proc Natl Acad Sci U S A $88,7815-7819$

29. Fischer, Y., Thomas, J., Sevilla, L., Munoz, P., Becker, C., Holman, G., Kozka, I. J., Palacin, M.,

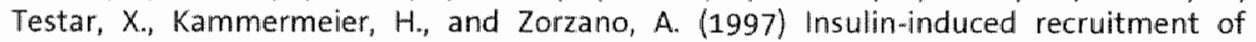
glucose transporter 4 (GLUT4) and GLUT1 in isolated rat cardiac myocytes. Evidence of the existence of different intracellular GLUT4 vesicle populations. J Biol Chem 272, 708.5-7092

30. Yeh, J. I., Gulve, E. A., Rameh, L., and Birnbaum, M. J. (1995) The effects of wortmannin on rat skeletal muscle. Dissociation of signaling pathways for insulin- and contractionactivated hexose transport. J Biol Chem 270, 2107-2111

31. Lemieux, K., Han, X. X., Dombrowski, L., Bonen, A., and Marette, A. (2000) The transferrin receptor defines two distinct contraction-responsive GLUT4 vesicle populations in skeletal muscle Diabetes $49,183-189$

32. Lopaschuk, G. D., Belke, D. D., Gamble, J., Itoi, T, and Schonekess, B. O. (1994) Regulation of fatty acid oxidation in the mammalian heart in health and disease. Biochim Biophys Acta $1213,263-276$

33. Hall, J. L., Lopaschuk, G. D., Barr, A, Bringas, J., Pizzurro, R. D., and Stanley, W. C. (1996) Increased cardiac fatty acid uptake with dobutamine infusion in swine is accompanied by a decrease in malonyl CoA levells. Cardiovasc Res $32,879-885$

34. Vila, M. C., and Farese, R. V. (1991) Insulin rapidly increases glycerol-3-phosphateacyltransferase activity in rat adipocytes. Arch Biochem Biophys 284, 366-368

35. Luiken, J. J., Dyck, D. J., Han, X. X., Tandon, N. N., Arumugam, Y., Glatz, J. F., and Bonen, A. (2002) Insulin induces the translocation of the fatty acid transporter FAT/CD36 to the plasma membrane. Am I Physiol Endocrinol Metab 282, E491-495

36. Shulman, G. I. (2000) Cellular mechanis ins of insulin resistance. $/$ Clin Invest 106, 171-176

37. Saltiel, A. R. (2001) New perspectives into the molecular pathogenesis and treatment of type 2 diabetes. Cell 104, 517-529

38. Unger, R. H. and Orci, L. (2001) Diseases of liporegulation: new perspective on obesity and related disorders. Faseb 1 15, 312-321 
39. Luiken, J. J., Arumugam, Y., Dyck, D. I., Bell, R. C., Pelsers, M. M., Turcotte, L. P., Tandon, N. N., Glatz, J. F., and Bonen, A. (2001) Increased rates of fatty acid uptake and plasmalemmal fatty acid transporters in obese Zucker rats. J Biol Chem $276,40567-40573$ 


\section{Zaprinast selectively modulates cardiac substrate preference by increasing glucose uptake without altering long-chain fatty acid uptake}

D.P.Y. Koonen' ${ }^{1}$, J. Willems ${ }^{1}$, M.M.A.L. Pelsers' ${ }^{1}$, W.A. Coumans ${ }^{1}$, S.L.M. Coort ${ }^{1}$, A. Bonen ${ }^{2}$, J. F.C. Glatz ${ }^{1}$, and J.J.F.P. Luiken ${ }^{1.3}$

1. Dept. of Molecular Genetics, Cardiovascular Research Institute Maastricht (CARIM), Maastricht University, NL-6200 MD Maastricht, the Netherlands

2. Dept. of Human Biology and Nutritional Sciences, University of Guelph, Guelph, ON, N1C 2 W1, Canada

3. Dept. of Biochemical Physiology and Institute of Biomembranes, Utrecht University, Utrecht, the Netherlands 


\section{Abstract}

Previously, elevations in glucose uptake were observed in cardiac myocytes treated with the CGMP-specific phosphodiesterase (PDE) inhibitor, zaprinast. Interestingly, zaprinast did not stimulate cardiac long-chain fatty acid (LCFA) uptake, suggesting that zaprinast can selectively modulate the substrate preference of the heart. Since zaprinast potentially has anti-diabetic properties, we determined the underlying mechanism by which zaprinast is able to stimulate glucose and not LCFA uptake. Upon verification that zaprinast exclusively stimulated glucose uptake into cardiac myocytes, we observed that zaprinast-stimulated glucose uptake was unrelated to elevations in intracellular cGMP level. In addition, the stimulation of glucose uptake by zaprinast was not related to a subcellular redistribution of the predominant cardiac glucose transporter, GLUT4, as demonstrated by unaltered plasma membrane and intracellular content of GLUT4. Full stimulation of glucose uptake is, however, known to represent a combined effect of GLUT4 translocation and GLUT4 activation. Notably, zaprinast-stimulated glucose uptake was non-additive to the effect of insulin on glucose uptake, and the effect of zaprinast on glucose uptake was markedly smaller than that of insulin. In addition, pre-treatment of cardiac myocytes with the P38 MAPK inhibitor, SB203580, blocked the stimulatory effect of zaprinast on glucose uptake and partially inhibited insulin-stimulated glucose uptake. Hence, zaprinast increases glucose uptake by stimulation of GLUT4 activation mediated by activation of p38 MAPK. In contrast, SB203580 did not inhibit insulin-stimulated LCFA uptake, suggesting that the stimulation of LCFA uptake by insulin is not mediated by $\mathrm{P} 38$ MAPK. Therefore, we rule out a role for P38 MAPK in the regulation of LCFA uptake by zaprinast and insulin in cardiac myocytes, explaining why zaprinast stimulates glucose and not LCFA uptake. This feature of zaprinast to selectively stimulate glucose uptake might be beneficial for the treatment of diabetic cardiomyopathies, in which glucose uptake is markedly reduced.

\section{Introduction}

Cardiac substrate utilization is highly sensitive to regulation by insulin. The insulininduced translocation of GLUT4 from intracellular storage compartments to the cell surface leading to an increase in cellular glucose uptake, is one of the best-characterized events in the regulation of substrate utilization by insulin. GLUT 1 , which is expressed at a substantial but lower level than GLUT4, is generally thought to play a key role in the regulation of basal glucose uptake in the heart $(1,2)$. Evidence is, however, accumulating to support the existence of GLUT1 containing intracellular vesicles, which can be recruited to the cell surface by insulin as well (3). Hence, these data suggest an additional, role for GLUT1 in the stimulation of glucose uptake in response to insulin.

The signaling processes responsible for the translocation of GLUT1 and GLUT4 have been the topic of intensive research. Insulin transmits its signal by binding to the insulin receptor, the activation of the receptor's intrinsic tyrosine kinase activity and the subsequent phosphorylation of downstream proteins, including insulin receptor substrate (IRS) 1 (4). The heterodimeric phosphatidylinositol-3-OH kinase (PI(3)K) is one 
of many proteins known to bind to IRS-1 (4). The activation of both components appears to be critical for an adequate insulin-stimulated tramslocation of GLUTA and GLUT1. Insulin is known to activate the serine/threonine kinase, Akt/PKB, which has been shown to function downstream of $P I(3) K(5,6)$. Although evidence is controversial (7), activation of Akt/PKB upon phosphorylation of Thr $r^{306}$ and Ser ${ }^{4 / 3}$ by PDK1 (8) is likely to play a role in the IRS-PI(3)K pathway leading to GLUT4 translocation (9).

insulin is known to activate a second signaling pathway (10-13), independent of the IRS$1 / \mathrm{Pl}(3) \mathrm{K}$ axis, but related to the activation of $\mathrm{p} 38$ mitogen-activated protein kinase ( $\mathrm{p} 38$ MAPK) (14-16). Phosphorylation of $\mathrm{p} 38$ MAPK on Thr ${ }^{480}$ and Tyr ${ }^{182}$ by upstream kinases is required for its activation (17). In contrast to $A$ KA $/ P K B$ activation, 138 MAPK activation is not associated with changes in the subcellular distribution of glucose transporters, but rather with an increase in their transport activity in adipose tissue (14, 16), L6 myotubes (14, 18) and skelletal muscle (15). Insulin stimulation of cardiac glucose uptake is, therefore, likely due to a combination of Akt/PKB-mediated transporter translocation and p38.mediated transporter activation.

Long-chain fatty acids (LCFAs) rather than glucose are the preferred energy substrate to sustain cardiac energy production (19). The bulk of LCFA uptake into cardiac myocytes is mediated by the putative LCFA transport protein, FAT/CD36 (20). Insulin, similar to its stimulatory effect on glucose uptake by inducing the translocation of GLUT4, has been shown to stimulate LCFA uptake through translocation of FAT/CD36 from intracellular stores to the plasma membrane (21). Furthermore, both insulin-inducible FAT/CD36 translocation and insulin-inducible GLUT4 translocation are dependent on the activation of PI(3)K (21). Whether LCFA transporter activation and, hence, activation of P38 MAPK Is. involved in stimulation of LCFA uptake by insulin is currently not known.

The similar regulation of translocation of both GLUT4 and FAT/CD36 does suggest that both transporters are stored in the same intracellular storage compartment, and travel to the plasma membrane by using the same intracellular trafficking machinery. Recently, we discovered that the mixed-type phosphodiesterase (PDE) inhibitor "dipyridamole, is able to selectively stimulate LCFA uptake by promoting translocation of FAT/CD 36 , but not that of GLUT4 (22). This finding implies that cardiac substrate preference can be regulated at the level of substrate transporters. It also suggests that agents that selectively stimulate substrate uptake can treat disorders in cardiac metabolism. Agents, that selectively stimulate LCFA uptake, like dipyridamole, can then hypothetically be used to restore the substrate balance in cardiac hypertrophy, in which LCFA utilization is depressed. In contrast, agents that selectively stimulate glucose uptake might be valuable in re-establishing, the substrate balance in diabetic cardiomyopathies, in which glucose uptake is markedly reduced. Interestingly, zaprinast, a cGMP-specific type 5 PDE inhibitor (23) might represent one of these glucose uptake-specific stimulatory agents potentially to be used in the treatment of diabetes. Previously, zaprinast has been used as agent to stimulate glucose uptake into skeletal muscle (24) and heart (25). Despite the fact that these studies did not address the topic of LCFA uptake, we recently observed that zaprinast did not stimulate LCFA uptake (22). Therefore our aim is, upon prior confirmation that zaprinast is an agent selectively stimulating glucose uptake, to 
investigate the mechanism by which zaprinast modulates substrate preference in cardiac myocytes. Since both zaprinast and insulin have the common ability to stimulate CGMP levels (25), we compared the effects of zaprinast on glucose and LCFA uptake into cardiac myocytes with those of other COMP elevating agents. In addition, we explored the possibility that zaprinast stimulates glucose uptake through (i) GLUT4 translocation involving $A k t / P K B$, and/or (ii) an increase in the intrinsic activity of glucose transporters involving P38 MAPK. The unraveling of the signaling and substrate-specific actions of zaprinast is expected to shed light on its potential to be used as anti-diabetic agent.

\section{Materials and Methods}

\section{Animals}

Male Lewis rats, weighing 180-250 g were used. Animals were housed in a temperaturecontrolled room on a 12:12 h light-dark cycle and fed a regular chow diet and water ad libitum. Ethical approval for all experimental procedures was obtained from the Experimental Animal Committee of Maastricht University.

\section{Materials}

$\left[1^{-14} \mathrm{C}\right]$ palmitic acid, 2-deoxy-D-[1- $\left.{ }^{3} \mathrm{H}\right]$ glucose, and CGMP assay kit were obtained from Amersham Life Science (Little Chalfont, UK.) Collagenase type 2 was from Worthington Biochemical Corporation (Lakewood, NJ, USA). BSA (fraction V), butanedione monoxime, phloritin, wortmannin, insulin, oligomycin, zaprinast, db-cGMP, and SNP were obtained from Sigma (St. Louis, MO, USA). SB-203580 was purchased from BIOMOL Research Laboratories Inc. (Sanver Tech, Heerhugowaard, NL). DR. N. Tandon, Otsuka, Bethesda MD, USA kindly provided antibodies against FAT/CD36, whereas GLUT4 antibodies were purchased from Sanver Tech (Heerhugowaard, NL), and phosphospecific antibodies to Akt $\left(\right.$ Ser $\left.^{473}\right)$ and $\mathrm{p} 38$ MAPK (Thr ${ }^{130}$ and Tyr ${ }^{2.82}$ ) and antibodies against Akt and p38 MAPK were bought from Cell Signaling Technologies (Leusden, NL).

\section{Isolation of cardiac myocytes}

Cardiac myocytes were isolated using a Langendorff perfusion system according to the procedure of Fischer et al. (Fischer Y, Life Sci 1991). For this, hearts were perfused at $37^{\circ} \mathrm{C}$ with a Krebs-Henseleit bicarbonate medium (medium A) supplemented with $0.7 \%$ (wt/vol) BSA, $15 \mathrm{mM}$ butanedione monoxime, and $0.075 \%$ collagenase type $11(299 \mathrm{u} / \mathrm{mg}$ ), and equilibrated with $95 \% \mathrm{O}_{2}$ and $5 \% \mathrm{CO}_{2}$, as previously described (20). The isolated cells were allowed to recover for $1.5 \mathrm{~h}$ at room temperature in medium $A$ supplemented with $1 \mathrm{mM} \mathrm{CaCl}$ and $2 \%$ (wt/vol) B5A (medium B). At the end of the recovery period, cells were washed and suspended in medium $B$ and used for uptake and fractionation studies, provided that $>80 \%$ of the cells were rod shaped and excluded tryphan blue. 


\section{Glucose and fatty acid utilization by cardiac myocytes}

Cells (2.0 ml; $5-8 \mathrm{mg}$ wet mass $/ \mathrm{mll})$, suspended in medium B without glucose, were preincubated in capped $20-\mathrm{ml}$ incubation vials for $15 \mathrm{~min}$ at $37^{\circ} \mathrm{C}$ under continuous shaking. To study palmitate uptake, $0.5 \mathrm{ml}$ of the $\left[1{ }^{14} \mathrm{C}\right]$ palmitate/BSA complex was added at the start of the incubations so that the final concentration of palmitate amounted to $100 \mu \mathrm{M}$ with a corresponding palmitate/BSA ratio of 0.3 . This palmitate/BSA complex was prepared as previously described (20). To study deoxyglucose uptake, $\left[{ }^{3} \mathrm{H}\right]$ deoxyglucose was added at the start of the incubations in 0.6 $\mathrm{ml}$ medium $\mathrm{B}$ without glucose to a final concentration of $100 \mu \mathrm{M}$. Cellular uptake of palmitate ( $3 \mathrm{~min}$ incubation) and of deoxyglucose ( $3 \mathrm{~min}$ incubation) were determined upon washing the cells three times for $2 \mathrm{~min}$ at $100 \mathrm{xg}$ in an ice-cold stop solution containing $0.2 \mathrm{mM}$ phloretin as previously described (20). The washing procedure did not affect cellular integrity as evaluated by microscopic inspection.

specific conditions for treatment of cell suspensions prior to substrate uptake assays are described in the figure legends. In general, cells $(2 \mathrm{ml} ; 5.8 \mathrm{mg}$ wet mass/ml), were incubated in the presence of selected pharmacological agents (added to the final concentration indicated) at $37^{\circ} \mathrm{C}$ for $15 \mathrm{~min}$ in a shaking water bath. In the case of SB203580 , cells were preincubated for $20 \mathrm{~min}$, followed by the addition of the second compound and supplementary incubation for $15 \mathrm{~min}$. After this treatment, aliquots of cell suspensions were withdrawn for the uptake assay described above. Sodium Nitroprusside (SNP) was prepared fresh in medium A before each experiment. Stock solutions of wortmannin, zaprinast, oligomycin, SB-203580, and db-CGMP were prepared in DMSO, which did not exceed a final concentration of $0.5 \%$ in the cell suspensions. At this concentration, DMSO did not affect cellular substrate utilization. Controls included additions of DMSO as well as incubations equivalent to treatment conditions.

\section{Subcellular fractionation of cardiac myocytes}

Cardiac myocytes $(2.25 \mathrm{~m} / 20-25 \mathrm{mg}$ wet mass $/ \mathrm{ml})$ were incubated for 15 min in medium $B$ in the absence and presence of additions. At the end of the incubation the total volume of cell incubations was quickly transferred to a tightly fitting 5-ml PotterElvejhem glass homogenizer on ice, containing $1 \mathrm{ml}$ of cold $\mathrm{H}_{2} \mathrm{O}$, after which $\mathrm{NaN}_{3}$ was added to a final concentration of $5 \mathrm{mM}$ in order to stop ATP-dependent vesicular trafficking events. Immediately hereafter cell suspensions were homogenized with 10 strokes. Subsequently, fractionation was carried out as described previously $(21,26)$. For determination of the GLUT4 and FAT/CD36 content in the plasma membrane (PM) and in low-density microsomes (LDM), aliquots of the membrane fractions were separated with SDS-polyacrylamide gel electrophoresis and Western blotting (see next section).

The purity of the fractions obtained by this fractionation procedure was previously checked (26). Specifically, the PM fraction is 13.5 -fold enriched with ouabain-sensitive $p$ nitrophenyl-phosphatase, whereas the specific activity of the sarcoplasmatic EGTAsensitive $\mathrm{Ca}^{2 *}$-ATPase was 3.6-fold decreased. In addition, no activity of p-nitrophenylphosphatase or of $\mathrm{Ca}^{2+}$-ATPase could be detected in the LDM fraction, indicating that this 
fraction was devoid of plasma membrane and of sarcoplasmic reticulum. Furthermore, caveolin-3 was found to be 2.9-fold more abundant in the PM fraction than in the LDM fraction (data not shown).

\section{Western blotting}

For determination of GLUT4 and FAT/CD36 content in plasma membrane (PM) and lowdensity microsomal (LDM) fractions, aliquots of the membrane fractions were separated on 4-15\% linear gradient gels (Tris-HCL Criterion gels; Bio-Rad laboratories, Veenendaal, NL) and transferred to Protran ${ }^{\star}$ nitrocellulose transfer membrane (Schleicher \& Schuell $\mathrm{GmbH}$, Dassel, D). Membranes were blocked and incubated overnight at $4^{\circ} \mathrm{C}$, as previously described (27). Immune complexes were detected with ECL (Amersham Pharmacia Biotech, Buckingham, UK) and quantified by densitometry.

\section{Measurement of cGMP}

Cells $(2.0 \mathrm{ml} ; 8-10 \mathrm{mg}$ wet mass $/ \mathrm{ml})$ were preincubated in medium $B$ under identical conditions as described for incubations with $\left[1-{ }^{14} \mathrm{C}\right]$-palmitate. Agonists were added to the cell suspensions at the concentrations indicated above. After $15 \mathrm{~min} 120 \mu \mathrm{l}$ cell sample was centrifuged in a microcentrifuge at $200 \times \mathrm{g}$ for $1 \mathrm{~min}$. The pellet was used for determination of intracellular cGMP levells using an enzyme-immunoassay kit from Amersham Life Sciences (UK) following the supplier's protocol without acetylation.

\section{Statistical Analyses}

All data are presented as means \pm S.E. for the indicated number of myocyte preparations. Statistical difference between groups of observations was tested with a paired Student's $t$-test. $P$ values equal to or less than 0.05 were considered significant.

\section{Results}

\section{Effect of elevations in intracellular cGMP levels on glucose and LCFA uptake in cardiomyocytes at rest.}

In order to study the role of cGMP in the selective effect of zaprinast on glucose uptake, the ability of zaprinast to elevate CGMP levels in cardiac myocytes was compared to that of other agents well known for their ability to increase intracellular cGMP levels. For this purpose, we selected (i) the cell-permeable cGMP analogue, dibutyryl-cGMP (db-cGMP), which will be hydrolyzed to cGMP upon cellular entry, and (ii) sodium nitroprusside (SNP), which, through stimulation of NO formation, activates guanylate cyclase (Fig. 6.11).

Zaprinast at a concentration of $12.5 \mu \mathrm{M}$, increased cGMP levels by 1.5-fold in accordance with its proposed ability to selectively inhibit CGMP type 5 phosphodiesterase (23). This degree of stimulation is similar to that reported in other studies using cardiac myocytes $(28,29)$. In addition, both db-CGMP and SNP resulted in markedly elevated cGMP levels (Table 6.1). Whereas zaprinast stimulated basal glucose uptake, LCFA uptake was unaltered by stimulation of cardiac myocytes with zaprinast. Despite the fact that $\mathrm{db}$ - 
CGMP and SNP elevated intracelluiar CGMP levels dose-dependently, neither basal glucose nor LCFA uptake was affected by db-CGMP and SNP.

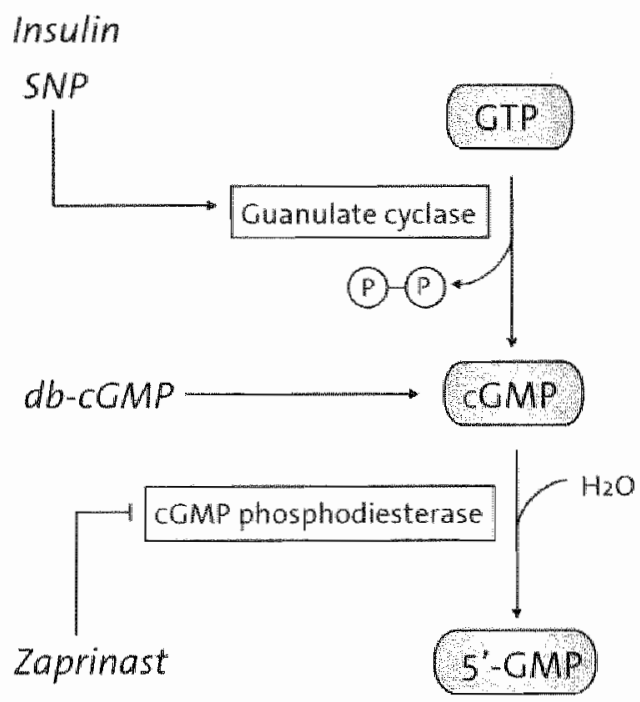

Figure 6.1. Formation and breakdown of CGMP. Insulin and Sodium Nitroprusside (SNP) stimulate the formation of CGMP by activation of guanylate cyclase, the enzyme responsible for the conversion of GTP into cGMP. Dibutyryl-cGMP (db-cGMP) is a cell-permeable CGMP analogue which will be hydrolyzed to $C G M P$ upon cellular entry. Zaprinast results in the elevation of CGMP by mediating the breakdlown of CGMP into $5^{\prime G M P}$ via inhibition of CGMP phosphodiesterase.

\begin{tabular}{lcc}
\hline Parameter & $\begin{array}{c}\text { cGMP content } \\
\text { (pmol/mg wetweight) }\end{array}$ & \% basalactivity \\
\hline Basal & $0.21 \pm 0.08$ & 100 \\
Zaprinast $(1 \mu M)$ & $0.18 \pm 0.04$ & 88 \\
Zaprinast $(12.5 \mu M)$ & $0.29 \pm 0.05$ & 137 \\
Zaprinst $(625 \mu M)$ & $0.30 \pm 0.05$ & 1.43 \\
db-cGMP $(30 \mu M)$ & $0.36 \pm 0.11$ & 174 \\
db-cGMP $(100 \mu M)$ & $0.52 \pm 0.01$ & 248 \\
db-CGMP $(300 \mu M)$ & $0.76 \pm 0.08$ & 362 \\
SNP (2.5mM) & $0.25 \pm 0.04$ & 118 \\
SNP(10mM) & $0.40 \pm 0.05$ & 192 \\
Insulin (10nM) & $0.55 \pm 0.06$ & 263 \\
\hline
\end{tabular}

Table 6.1. Effect of CGMP-elevating agents on intracellular CGMP levels. 


\section{Effects of zaprinast on deoxyglucose uptake}

When the effect of zaprinast on deoxyglucose uptake was investigated as function of its concentration, the lowest concentration tested, i.e., $0.2 \mu \mathrm{M}$, already yielded a 1.7 -fold increase (Fig. 6.2A). At $12.5 \mu \mathrm{M}$ the increase amounted to 2.2 -fold, and at higher concentrations there was no further increase in deoxyglucose uptake. In contrast to zaprinast, $d b-c G M P$ and SNP had no effect on deoxyglucose uptake at all concentrations tested (Fig. 6.2B).
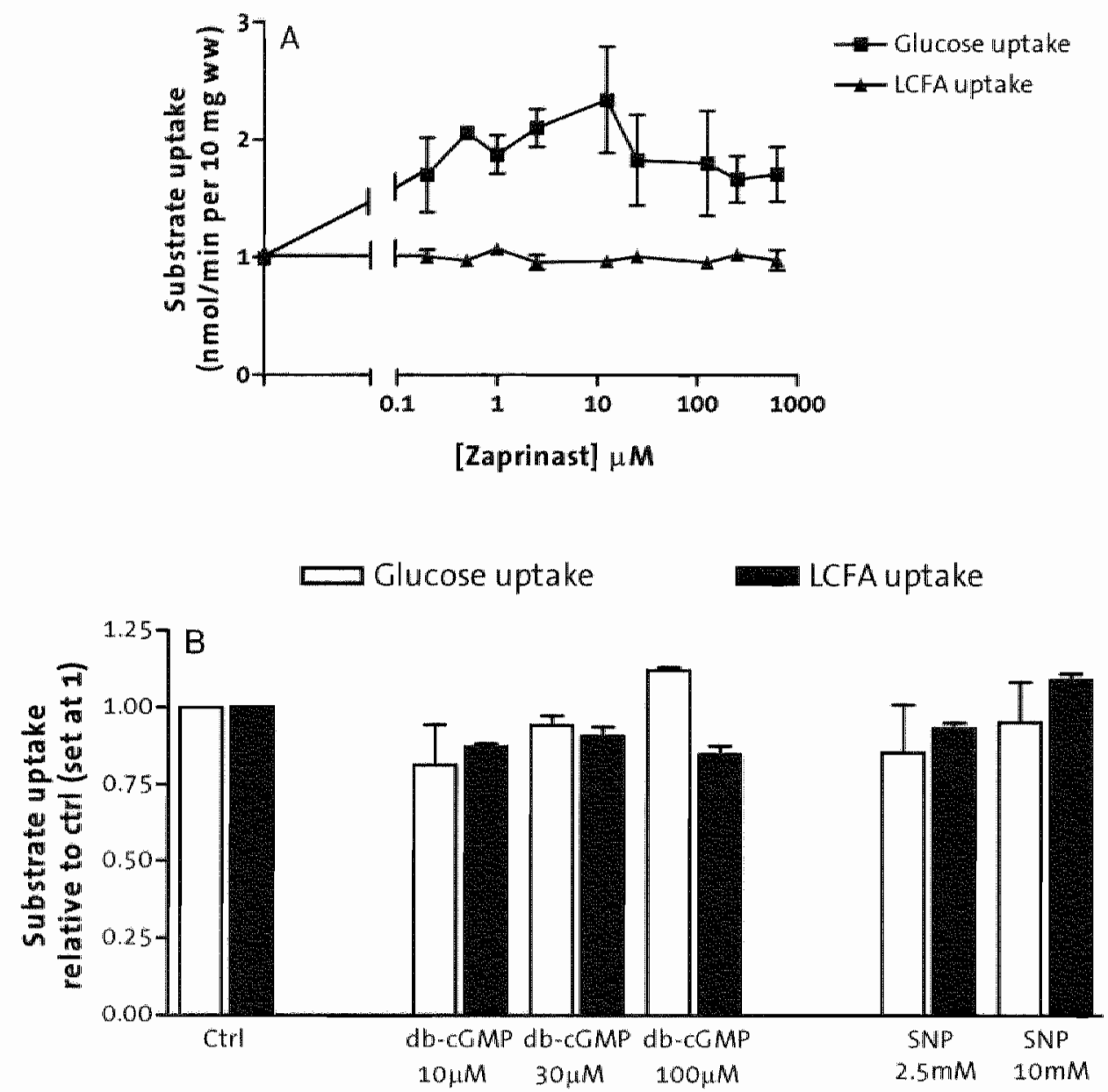

Figure 6.2. Effect of zaprinast (A), and sodium nitroprusside (SNP) and dibutyryl-cGMP (db-CGMP) (B) on substrate uptake. Cell suspensions were incubated in the absence of additions (ctrl) or presence of zaprinast (ranging from $0.2 \mu \mathrm{M}$ to $625 \mu \mathrm{M} / \mathrm{l}$ final concentration), $10 \mu \mathrm{M}, 30 \mu \mathrm{M}$ and $100 \mu M$ db-CGMP, and $2.5 \mathrm{mM}$ and $10 \mathrm{mM} 5 \mathrm{NP}$. Upon $15 \mathrm{~min}$ of incubation, palmitate and deoxyglucose uptake studies were performed ( $3 \mathrm{~min}$ ). Ctrl data is set at 1 , and data are expressed as means \pm SE of $n=4.6$ experiments carried out with different cardiomyocyte preparations. " Significantly different from ctrl. 


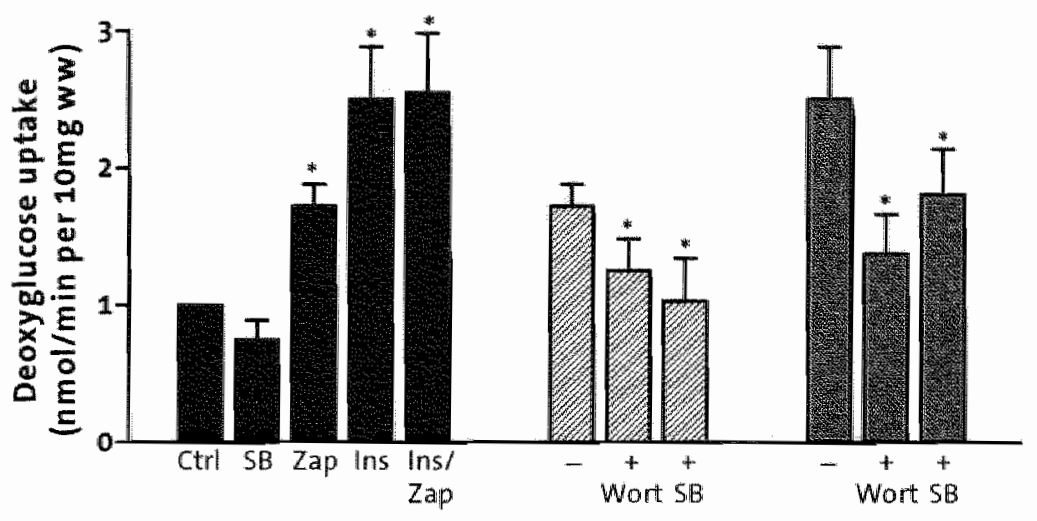

+ zapr inast $25 \mu M$ +insulin 1onM

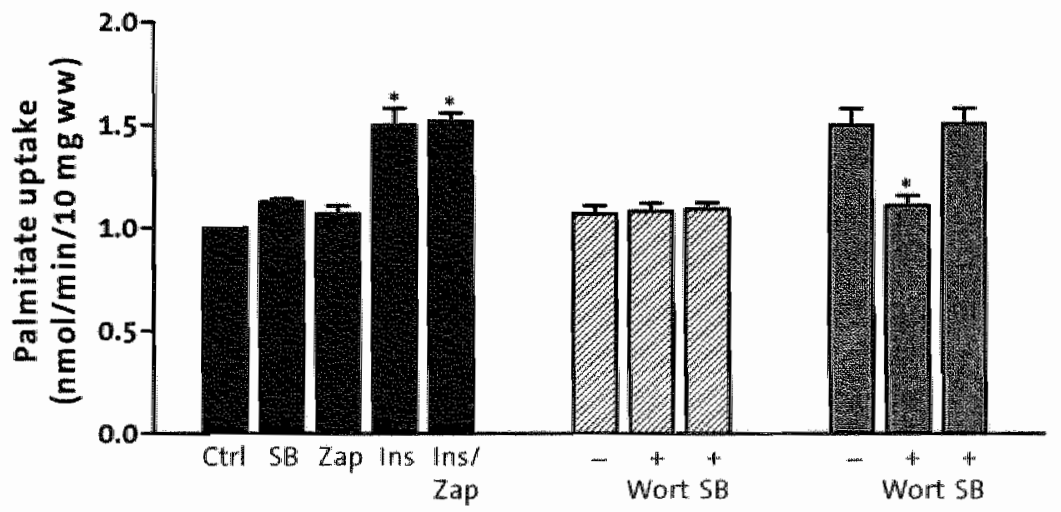

Figure 6.3. Effect of PI(3)K (Wortmannin)- and P38 MAPK (SB-203580)-inihitors on insulin-and zaprinast-stimulated deoxyglucose and palmitate uptake. Cell suspensions were incubated in the

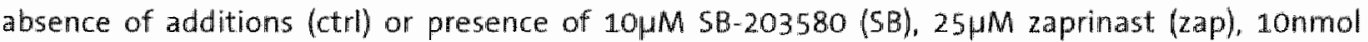
insulin (ins), insulin + zaprinast (ins/zap), zaprinast + 200uM wortmannin (mid panel), zaprinast * SB-203580 (mid panel), insulin + wortmannin (right panel), and zaprinast + SB 203580 (right panel). Upon 15 min of incubation, palmitate and deoxyglucose uptake studies were performed ( 3 min). Ctrl data is set at 1 , and data are expressed as means \pm SE of $n=3$ experiments carried out with different cardiomyocyte preparations. "Significantly different from ctrl.

To further unravel the stimulating action of zaprinast on deoxyglucose uptake, $25 \mu M$ zaprimast was added to suspensions of cardiac myocytes in the presence of insulin and inhibitors of PI3K (wortmannin) and P38 MAPK (SB-203580) (Fig. 6.3). Insulin stimulated 
deoxyglucose uptake by 2.8-fold, and zaprinast did not further enhance insulinstimulated deoxyglucose uptake. The PI(3)K inhibitor wortmannin, at a concentration of $200 \mathrm{nM}$, had no effect on deoxyglucose uptake in the absence of other additions, but was able to largely reduce insulin-stimulated deoxyglucose uptake. The specific p38 inhibitor 5B203580 did not influence deoxyglucose uptake by itself. More importantly, in its presence, insulin-stimulated deoxyglucose uptake was partly inhibited whereas zaprinast-stimulated deoxyglucose uptake was completely inhibited.

\section{Effects of zaprinast on palmitate uptake}

Within the concentration range tested, zaprinast did not influence palmitate uptake (Fig. 6.2A). Neither db-CGMP nor SNP, at the concentrations tested, altered palmitate uptake rates (Fig. 6.2B). In contrast to zaprinast, insulin stimulated palmitate uptake by 1.5-fold, in accordance with previous observations (Fig. 6.3) (21, 30). The respective PI(3) K and p38 MAPK inhibitors, wortmannin and SB-203580, had neither an effect on palmitate uptake by themselves, but exerted opposite effects when added in combination with insulin. In this respect, wortmannin completely inhibited insulin-stimulated palmitate uptake, whereas SB203580 had no effect on insulin-stimulated palmitate uptake (Fig. 6.3).

\section{Effect of zaprinast on the subcellular localization of GLUT4 and FAT/CD36}

Subcellular fractionation of cardiac myocytes was carried out in order to examine whether, or not, zaprinast stimulated glucose uptake through translocation of GLUT4 to the plasma membrane. For this purpose cardiac myocytes were incubated with $25 \mu \mathrm{M}$ zaprinast or, for comparison, with $10 \mathrm{nM}$ insulin. Insulin reduced the content of GLUT4 in the LDM fraction and simultaneously increased the content of GLUT4 in the PM fraction (Fig. 6.4), confirming the well-described insulin-mediated GLUT4 translocation event (3). In contrast, zaprinast was without effect on the contents of GLUT4 in the LOM and PM fractions, rejecting GLUT4 translocation as mechanism responsible for zaprinast-induced glucose uptake. When considering subcellular distribution of FAT/CD36 upon treatment with insulin and zaprinast, a similar response pattern was observed when compared with GLUT4 (Fig. 6.4). Thus, insulin, but not zaprinast, stimulated translocation of FAT/CD36 from intracellular stores to the sarcolemma.

\section{Effects of zaprinast on insulin-inducible signaling enzymes}

In the present study, we have used phosphospecific antibodies to detect the phosphorylation of Akt/PKB, since phosphorylation of this enzyme has been shown to correlate with its activity (31). Although dual phosphorylation of Akt/PKB is required for full stimulation (31), the phosphorylation status of the enzyme can be measured using phosphospecific antibodies directed to either of these two sites (18). Cell lysates prepared from cardiac myocytes stimulated with insulin and/or zaprinast were immunoblotted for Akt/PKB phosphorylated at Ser ${ }^{473}$. We were unable to detect Ser ${ }^{473}$ phosphorylation in cell lysates from non-stimulated cardiac myocytes, indicating no or 
very low activity of $A$ KU/PKB under basal conditions (Fig. 6.4). Insulin addition resulted in the well-documented rise in phosphorylation of $A k t / P K B(5,6)$, but zaprinast at the concentrations tested (i.e. $12.5 \mu \mathrm{M}, 25 \mu \mathrm{M}$, and $125 \mu \mathrm{M}$ ) was without effect. Thus, insulin-induced GLUT4 translocation is dependent on the activation of AkT/PKB.
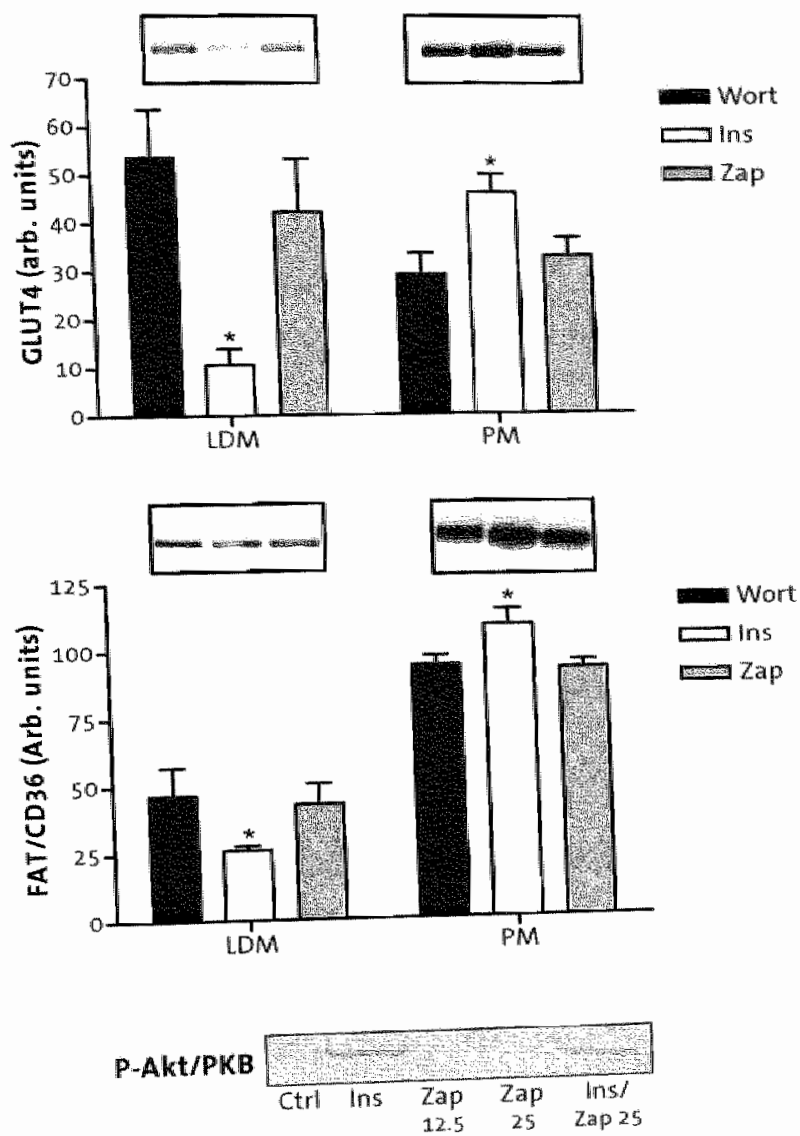

Figure 6.4. Effect of insulin and zaprinast on subcellular distribution of GLUT4 and FAT/CD36 in cardiac myocytes and phosphorylation of Akt/PKB. I solated cardiac myocytes were incubated for 15 min in the presence of $200 \mathrm{nM}$ wortmannin (wort). $10 \mathrm{MM}$ insulin (ins) or $25 \mu \mathrm{M}$ zaprinast, after which NaN3 was added to a final concentration of $5 \mathrm{mM}$ to stop ATP-demanding processes. Immediately thereafter, cells were frozen in liquid nitrogen, and upon thawing were subjected to subcellular fractionation. The collected fractions (intracellular, LDM; plasma membrane, PM) were analysed on the relative contents of GLUT4 and FAT/CD36. Transporter content (arbitrary units) is expressed as means \pm SE of 4 experiments carried out with different cardiomyocyte preparations. Representative westerm blots are shown for GLUT4 and FAT/CD 36. Ser. Akt/PKB phosphorylation was detected in lysates derived from cardiac myocytes treated with insulin, $12.5 \mu M$ and $25 \mu M$ zaprinast, and insulin $+25 \mu \mathrm{M}$ zaprinast." significantly different from control $(P<0.05)$ 


\section{Discussion}

While testing several PDE inhibitors on their ability to enhance LCFA uptake, we recently unmasked dipyridamole as a potent agent to stimulate the uptake of LCFAs into cardiac myocytes (22), whereas other PDE inhibitors, including zaprinast, lacked this stimulatory effect on LCFA uptake. Since, zaprinast has been used to stilmulate glucose uptake in cardiac myocytes $(25,32)$, zaprinast might function as selective modulator of cardiac substrate preference with putative anti-diabetic properties. This study describes the selective effect of zaprinast on cardiac substrate uptake and emphasizes several novel findings in the regulation of cardiac glucose and LCFA uptake. The present study shows that 1) elevations in CGMP level are not related to the stimulation of glucose uptake by zaprinast, ii) GLUT4 activation instead of GLUT4 translocation is the main mechanism by which zaprinast performs the stimulatory action on cardiac glucose uptake, iii) zaprinast stimulates glucose uptake through the activation of a PI(3)K- and P38 MAPK-dependent but Akt/PKB unrelated signaling cascade. iv) Finally, we emphasize the novel finding that activation of P38 MAPK plays an essential role in the activation of insulin-stimulated glucose transport, but not in insulin-stimulated LCFA transport.

\section{Cardiac substrate uptake is independent of intracellular cGMP levels}

One of insulin's best-characterized metabolic effects is the regulation of glucose transport. Insulin has been proposed to mediate these effects by raising the intracellular CGMP concentration. Hence, CGMP has been suggested to play a significant role in the regulation of glucose uptake in heart and muscle. Like insulin, the PDE inhibitor zaprinast has also been shown to elevate CGMP levels intracellularly and to increase glucose transport into cardiac myocytes (25). Although CGMP levels were markedly increased by zaprinast, db-CGMP and SNP, only zaprinast stimulated basal glucose uptake, confirming previous findings for zaprinast and SNP in cardiac myocytes (25). Simillar results have been found for the CGMP analogue, db-CGMP, which failed to alter basal glucose uptake in isolated skeletal muscle (33). The present study, therefore, does not support a role for the involvement of CGMP in the regulation of glucose uptake by zaprinast and indicates the involvement of a different mechanism to explain its selective effect on substrate uptake. In addition, we observed the novel finding that LCFA uptake is not mediated by intracellular cGMP levels.

\section{Effect of zaprinast at the level of glucose transporters}

Several studies in adipocytes and skeletal muscle have provided evidence to suggest that at least two events are required for full stimulation of glucose uptake by insulin, that is translocation and activation of GLUT4 (12-15). Therefore, we used subcellular fractionation of cardiac myocytes to unmask the underlying mechanism in the stimulation of glucose uptake by zaprinast. Whereas insulin induced the translocation of GLUT4 from intracellular stores to the sarcolemma, zaprinast was unable to influence the subcellular distribution of GLUT4 (Fig. 6.4). We also regard it as unlikely that zaprinast 
would stimulate GLUT1 translocation in the absence of GLUT4 recycling, because GLUT 1 and GLUT4 share intracellular compartments and vesicular trafficking machinery as well as the key signaling enzymes, $P I(3) K$ and $A K t / P K B$ (for review see (34)). Hence, it is hypothesized that zaprinast enhances glucose uptake by stimulating the intrinsic activity of glucose transporters instead.

\section{Glucose-specific effects of zaprinast on intracellular signaling in cardiac myocytes}

In unravelling the stimulatory effect of zaprinast on glucose uptake, we observed that zaprinast-stimulated deoxyglucose uptake was non-additive to insulin-stimulated deoxyglucose uptake (Fig. 6.3), indicating that zaprinast and insulin use the same mechanism to stimulate glucose uptake. The effect of zaprinast was, however, markedly smaller than that of insulin, suggesting that zaprinast only stimulates a selective part of the insulin-signaling cascade. In previous reports, p38 MAPK has been suggested to represent an integral component of the signaling pathway regulating GLUT4 activity $(14$, 16, 18). GLUT4 is, however, not likely to represent a direct target of P38 MAPK (35). The major phosphorylated residue in GLUT4, 5er ${ }^{488}$, does not lie within a P38 MAPK consensus phosphorylation site (35), indicating that other targets are possibly involved as well.

To examine the potential involvement of p38 MAPK as underlying mechanism in the stimulation of glucose uptake by zaprinast, the specific p38 alpha and bèta MAPKinhibitor, SB203580 (14), was used. Notably, zaprinast-stimulated deoxyglucose uptake was inhibited by pre-treatment of cardiac myocytes with SB203580 (fig. 6.3). Moreover, the absolute rate of stimulation of deoxyglucose uptake by zaprinast aver basal equalized the inhibition of insulin-induced deaxyglucose uptake by SB203580. Hence, it can be deduced that $\sim 30 \%$ of the insulin-effect on glucose uptake is mediated by p38 MAPK-induced activation of glucose transporters, confirming previous findings in skeletal muscle (15).

Additional evidence to support a role for GLUT4 activation by P38 MAPK and not GLUT4. translocation in zaprinast-stimulated glucose uptake was derived by using phosphospecific antibodies against phosphorylation of $A k t / P K B$ at $\operatorname{ser}^{A 73}$. Despite the fact that some controversy exist regarding a role for AKt/PKB in the insulin signaling pathway leading to GLUT4 translocation (7). Ser ${ }^{4 \%}$ phosphorylation of Akt/PKB has been observed in cardiac myocytes treated with insulin (Fig. 6.4). In contrast, Akt/PKB phosphorylation was not induced in zaprinast-treated cardiomyocytes (Fig. 6.4). Hence, these findings not only rule out a rolle for AKt/PKB in GLUT4 activation, they also indicate that zaprinast selectively stimulates glucose transporter activation and not translocation.

\section{Divergence of insulin-induced GLUT4 translocation and activation signaling pathways}

Both insulin-and zaprinast-stimulated deoxyglucose uptake were inhibited by the PI(3)Kspecific inhibitor, wortmannin. This inhibition was equally effective at $200 \mathrm{nM}$ and $50 \mathrm{nM}$ of wortmannin, which latter concentration is sufficiently low to make it unlikely that 
wortmannin has non-specific side effects (36). Since zaprinast does not stimulate

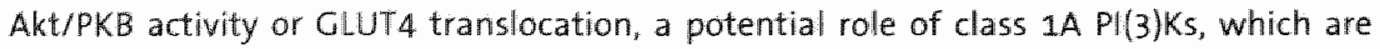
firmly established to be upstream of Akt/PKB (37,38), can be ruled out. Hence, Pl(3)Ks other than class $1 \mathrm{~A}$ (e.g. class $1 \mathrm{~B}, 11$ or 111 PI(3) Ks $(39,40)$ ) might be responsible for stimulation of P38 MAPK by zaprinast and subsequent activation of glucose transporters. Interestingly, there have been reports linking PI(3)K to activation of the family of MAPKS. which are in line with the existence of a putative signaling pathway induced by zaprinast and include the selective stimulation of a non selective stimulation of a non-class $1 \mathrm{~A}$ PI(3)K member upstream of P38 MAPK (41,42). Integrating the present findings into the total range of insulin-induced effects on glucose uptake, we support the view that insulin stimulates glucose uptake through a combination of Akt/PKB-mediated transporter translocation and P38 MAPK-mediated transporter activation in the heart, confirming previous observations in adipocytes and skeletal muscle $(15,16)$. Moreover, as summarized in figure 6.5, we hypothesize that the branch-point of insulin-signaling leading to separate Akt/PKB- and P38 MAPK activation is at the level of PI(3)K.

\section{Lack of effects of zaprinast on LCFA uptake}

Whereas zaprinast stimulates deoxyglucose uptake into cardiac myocytes, zaprinast does not affect LCFA uptake (fig. 6.2A). The inability of zaprimast to stimulate LCFA uptake and FAT/CD36 translocation (Fig. 6.4) is in contrast with the ability of insulin to stimulate both events (present study and (21). Since the P38 MAPK inhibitor, SB203580, did not inhibit insulin-induced LCFA uptake (Fig. 6.3), it might be suggested that insulin-induced LCFA uptake is not mediated by activation of p38 MAPK. Hence, it might be suggested that insulin stimulates LCFA uptake solely through activation of the classical class-1A $\mathrm{PI}(3) \mathrm{Ks}$ and possibly Akt/PKB, and not through p38 MAPK signaling. Accordingly, this will automatically explain the sellective effect of zaprinast on the stimulation of glucose uptake in which 38 . MAPK is partially involved.

\section{Conclusion}

This is the first study to assess whether the activation of P38 MAPK as possible mechanism by which insulin might regulate the uptake of LCFAs. Apparently, insulin stimulates LCFA uptake solely by translacation of FAT/CD36, whereas both translocation and activation are involved in insulin mediated glucose uptake. Given the observation that zaprinast does not stimulate LCFA uptake, and the P38 MAPK inhibitor, SB203580, does not inhibit insulin-induced LCFA uptake, we rule out a possible role for P38 MAPK in the regulation of LCFA uptake by both zaprinast and insulin in cardiac myocytes. Hence, zaprinast is able to selectively stimulate glucose uptake through the activation of components of the p38 MAPK signaling cascade. This feature of zaprinast to specifically interfere in cardiac substrate uptake renders a great therapeutic potential for the treatment of diabetic cardiomyopathies. As selective stimulator of glucose uptake, zaprinast might be extremely valuable in alleviating the diabetic profile in which glucose uptake is depressed. 


\section{Acknowledgements}

These studies were funded by grants from the Netherlands Organization for Scientific Research (ZonMW:903-39-194), the Canadian Institutes of Health Research (CIHR), the Natural Sciences and Engineering Research Council of Canada (NSERC), and the Canada Research Chair program.

A. Bonen is Canada Research Chair in Metabolism and Health.

J.F.C.Glatz is Netherlands Heart Foundation Professor of Cardiac Metabolism.

J.J.F.P. Luiken is a recipient of a VIDI-Innovation Research Grant from the Netherlands

Organization for Scientific Research (NWO-ZonMw grant 016.036.305). 


\section{References}

1. Marette, A., Richardson, J. M., Ramlal, T., Balon, T. W., Vranic, M., Pessin, J. E., and Klip, A. (1992) Abundance, localization, and insulin-induced translocation of glucose transporters in red and white muscle. Am I Physiol 263, C443-452

2. Zorzano, A., Sevilla, L., Camps, M., Becker, C., Meyer, J., Kammermeier, H., Munoz, P., Guma, A. Testar, $X_{.,}$Palacin, M. Blasi, 1., and Fischer, $Y$. (1997) Regulation of glucose transport, and glucose transporters expression and trafficking in the heart: studies in cardiac myocytes. Am $J$ Cardiol 80, 65A-76A

3. Fischer, Y., Thomas, J., Sevilla, L., Munoz, P., Becker, C. Holman, G., Kozka, I. J., Palacin, M.,

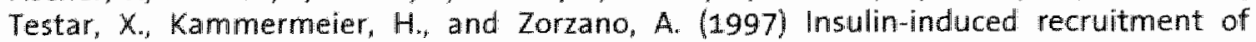
glucose transporter 4 (GLUT4) and GLUTI in isollated rat cardiac myocytes. Evidence of the existence of different intracellular GLUT4 vesicle populations. J Biol Chem 272, 7085 7092

4. White, M. F. (1997) The insulin signalling system and the IRS proteins. Diabetologia 40 Suppl 2, 52-17

5. Brozinick, J. T., Jr., and Birnbaum, M. J. (1998) Insulin, but not contraction, activates Akt/PKB in isolated rat skeletal muscle. J Biol Chem 273, $14679-14682$

6. Kohn, A. D., Summers, S. A., Birnbaum, M. J., and Roth, R. A. (1996) Expression of a constitutively active Akt Ser/Thr kinase in 3T3-L1 adipocytes stimulates glucose uptake and glucose transporter 4 translocation. $J$ Biol Chem 271, 31372-31378

7. Kitamura, T., Ogawa, W. Sakaue, H., Hino, Y., Kuroda, S., Takata, M., Matsumoto, M., Maeda, T., Konishi, H., Kikkawa, U., and Kasuga, M. (1998) Requirement for activation of the serine-threonine kinase Akt (protein kinase B) in insulin stimulation of protein synthesis but not of glucose transport. Mol Cell Biol 18, 3708-3717

8. Alessi, D. R., James, S. R., Downes, C. P., Holmes, A. B., Gaffney, P. R., Reese, C. B., and Cohen, $P$. (1997) Characterization of a 3-phosphoinositide-dependent protein kinase which phosphorylates and activates protein kinase Balpha. Curr Biol 7, 261-269

9. Bandyopadhyay, G., Kanoh, Y., Sajan, M. P., Standaert, M. L., and Farese, R. V. (2000) Effects. of adenoviral gene transfer of wild type, constitutively active, and kinase-defective protein kinase C-lambda on insulinmstimulated glucose transport in L6 myotubes. Endocrinology 141, 4120-4.127

10. Baly, D. L., and Horuk, R. (1987) Dissociation of insulin-stimulated glucose transport from the translocation of glucose carriers in rat adipose cells. J Biol Chem 262, 21-24

11. Joost, H. G., Weber, T. M. Cushman, S. W., and Simpson, I. A. (1986) Insulin-stimulated glucose transport in rat adipose cells. Modulation of transporter intrinsic activity by isoproterenol and adenosine. J Biol Chem 261, 10033-10036

12. Hausdorff, S. F., Fingar, D. C., Morioka, K., Garza, L. A., Whiteman, E. L., Summers, S. A., and Birnbaum, M. J. (1999) Identification of wortmannin-sensitive targets in 3T3-L.1 adipocytes. Dissociationoof insulin-stimulated glucose uptake and glut 4 translocation. $J$ Bial Chem 274, 24677-24684

13. Somwar, R., Kim, D. Y., Sweeney, G., Huang, C., Niu, W., Lador, C., Ramlal, T., and Klip, A. (2001) GLUT4 translocation precedes the stimulation of glucose uptake by insulin in muscle cells potential activation of GLUT4 via p38 mitogen-activated protein kinase. Biochem I 359, 639-649

14. Sweeney, G., Somwar, R., Ramlal, T., Volchuk, A., Ueyama, A., and Klip, A. (1999) An inhibitor of p38 mitogen-activated protein kinase prevents insulin-stimulated glucose transport but not glucose transporter translocation in $3 \mathrm{T3}$ L 1 adipocytes and $L 6$ myotubes.J Biol Chem 274, 10071-10078

15. Somwar. R., Perreault, M., Kapur, S., Taha, C., Sweeney, G., Ramlal, T., Kim, D. Y., Keen, J., Cote, C. H., Klip, A., and Marette, A. (2000) Activation of p38 mitogen-activated protein kinase alpha and beta by insulin and contraction in rat skeletal muscle: potential role in the stimulation of glucose tramsport. Diabetes $49,1794-1800$

16. Somwar, R., Koterski, S., Sweeney, G., Sciotti, R., Djuric, S., Berg, C., Trevillyan, J., Scherer, P. E. Rondinone, C. M, and Klip, A. (2002) A dominant-negative P38 MAPK mutant and novel selective inhibitors of P38 MAPK reduce insulin-stimulated glucose uptake in 3 T3-L1 adipocytes without affecting GLUT4 translocation. J Biol Chem 277, 50386-50395 
17. Raingeaud, J., Gupta, S., Rogers, J. S., Dickens, M. Han, J., Ulevitch, R. I., and Davis, R. J. (1995) Pro-inflammatory cytokines and environmental stress cause p38 mitogenactivated protein kinase activation by dual phosphorylation on tyrosine and threonine. $f$ Biol chem $270,7420-7426$

18. Somwar, R., Niu, W., Kim, D. Y., Sweeney, G., Randhawa, V. K., Huang, C., Ramlal, T." and Klip, A. (2001) Differential effects of phosphatidylimositol 3 -kinase inhibition on intracellular signals regulating GLUT4 translocation and glucose transport. $J$ Biol Chem $276,46079-46087$

19. Van der Vusse, G. J., Glatz, J. F., Stam, H. C, and Reneman, R. S. (1992) Fatty acid homeostasis in the normoxic and ischemic heart. Physiol Rev 72, 881-940

20. Luiken, J. J., van Nieuwenhoven, F. A. America, G., van der Vusse, G. J., and Glatz, J. F. (1997) Uptake and metabolism of palmitate by isolated cardiac myocytes from adult rats: involvement of sarcolemmal proteins. J Lipid Res $38,745-758$

21. Luiken, J. J., Koonen, D. P., Willems, J., Zorzano, A., Becker, C., Fischer, Y., Tandon, N. N., Van Der Vusse, G. I., Bonen, A., and Glatz, J. F. (2002) Insulin stimulates long-chain fatty acid utilization by rat cardiac myocytes through cellular redistribution of FAT/CD36. Diabetes $51,3113-3119$

22. Luiken, I. J.F. P., Coort, 5. L. M. Willems, J. Coumans, W. A., Bonen, A., and Glat2, J. F. C. (2004) Dipyridamole Alters Cardiac Substrate Preference by Inducing Translocation of FAT/CD36, but Not That of GLUT 4. Mol Pharmacol 65, 639-645

23. Shafiee-Nick, R., Pyne, N. J., and Furman, B. L. (1995) Effects of type-selective phosphodiesterase inhibitors on glucose-induced insulin secretion and islet phosphodiesterase actiwity. Br J Pharmacal 115, 1486-1492

24. Young, M. E., Clark, J. F, and Leighton, B. (1997) Zaprinast raises glucose utilisation in SHR skeletal muscle. Biochem 5 oc Trans 25, 4015

25. Shanahan, M. F., and Edwards, B. M. (1989) Stimulation of glucose transport in rat cardiac myocytes by guanosine $3^{\prime}, 5^{\prime \prime}$-monophosphate. Endocrinology 125, 1074-1081

26. Fischer, Y., Thomas, J., Rosen, P., and Kammermeier, H. (1995) Action of metformin on glucose tramsport and glucose transporter GLUT1 and GLUT4 in heart muscle cells from healthy and diabetic rats. Endocrinology $136,412-420$

27. Koonen, D. P., Coumans, W. A., Arumugarn, Y., Bonen, A., Glatz, J. F., and Luiken, J. J. (2002) Giant membrane vesicles as a model to study cellular substrate uptake dissected from metabolism. Mol Cell Biochem 239, 121-130

28. Clemo, H. F., and Baumgarten, C.M. (1995) CGMP and atrial natriuretic factor regulate cell volume of rabbit atrial myocytes. Circ Res $77,741-749$

29. Straznicka, M., Gong, G., Yan, L., Scholz, P. M., and Weiss, H. R. (1999) Cyclic GMP protein kinase mediates negative metabolic and functional effects of cyclic GMP in control and hypertrophied rabbit cardiac myocytes / Cardiovasc Pharmacol 34, 229-236

30. Luiken, J. J., Coort, S. L., Willems, J., Coumans, W. A., Bonen, A., van der Vusse, G. J., and Glatz, I. F. (2003) Contraction-induced fatty acid translocase/CD36 translocation in rat cardiac myocytes is mediated through AMP-activated protein kinase signaling. Diabetes $52,1627-1634$

31. Alessi, D. R., Andjelkovic M., Caudwell, B., Cron, P., Morrice, N., Cohen, P., and Hemmings, B. A. (1996) Mechanism of activation of protein kinase B by insulin and IGF-1. Embo / 15 , 6541.6551

32. Luiken, J. J., Willems, J., Coort, S. L., Coumans, W. A., Bonen, A., Van Der Vusse, G. J., and Glatz, 1. F. (2002) Effects of CAMP modulators on long-chain fatty-acid uptake and utilization by electrically stimulated rat cardiac myocytes. Biochem 1367,881-887

33. Kapur, S., Bedard, S., Marcotte, B., Cote, C. H., and Marette, A. (1997) Expression of nitric oxide synthase in skeletal muscle: a novel role for nitric oxide as a modulator of insulin action. Diabetes $46,1691-1700$

34. Luiken, J. J., Coort, S. L., Koonen, D. P., Van Der Horst, D. J., Bonen, A., Zorzano, A., and Giatz, J. F. (2004) Regulation of cardiac long-chain fatty acid and glucose uptake by translocation of substrate transporters. Pflugers Arch

35. Kandror, K. V. (2003) A long search for Glut4 activation. 5ci STKE 2003, PE 5 
36. Nakanishi, 5, Catt, K. J, and Balla, T. (1995) A wortmannin-sensitive phosphatidylinositol 4kinase that regulates hormone-sensitive pools of inositolphospholipids. Proc Natl Acad SCIUSA $92,5317-5321$

37. Alessi, D. R, and Downes, C. P. (1998) The role of Pl 3 -kinase in insulin action. Biochim Biophys Acta 1436, 151-164

38. Shepherd, P. R. Withers, D. J., and Siddle, K. (1998) Phosphoinositide 3-kinase: the key switch mechanism in insulin signalling. Biochem 333 (Pt 3), 471-490

39. Vanhaesebroeck. B., Leevers, 5. J., Panayotou, G., and Waterfield, M. D. (1997) Phosphoinositide 3-kinases: a conserved family of signal transducers. Trends Biochem SCi $22,267-272$

40. Wymann, M. P., and Pirola, L. (1998) Structure and function of phosphoinositide 3-kinases. Biochim Biophys Acta 1436, 127-150

41. GalverRoperh, I., Rueda, D., Gomez del Pulgar, T., Velasco, G., and Guzman, M. (2002) Mechanism of extracellular signal-regulated kinase activation by the CB(1) cannabinoid receptor. Mol Pharmacol 62, 1385-1392

42. Yart, A., Laffargue, M., Mayeux, P., Chretien, S., Peres, C., Tonks, N., Roche, S., Payrastre, B., Chap, H., and Raynal, P. (2001) A critical role for phosphoinositide 3-kinase upstream of Gab1 and SHP2 in the activation of ras and mitogen-activated protein kinases by epidermal growth factor. I Biol Chem 276, 8856-8864 
General discussion 


\section{Introduction}

The existence of transport proteins to facilitate the uptake of specific substrates is not an uncommon phenomenon. The plasma membrane of most tissue cells contains a sophisticated set of substrate specific transporter proteins, including, glucose transporter isoforms (GLUTS), monocarboxylate transporters (MCTs), long-chain fatty acid (LCFA) transporters, as well as multiple transport systems for the cellular exchange of amino acids $(1-6)$.

Fatty acid translocase (FAT)/CD36 is one of the putative LCFA transport proteins involved in the facilitation of cellular LCFA uptake (7-9). Like the glucose transporter GLUT4, FAT/CD36 does not have a mere facilitative function in maintaining the energy requirements of the tissue cells, evidence has indicated a regulatory role for this protein in cellular LCFA uptake as well $(10,11)$. The studies described in this thesis, therefore, explored the role of FAT/CD36 in the chronic and acute regulation of LCFA uptake in rat heart and skeletal muscle. In specific, attention was drawn to unravel the concept of FAT/CD36 recruitment in mediating insulin-stimulated LCFA uptake in cardiac muscle. The main aspects of the effects of 1) alterations in skeletal muscle activity (chronic stimulation/denervation), and 2) insulin stimulation on LCFA uptake and FAT/CD36 translocation will be discussed in detail below. The final section highlights the therapeutic potential of agents that selectively stimulate cardiac substrate preference to correct for alterations in substrate uptake, as observed in cardiac hypertiophy and diabetic cardiomyopathies.

\section{Regulation of LCFA uptake in skeletal muscle and heart}

In the basal (non-stimulated) state, FAT/CD36 is equally distributed between the plasma membrane and the intracellular compartment in skeletal muscle and heart (11, 12). Physiological stimuli (insulin, exercise, dietary interventions) $(10,13-20)$ and pathophysiological conditions (insulin resistance, diabetes, obesity) (21-24) have a profound impact on the regulation of cellular LCFA uptake in skeletal muscle and heart by altering the plasma membrane abundance of FAT/CD36. Although the end-result might be similar, different mechanisms have been shown to underlie this increase at the plasma membrane. In heart and skeletal muscle, LCFA uptake can be regulated by a) altering the total FAT/CD36 protein content, thereby increasing FAT/CD36 at the plasma membrane, or b) without altering the total protein content but by changing the distribution of FAT/CD36 between the endosomal pool and the cell surface (20).

In general, regulation of LCFA uptake in response to long-term stimuli as exercise training and chronic muscle stimulation involves the upregulation of FAT/CD 36 expression (chapter 4) (20), whereas acute stimuli as contractions ( $<30 \mathrm{~min}$ ) and shortterm insulin stimulation induce the translocation, i.e. relocation of intracellular stored FAT/CD36 to the cell surface (chapter 5). This time-dependent relationship might, however, not be as explicit as defined above. Microarray data provided evidence that FAT/CD36 expression is increased by 5 -fold in human skeletal muscle during a 3 -h hyperinsulinemic euglycemic clamp (25). 7 days of muscle inactivity (denervation) were 
able to reduce the amount of LCFAs taken up, but not by downregulation of the total content of FAT/CD36 present in the muscle (chapter 4) (20). Instead, 7 days of sciatic nerve denervation induced a $24 \%$ reduction in surface FAT/CD 36, most likely by relocation of this putative LCFA transport protein towards the endosomal storage compartments. On the opposite, elevated LCFA uptake rates have been observed in obese Zucker rats and in skeletal muscle of obese and type 2 diabetic patients $(21,24)$. This long-term adaptation of LCFA uptake was rather associated with a permanent redistribution of FAT/CD36 towards the plasma membrane than with an altered expression of total muscle FAT/CD36 $(21,24)$. Likewise, the plasma membranes cardiac myocytes obtained from hearts of pre-diabetic obese Zucker rats displayed an elevated $(+74 \%)$ amount of FAT/CD36 at the expense of intracellular stored FAT/CD36 (23). Thus, transporter relocation is an important mechanism by which cardiac and skeletal muscle cells are capable of adapting to both acute (insulin, short-term contractile activity) as well as chronic (denervation, insulin-resistance, diabetes) alterations in their energy requirements. Despite the fact that a change in the level of gene and protein expression has been commonly seen as underlying mechanism in this adaptation process, these two parameters are clearly not always altered. An intracellular translocation (i.e. relocation) of substrate transporters might, therefore easily be overlooked as underlying mechanism in the regulation of substrate uptake, when the experimental setup is confined to measuring mRNA expression and total protein levels.

\section{Insulin-mediated glucose uptake}

\section{GLUT4 translocation}

Insulin regulates a variety of biological processes and metabolic pathways, including the cellular uptake of glucose in skeletal muscle (26-28) and heart (chapter 6). While several of the key molecules participating in the specific signal transduction cascades have been identified, the precise steps between insulin binding to the alpha-subunit of the insulin receptor and stimulation of glucose transport are not entirely delineated yet. Critical for a proper insulin action on glucose transport is the activation of phosphatidylinositol-3$\mathrm{OH}$ kinase $(\mathrm{PI}(3) \mathrm{K})$, which has been found to play a predominant role in the translocation of GLUT4. Chemical inhibition of PI(3)K, and expression of dominant negative mutants of PI(3)K, all inhibit insulin-stimulated GLUT4 translocation and glucose uptake $(29,30)$. Moreover, overexpression of the wild-type or constitutively active mutant of PI(3)K has been reported to promote glucose transport activity and GLUT4 translocation (31.32).

Several downstream mediators of PI(3)K have been reported, including phosphoinositidedependent protein kinase-1 (PDK-1) activated by a lipid product of PI(3)K phosphatidylinositol 3,4,5-triphosphate (Ptdlns (3,4,5)P3) (33). PDK-1 is known to directly phosphorylate and activate the serine/threonine kinase AKt/PKB (34) and the atypical PKC's, PKC-zèta and lambda (35). Although contradictory findings on GLUT4 translocation have been obtained by the overexpression of dominant negative Akt mutants $(36,37)$, overexpression of a constitutively Akt has been shown to promote 
GLUT4 translocation (38). Notably, insulin treatment of cardiomyocytes has been shown to result in both phosphorylation of Akt/PKB and GLUT4 translocation towards the cell surface (Koonen DPY, Luiken JJFP, unpublished observations), confirming previous findings $(39,40)$. Strikingly, whereas glucose uptake was increased by the PDE type $V$ inhibitor, zaprinast, neither Akt/PKB was phosphorylated nor GLUT4 translocation was observed in cardiac myocytes (chapter 6). Hence, these data collectively suggest a favourable role of Akt/PKB in insulin-induced GLUT4 translocation and glucose transport. Considerable evidence supports a role for the atypical PKC isoforms as more downstream effectors for the insulin-induced activation of GLUT4 translocation and glucose transport $(41,42,43)$. Overexpression of a dominant-negative mutant of PKC-zèta and -lambda has been shown to inhibit insulin-stimulated glucose transport and GLUT4 translocation in muscle cells $(41,44)$. In addition, overexpression of wild-type PKC-zèta in muscle in vivo has been reported to enhance both basal and insulin-stimulated glucose transport (45).

\section{GLUT4 activity}

Although GLUT4 translocation is of critical importance in the acute regulation of insulininduced glucose uptake, the recruitment of GLUT4 to the cell surface in response to insulin is not sufficient to achieve a maximal increase in glucose uptake $(27,46,47)$. At least two events appear to culminate in the acute regulation of glucose uptake by insulin: translocation and activation of GLUT4 (47).

Insulin binding to the insulin receptor has previously been shown to activate an additional signaling pathway, linking P38 MAPK to the regulation of intrinsic GLUT4 activity in skeletal muscle $(27,48,49)$. By using the PDE type V/VI inhibitor zaprinast evidence was found for the involvement of p38 MAPK signaling in the regulation of glucose uptake in isolated cardiac myocytes (chapter 6). Although zaprinast increased glucose uptake by approximately 1.7 fold, translocation of GLUT4 was not observed, whereas zaprinast-stimulated glucose uptake was completely reduced by the p38 MAPK inhibitor SB 203580. Similar to previous findings in skeletal muscle (27), insulinstimulated glucose uptake in cardiac myocytes was reduced up to $30 \%$ by the use of the P38 MAPK inhibitor SB 203580 (chapter 6). Hence, regulation of GLUT4 activity is likely to represent an essential component in the acute regulation of glucose uptake in response to insulin.

The insulin-signaling pathway leading to 338 MAPK phosphorylation and stimulation of GLUT4 activity is not well characterized, and remains yet to be identified. A potential role of class $1 \mathrm{~A} \mathrm{PI(3)Ks} \mathrm{can,} \mathrm{however,} \mathrm{be} \mathrm{ruled} \mathrm{out,} \mathrm{since} \mathrm{zaprinast} \mathrm{did} \mathrm{not} \mathrm{stimulate} \mathrm{Akt/PKB}$ activity and GLUT4 translocation (chapter 6). In contrast, zaprinast-stimulated glucose uptake is sensitive to inhibition by the PI(3)K-inhibitor, wortmannin. Hence, PI(3)Ks other than class $1 \mathrm{~A}$ might mediate the activation of P38 MAPK by both zaprinast and insulin, resulting in GLUT4 activation.

In addition, insulin has been found to stimulate the activity of cdc42, a member of the Rho family of small guanosine $5^{\prime}$-triphosphate (GTP)-binding proteins (50). cdc42 and Rac1, another Rho family member involved in actin rearrangement, have been linked to 
the regulation of P38 MAPK via stimulation of p21-activated kinases (51). Notably, p38 MAPK can be directly activated via phosphorylation by MKK6, which is highly expressed in cardiac and skeletal muscle (52). Since MKK6 can be activated in turn by stepwise activation of Rac-and p21-activated kinases $(52,53)$, it might be hypothesized that a similar cascade is involved in the regulation of the intrinsic activity of GLUT4 in response to insulin.

\section{Insulin-mediated LCFA uptake}

\section{FAT/CD36 translocation}

In comparison to the detailed description of the molecular mechanisms involved in insulin-stimulated glucose uptake, studies describing the signaling cascade in insulinstimulated LCFA uptake are just recently being performed. Not surprisingly, the information is scarce and confined to the major protein kinases (PI(3)K, Akt/PKB) known to be involved in the regulation of cellular glucose uptake. Nonetheless, the obtained results are indicative of signaling cascades potentially involved in LCFA transport.

Insulin's stimulating effect on the cellular uptake of LCFAs in cardiac myocytes was fully blocked by phloretin, sulpho-N-succinimidyl-palmitate (SSP), and wortmannin, indicating the involvement of both FAT/CD36 and the dependence of $\mathrm{PI}(3) \mathrm{K}$ (chapter 5). Pharmacological inhibition of PI(3)K has previously been reported to prevent both the insulin-induced increase in LCFA uptake and insulin-induced FAT/CD36 translocation in skeletal muscle (16). Thus, insulin-induced FAT/CD36 transiocation, like GLUT4 translocation, requires the activation of $\mathrm{PI}(3) \mathrm{K}$ in cardiac and skeletal muscle.

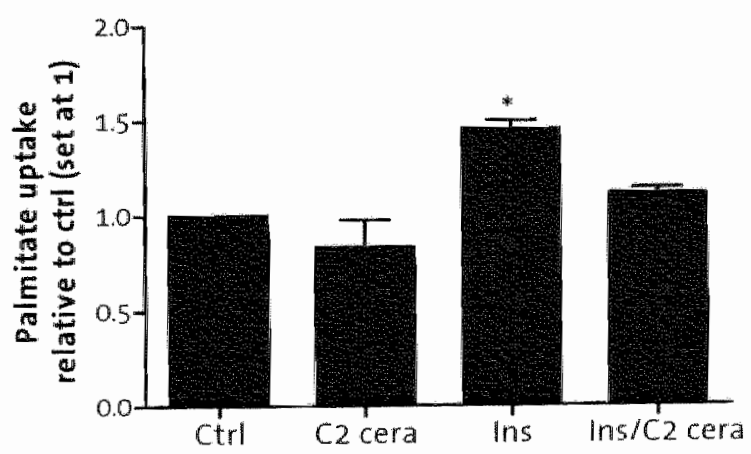

Figure 7.1. Effect of C2-ceramide on basal and insulin-induced palmitate uptake in cardiac myocytes. Cell suspensions were incubated in the presence of either $C 2$-ceramicle $\left(100 \mu \mathrm{M} / 1 ; \mathrm{C2}_{2}\right.$ ceral, insulim (10 nmol/l; ins), or insulin + C2-ceramide (ins/C2 cera) for 1 hour Insulin was added at $45 \mathrm{~min}$ for a final $15 \mathrm{~min}$ incubation and palmitate uptake was measured as described in chapter 6. Data are presented as means $\pm 5 E ; n=3$ independent experiments. Untreated cell suspension (ctrl) is set at 1 and corresponds to $22.3 \mathrm{nmol} / \mathrm{min}$ per $\mathrm{g}$ wet mass). 
In contrast, the molecular signaling mechanisms by which activation of PI(3)K leads to FAT/CD 36 translocation remains largely undefined. Based upon previous findings related to insulin-induced GLUT4 translocation, AKt/PKB and atypical PKCs might be implicated as essential components in the insulin-signaling cascade leading to FAT/CD36 translocation. Studies have not, yet, been performed to highlight a role for atypical PKCS in insulin-stimulated LCFA uptake. Preliminary data, however, do suggest the involvement of the serine/threonine kinase $A k t / P K B$ in insulin-induced LCFA translocation in cardiac myocytes (DPY Koonen, MMAL Pelsers, JFC Glatz, and JJFP Luiken, unpublished observations). Insulin-stimulated LCFA uptake was reduced in the presence of C2-ceramide $(100 \mu M)$, a cell-permeable ceramide analogue (figure 7.1 ), which has previously been shown to inhibit the insulin activation of PKB without affecting upstream components of insulin signaling, such as IRS-1 and PI(3)K (54). These preliminary findings, therefore, suggest that Akt/PKB is a likely candidate to play a role in the insulin signaling cascade involved in FAT/CD36 translocation downstream of $\mathrm{PI}(3) \mathrm{K}$.

\section{FAT/CD36 activity}

Despite an apparent involvement of MAPK-signaling in the regulation of glucose uptake by insulin in skeletal muscle and heart, the P38 MAPK inhibitor SB 203580 did not inhibit the insulin-mediated increase in LCFA uptake in cardiac myocytes (chapter 6). The present data, therefore, do not support a potential role for P38 MAPK in the insulinmediated regulation of LCFA uptake (chapter 6). Hence, it is tempting to speculate that translocation of FAT/CD36 is highly sufficient to account for the insulin-induced stimulation of LCFA uptake and that altering the intrinsic activity of FAT/CD36 is not an essential component in insulin-induced regulation of LCFA uptake.

In contrast, an increase in intrinsic activity of FAT/CD36 has been reported in cardiac myocytes incubated with the PDE inhibitors milrinone and 3-isobutyl-1-methylxanthine (IBMX) (55). Although studies have not yet been performed to unravel the mechanism involved in this regulation of FAT/CD36 activity, there is evidence to suggest a role for P38 MAPK to mediate this process. A crosstalk has been observed between distinct MAPK cascades as well with protein kinases from other pathways, such as PKC and the CAMPdependent protein kinase A (PKA) (56-58). In specific, activation of p38 MAPK in response to milrinone has been perceived in relation to increments in intracellular CAMP level and subsequent activation of PKA (58). A similar mechanism might, therefore, account for the increase seen in intrinsic activity of FAT/CD36 in cardiac myocytes upon treatment with milrinone. At present, there is no data available to link other components of MAPK signaling cascades, e.g. the extracellular signal-regulated kinases (erk) 1 (p44 MAPK) and 2 ( 422 MAPK), and the stress-activated protein kinase (SAPK)/Jun $\mathrm{N}$-terminal kinases (INK) to the acute regulation of FAT/CD36 activity in heart and skeletal muscle. 


\section{Contraction-mediated recruitment of GLUT4 and FAT/CD36}

In contrast to the PI(3)K-dependent mechanism of insulin stimulated LCFA uptake, stimulation of LCFA uptake by contractions does not involve the activation of PI(3)K as signaling intermediate (chapter 5. (15)). Instead, contraction-induced FAT/CD36 translocation is highly dependent on the activation of the metabolic sensor AMPK, which can be activated in response to exercise or by pharmacological intervention through the mitochondrial inhibitor oligomycin and the cell-permeable adenosine analogue AICAR (figure 2.4) (59). Despite the apparent involvement of AMPK in contraction-induced substrate uptake, there is little insight into intracellular signaling factors that operate distally from AMPK. Studies in cardiac myocytes treated with phorbol 12-myristate 13acetate (PMA), a cell permeable diacylglycerol (DAG) analogue, have provided evidence for the involvement of the conventional and novel class of protein kinase $C$ (PKC) isoforms in the stimulation of contraction-induced glucose and LCFA uptake (60). In addition, preliminary data demonstrated that in the presence of specific PKC inhibitors activation of AMPK does not result in translocation of substrate transporters (JJFP Luiken, J Willems, SLM Coort, and JFC Glatz, unpublished observations). Thus, it is very likely that conventional and novel PKC isoforms are a downstream target of AMPK in the contraction-induced signaling pathway leading to the translocation of GLUT4 and FAT/CD 36. However, alterations in the activity of the atypical PKC isoforms, PKC-zèta and -lambda, have been observed upon exercise in mouse and human skeletal muscle $(43,61$, 62) Moreover, myristoylated PKC-zèta pseudosubstrate has been shown to block AICARinduced glucose uptake in L6 myotubes (61), suggesting that each of the identified PKC classes are likely to be involved in the acute regulation of glucose uptake.

Both exercise and AICAR treatment acutely increased atypical PKC activity by a mechanism dependent on the activation of the extracellular signal-regulated kinases (ERK), leading to the subsequent activation of phospholipase D (PLD), the generation of phosphatidic acid (PA), and the direct activation of aPKCS (61). This activation of aPKCS is, however, $\mathrm{Pl}(3) \mathrm{K}$-and PKB independent $(43,61)$, and most likely appears to be mediated by the activation of the non-receptor tyrosine kinase, proline-rich tyrosine kinase-2 (PYK2) (61). Hence, it might be interesting to investigate whether a similar cascade is involved in AICAR-induced FAT/CD36 translocation in heart.

In addition to the stimulation of P38 MAPK by insulin, exercise, contraction and AlCAR treatment also activate $\mathrm{P} 38$ MAPK in rat skeletal muscle $(27,47,63,64)$. Incubation of isolated EDL muscles with the P38 MAPK inhibitor SB203580 reduced contractionstimulated glucose uptake by approximately $50 \%$, indicating that contraction, similar to insulin, stimulates both GLUT4 translocation and GLUT4 activation (27). Since the effect of AICAR on glucose uptake was abrogated by SB203580, it has been suggested that $p 38$ MAPKalpha and -bèta act downstream of AMPK to stimulate glucose uptake (64). Whether contraction- , AICAR-, or oligomycin-stimulated LCFA uptake is partly mediated via the activation of P38 MAPK is not known, and would be an interesting topic for further research. 


\section{Insulin and contraction: independent pathways?}

Insulin and contractile activity are the major regulators of substrate uptake. Simultaneous stimulation of both pathways results in an additive increase in the rate of LCFAs taken up, suggesting that insulin and contractile activity do not share a common pathway for the recruitment of endosomally stored FAT/CD36. This, however, does not rulle out the possibility that downstream of $\mathrm{PI}(3) \mathrm{K}$ both signaling pathways converge and share one or more distal steps. Of the insulin-activated protein kinases, Akt/PKB has neither been found to be activated by exercise in skeletal muscle (65), nor in oligomycintreated cardiac myocytes (DPY Koonen and JJFP Luiken, unpublished observations).

The atypical PKC5-zèta/lambda and P38 MAPK are, however, likely candidates that may play a role in the regulation of both exercise- and insulin-related substrate uptake ( 43 , 61, 62, 66). Apparently, both kinases can be activated by insulin and exercise/AICAR, but via a PI(3)K- and AMPK-dependent signaling cascade, respectively. Hence, these findings suggest two independent pathways for the regulation of glucose and LCFA transport regardless of mutual kinases involved, as summarized in figures 7.2 and 7.3 .

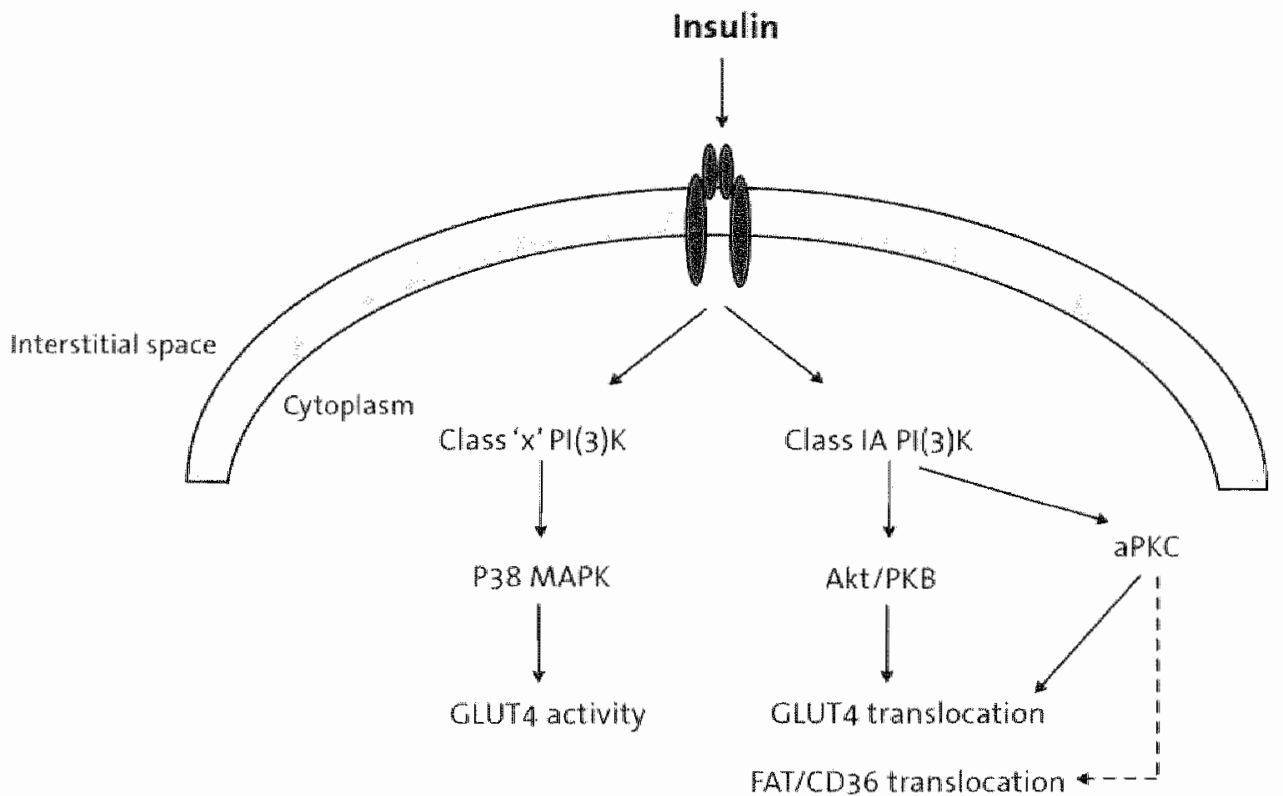

Figure 7.2. Schematic representation of signaling pathways involved in the stimulation of glucose and LCFA uptake by insulin. Two events, mediated by different phosphatidylinositol-3-OH (PI(3)K) classes, are required for full stimulation of glucose uptake by insulin, that is, GLUT4 translocation and GLUT4 activation. The classical type 1A PI(3)K are involved in the translocation of GLUT4 to the cell surface through the activation of both AKt/PKB and atypical PKC (aPKC). GLUT4 activation is mediated via the activation of $\mathrm{P} 38$ MAPK mediated by an as yet unknown class ' $\mathrm{X}$ ' PI(3)K. In contrast to insulin-stimulated glucose uptake, insulin-stimulated LCFA uptake is solely dependent on FAT/CD36 translocation. 


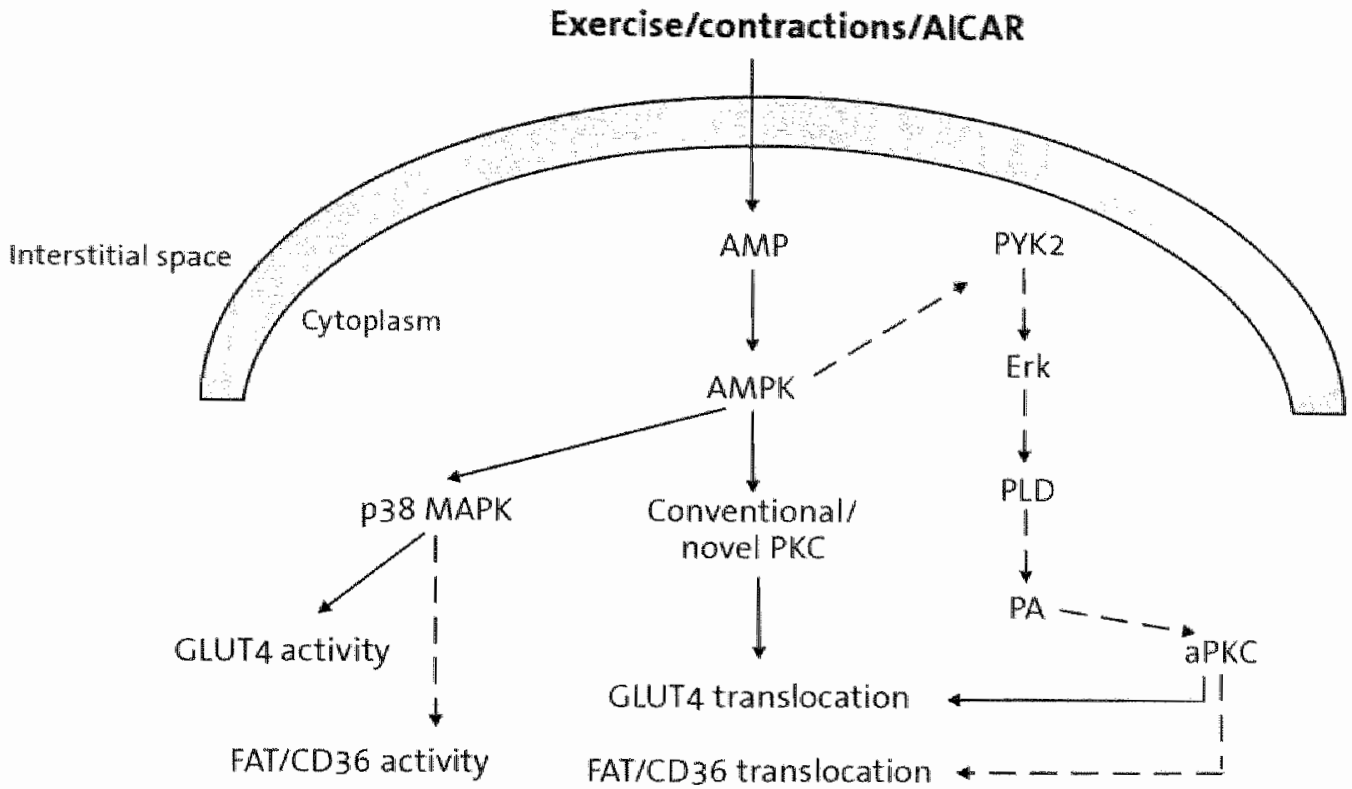

Figure 7.3. Schematic representation of the (potential) signaling pathways involved in the regulation of contraction-induced glucose and LCFA uptake. Regulation of both glucose and LCFA uptake in response to exercise, contractions, and AICAR treatment is mediated via activation of AMP kinase (AMPK). Two downstream targets of AMPK have been identified, that is, the conventional and novel PKCs (c/n PKC) and P38 MAPK. Whereas stimulation of $c / n$ PKC results in both GLUT4 and FAT/CD36 translocation, activation of 338 MAPK is involved in the regulation of GLUT4 activity and possibly FAT/CD36 activity. In addition, aPKC plays a role in GILTT4 translocation and perhaps in FAT/CD36 translocation as well. Although conclusive evidence can not be drawn, this activation of aPKCs most likely appears to be mediated by the AMPK-induced activation of the non-receptor tyrosine kinase, prolinemich tyrosine kinase-2 (PVK2) (61). This activation then results in the stepwise activation of the extracellular signal-regulated kinases (Erk), phospholipase D (PLD). the generation of phosphatidic acid (PA), and the activation of aPKC5 (61).

\section{Directions for future research: modulation of substrate preference in the heart}

In the healthy heart glucose and LCFA utilization are finely tuned and there is a distinctive balance between the utilization of these metabolic substrates. However, in chronic cardiac disease, including cardilac hypertrophy and failure (67,68), and diabetic cardiomyopathy (69-71), this balance is upset and the substrate preference of the heart is altered. During development of cardiac hypertrophy, there is a gradual decrease in cardiac LCFA utilization, which is partly compensated for by an increase in glucose utilization (67). This shift in substrate preference is accompanied by impaired cardiac functioning, and deteriorates when the hypertrophy develops towards cardiac failure 
(68). Conversely when the cardiac substrate balance is forced to change into the direction of decreased LCFA utilization, development of cardiac hypertrophy is evoked, as previously observed in rodent studies $(72,73)$. In man, inborn errors of LCFA betaoxidation allso lead to hypertrophic cardiomyopathies (74).

The diabetic heart suffers from impaired glucose uptake, and therefore relies almost completely on LCFAs for metabolic energy production (69). This shift in substrate utilization is accompanied by a decreased contractile performance of the diabetic heart. In addition, an important feature of the diabetic heart is a dramatic increase in myocardial triacylglycerol (TAG) content (75-78). As described in chapter 2, TAG on itself does not appear to have adverse effects, but can be subsequently converted into the lipid intermediates, diacylglycerol (DAG), ceramides and long-chain acyl-CoA, which have been linked to the development of insulin resistance. Collectively these findings suggest that cardiac functioning is dependent on a proper balance of substrates utilized for energy production. Hence, modulation of cardiac substrate preference aimed at correcting this dysbalance might be clinically beneficial in both cardiac hypertrophy and diabetic cardionyopathies.

It should also be emphasized that the substrate transporters GLUT4 and FAT/CD36 play an important role in maintaining a proper cardiac function. This is not only evidenced by several rodent studies in which FAT/CD36 or GLUT4 is deficient or absent (79-81), but also in diverse human studies (24,82-84). In addition, translocation of GLUT4 and FAT/CD36 have both been found to be disturbed $(21,85)$, but this impairment results in opposite effects on their subcellular distribution, i.e., GLUT4 is retained in the intracellular compartments, whereas FAT/CD36 is retained at the cell surface. Hence, unravelling the underlying mechanisms and signaling pathways involved in GLUT4 and FAT/CD36 translocation might be extremely valuable to gain insight into the mechanisms of glucose and LCFA uptake. In specific, differences observed in the regulation of GLUT4 and FAT/CD 36 can help to identify therapeutic strategies to allow selective manipulation of substrate transporter recruitment and to restore cardiac substrate balance. For instance, dipyridamole, was found to selectively stimulate LCFA uptake by inducing the translocation of FAT/CD36 towards the cell surface in cardiac myocytes, whereas glucose uptake and GLUT4 distribution were umaitered (86). Dipyridamole could, therefore, be useful as therapeutic agent to counteract the development of cardiac hypertrophy by correcting the reduction in cardiac LCFA uptake (86). In contrast, zaprinast might be clinical interesting to alleviate the diabetic profile, since zaprinast was found to selectively enhance glucose uptake, however, not by inducing GLUT4 translacation but by stimulating GLUT4 activity instead (chapter 6). Considering the observation that P38 MAPK is not involved in the insulin-induced regulation of LCFA uptake, P38 MAPK might provide a valuable target to restore the reduction in glucose uptake seen in diabetic cardiomyopathies. Future studies should, therefore, be directed towards studying the underlying mechanisms and signaling pathways involved in the regulation of cellular glucose and LCFA uptake. 


\section{References}

1. Poole, R. C., and Halestrap. A. P. (1993) Transport of lactate and other monocarboxylates across mammalian plasma membranes. Am J Physiol 264. C761-782

2. Palacin, M., Estevez, R., Bertran, J., and Zorzano, A. (1998) Molecular biology of mammalian plasma membrane amino acid transporters. Physiol Rev $78,969-1054$

3. Halestrap, A. P., and Price, N. T. (1999) The proton-linked monocarboxylate transporter (MCT) family: structure, function and regulation. Biochem $/ 343 \mathrm{Pt} 2,281-299$

4. Hyde, R., Peyrollier, K., and Hundal, H. 5. (2002) Insulin promotes the cell surface recruitment of the SAT2/ATA2 system A amino acid transporter from an endosomal compartment in skeletal muscle cells. J Biol Chem 277, 13628-13634.

5. Joost, H. G., Bell, G. I., Best, J. D., Birnbaum, M. J., Charron, M. J., Chen, Y. T., Doege, H., James, D. E, Lodish, H. F., Moley, K. H., Moley, J. F. Mueckler, M., Rogers, 5. Schurmann, A., Seino, 5. and Thorens, B. (2002) Nomenclature of the GLUT/SLC2A family of sugar/polyol transport facilitators. Am J Physiol Endocinol Metab 282, E974-976

6. Wood, I. S., and Trayhurn, P. (2003) Gllucose transporters (GLUT and SGIT): expanded families of sugar transport proteins. Br Nutr $89,3-9$

7. Berk, P. D., Zhou, S. L., Kiang, C. L., Stump, D., Bradbury, M., and isola, L. M. (1997) Uptake of long chain free fatty acids is selectively up-regulated in adipocytes of Zucker rats with genetic obesity and non-insulin-dependent diabetes mellitus. J Biol Chem 272,8830-8835

8. Hui, T. Y. and Bernlohr, D. A. (1997) Fatty acid transporters in animal cells. Front Biosci 2. d $222-231$

9. Bonen, A., Benton, C. R., Campbell, S. E. Chabowski, A., Clarke, D. C., Han, X. X., Clatz, J. F., and Luiken, J. J. (2003) Plasmalemmal fatty acid transport is regulated in heart and skeletal muscle by contraction, insulin and leptin, and in obesity and diabetes. Acta Physiof Scand $178,347-356$

10. Bonen, A., Dyck, D. J., Ibrahimi, A., and Abumrad, N. A. (1999) Muscle contractile activity increases fatty acid metabolism and transport and FAT/CD36. Am J Physiol 276, E642-649

11. Bonen, A., Luiken, J. J., Arumugam, Y., Glatz, J. F., and Tandon, N. N. (2000) Acute regulation of fatty acid uptake involves the cellular redistribution of fatty acid translocase. I Biol Chem 275, 14501-14508

12. Muller, H. Deckers, K., and Eckel, J. (2002) The fatty acid translocase (FAT) CD36 and the glucose transporter GLUT4 are localized in different cellular compartments in rat cardiac muscle. Biochem Biophys Res Commun 293, $665-669$

13. Nisoli, E., Carruba, M. O., Tonello, C., Macor, C., Federspil, G., and Vettor, R. (2000) Induction of fatty acid translocase/CD36, peroxisome proliferator-activated receptorgamma2, leptim, uncoupling proteins 2 and 3, and tumor necrosis factor-alpha gene expression im human subcutaneous fat by lipid infusion. Diabetes $49,319-324$

14. Fabris, R., Nisoli, E., Lombardi, A. M., Tonello, C., Serra, R., Granzotto, M., Cusin, I., RohnerJeanrenaud, F, Federspil, G., Carruba, M. O, and Vettor, R. (2001) Preferential channeling of energy fuels toward fat rather than muscle during high free fatty acid avalability in rats. Diabetes $50,601-608$

15. Luiken, J. J, Koonen, D. P., Willems, J., Zorzano, A., Becker, C. Fischer, Y. Tandon, N. N., Van Der Vusse, G. J. Bonen, A., and Glatz, J. F. (2002) Insulin stimulates long-chatin fatty acid utilization by rat cardiac myocytes through cellular redistribution of FAT/CD 36. Diabetes $51,3113-3119$

16. Luiken, 1. J., Dyck, D. J., Han, X. X., Tandon, N. N., Arumugam, Y., Glatz, J. F., and Bonen, A. (2002) Insulin induces the translocation of the fatty acid transporter FAT/CD36 to the plasma membrane. Am J Physiol Endocrinol Metab 282, E491-495

17. Sukhotnik. I.. May, N., Gork, A. S., Chen, M., Drongovski, R. A., Coran, A. G., and Harmon, C. $M .(2002)$ Effect of bowell resection and high-fat diet on heart CD36/fatty-acid translocase expression in a rat model of short-bowel syndrome. Pediatr Surg int 18,620-623

18. Tunstall, R. J., Mehan, K. A., Wadley, G. D., Collier, G. R., Bonen, A. Hargreawes, M., and Cameron-5mith, D. (2002) Exercise training increases lipid metabolism gene expression in human skelletal muscle. Am J Physiol Endocrinol Metab 283, E66-72 
19. Tucker, M. Z., and Turcotte, L. P. (2003) Aging is associated with elevated muscle triglyceride content and increased insulin-stimulated fatty acid uptake. Am $J$ physiol Endocrinol Metab

20. Koonen, D. P., Benton, C. R., Arumugam, Y., Tandon, N. N., Calles-Esicandon, J., Glatz, J. F., Luiken, J. J., and Bonen. A. (2004) Different mechanisms can alter fatty acid transport when muscle contractile activity is chronically altered. Am I Physiol Endocrinol Metab 286 , E1042-1049

21. Luiken, J. 1., Arumugam, Y., Dyck, D. J, Bell, R. C., Pelsers, M. M., Turcotte, L. P., Tandon, N. N., Glatz, J.F., and Bonen, A. (2001) Increased rates of fatty acid uptake and plasmalemmal fatty acid transporters in obese Zucker rats. I Biol Chem 276, 40567-40573

22. Steimberg, G. R., Dyck, D. J., Calles-Escandon, J., Tandon, N. N., Luiken, J. J., Glatz, J. F., and Bonen, A. (2002) Chronic leptin administration decreases fatty acid uptake and fatty acid transporters in rat skeletal muscle. J Biol Chem 277, 8854-8860

23. Coort, S. L, Luiken, J. J. Van Der Vusse, G. J., Bonen, A., and Glatz, J. F. (2004) Increased FAT (fatty acid translocase)/CD36-mediated long-chain fatty acid uptake in cardiac myocytes from abese Zucker rats. Biochem Soc Trans 32,83-85

24. Bonen, A., Pairolin, M. L., Steímberg, G. R., Calles-Escandon, J., Tandon, N. N., Glatz, J. F., Luiken, J. J., Heigenhauser, G. J., and Dyck, D. J. (2004) Triacylglycerol accumulation in human obesity and type 2 diabetes is associated with increased rates of skeletal muscle fatty acid transport and increased sarcolemmal FAT/CD36. Faseb J

25. Rome, S., Clement, K., Rabasa Lhoret, R, Loizon, E., Poitou, C., Barsh, G. S., Riou, J. P., Laville, M., and Vidal. H. (2003) Micraarray profiling of human skeletal muscle reveals that insulin regulates approximately 800 genes during a hyperinsulinemic clamp. I Biol Chem 278 , $18063-18068$

26. Somwar, R., Niu, W., Kim, D. Y., Sweeney, G., Randhawa, V. K., Huang, C., Ramlal, T., and Klip, A. (2001) Differential effects of phosphatidylinositol 3-kinase inhibition on intracellular signals regulating GLUT4 translocation and glucose transport. I Biol Chem $276,46079-46087$

27. Somwar, R., Perreault, M., Kapur, S., Taha, C., Sweeney, G., Ramlal, T., Kim, D. Y., Keen, J., Cote, C. H., Klip, A., and Marette, A. (2000) Activation of p38 mitogen-activated protein kinase alpha and beta by insulin and contraction in rat skeletal muscle: potential role in the stimulation of glucose transport. Diabetes $49,1794-1800$

28. Furtado, L. M., Somwar, R., Sweeney, G., Niu, W., and Klip, A. (2002) Activation of the glucose transporter GLUT4 by insulin. Biochem Cell Biol $80,569-578$

29. Cheatham, B., Vlahos, C. I., Cheatham, L., Wang, L., Blenis, J., and Kahn, C. R. (1994) Phosphatidylinositol 3 -kinase activation is required for insulin stimulation of pp70 56 kinase, DNA synthesis, and glucose transporter translocation. Mol Cell Biol 14, 4902-4911

30. Haruta, T., Morris, A. J., Rose, D. W., Nelson, J. G., Mueckler, M., and Olefsky, J. M. (1995) Insulin-stimulated GLUT4 translocation is mediated by a divergent intracellular signaling pathway. J Biol Chem 270, 27991-27994

31. Katagiri, H., Asano, T., Ishihara, H., Inukai, K., Shibasaki, Y., Kikuchi, M., Yazaki, Y., and Oka, Y. (1996) Overexpression of catalytic subunit p110alpha of phosphatidylinositol 3 -kinase increases glucose transport activity with translocation of glucose transporters in $3 T 3-L 1$ adipocytes. J Biol Chem 271, 16987-16990

32. Frevert, E. U., and Kahm, B. B. (1997) Differential effects of constitutively active phosphatidylinositol 3-kinase on glucose transport, glycogen synthase activity, and DNA synthesis in 3T3-L1 adipocytes. Mol Cell Biol 17, 190-198.

33. Vanhaesebroeck, B, and Alessi, D. R. (2000) The PI3K-PDK1 connection: more than just a road to PKB. Biochem I 346 Pt $3,561-576$

34. Alessi, D. R., James, S. R., Downes, C. P., Holmes, A. B., Cuaffney, P. R., Reese, C. B., and Cohen, P. (1997) Characterization of a 3-phosphoinositide-dependent protein kinase which phosphorylates and activates protein kimase Balpha. Curr Biol 7, 261-269

35. Le Good, J. A., Ziegler, W. H., Parekh, D. B., Alessi, D. R., Cohen, P., and Parker, P. J. (1998) Protein kinase $C$ isotypes controlled by phosphoinositide 3 -kinase through the protein kinase PDK1. Science 281, 2042-2045 
36. Kitamura, T., Ogawa, W., Sakaue, H., Hino, Y., Kuroda, S., Takata, M., Matsumoto, M., Maeda, T., Konishi, H., Kikkawa, U. and Kasuga, M. (1998) Requirement for activation of the serine-threonine kinase Akt (protein kinase B) in insulin stimulation of protein synthesis but not of glucose transport. Mol Cell Biol 18, 3708-3717

37. Wang, Q., Somwar, R., Bilan, P. J., Liu, Z., Jin, I., Woodgett, J. R, and Klip, A. (1999) Protein kinase B/Akt participates in GLUT4 tramslocation by insulin in L6 myoblasts. Mal Cell Biol $19,4008-4018$

38. Kohn, A. D., Summers, S. A., Birnbaum, M. J." and Roth, R. A. (1996) Expression of a constitutively active Akt Ser/Thr kinase in 3T3-L1 adipocytes stimulates glucose uptake and glucose transporter 4 translocation. J Biol Chem 271, 31372-31378

39. Tardif, A., Julien, N., Chiasson, J. L., and Coderre, L. (2003) Stimulation of glucose uptake by chronic vanadate pretreatment in cardiomyocytes requires $\mathrm{PI} 3$-kinase and P38 MAPK activation. Am I Physiol Endocrinal Metab 284, E1055-1064

40. Donthi, R. V., Huisamen, B., and Lochner, A. (2000) Effect of vanadate and insulin on glucose transport in isolated adult rat cardiomyocytes. Cardiovasc Drugs Ther 14, 463-470

41. Bandyopadhyay, G., Standaert, M. L., Galloway, L., Moscat, J., and Farese, R. V. (1997) Evidence for involvement of protein kinase $C(P K C)$-zeta and noninvolvement of diacylglycerol-sensitive PKCs in insulin-stimulated glucose transport in L6 myotubes. Endocrinology 138, 4721-4731

42. Krook, A., Roth, R. A. Jiang, X. J., Zierath, J. R., and Wallberg-Henriksson, H. (1998) Insulinstimulated Akt kinase activity is reduced in skeletal muscle from NIDDM subjects. Diabetes $47,1281-1286$

43. Beeson, M., Sajan, M. P., Dizon, M., Grebenev, D., Gomez-Daspet, J., Miura, A., Kanoh, Y., Powe, J., Bandyopadhyay, G., Standaert, M. L., and Farese, R. V. (2003) Activation of protein kinase C-zeta by insulin and phosphatidylinosital-3,4,5-(PO4)3 is defective in muscle in type 2 diabetes and impaired glucose tolerance: amelioration by rosiglitazone and exercise. Diabetes $52,1926-1934$

44. Bandyopadhyay, G., Kanoh, Y., Sajan, M. P.., Standaert, M. L., and Farese, R. V. (2000) Effects of adenoviral gene transfer of wild-type, constitutively active, and kinase-defective protein kinase C-lambda on insulin-stimulated glucose transport in 16 myotubes. Endocrinology 141, 4120-4127

45. Etgen, G. J., Valasek, K. M. Broderick, C. L., and Miller, A. R. (1999) In vivo adenowiral delivery of recombinant human protein kinase C-zeta stimulates glucose transport activity in rat skeletal muscle. I Biol Chem 274, 22139-22142

46. Hansen, P. A., Wang, W., Marshall, B. A., Holloszy, J. O., and Mueckler, M. (1998) Dissociation of GLUT4 translocation and insulin-stimulated glucose transport in transgenic mice overexpressing GLUT1 in skeletal muscle. J Biol Chem 273, 181.73-181.79

47. Sweeney, G., Somwar, R., Ramlal, T., Volchuk, A., Ueyama, A., and Klip. A. (1999) An inhibitor of 388 mitogen-activated protein kinase prevents insulin-stimulated glucose transport but not glucose transporter translocation in $3 T 3-\mathrm{L} 1$ adipocytes and 16 myotubes. I Biol Chem 274, 10071-10078

48. Moxham, C. M. Tabrizchi, A., Davis, R. J., and Malbom, C. C. (1996) Jun N.terminal kinase mediates activation of skeletal muscle gllycogen symthase by insulin in vivo. $J$ Biol chem $271,30755-30773$

49. Guo, J. H., Wang, H. Y., and Malbon, C. C. (1998) Conditional, tissue-specific expression of Q205L Galphai2 in vivo mimics insulin activation of culum $\mathrm{N}$-terminal kinase and p38 kinase. J Biol Chem 273, 16487-16493

50. Mackay, D. J., and Hall, A. (1998) Rho GTPases. J Biol Chem 273. 20685-20688

51. Hammarberg, C. Fredholm, B. B., and Schulte, G. (2004) Adenosine A3 receptor-mediated regulation of $\mathrm{P} 38$ and extracellullar-regulated kinase ERK1/2 via phosphatidylinositol-3'kinase. Biochem Pharmacol 67, 129-134

52. Paul, A., Wilson, S., Belham, C. M. Robinson, C. J., Scott, P. H., Gould, G. W., and Plevin, R. (1997) Stress-activated protein kinases: activation, regulation and function. Cell Signal 9. 403-410 
53. Cohen, P. (1997) Thes search for physiological substrates of MAPK and SAP kinases in mammallan cells. trends Cell Biol $7,353-361$

54. Schmitz-Peiffer, C., Craig, D. L, and Biden, T. J. (1999) Ceramide generation is sufficient to account for the inhibition of the insulin-stimulated PKB pathway in C2C12 skeletal muscle cells pretreated with palmitate. I Biol Chem 274, 24202-24210

55. Luiken, J. J. Willems, J., Coort, 5. L, Coumans, W. A., Bonen, A., Van Der Vusse, G. J., and Glatz. J. F. (2002) Effects of CAMP modulators on long-chain fatty-acid uptake and utilization by electrically stimulated rat cardiac myocytes. Biochem / 367, 881-887

56. Burgering, B. M. and Bos, J. L. (1995) Regulation of Ras-mediated signalling: more than one way to skin a cat. Trends Biochem Sci 20, 18-22

57. Blanco-Aparicio, C., Torres, J., and Pulido, R. (1999) A novel regulatory mechanism of MAP kinases activation and nuclear translocation mediated by PKA and the PTP-5L tyrosine phosphatase. J Cell Biol 147, 1129.1136

58. Sanada, S. Kitakaze, M., Papst, P. J., Asanuma, H., Node, K., Takashima, S., Asakura, M. Ogita, H., Liao, Y., Sakata, Y., Ogai, A., Fukushima, T., Yamada, J., Shinozaki, Y., Kuzuya, T., Mori, H. Terada, N., and Hori, M. (2001) Cardioprotective effect afforded by transient exposure to phosphodiesterase 11 inhibitors: the role of protein kinase $A$ and $p 38$ mitogen-activated protein kinase. Circulation 104, 705-710

59. Luiken, J. J., Coort, S. L., Willems, ل., Coumans, W. A., Bonen, A., van der Vusse, G. J., and Clatz, J. F. (2003) Contraction-induced fatty acid translocase/CD36 translocation in rat cardiac myocytes is mediated through AMP-activated protein kinase signaling. Diabetes $52,1627-1634$

60. Luiken, J. J., Coort, S. L, Koonen, D. P., Bonen, A.v and Glatz, J. F. (2004) Signalling components involved in contraction-inducible substrate uptake into cardiac myocytes. Proc Nutr $50 \mathrm{C} 63,1.8$

61. Chen, H. C., Bandyopadhyay, G., Sajan, M. P., Kanoh, Y., Standaert, M., Farese, R. V., Ir., and Farese, R. V. (2002) Activation of the ERK pathway and atypical protein kinase C isoforms in exercise- and aminoimidazole-4-carboxamide-1-beta-D-riboside (AICAR)-stimulated glucose transport. J Biol Chem 277, 23554-23562

62. Perrini, S., Henriksson, J., Zierath, J. R., and Widegren, L. (2004) Exercise-induced protein kinase C isoform-specific activation in human skeletal muscle. Diabetes 53, 21-24

63. Goodyear, L. J., Chang, P. Y., Sherwood, D. I. Dufresne, S. D., and Moller, D. E. (1996) Effects of exercise and insulin on mitogen-activated protein kinase signaling pathways in rat skeletal muscie. Am J Physiol 271, E403-408

64. Lemieux, K., Konrad, D., Klip, A., and Marette, A. (2003) The AMP-activated protein kinase activator AICAR does not induce GLUTA translocation to transwerse tubules but stimulates glucose uptake and p38 mitogen-activated protein kinases alpha and beta in skeletal muscle. Faseb/17.1658-1665

65. Sherwood, D. J., Dufresne, S. D., Markuns, J. F., Cheatham, B., Moller, D. E., Aronson, D., and Goodyear, L. J. (1999) Differential regulation of MAP kinase, p7o(S6K), and Akt by contraction and insulin in rat sketetal muscle. Am J Physiol 276, E870-878

66. Kim, Y. B., Kotani, K. Ciaraldi, T. P., Henry, R. R., and Kahn, B. B. (2003) insulin-stimulated protein kinase $C$ lambda/zeta activity is reduced in skeletal muscle of humans with obesity and type 2 diabetes: reversal with weight reduction. Diabetes 52, 1935-1942

67. Kagaya, Y., Kanno, Y. Takeyama, D., Ishide, N., Maruyama, Y., Takahashi, T., Ido, T., and Takishima, T. (1990) Effects of long-term pressure overlload on regional myocardial glucose and free fatty acid uptake in rats. A quantitative autoradiographic study. Circulation 81, 1353-1361

68. van der Vusse, G. J., van Billsen, M., and Glatz, J. F. (2000) Cardiac fatty acid uptake and transport in health and disease. Cardiovasc Res 45, 279-293

69. Stanley. W. C., Lopaschuk, G. D., and McCormack, 1. G. (1997) Regulation of energy substrate metabolism in the diabetic heart. Cardiovasc Res $34,25-33$

70. Rodrigues, B. Cam, M. C., and McNeill, J. H. (1998) Metabolic disturbances in diabetic Cardiomyopathy. Mol Cell Biochem 180,53-57

71. Shulman, G. I. (2000) Cellular mechanisms of insulin resistance. J Clin /nvest 106, 171.176 
72. Binas, B., Danneberg, H., McWhir, J., Mullins, L., and Clark, A. J. (1999) Requirement for the heart-type fatty acid binding protein in cardiac fatty acid utilization. Faseb $/ 13,805-812$

73. Broderick, T. L., Christos, S. C, Wolf, B. A., DiDomenico, D., Shug, A. L., and Paulson, D. J. (1995) Fatty acid oxidation and cardiac function in the sodium pivalate model of secondary carnitine deficiency. Metabolism 44, 499-505

74. Kelly, D. P., and Strauss, A. W. (1994) Inherited cardiomyopathies. N Engl J Med 330, 913 919

75. Zhou, Y.-T., Grayburn, P., Karim, A., Shimabukuro, M., Higa, M., Baetens, D., Orci, L., and Unger, R. H. (2000) Lipotoxic heart disease in obese rats: Implications for human obesity. PNAS 97, 1784-1789

76. Young, M. E., Guthrie, P. H., Razeghi, P., Leighton, B., Abbasi, 5., Patil, S., Youker, K. A., and Taegtmeyer, H. (2002) imparred longuchain fatty acid oxidation and contractile dysfunction in the obese Zucker rat heart. Diabetes $51,2587-2595$

77. Atkinson, L. L., Kozak, R., Kelly, S. E, Onay Besikci, A., Russell, J. C, and Lopaschuk, G. D. (2003) Potential mechanisms and consequences of cardiac triacylglycerol accumulation in insulin-resistant rats. Am I Physiol Endocrinol Metab 284. E923-930

78. Coort, S. L., Hasselbaink, D. M. Koonen, D. P., Willems, I, Coumans, W. A., Chabowski, A., Van Der Vusse, G. J., Bonen, A.. Glatz, J. F., and Luiken, J. I. (2004) Enhanced Sarcolemmal FAT/CD36 Content and Triacylglycerol Storage in Cardiac Myocytes From Obese Zucker Rats. Diabetes 53,1655-1663

79. Coburn, C. T., Knapp, F. F. Jr., Febbraio, M., Beets, A. L., Silverstein, R. L., and Abumrad, N. A. (2000) Defective uptake and utilization of long chain fatty acids in muscle and adipose tissues of CD36 knockout mice. I Biol Chem 275, 32523-32529

80. Hajri, T., Han, X. X., Bonen, A., and Abumrad, N. A. (2002) Defective fatty acid uptake modulates insulin responsiveness and metabolic responses to diet in CD 36 -null mice. $J$ Clin Invest 109, 1381-1389

81. Kuang, M., Febbraio, M., Wagg, C., Lopaschuk, G. D., and Dyck, J. R. (2004) Fatty Acid Translocase/CD36 Deficiency Does Not Energetically or Functionally Compromise Hearts Before or After Ischemia. Circulation

82. Tanaka, T., Sohmiya, $\mathbb{K}$., and Kawamura, K. (1997) is CD36 deficiency an etiology of hereditary hypertrophic cardiomyopathy? I Mol Cell Cardiol 29, 121-127

83. Tanaka, T., Nakata, T., Oka, T., Ogawa, T., Okamoto, F., Kusaka, Y., Sohmiya, K., Shimamoto, K., and Itakura, K. (2001) Defect in human myocardial long-chain fatty acid uptake is caused by FAT/CD 36 mutations. I Lipid Res $42,751-759$

84. Lepretre, F., Vasseur, F., Vaxillaire, M., Scherer, P. E., Ali, S., Linton, K., Aitman, T., and Froguel, P. (2004) A CD36 nonsense mutation associated with insulin resistance and familial type 2 diabetes. Hum Mutat 24, 104

85. Coodyear, L. J., and Kahn, B. B. (1998) Exercise, glucose transport., and insulin sensitivity. Annu Rev Med 49.235-261

86. Luiken, J. J. F. P., Coort, 5. L. M. Willems, J., Coumans, W. A., Bonen, A., and Giatz, J. F. C. (2004) Dipyridamole Alters Cardiac Substrate Preference by Inducing Translocition of FAT/CD 36, but Not That of GLUT4. Mol Pharmacol 65, 639-645 
Summary/samenvatting

Curriculum Vitea

List of Publications

Dankwoord/Acknowledgements 


\section{Summary}

Glucose and long-chain fatty acids (LCFAs) are the predominant energy substrates for skeletal muscle and heart. Since cardiac and skeletal muscles do not hold an unlimited storage capacity, these tissues rely heavily on the continuous supply of both glucose and LCFAs derived from the circulation. Cellular LCFA uptake is facilitated by putative LCFA transport proteins residing in the plasma membrane of the cell. The bulk of LCFA uptake into (cardiac) myocytes is mediated by fatty acid translocase (FAT)/CD36. Overwhelming evidence was obtained from the generation of transgenic mouse models with either muscle-targeted overexpression of FAT/CD36 or complete absence of the gene for FAT/CD36 (FAT/CD36 knockout mice). These models not only emphasized a physiological role for FAT/CD36 by illustrating that altered changes in muscle LCFA uptake rates paralleled the changes in FAT/CD36 expression, they also demonstrated the importance of the LCFA uptake process to overall LCFA metabolism and glucose utilization.

Like the glucose transporter GLUT4, FAT/CD36 localization is not restricted to the sarcolemma and an intracellular storage compartment for FAT/CD36 has been found. When compared to cellular glucose uptake by GLUT4, the uptake mechanism of LCFAS and its regulation are only poorly understood. However, there are some indications to suggest that a similar regulatory mechanism accounts for cellular LCFA uptake as well. The studies described in this thesis investigate the possible role of FAT/CD36 translocation as underlying mechanism in the acute and chronic regulation of LCFA uptake in heart and skeletal muscle. In addition, a first attempt has been made to unravel the signal transduction cascades involved in insulin-induced FAT/CD36 translocation.

CHAPTER 1 gives a brief description of the main signaling cascades involved in the biological effects of insulin on the regulation of glucose, protein and lipid metabolism. An introduction is given in the main process of cellular LCFA and glucose uptake and the glucose transporters predominantly involved in glucose uptake in heart and skeletal muscle are discussed. After presenting two specific models which are used throughout this thesis, that is giant sarcolemmal vesicles and cardiomyocytes, a thesis outline is provided.

Besides FAT/CD36, two other putative transport proteins are involved in proteinmediated ICFA uptake, plasma membrane fatty acid binding protein (FABPpm) and fatty acid transport protein (FATP). Although direct proof has not been provided, indirect evidence suggest an interaction of FAT/CD36 with each of these transport proteins. In chapter 2 background information is given about FAT/CD36, FABPpm and FATP, and four hypothetical models of LCFA uptake are described. In addition a review of current concepts and ideas on the regulation of LCFA uptake by insulin and electrical contractions is provided. The potential involvement of candidate proteins (protein kinase $A$ (PKA), protein kinase B (Akt/PKB), protein kinase C (PKC), and mitogen-activated protein kimase (MAPK)) as part of the independent signal transduction kinases induced by insulin and electrical stimulation are highlighted. Finally this chapter describes the current evidence to indicate a role for a disturbed FAT/CD36 translocation in heart-and skeletal muscle of obese and insulin-resistant rats. 
To verify whether giant sarcolemmal vesicles can be used as experimental tool system in LCFA uptake studies and to detect plasma membrane alterations in transport proteins, giant vesicles from heart, liver, muscle and adipose tissue were characterized. Therefore, we examined of which cell types (parenchymallendothelial), membrane-domains or cell regions these giant sarcolemmal vesicles consist. In addition, we determined the existence of FAT/CD36, FABPpm and GLUT4, and of cytoplasmic FABP (FABPC), the intracellular counterpart of albumin. As mentioned in CHAPTER 3, giant vesicles not only consist of parenchymal cells but specific plasma membrane domains, like caveolae which are known to be involved in membrane transport processes, are also represented. Since giant vesicles do not contain subcellular organelles (i.e. mitochondria), but FABPC as well as the transport proteins, FAT/CD 36, FABPpm and GLUT4, these giant sarcolemmal vesicles can be very well used to study the uptake mechanism of both glucose and LCFAs in the absence of metabolism (i.e. oxidation).

Skeletal muscle metabolism is remarkably capable of adapting to changes in muscle activity pattern. While it has been shown that increased muscle activity can increase FAT/CD36 and FABPpm, as well as LCFA transport, the effects of reducing muscle activity on LCFA transport and transport proteins are not known. In previous studies, it: was demonstrated that LCFA uptake is subject to short-term regulation by a brief period of muscle contraction, involving the translocation of FAT/CD36 from intracellular stores to the sarcolemma. In this respect, it is important to account for changes in LCFA transport by examining both the total muscle content and the plasmalemmal content of FAT/CD36 and FABPPm. CHAPTER 4 therefore describes the effects of altered muscle activity on LCFA transport and the mechanisms involved. For this, we either chronically stimulated or denervated rat hindlimb muscle for a period of 7 consecutive days and measured the total muscle content of FAT/CD36 and FABPpm in these muscles. We used giant sarcolemmal vesicles to measure the rates of LCFA transport and the plasmalemma! content of FAT/CD36 and FABPpm. In this chapter evidence is provided that chronic alterations in muscle activity can alter the rates of LCFA transport via different mechanisms, either 1) by increasing the total muscle content of FAT/CD 36 and FABPpm resulting in a concomitant increase at the sarcolemma, or 2) by reducing the plasma membrane content of the proteins, in the absence of any changes in their total muscle content.

Besides a short-term period of electrical stimulation, insulin is also capable of increasing LCFA transport rates in skeletal muscle by inducing FAT/CD36 translocation to the sarcolemma. Chapter 5 describes the direct of effect of insulin on cellular uptake of LCFAS by the heart and provides the novel finding of insulin to induce FAT/CD36 translocation in heart in addition to the well-known effect of insulin to stimulate glucose uptake and GLUT4 translocation. Moreover, evidence was found for two independent pathways mediating the insulin-and contraction-induced regulation of LCFA uptake in cardiac myocytes, confining a phosphatidylinositol-3-OH-kinase-dependent mechanism to insulin-induced LCFA uptake.

Although the regulation of LCFA and glucose uptake appear to be identical, we recently observed evidence that zaprinast, a CGMP-specific phosphodiesterase inhibitor, 
selectively modulated the substrate preference of the heart by stimulating glucose uptake and not LCFA uptake. Notably, these observations suggest that different mechanisms are involved in the regulation of glucose and LCFA uptake. Since zaprinast potentially has anti-diabetic properties, we determined the underlying mechanism by which zaprinast is able to selectively stimulate glucose uptake, as described in CHAPTER 6 . Moreover, we rule out a role for P38 MAPK in the stimulation of insulim-induced LCFA uptake in cardiac myocytes, suggesting that FAT/CD 36 translocation and not activation is involved in the effect of insulin on LCFA uptake.

In the final chapter (CHAPTER 7), the main results of the studies presented in this thesis are discussed and put into a broader perspective. Suggestions for future research as well as clinical implications in respect to FAT/CD36 as therapeutic potential are given. 


\section{Samenvatting}

Naast glucose als substraat zijn het hart- en de skeletspieren voor hun energiebehoefte voor een belangrijk deel afhankelijk van de verbranding van vetzuren. Een continue aanvoer van deze voedingsstoffen is gewenst, aangezien er slechts een beperkte opslagcapaciteit voorhanden. Het grootste deel van de vetzuren wordt door de hart-en skeletspiercel opgenomen met behulp van zogenaamde transporteiwitten, die zich in de plasmamembraan van de cel bevinden. Fatty acid translocase (FAT)/CD36 is verantwoordelijk voor meer dan de helft van de cellulaire opname van vetzuren in harten skeletspiercellen en neemt daarmee een prominente plats in binnen het eiwitgemedieerde vetzuuropname proces. De fysiologische betekenis van dit transporteiwit werd nadrukkelijk bevestigd door de ontwikkeling van transgene diemodellen gericht op zowel spierspecifieke overexpressie van FAT/CD36 of juist deletie van het FAT/CD36 gen. Deze diermodellen lieten niet alleen een parrallel zien tussen veranderingen in vetzuurtransportsnelheid en expressie van FAT/CD36 in de spier, maar benadrukten ook het belang van het vetzuuropname proces voor het vetzuur-en glucose metabolisme in het algemeen.

Net als GLUT4, de voornaamste glucose transporter in hart-en skeletspiercellen, bevindt FAT/CD36 zich niet uitsluitend in de plasmamembraan van de cel, maar komt dit eiwit ook voor in intracellulaire compartimenten. Ten opzichte van het bekende fenomeen dat de cellulaire glucose opname gereguleerd wordt door de hoeveelheid GLUT4 op de celmembraan, zijn er slechts aanwijzingen dat FAT/CD36 via eenzelfde mechanisme im staat is om de vetzuuropname te reguleren. De studies die in dit proefschrift beschreven worden, onderzoeken de mogelijke rol van het translocatiemechanisme van FAT/CD 36 in de chronische en acute regulatie van vetzuuropname in het hart en de skeletspier vam de rat. Daarnaast is het signaaltransductiemechanisme onderzocht waarmee externe acute stimuli, zoals insuline en kortdurende elektrische contracties de translocatie van FAT/CD36 in deze weefsels kunnen induceren.

In HoOrDSTuk 1 wordt een beknopte beschrijving gegeven van de signaaltransductiecascades die betrokken zijn bij de insuline-gemedieerde regulatie van het glucose-, eiwiten vetzuurmetabolisme. Daarnaast wordt de aandacht gevestigd op vetzuur- en glucose opname in het algemeen en komen behalve de vetzuurtransporter FAT/CD36 ook de belangrijkste glucosetransporters woor het hart en de skeletspier, GLUT1 en GLUT4, specifiek aan bod. Na een kennismaking met de twee modellen die in het proefschrift gebruikt worden om de opname en de regulatie van vetzuren te bestuderen, namelijk giant sarcolemmal vesicles en cardiomyocyten, wordt de opzet van het proefschrift uiteengezet.

Naast FAT/CD36 zijn nog twee transporteiwitten betrokken bij de eiwit-gemedieerde vetzuuropname, te weten plasma membraan fatty acid binding protein (FABPpm), en fatty acid transport protein (FATP). Hoewel concrete aanwijzingen nog niet geleverd zijn, is er indirect bewijs voorhanden om te veronderstellen dat FAT/CD36 met elk van deze eiwitten een interactie aangaat. In HoOFDSTuk 2 wordt dieper ingegaan op deze drie vetzuurbindende eiwitten en worden vier hypothetische modellen van vetzuuropname uitgewerkt. Daamaast beschrijft dit hoofdstuk de stand van zaken omtrent de acute 
regulatie van de vetzuuropname in hart en skeletspieren onder invloed van insuline en elektrische stimulatie. De onafhankelijke signaaltransductiecascades behorende bij de acute stimulatie van FAT/CD36 tramslocatie en potentiële kandidaateiwitten die binnen deze cascades een belangrijke rol kunnen spelen zoals proteine kinase $A$ (PKA), proteine kinase B (Akt/PKB), proteine kinase C (PKC), en mitogen-activated proteine-kinase (MAPK) komen aan de orde. De aanwijzingen voor een verstoorde translocatie van FAT/CD36 in hart- en skeletspier van obese en insuline-resistente ratten worden eveneens besproken. Om te verifieren of giant sarcolemmal vesicles als onderzoeksmodel in vetzuuropnamestudies gebruikt kunnen worden om veranderingen in transporteiwitten op de plasmamembraan aan te tonen, hebben we onderzocht uit welke cellen (parenchymaal of endotheel) en celgedeeltes/compartimenten (onder andere caveolae en T-tubuli) de plasmamembraan van giant vesicles opgebouwd is. Ook hebben we de aanwezigheid bepaald van FAT/CD36, FABPpm en CLUT4, en van cytoplasmatisch FABP (FABPC), de intracellulaire tegenhanger van albumine. Zoals vermeld in HOOFDSTUK 3 blijkt dat giant sarcolemmal vesicles niet alleen opgebouwd zijn uit de plasmamembraan van parenchymale cellen, maar ook dat specifieke plasmamembraan domeinen betrokken bij membraan transport processen zoals caveolae vertegenwoordigd zijn. Aangezien subcellulaire organellen waaronder mitochondriën ontbreken, maar zowel de substraat transporters als FABPC aangetoond konden worden in deze giant sarcolemmal vesicles, kunnen deze vesicles bij uitstek toegepast worden ter bestudering van het opname mechanisme van glucose en vetzuren in afwezigheid van metabole processen (bijv. $\beta$ oxidatie).

Skeletspieren kunnen hun energiebehoefte gemakkelijk aanpassingen aan eventuele veranderingen in het spieractiviteitspatroon. Uit eerder onderzoek is gebleken dat een verhoogde spieractiviteit zowel een toename teweegbrengt in de vetzuurtransportsnelheid als ook in de hoeveelheid beschikbare transporteiwitten van FAT/CD36 en FABPpm in de spier. Echter, het is niet bekend wat het effect is van een afname van spieractiviteit op deze parameters. Bovendien blijkt uit eerder onderzoek dat het toebrengen van kortdurende elektrische stimulaties de vetzuuropname in staat is te reguleren door middel van het induceren van FAT/CD36 translocatie naar de plasmamembraan. Het is daarom belangrijk om veranderingen in vetzuurtransport snelheid te relateren aan zowel het totale gehalte van FAT/CD36 en FABPpm in de spier als ook aan de hoeveelheid van deze eiwitten op de sarcolemma. in Hoofostuk 4 wordt het effect van veranderingen in spieractiviteit op vetzuurtransport en de hierbij betrokken mecchanismen behandeld. Hiervoor, was het van belang om de achterpootspieren van de rat gedurende een aaneengesloten periode van 7 dagen ofwel chronisch te stimuleren of te denerveren. Vervolgens werd het totale gehalte van FAT/CD36 en FABPpm in deze spieren bepaald. De vetzuurtransportsnelheid alsmede de hoeveelheid van deze transporteiwitten op de plasmamembraan werd gemeten met behulp van giant sarsolemmal vesicles geisoleerd uit deze spieren. In dit hoofstuk wordt bewijs geleverd dat chronische veranderingen in spieractiviteit de vetzuurtransportsneleheid via verschillende mechanismen kunnen beïnvloeden. Ten eerste door middel van het verhogen van de totale hoeveelheid aan transporteiwitten en ten tweede door 
het verminderen van het gehalte van FAT/CD36 en FABPpm op de plasmamembraan, zonder dat er een verandering optreedt in het totale aantal transporteiwtitten in de spier. Uit recent onderzoek is gebleken dat naast kortdurende elektrische stimulaties ook insuline in staat is om in de skeletspier de vetzuuropname te stimuluren via het verhogen van het gehalte van FAT/CD36 op de plasmamembraan. HoofDsTuk 5 beschrijft de nieuwe bevinding dat, insuline niet alleen de glucose opname stimuleert via GLUT4. translocatie, maar ook de vetzuuropname positief beïnvloedt via het induceren van FAT/CD36 translocatie naar de plasmamembraan. Daarnaast blijken insuline en contracties niet via hetzelfde signaaltransductiemechanisme de vetzuuropname te reguleren waarbij activering van phosphatidylinositol-3-OH-kinase $(\mathrm{PI}(3) \mathrm{K})$ alleen betrokken is bij het effect van insuline op de vetzuuropname.

Hoewel de regulatie van glucose als vetzuren identiek lijkt te zijn, komt uit recent onderzoek naar voren dat zaprinast, een CGMP-phosphodiesterase remmer, in staat is om de substraatvoorkeur voor het hart selectief te beïnvloeden. Zonder de vetzuuropname te veranderen, wordt de glucose opname van het hart verhoogd, wat erop duidt dat verschillende mechanismen betrokken zijn bij de regulatie van glucose- en vetzuuropname. Aangezien zaprinast hypothetisch gezien bij diabetes gebruikt kan worden om de glucose opname te stimuleren, wordt in HOOFDSTUK 6 het mechanisme ontrafeld van het specifieke effect van zaprinast op de glucoseopname in het hart. Op basis van de bevindingen kunnen we eveneens een rol voor P38 MAPK in de insulinegeïduceerde stimulatie van de vetzuuropname uitsluiten waardoor vermoedelijk alleen FAT/CD36 translocatie en niet FAT/CD36 activatie als onderliggend mechanisme hierbij betrokken zijn.

IN HoOFDSTUK 7 worden uiteindelijk de belangrijkste resultaten van dit proefschrift bediscussieerd en in een breder perspectief gesplaatst. Tenslotte worden in dit hoofdstuk suggesties voor verder onderzoek en potentiële klinische toepassingen van FAT/CD36 aan de orde gebracht. 


\section{Curriculum Vitae}

Debby Koonen was born in Brunssum on June 30, 1976, and grew up in Schinveld. She completed her secondary education at the Romboutscollege in Brunssum in 1994. In the same year, she started her academic education at Maastricht University, where she studied Health Sciences with Movement Sciences as specialization. She conducted her first internship at the department of Psychiatry \& Neuropsychology at Maastricht University under supervision of Prof. Dr. W. Riedel, Dr. J. Schmitt and Dr. J. Adam. During this 6-month period she studied the influence of environmental temperature and physical exercise on cognitive performance. In October 1998 she travelled to Australia to undertake a second internship at the department of Biomedical sciences at the University of Wollongong, where she had the privilege to work with Dr. N.A.S. Taylor in his sophisticated climatic chamber. Under supervision of Prof. Dr. H. Kuipers and Dr. $H$. Keizer, evidence was sought for a possible causal relation between a change in muscle temperature and the sweating response during one-legged cycling exercise.

On August 31, 1999, she obtained her MSc degree and from January 2000 until December 2003 she was appointed as a PhD student to the Faculty of Medicine at Maastricht University. Under supervision of Prof. Dr. J. F.C. Glatz and Dr. J.J.F.P. Luiken she worked at the department of Physiology (3,5 years) and Mollecular Genetics ( 0,5 year).

In 2001 she was awarded with the Van Walree Fund to undertake a 4-month working visit to Prof. Dr. A. Bonen at the Department of Kinesiology at Waterloo University, Canada. During this period she learned to isolate giant sarcolemmal vesicles and to apply electrical stimulation and denervation to rat hindlimb muscles in vivo. As a member of the Cardiovascular Research Institute Maastricht (CARIM) she obtained the CARIM Certificate in 2003.

On October $1^{\text {st }}, 2004$, she will join the research group of Dr. J.R.B. Dyck at the department of Pediatrics at the University of Alberta, Edmonton, Canada. As a postdoctoral fellow she will expand her knowledge on FAT/CD36 in the upcoming two years. Meanwhile, she is a member of the Luiken-VIDI-team to finalise ongoing FAT/CD36 projects at the department of Molecular Genetics. 


\section{List of Publications}

1. Koonen, D.P.Y., Coumans, W.A., Arumugam Y., Bonen, A., Glatz, J.F.C. and Luiken, J.J.F.P. Characterization of giant membrane vesicles: a new tool to study cellular substrate uptake in the absence of metabolism. Mol Cell Biochem 239:121-30, 2002.

2. Luiken, J.J.F.P., Koonen, D.P.Y., Willems J., Zorzano A., Becker C., Fischer Y., Tandon N.A., van der Vusse G.J., Bonen A., and Glatz J.F.C. Insulin stimulates long-chain fatty acid utilization by rat cardiac myocytes through cellular redistribution of FAT/CD 36. Diabetes 51(10):3113-9, 2002.

3. Luiken J.J.P., Koonen D.P.Y., Coumans W.A., Pelsers M.M.A.L., Binas B., Bonen A., and Glatz J. F. $P$. Long-chain fatty acid uptake by skeletal muscle is impaired in homozygows, but not heterozygous, heart-type-FABP null mice. Lipids 38(4):491-6, 2003.

4. Joost J.F.P. Luiken, Susan L.M. Coort, Debby P.Y. Koonen, Dick J. van der Horst, Arend Bonen, Antonio Zarzano, Jan F.C. Glatz. Regulation of cardliac long-chain fatty acid and glucose uptake by translocation of substrate transporters. Pfiugers Arch. 448(1):1-15, 2004.

5. Arend Bonen, Shannon E. Campbell, Carley R. Benton, Adrian Chabowski, Susan L.M. Coort, Xiao-Xia Han, Debby P.Y. Koonen, Jan F.C. Glatz and Joost J.F.P.Luiken. Regulation of fatty acid tramsport by fatty acid translocase/CD36. Proc Nutr 5oc 63:245-9, 2004.

6. Joost J.F.P.Luiken, Susan L.M. Coort, Debby P.Y. Koonen, Arend Bonen, and Jan F.C. Glatz. Signalling components involved in contraction-inducible substrate uptake into cardiac myocytes. Proc Nutr Soc 63:251-8, 2004.

7. Debby P.Y. Koonen, Yoga Arumugam, Jan J.F.C. Glatz, Joost J.F.P. Luiken, Arend Bonen. Different mechanisms can alter fatty acid transport when muscle contractile activity is chronically altered. Am I Physiol Endocrinol Metab. 286(5): E1042-9,2004.

8. S.L.M. Coort, D.M. Hasselbaink, D.P.Y. Koonen, J. Willems, W.A. Coumans, G.J. van der Vusse, A. Bonen, J.F.C. Glatz and J.J.F.P. Luiken. Enhanced sarcolemmal FAT/CD36 content and triacylglycerol storage in cardiac myocytes from obese Zucker rats. Diabetes 53(7):165563,2004 .

9. Debby P.Y. Koonen, Jan F.C. Glatz, Arend Bonen, and Joost J.F.P. Luiken. Long chain fatty acid uptake and FAT/CD36 translocation in heart and skeletal muscle (Biochimica et Biophysica Acta-Molecular and Cell Biology of Lipids, accepted).

10. D.P.Y. Koonen, J. Willems, M.M.A.L. Pelsers, W.A. Coumans, S.L.M. Coort, A. Bonen, J.F.C. Glatz, J.J.P. Luiken. Zaprinast selectively modulates cardiac substrate preference by increasing glucose uptake without altering long-chain fatty acid uptake. (in preparation). 


\section{Dankwoord/Acknowledgements}

Na maanden van "nee, nu even niet want ik moet nog wat... is eindelijk de finish in zicht. Een voorlopige versie van dankwoord doc staat op mijn scherm te wachten om als definitieve versie opgeslagen te worden in mijn PROEFSCHRIFT map. Ik zucht nog maar eens een keer diep, zoals zovaak de laatste tijd, maar dit keer van verlichting. Het is jammer dat ze regen voorspeld hebben vandalag, anders hadden we straks lekker door het bos kunnen fietsen.

Er komt een glimlach op mijn gezicht als ik aan iedereen denk die mij in de afgelopen 4,5 jaar op welk front dan ook heeft bijgestaan. Ach, het zal niemand verbazen dat ik geheel tegen de regels in eerst graag het woord will richten tot mijn co-promotor. Zeergeleerde Dr. J.J.F.P. Luiken, VIDH-laureaat, beste Joost, aan jou heb ik zoveel te danken dat een paar regels absoluut niet genoeg zijn. لlij was het die mijn dagelijkse begeleiding zonder gemopper op je nam en mij kennis heeft laten maken met jouw manier van wetenschap bedrijven. Afgezien van het feit dat samen proeven doen voor mij een ware survivaltocht is, vormt jouw gedrevenheid en enthousiasme de BASIS en de RODE DRAAD van mijn proefschrift. De vele kopjes koffie die we samen gedronken hebben omdat ik weer eens onverklaarbare resultaten had, en ik volgens jou niet in paniek mocht raken, zitten in mijn geheugen gegrift. Joost, het moet af en toe geen gemakkelijke opgave zijn geweest. en zeker niet op vrijdagmiddagen. Zou het misschien aan onze geboortedatum liggen?

Weledelgeleerde Prof. Dr. J.F.C. Glatz, geachte promotor, beste Jan, ook jij hebt absoluut je steentje bijgedragen aan dit geheel. Ondanks je drukke schema had je altijd wel even tijd voor mij en dat heb ik enorm gewaardeerd. Je hebt een geweldig gevoel voor humor. je voorliefde voor 'kaders" en 'kopjes' deel ik echter niet. Dank voor het in mij gestelde vertrouwen tijdens de sollicitatieprocedure, het blijkt maar weer eens dat ervaring niet alles is wat telt.

Prof. Dr. A Bonen, highly esteemed opponent, thank you for you hospitality during my stay in your lab in Waterloo. Although you think that I have an invisible/imaginary boyfriend, I am really getting married this September. Thank you for letting us stay in your cottage in Kingston, it was quite an experiencel Most of all I appreciate the reading and corrections you've done to improve our articles. I have this feeling that we'll meet again in Edmonton, if so l'll buy you a beer!

Will (pacifist in hart en nieren) speciaal woord van dank gaat uit naar jou, niet alleen voor het introduceren van de noodzakelijke klassiekers, maar ook voor de westerns en alle overige technieken die jij mij als afgestudeerd bewegingswetenschapper in vrij korte tijd hebt bijgebracht. Bovendien zou ik hier nu niet gestaan hebben alls jij je best (l) niet gedaan had 4 jaar geleden. Gelukkig heb je het briesend paard al geintroduceerd bij de Mol-genners en dus kan ook deze klassieker gelukkig niet verloren gaan. Ho ho, ja hoor Will, ik hoor het je in de verste verte alweer roepen ... tijd dus voor de volgende personen in dit rijtje. 
Als braaf klein meisje, kwam ik ruim vier jaar geleden op een echte mannenkamer terecht. Wat ik daar aantrof was even slikken: een Maastrichter Geis, een rokende Brinkmann, en een Rotterdamse voetballer, ja familie van... Heel snel hebben jullie mij ingewijd in jullie mannenwereld en mij de beste opleiding gegeven die er bestaat, daar kan het CARIM-certificaat echt niet tegenop!

Joep, jij was het snelste weg, eerst naar de dochter van Nada daarna naar Amsterdam. Van stimulerende discussies tot zakkende bureaustoelen en Kyodai-wedstrijden, ik heb genoten op 'onze' kamer.

Dr. Hasselbaink, zeer geleerde opponent, beste Danny, ik niet op jouw kaft, maar jij wel in mijn corona, wilde je daarom misschien toch onze ceremoniemanager zijn? We delen lief en leed en ook al wil je graag al je vrienden bij jou in de buurt hebben, ik kan echt niet beloven dat ik ooit naar het Noorden verhuis! Misschien is een weekendje Limburg ook wel relaxed zo af en toe?

Jodil, we hebben (on-ybewust veel van elkaar geleerd. Ik vind het gewoonweg B-E-A-utiful dat jij één van mijn paranimfen bent. Flink gelachen, getapdanst op het lab, maar vooral hard door gepipetteerd. Ik denk dat wij beiden voor de rest van ons leven al genoeg afgeteld hebben van 7 naar 1 . I mis je energie op het lab en je bulderende lach, kom je me een keertje opzoeken in Canada? Je hebt speciaal voor mij uren door de grotten in België gelopen op zoek naar die ene mooie foto voor mijn kaft. Het is je gelukt, en ik ben een van de weinigen met een scanbaar boekje. Prachtig!

Ontzettend blij ben ik ook met Roy, mijn andere paranimf, jullie sterke mannen slepen me er wel doorheen, niet? Roy, je bent een meester in het verzinnen van bijnamen, ik wacht echter nog steeds op de formatie van je nieuwe band 'Sugarlee Roy and the Megakariocytes; al ben ik bang dat deze er nooit van zal komen. Heel veel succes met het afronden van jouw proefschrift en ik wacht met spanning op je eerste journalistieke werk. Zet hem op!

Beste oud-collega's van fysiologie 3.5 jaar lang was ik er elke dag, het laatste jaar slechts af en toe. Andries (1 oktober, ik zal aan je denken), Karin, Kristel, Hans (Kleine man), Martijn, Jeanine, Richard, Miriam, Anita, Veerle, Geertje, Theo, Peter, Ger, Frans, Marc, Bart, Luc, Viviane, de secretaresses Jos, Karin, Claire en Linda en alle overige leden van Elektrofysiologie, Microcirculatie en Cardiologie die ik met enige regelmaat tegenkwam, en ook Jart natuurlijk, bedankt.

Dan over naar mijn huidige collega's. De overstap was vooraf verontrustend te noemen zo in mijn laatste AlO-jaar, maar heeft ronduit voortreffelijk uitgepakt. Beste Marten, Willma, Lee, Anne, Ronit, Daniëlle, Menno, Marion, Monique en Patrick, Meneer van Eijs, Arjan, Mathijs, Kristiaan (wat is het heerlijk om jou te plagen), Petra en Sander, Stijn, 
Vivian, Iris, Willem, Maurice en Daniëlle (veel geluk samen en met de kids), jullie warmte is ongekend, en ik ben blij dat ik de mogelijkheid heb gehad jullie te leren kennen.

Mijn 'nieuwe' kamergenoten, Hanneke (mijn waste-bakje zall nooit meer hetzelfde zijn), Celine (sorry, for the times that I locked you up in our room), dr. Sophia (congratulations), en Frank (jij bent mijn levende boksbal, gelukkig zijn wij beiden niet moordzuchtig, maar ik moet bekennen dat het inderdaad tijd is voor manneljk evenwicht op deze kamer).

Daarnaast een woord van dank aan de meiden van het Luiken-VIDI-team: Susan en Dapha. Susan, je bent er bijna. Net voor het ter drukke gaan heb je de speld in de hooiberg gevonden. Geweldig, leidt dit toch nog tot een carrière-switch? Ik zal onze mannelijke ratten die opeens vrouwtjes bleken te zijn nooit meer vergeten. Heel veel succes met de afronding van jouw proefschrift en je promotie. Dapha, ons nieuwste lid, je bent een waardig opvolgster. lemand die na mij met Susan een gedeelde tweede plek kan opeisen in de Mol Gen 2004 EK voetbalpool heeft zeker een plekje verdient in ons team. Welkom!

The (old-)people of the Bonen's lab: Yoga (you'll be my second mum forever), X-X, Adrian, Carley, Shannon, and Lisa, you all have made me feel at home, thanks a lot.

A speciaal woord van dank gaat uit naar de heren van de spoelkeuken, want zij hebben er 4 jaar lang voor gezorgd dat het glaswerk keer op keer netjes schoon werd, zij het af en toe met enig commentaar.

Pap en mam, mijn trouwe supporters, jullie hebben mij de eerste opstap gegeven in de richting waar ik nu ben. I sta nu al heel wat jaren op eigen benen, en dat hebben jullie geweten ook. Eerst een stage in Australië, toen alleen naar Canada, en nu binnen niet al te lange tijd voor twee jaar weg. Jullie hebben mijn keuzes altijd gerespecteerd en gestimuleerd. Hartstikke bedankt, zonder jullie onvoorwaardelijke steun, wordt alles een stuk moeilijker! Mam, bedankt voor het inprenten van de woorden: "klein maar dapper", het doet wonderen!

In 4 jaar tijd was er een ware babyboom in de familie: Thijs, Frans, Anne en Bram, jullie zijn belangrijker dan jullie beseffen. Een uurtje of 2 met jullie en alle stress is vergeten.

Gertie en Fred, bedankt voor het gemak waarmee Tim en ik even snel konden komen eten, voor het lenen van het rode autootje op alle uiterst kritieke momenten, alle koffie op weg naar huis, het heeft ons een hele hoop tijd bespaart. Bedankt ook voor het verstrekken van de achtergrond muziek, zodat ik op het laatst heerlijk relaxed heb kunnen schrijven.

Tim, de nuchterheid waarmee jij tegen bepaalde zaken aankijkt (dan moet je ook niks schrijven als je het toch weer gaat deleten) is uitermate verfrissend te noemen. Ontzettend bedankt voor al je begrip, als ik weer eens niet wilde gaan mountainbiken of fietsen en gefrusteerd door het huis liep te lanterfanten (Danny, bedankt!). Je bent 
degene die relativeert, me kalmeert en stimuleert. We hebben al heel wat van de wereld gezien dankzij de EK, WK, en alle mountainbikewedstrijden voor de wereldbeker waar we samen geweest zijn. Nu gaan we samen naar het buiterland. Zonder jouw steun had ik mijn nieuw baan nooit kunnen accepteren. Ik vind het echt jammer dat je volgend jaar (2005) nog net geen 30 bent, anders had je in onze nieuwe stad deel kunnen nemen aan de World Masters Games, je zou ook ééns een keer wel Geluk hebben, hè!

Tot slot, diegenen die ik per ongeluk vergeten ben, ook jullie worden vriendelijk bedankt.

\section{PROOST,}

MAAK ER WAT MOOIS VAN!

DEBBY

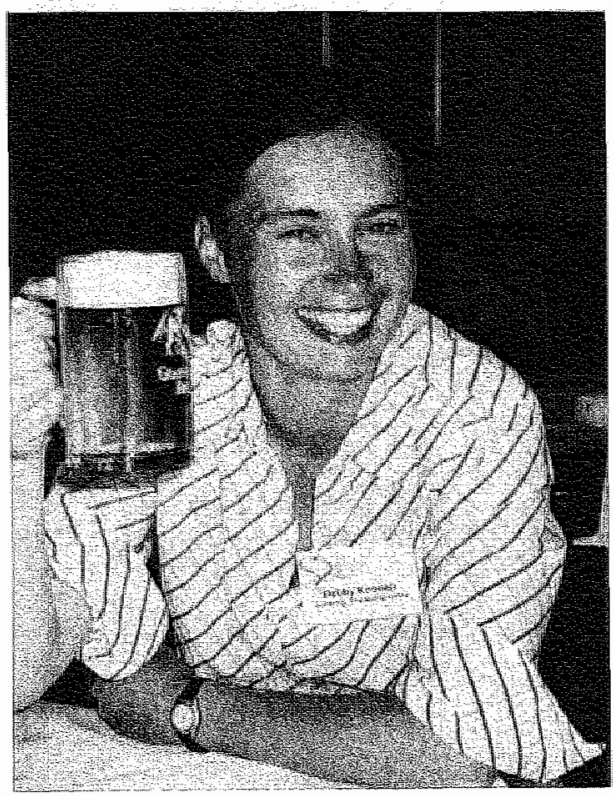

